PRENYL PRAXIS: A METHOD FOR DIRECT

\title{
PHOTOCATALYTIC DEFLUOROPRENYLATION
}

\author{
By \\ SONAL PRIYA \\ Bachelor of Science in Chemistry \\ University of Delhi \\ New Delhi, Delhi \\ 2014
}

Submitted to the Faculty of the

Graduate College of the

Oklahoma State University

in partial fulfillment of

the requirements for

the Degree of

MASTER OF SCIENCE

December, 2018 


\section{PRENYL PRAXIS: A METHOD FOR DIRECT PHOTOCATALYTIC DEFLUOROPRENYLATION}

Thesis Approved:

\begin{tabular}{c} 
Dr Jimmie D. Weaver III \\
\hline Thesis Adviser \\
Dr Frank D. Blum \\
\hline Dr Richard A. Bunce \\
\hline
\end{tabular}




\section{ACKNOWLEDGEMENTS}

I would like to express my gratitude to my advisor Dr. Jimmie D. Weaver for his immense support during my M.S. study. His immense knowledge, skillful guidance and constant motivation to excel in the field of chemistry really helped me to realize my potential.

I would also like to acknowledge my committee members Dr. Richard Bunce and Dr Frank Blum for their valuable inputs and helpful suggestions.

I fully enjoyed working in a healthy research lab environment and must also thank all my lab mates Anuradha, Sameera, Amandeep, Jon, Kamaljeet, Kip, Mo, Manjula, Winston and Ryne. It was a great pleasure sharing ideas and learning from each other. 
Name: SONAL PRIYA

Date of Degree: DECEMBER, 2018

Title of Study: PRENYL PRAXIS: A METHOD FOR DIRECT PHOTOCATALYTIC DEFLUOROPRENYLATION

\title{
Major Field: CHEMISTRY
}

\begin{abstract}
The prenyl fragment represents the most basic building block in terpenoids, a family of numerous and structurally diverse natural products that are known to possess interesting biological properties. In contrast, multifluorinated arenes are an important class of compounds that have found great utility in agricultural, material, and pharmaceutical industries. Fluorine substitution has been shown to impart a number of positive attributes including resistance to metabolic degradation, enhanced lipophilicity, and improved binding and passive diffusion of compounds across membranes. While allylation chemistry is well developed, effective prenylation strategies have been less forthcoming. Herein, we describe the defluoroprenylation via photocatalysis, a powerful method that provides access to "hybrid molecules" containing both the functionality of a prenyl group and fluorinated arenes. This approach involves direct prenyl group transfer under very mild conditions, displays excellent functional group tolerance, and relatively short reaction times $(<4 \mathrm{~h})$, which is the fastest photocatalytic $\mathrm{C}-\mathrm{F}$ functionalization developed to date. Additionally, the strategy can be further extended to include allyl and geranyl (10 carbon fragment) transfer. Another prominent finding is a reagent dependent switch in regioselectivity of the major product from para to ortho $\mathrm{C}-\mathrm{F}$ functionalization.
\end{abstract}




\section{TABLE OF CONTENTS}

$\begin{array}{lll}\text { Chapter } & \text { Page }\end{array}$

I. PRENYL PRAXIS: A METHOD FOR DIRECT PHOTOCATALYTIC DEFLUOROPRENYLATION ……………………….....................................

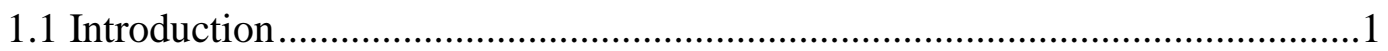

1.2 Development of photocatalytic defluoroprenylation reactions ............................5

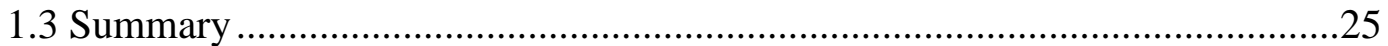

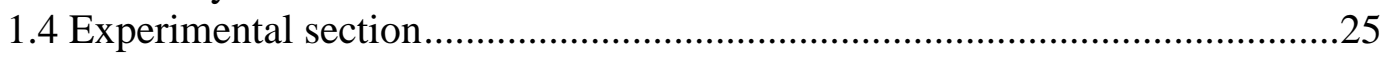

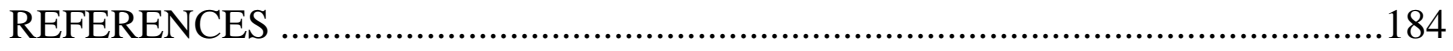

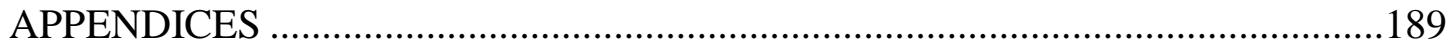




\section{LIST OF TABLES}

Table

Page

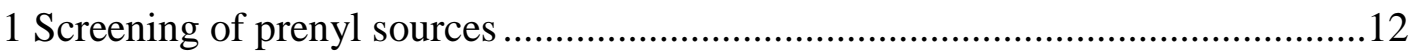

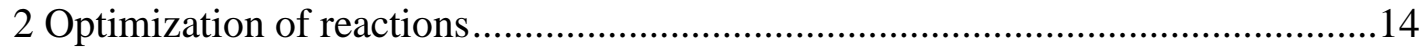

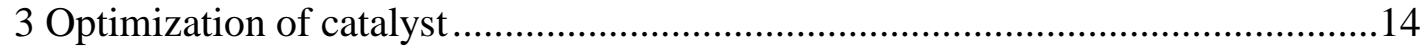

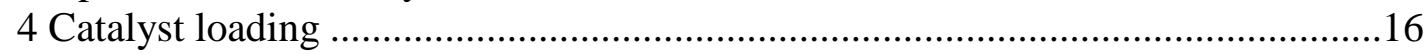

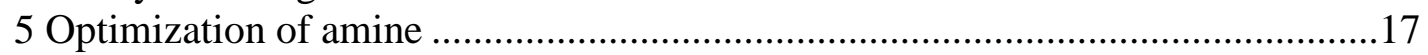

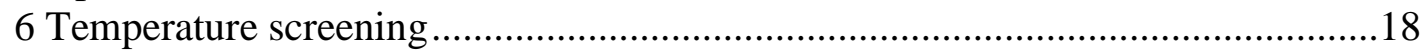

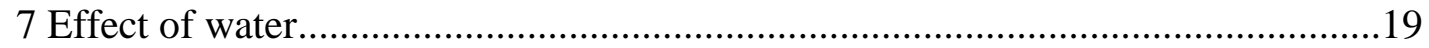

8 Experiments investigating the inhibitory effect of pentafluorophenol .................20

9 Effect of TEMPO on the rate and selectivity of reaction..................................21

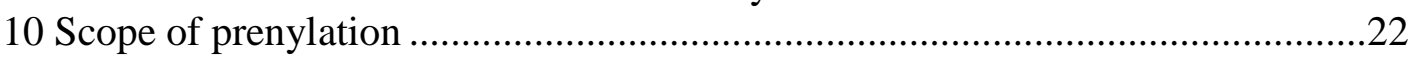

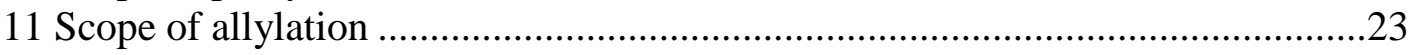

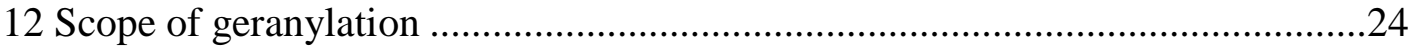

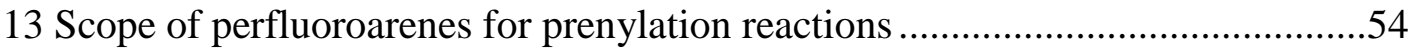

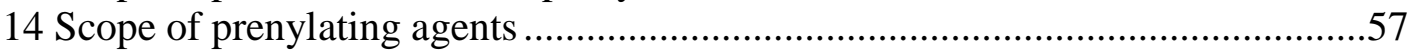

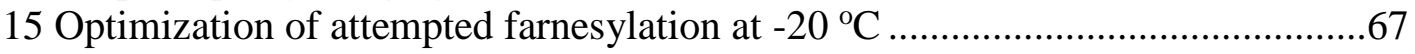

16 Change in product ratios on varying conditions ..........................................67

17 Evidence for no post-reaction isomerization in geranylated products ................79 


\section{LIST OF FIGURES}

$\begin{array}{lll}\text { Figure } & \text { Page }\end{array}$

1 Some common examples of terpenes...........................................................2

2 Fluorines in pharmaceutical industries ........................................................4

3 Agrochemicals containing fluorinated arenes...............................................

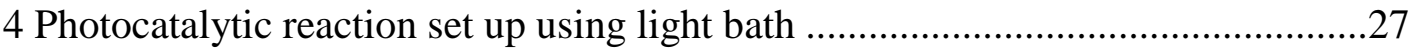

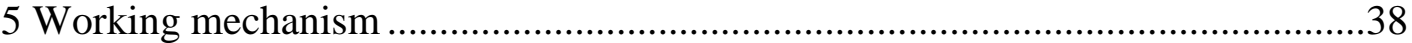

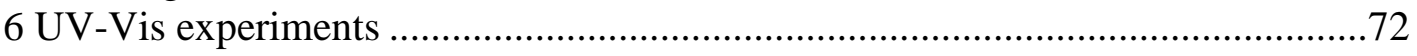

7 NMR titration experiments: variations in geranyl ether (without DIPEA) ............76

8 NMR titration experiments: variations in geranyl ether (with DIPEA) .................77

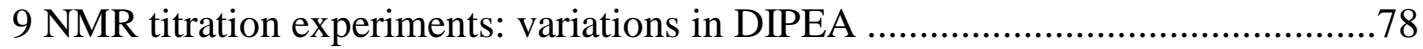

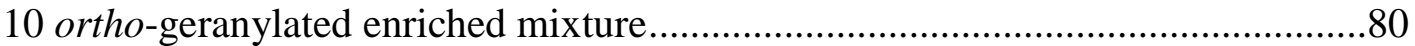

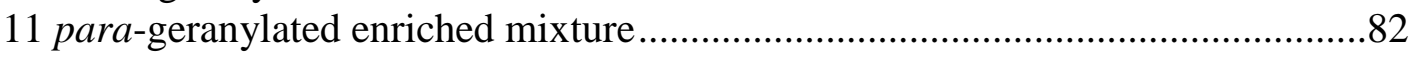




\section{LIST OF SCHEMES}

Scheme

Page

1 Challenges associated with transferring a prenyl group ...................................6

2 Unfavorable 'path a' to access prenylated indole alkaloids via cationic prenyl species 6

3 Kambe's approach to achieve prenylation on perfluoroarenes ............................6

$4 \mathrm{C}-\mathrm{H}$ allylation of multifluoroarenes ................................................................. 7

5 Palladium catalyzed allylation on perfluoroarenes using allyl carbonates ............. 7

6 Indirect prenylation via cross-metathesis...........................................................

7 Photocatalytic C-F functionalization of perfluoroarenes ................................. 9

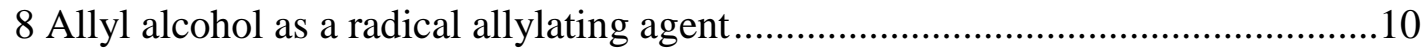

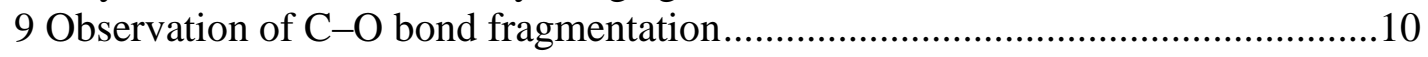




\section{CHAPTER I}

\section{PRENYL PRAXIS: A METHOD FOR DIRECT PHOTOCATALYTIC DEFLUOROPRENYLATION}

\subsection{Introduction}

The prenyl group is the most basic building block of terpenoid natural products and thus possesses interesting biological properties. ${ }^{1}$ Terpenes are a large and varied class of organic compounds that are known to possess a variety of impressive biological properties. ${ }^{2}$ These diverse bioactive structures have been widely utilized in delivering pharmacological properties, ${ }^{3}$ used as natural flavoring compounds in food industry ${ }^{4}$ and are the primary constituents of essential oils of a variety of medicinal plants and flowers. ${ }^{5}$ Some of the common terpenes (Figure 1.1) include myrcene (known for its highly sedative effects), ${ }^{6}$ limonene (common in citrus and a known anti-depressant), ${ }^{6-7}$ terpinolene (with woody aroma, slight sedative, antioxidant, anticancer and antibacterial),${ }^{8}$ beta-caryophyllene (gastroprotective and a strong anti-inflammatory with a woody, peppery taste), ${ }^{9} \alpha$-pinene (energetic and therapeutic common in pine needles), ${ }^{10}$ humulene (main constituent of hops, strong anti-inflammatory agent and hunger-suppressant). ${ }^{11}$ All terpenoids are synthesized from the same five-carbon building blocks (dimethylallyl pyrophosphate and isopentenyl pyrophosphate) but their structures and functions can be manipulated to meet specific requirements. ${ }^{12}$ These molecules have led to six major drug classes 


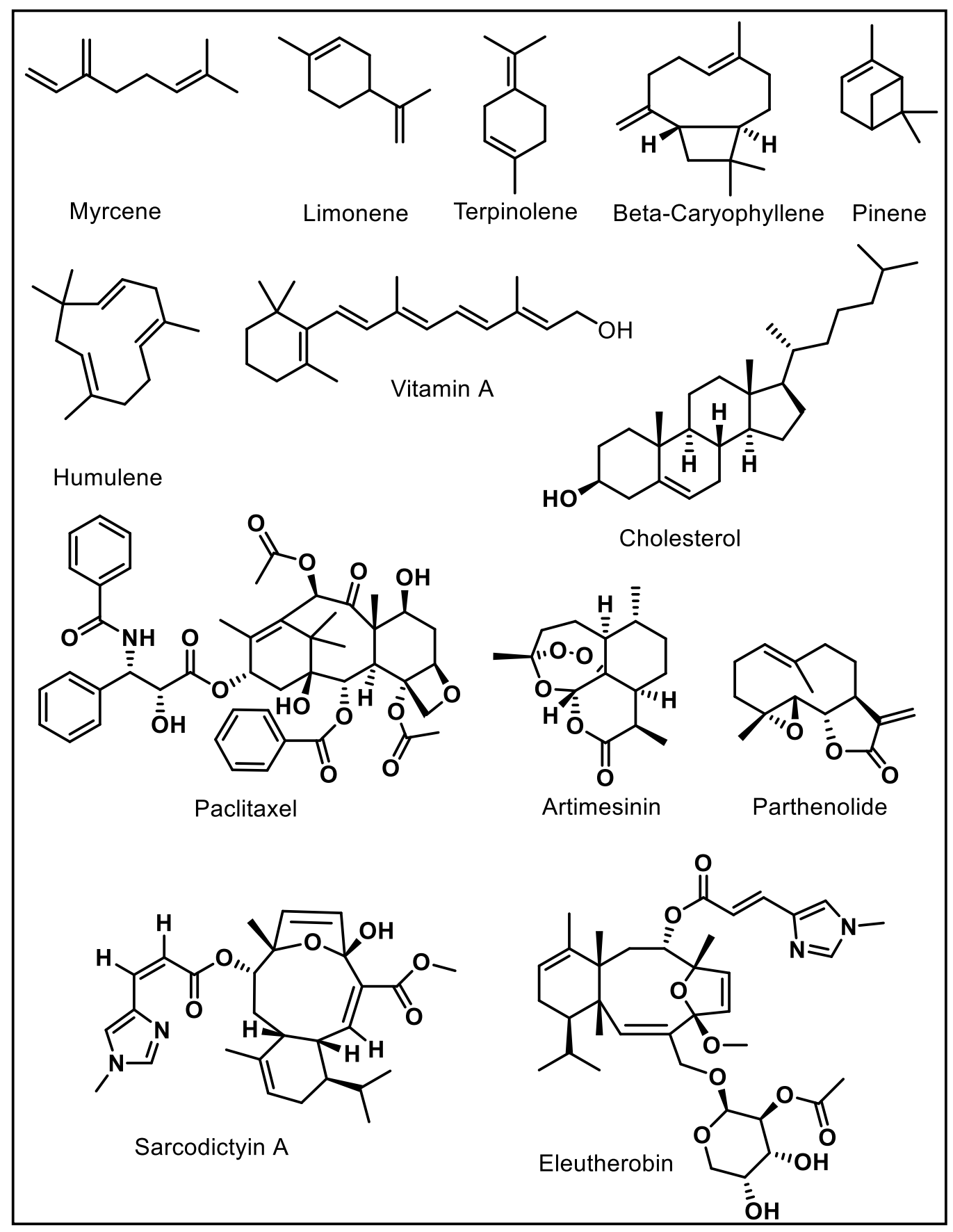

Figure 1.1: Some common examples of Terpenes.

over the last century, namely steroids, artemisinins, tocopherols, taxanes, ingenanes and cannabinoids. Some of the renowned terpene-based drugs include the anticancer drug Taxol (Paclitaxel) and the antimalarial drug Artimesinin (a sesquiterpene lactone). ${ }^{13}$ Parthenolide, 
another sesquiterpene lactone, exhibits exceptional anticancer and anti-inflammatory properties, that makes it a prominent drug candidate in development studies. Over the last 40 years, a large family of marine terpenes have also received attention for thier promising potential in medical applications. For instance, sarcodictyin A and eleutherobin from the Australian soft coral eleutherobia sp. and the stoloniferan coral sarcodictyon roseum respectively, are known to exhibit potent antitumor activity against a variety of tumor cells. ${ }^{14}$ Thus, there is no doubt that terpenoids will play an increasingly important role in drug development in the future.

Another class of compounds that have found great utility in the medical field are the multifluorinated arenes. ${ }^{15}$ They make up an important class of anthropogenic molecules that are highly relevant to the pharmaceutical (Figure 1.2), ${ }^{16}$ material ${ }^{17}$ and agrichemical industries (Figure 1.3) ${ }^{18}$ It is a well-known fact that fluorine's electronegativity, size, imparted lipophilicity, and electrostatic interactions can influence the chemical reactivity of a compound to a great extent. ${ }^{15 a-c, 15 e}$ In the pharmaceutical area, a number of fluorinated compounds with impressive activities have been successfully introduced into the market (Figure 1.2) as anti-depressants, antiinflammatory agents, antipsychotic drugs, antimalaria compounds, antiviral agents, anaesthetics and steroids. ${ }^{19}$ Fluorinated compounds are not only resistant to metabolic degradation, owing to the strong $\mathrm{C}-\mathrm{F}$ bond $\left(110 \mathrm{kcal} / \mathrm{mol}\right.$ for $\left.\mathrm{CH}_{3}-\mathrm{F}\right)$ but also enhance compound lipophilicity. This may result in improved passive diffusion of compounds across membranes which can be highly desirable when synthesizing drugs. ${ }^{20}$

Despite of the great importance that fluorinated molecules demonstrates, methods to build these valuable molecules largely depend on just a handful of rather harsh reactions, such as the Balz-Schiemann decomposition of an aryl diazonium tetrafluoroborate salt, ${ }^{21}$ or the high temperature $\left(\mathrm{ca} 230{ }^{\circ} \mathrm{C}\right.$ ) halex process. ${ }^{22}$ This limitation has led to dependence on commercially available pre-fluorinated building blocks that can simply be incorporated into other molecules. 
Almost certainly, this leads to incomplete structural activity relationships studies and understanding of fluorine's effects.

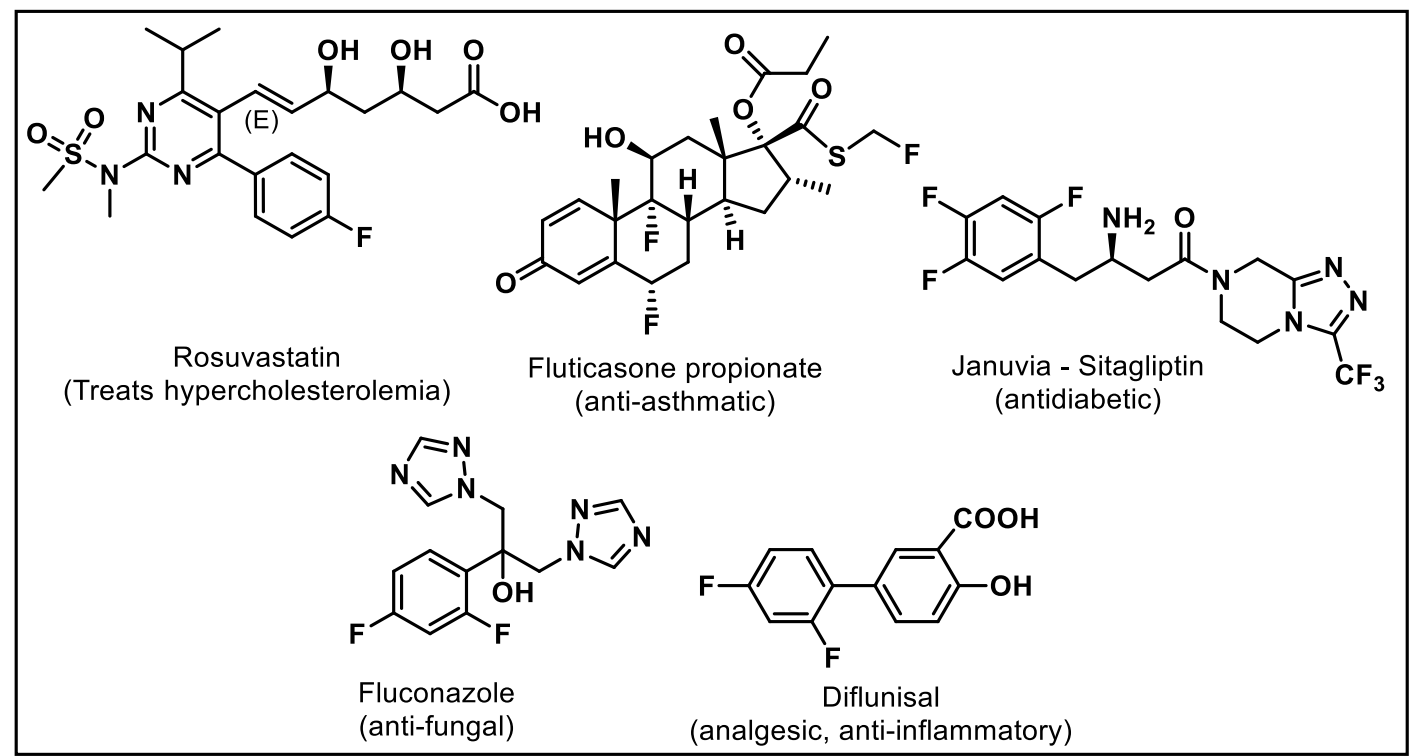

Figure 1.2: Fluorine in pharmaceutical industry<smiles>O=C(NC(=O)c1c(F)cccc1F)Nc1cc(Cl)c(F)c(Cl)c1F</smiles>

Teflubenzuron (Insecticide)<smiles>C/C(=N\NC(=O)Nc1cc(F)cc(F)c1)c1ncccc1C(=O)O</smiles>

Diflufenzopyr (Herbicide)<smiles>O=C(NC(=O)c1c(F)cccc1F)Nc1cc(Cl)c(Oc2ncc(C(F)(F)F)cc2Cl)c(Cl)c1</smiles><smiles>CO/N=C(/C(=O)OC)c1ccccc1CO/N=C(\C)c1cccc(C(F)(F)F)c1</smiles>

Trifloxystrobin (Fungicide)

Figure 1.3: Agrochemicals containing fluorinated arenes 


\subsection{Development of photocatalytic defluoroprenylation reactions}

Building on the C-F functionalization strategy put forth by Braun, ${ }^{23}$ Richmond, ${ }^{24}$ Uneyama ${ }^{25}$ and many others ${ }^{26}$ we developed reactions that start with inexpensive highly fluorinated arenes, and obtain more complex fluorinated arenes via selective C-F functionalization. As a result, the complexity of the fluorinated molecules that have now become accessible far exceeds that of previously synthesized derivatives. In this vein, we were drawn to the prenyl motif due to its ubiquity in nature as well as its synthetic versatility. Accomplishing this goal would allow us to wed the natural prenyl group and the unnatural perfluoroarenes to give hybrid molecules.

While allylation chemistry is relatively well developed, there are a number of challenges that arise while attempting prenylation (Scheme 1.1). Remarkably, this is a result of the two additional methyl groups found within the prenyl group. As electrophiles, they are prone to elimination. ${ }^{27}$ Previously, Danishefsky and co-workers ${ }^{27 a}$ proposed a cationic prenyl species to access prenylated indole alkaloids (Scheme 1.2), but the use of this synthon in enantioselective transformations has remained undeveloped. As an anion, prenylation causes regioselectivity issues similar to that observed by Kambe. ${ }^{28} \mathrm{He}$ demonstrated that copper(II) chloride could facilitate the formation of a prenyl magnesiate that would then undergo uncatalyzed addition to the perfluoroarene (Scheme 1.3). The major product results from linear addition of the most stable prenyl metal species, but also gives rise to a total of 4 isomers in substantial quantities in a combined yield (67\%), where the major isomer (2) resulted from the reductive coupling at the internal carbon of unsubstituted $\mathrm{C}-\mathrm{C}$ double bond. Also, the use of a prenyl radical might lead to selectivity in the addition, but addition to arene would be highly endothermic. 

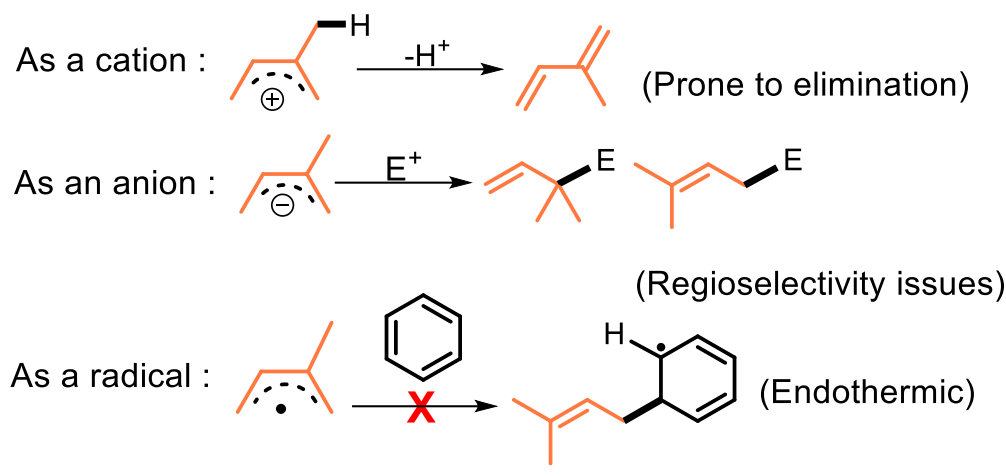

Scheme 1.1: Challenges associated with transferring a prenyl group

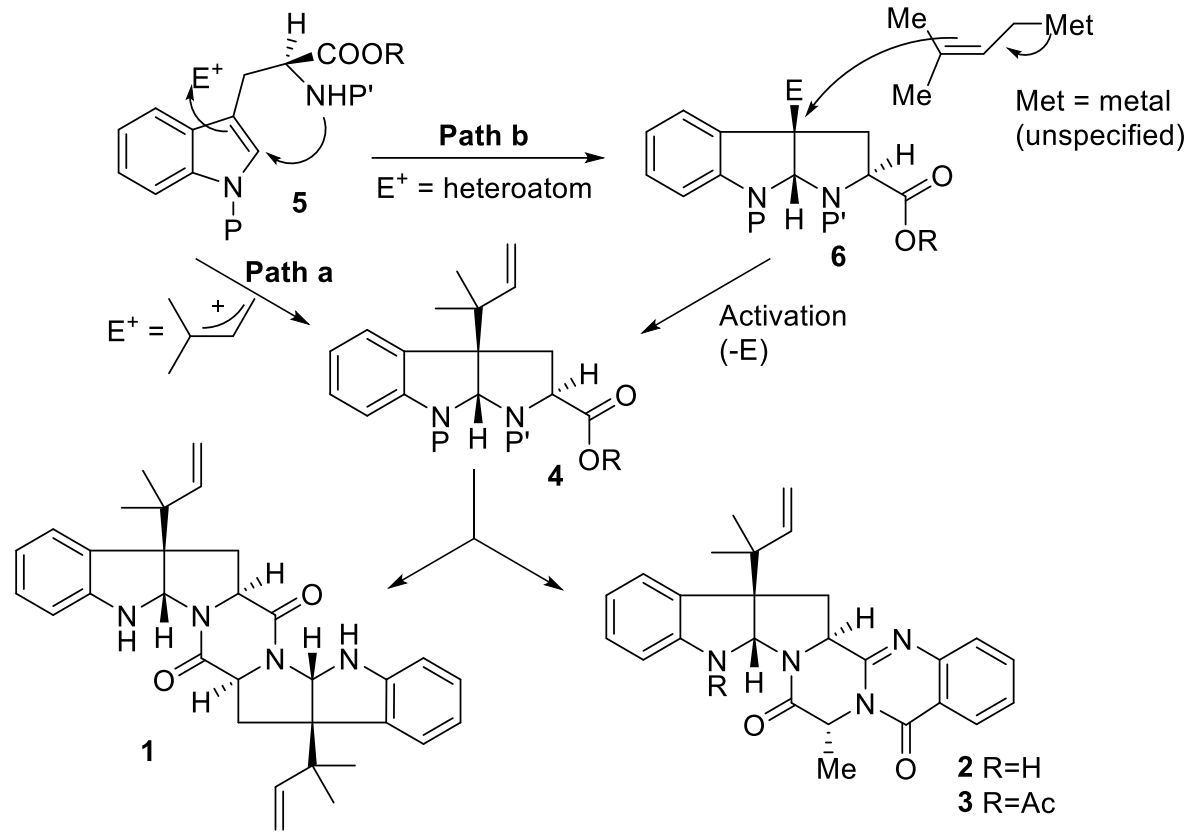

Scheme 1.2: Unfavorable 'path a' to access prenylated indole alkaloids via cationic prenyl species

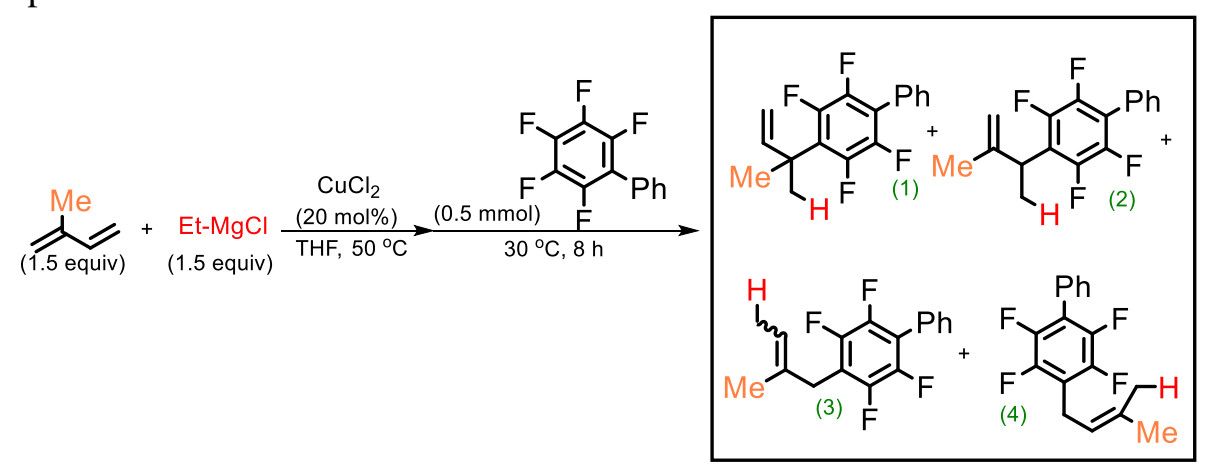

$67 \% ;(1):(2):(3):(4)=2: 77: 10: 11 ; E / Z=50 / 50$

Scheme 1.3: Kambe's approach to achieve prenylation on perfluoroarenes 
Several strategies have been explored to achieve related allylation on perfluoroarenes ${ }^{29}$ via $\mathrm{C}-\mathrm{F}$ functionalization both directly and indirectly. Sukbok and co-workers ${ }^{29 \mathrm{f}}$ have shown that $\mathrm{C}-\mathrm{H}$ functionalization of highly fluorinated arenes could be attained by using a $\mathrm{Cu}(\mathrm{NHC})$ catalyst, which has become increasingly relevant with recent improvements to hydrodefluorination technologies, ${ }^{26 b, 30}$ but at the very least, requires two steps (Scheme 1.4).

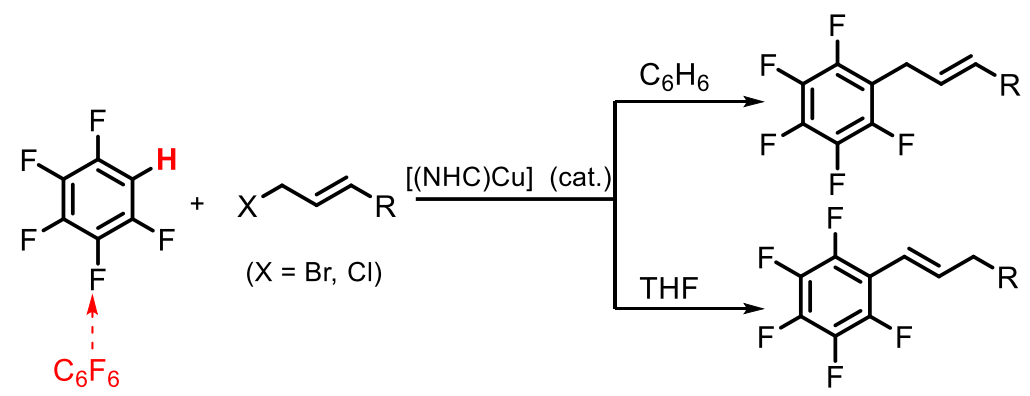

Scheme 1.4: C-H allylation of multifluoroarenes

Allylation on perfluoroarenes has also been achieved by Zhang and co-workers ${ }^{29 b}$ in 2011 (Scheme 1.5). They employed $\mathrm{Pd}(\mathrm{OAc})_{2}$ to carry out this transformation using allyl carbonates and partially fluorinated arenes. While this was a great strategy, the reaction conditions required relatively high temperatures (over $100{ }^{\circ} \mathrm{C}$ ) for extended periods (12 hours) and its applicability to other fluorinated arenes could only be expanded as far as hydrodefluorination was possible since it took place via $\mathrm{C}-\mathrm{H}$ functionalization.
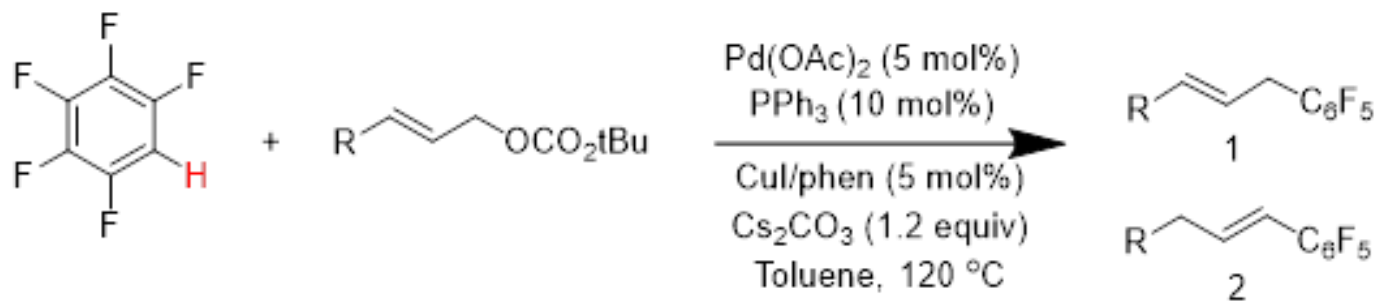

Scheme 1.5: Palladium catalyzed allylation on polyfluoroarenes using allyl carbonates 
Other indirect workarounds such as allylation followed by cross-metathesis with isobutene to install the remaining geminal dimethyl group have also been employed to accomplish prenylation. For instance, Porco and co-workers ${ }^{31}$ employed indirect allylation followed by crossmetathesis to achieve prenylation in order to access a class of polyprenylated acylphloroglucinols (Scheme 1.6).
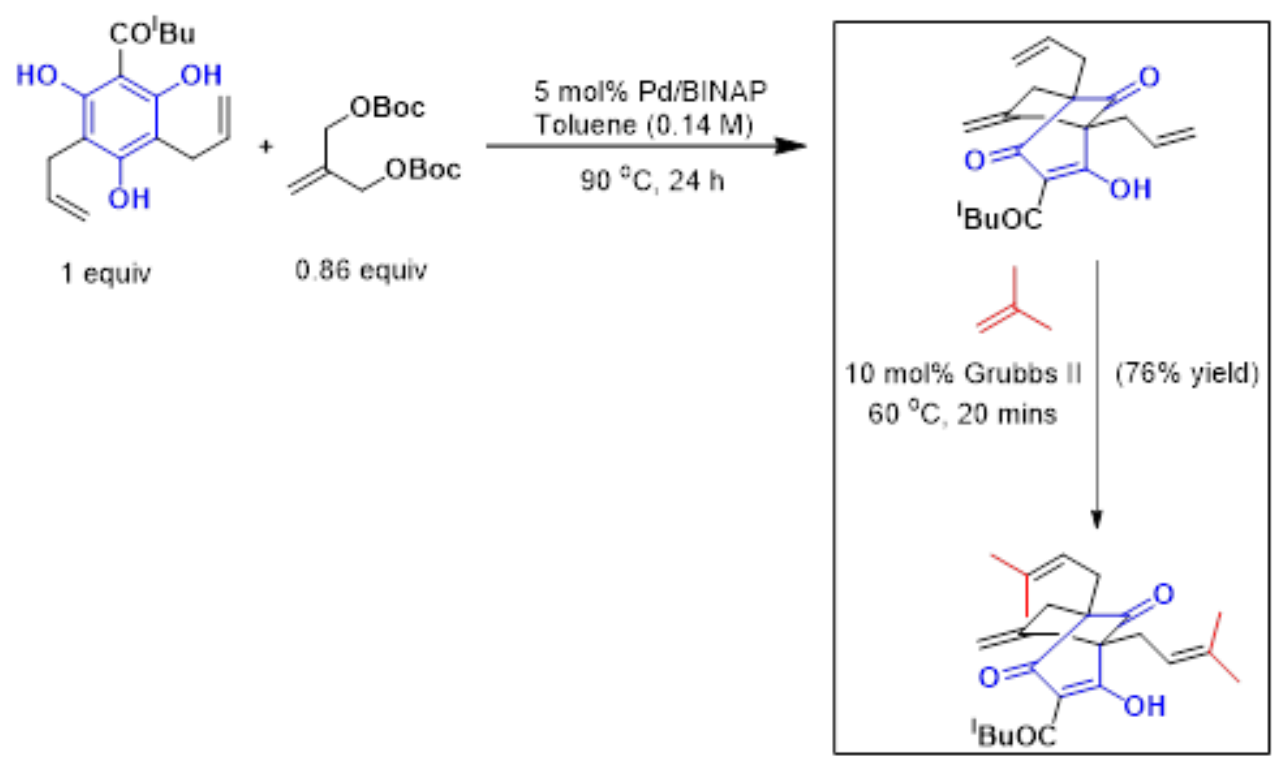

Scheme 1.6: Indirect prenylation via cross-metathesis

Previously, the Weaver group has shown that upon photocatalytic electron transfer to a perfluoroarene, an unstable radical anion forms, which then undergoes mesolytic cleavage to extrude a fluoride and a perfluoroaryl radical (Scheme 1.7). ${ }^{30,} 32$ This approach solves several challenges associated with the short, remarkably strong, and nonpolarizable $\mathrm{C}-\mathrm{F}$ bond. As a result, the $\mathrm{C}-\mathrm{F}$ bond is both kinetically and thermodynamically robust. Furthermore, even if the bond is broken, and fluoride is formed, fluoride often forms strong and stable metal-F bonds that can lead to poor catalyst turnover, thereby making metal-catalyzed processes difficult. Thus, it was possible to achieve hydrodefluorination on perfluoroarenes ${ }^{30 d}$ by accessing the perfluoroaryl radical generated in the reaction which could abstract a hydrogen atom from amine radical cation. Perfluoroaryl radical was also utilized to intercept with an alkene to form $\mathrm{C}-\mathrm{C}$ alkylated product with the addition taking place selectively at the unsubstituted position of the alkene. ${ }^{33}$ 


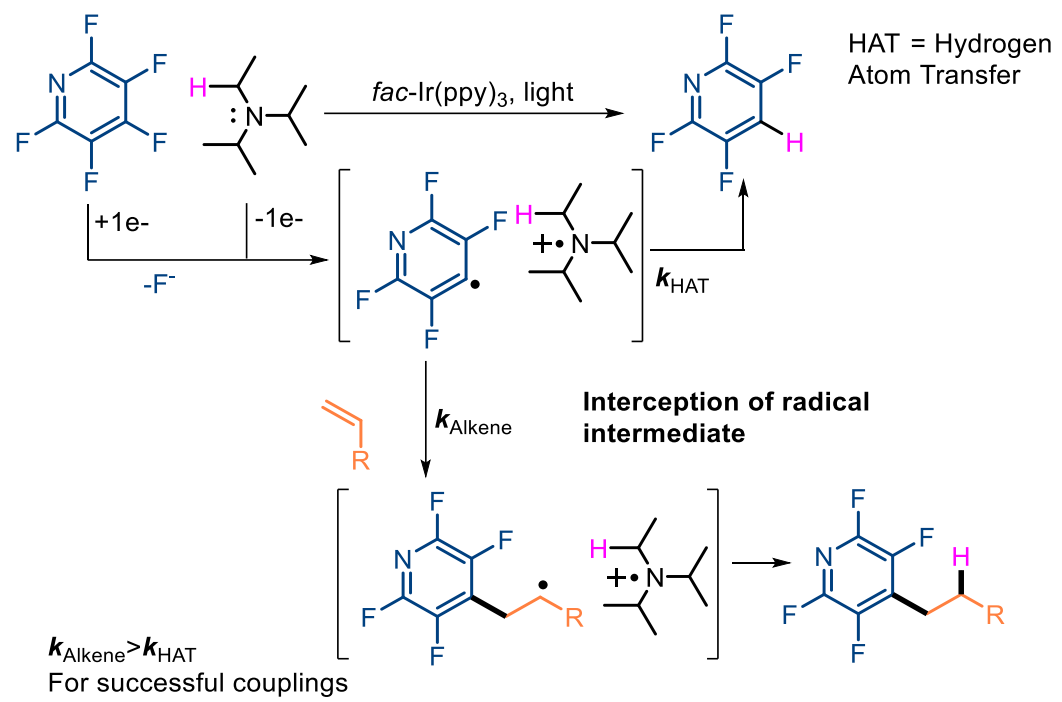

Scheme 1.7: Photocatalytic C-F functionalization of perfluoroarenes

Inspired by the work of Zard who has popularized a number of allyl radicophiles, ${ }^{34}$ (olefins with captodative substitution ${ }^{35}$ ) we envisioned that such a reagent could be designed to facilitate photocatalytic C-F prenylation. Our hope was that this radicophile would intercept the photocatalytically generated perfluoroaryl radical to regioselectively generate the key $\mathrm{C}-\mathrm{C}$ bond. The addition would result in an alkyl radical intermediate that we hoped to entice to undergo homolytic fragmentation of the $\beta$-leaving group, unmasking the prenyl group. We anticipated that the nature of the leaving group would be key to preventing simple hydrogen atom transfer (HAT) to the radical. ${ }^{32 b}$ Zard and co-workers developed systems that could combine the use of allylic alcohol derivatives and readily available xanthates under metal-free conditions to make alkenes, aldehydes, saturated and unsaturated ketones through homolytic cleavage of the normally strong $\mathrm{C}-\mathrm{O}$ or $\mathrm{C}-\mathrm{C}$ bond. ${ }^{34 \mathrm{~b}}$ The activated allylic alcohol derivatives could be synthesized in two steps from aldehydes or ketones. They could also be obtained by base-induced opening of epoxides. In order to use allylic alcohols for allylation, an easily introducible appendage, (Y, Scheme 1.8), was needed that would weaken the strong $\mathrm{C}-\mathrm{O}$ bond and render it prone to radical fragmentation. In an attempt to construct dihydrobenzofurans via a radical addition-cyclization sequence (Scheme 1.9), they observed pent-4-enenitrile instead of the expected dihydrobenzofuran. The $\beta$ - 
fragmentation was seen to be faster than either the reversible cyclization or the oxidation step. Apart from the gain in entropy, the driving force for $\beta$-scission could presumably be the relative weakness of the $\mathrm{C}_{\mathrm{alkyl}}-\mathrm{O}$ bond which is weakened due to the formation of a stabilized phenoxyl radical.

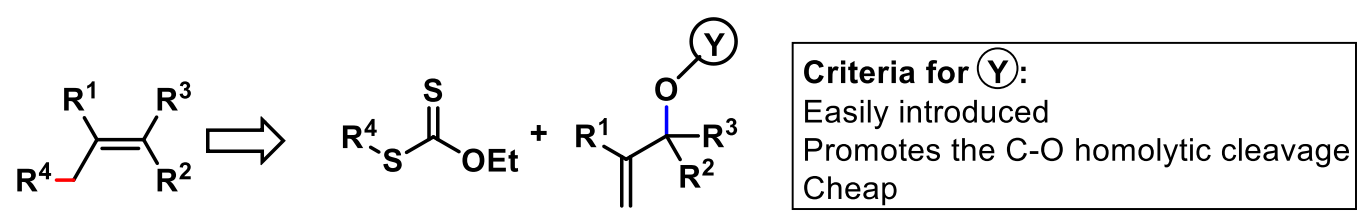

Scheme 1.8: Allyl alcohol as a radical allylating agent

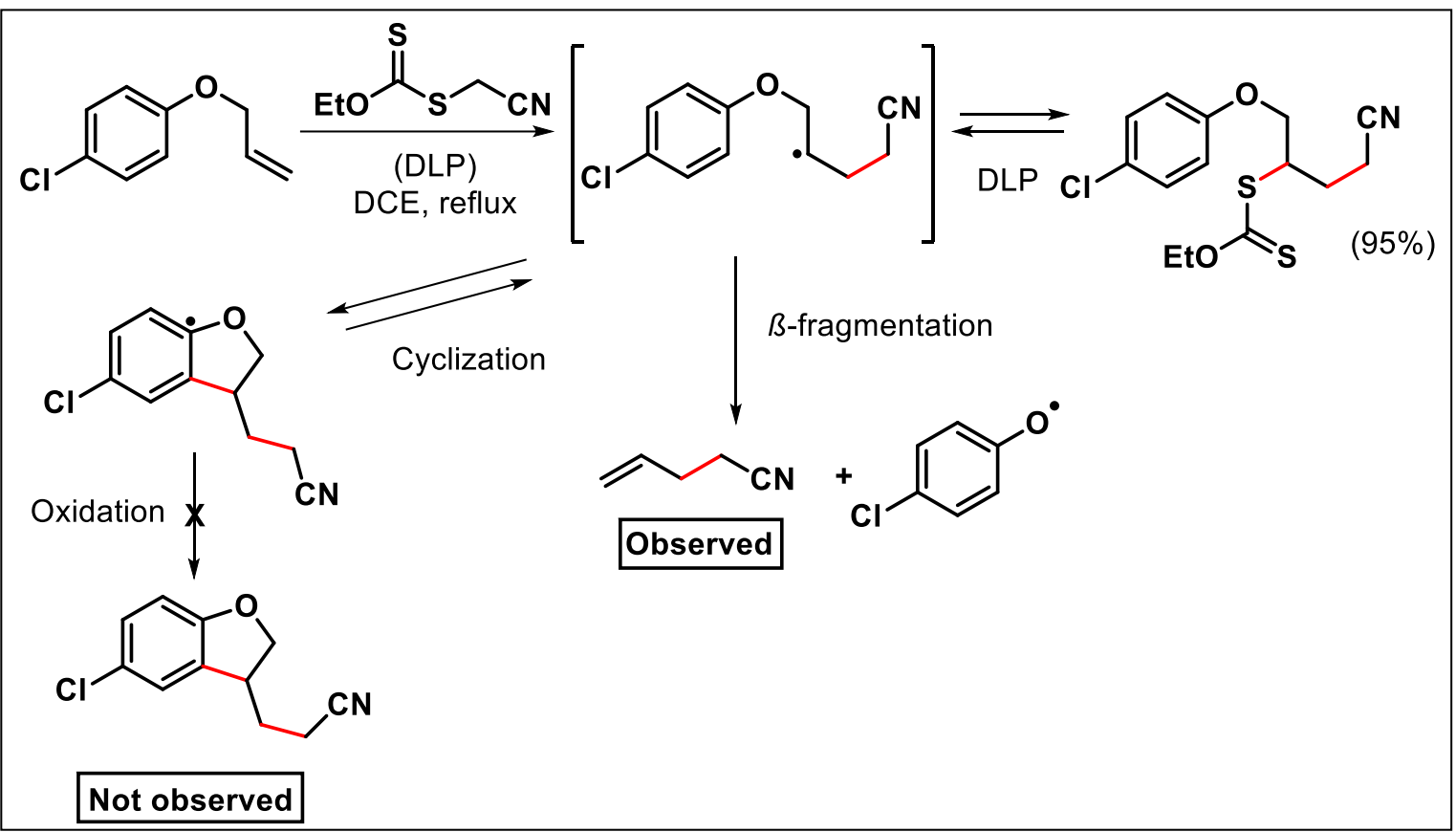

Scheme 1.9: Observation of $\mathrm{C}-\mathrm{O}$ bond fragmentation

Therefore, Zard demonstrated that the $\mathrm{C}-\mathrm{O}$ bond of allyl alcohol $(80.1 \mathrm{kcal} / \mathrm{mol} \mathrm{BDE})^{36} \mathrm{can}$ be weakened by converting the hydroxy to an aryloxy group; rendering it susceptible to homolytic fragmentation. ${ }^{34,37}$ This stabilization is mirrored by the phenoxy radical $(\mathrm{PhO}-\mathrm{H}$ BDE $=87.3$ $\mathrm{kcal} / \mathrm{mol})$ which is more stable than hydroxyl radical $(\mathrm{HO}-\mathrm{H} \mathrm{BDE}=119.3 \mathrm{kcal} / \mathrm{mol}){ }^{38}$ 
Thus, we began our investigation with the hope of finding a group capable of activating the $\mathrm{C}-\mathrm{O}$ bond towards homolytic fragmentation (Table 1.1). As expected, reaction with isoprenyl alcohol (Figure 13, 2a) itself simply results in hydroarylation of the alkene, ${ }^{32 c}$ highlighting the need for an activating group that can increase the rate of fragmentation. Next, we assessed the 6halopyridine motif $(\mathbf{2 b}, \mathbf{2 c})$ previously explored by $\operatorname{Zard}^{37}$ in lauroyl peroxide mediated transfer of xanthates to olefins. The pyridyl group is conveniently introduced via nucleophilic addition of isoprenyl alcohol to the corresponding fluoroarene. We were delighted to see the desired prenylated product (3a) in $54 \%$ and $43 \%$ respectively. The mass balance was primarily comprised of hydrodefluorination (HDF) as well as an oxidized version of the desired product, which was only identified by GCMS. However, reagents $\mathbf{2 b}$ and $\mathbf{2 c}$ both underwent competitive [3,3]sigmatropic rearrangement, which further complicated the situation and necessitated higher reagent loading to compensate for this background reaction that effectively reduced the concentration of the prenyl transfer reagent present in solution. By blocking the ortho position with an ester group and increasing the steric demand (2d), we hoped to curtail both the rearrangement and the oxidation. Indeed, we halted the rearrangement, but unfortunately, this reagent did not deliver the desired prenylated product, but instead yielded only hydrodefluorination (HDF) product. This behavior is perhaps due to competitive and unproductive electron transfer to $\mathbf{2 d}$ rather than the perfluoroarene. 
Table 1.1: Screening of prenyl sources

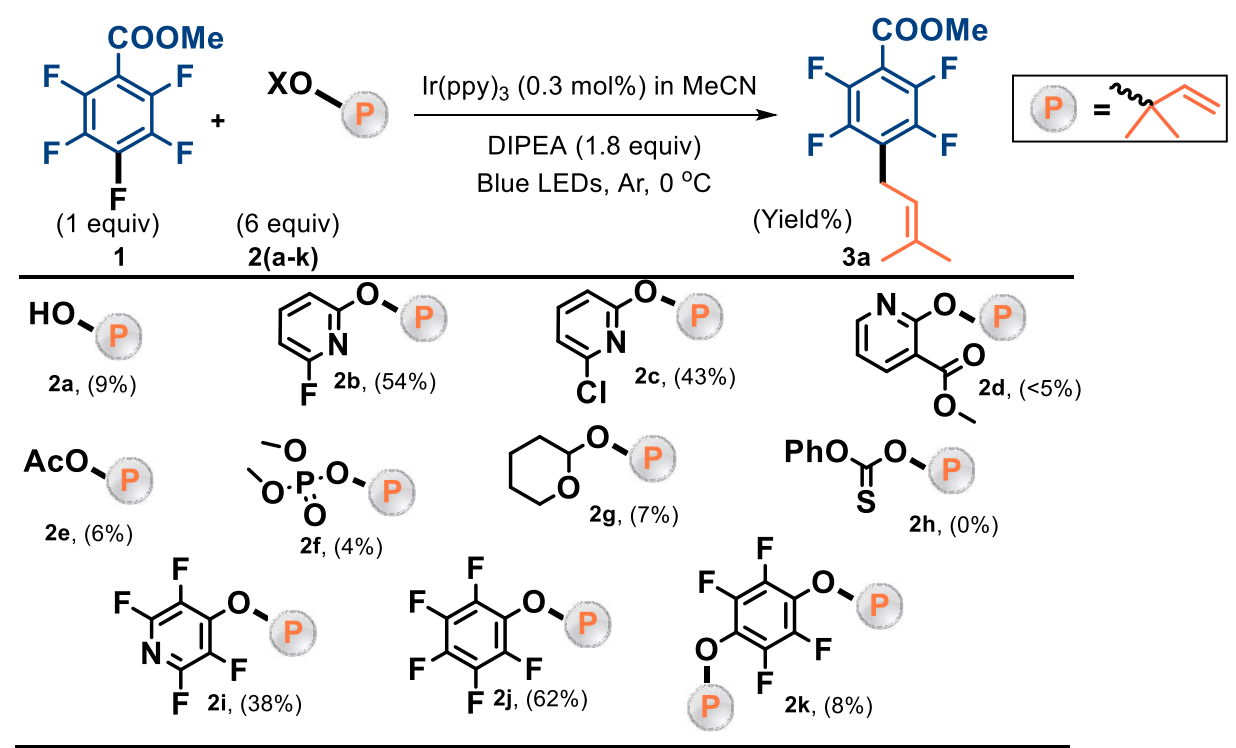

Observed: 2a - HDF, amine addition, C-O coupling, 2b and 2c-HDF, oxidized prenylation, [3,3]-rearrangement, $2 \mathbf{d}->90 \% \mathrm{HDF}, \mathbf{2 e}-\mathrm{HDF}, \mathrm{C}-\mathrm{O}$ coupling, multiple side products, $\mathbf{2 f}$ - mostly HDF, multiple side products, $\mathbf{2 g}$ - HDF, incomplete conversion, $\mathbf{2} \mathbf{h}$ - HDF, multiple side products, $\mathbf{2} \mathbf{i}$ - HDF, $\mathbf{2} \mathbf{j}$ - HDF, $\mathbf{2 k}$ - HDF.

The importance of a weak $\mathrm{C}-\mathrm{O}$ bond can be observed in low yields of $\mathbf{2 e}$ and $\mathbf{2 f}$, which would be expected to work better if the $\mathrm{C}-\mathrm{O}$ bond were to break heterolytically. However, substrates $\mathbf{2 g}$ and $\mathbf{2 h}$ were expected to have a weaker $\mathrm{C}-\mathrm{O}$ bond and still failed to give improved yields. We next evaluated aryl ethers formed from the perfluoroarene ( $\mathbf{2} \mathbf{i}$ and $\mathbf{2 j}$ ). We were pleased to see that these prenyl transfer reagents afforded the desired product, with HDF as the only by-product. It is possible that the fluorines on the reagent serve to prevent rearrangement and sterically reduce the activity of the resulting aryloxy radical, potentially involved in the formation of the previously observed oxidized product. However, 2k displayed significantly decreased activity even though it contained two prenyl groups. Given the positive results and the simple nature of $\mathbf{2} \mathbf{j}$ we opted to use it for further reaction development.

Using conditions that had facilitated C-F reductive alkylation, ${ }^{32 b}$ using Blue LEDs we irradiated methyl pentafluorobenzoate and diisopropylethyl amine (DIPEA) as the electron source, along with 6 equiv of $\mathbf{2 j}$ at $0{ }^{\circ} \mathrm{C}$. Previously, we observed that lowering the temperature could reduce the amount of competitive HDF in the related $\mathrm{C}-\mathrm{F}$ arylation reaction. ${ }^{32 \mathrm{~d}} \mathrm{We}$ were 
pleased to see that the desired $\mathrm{C}-\mathrm{C}$-coupled product was formed as the major product in decent yield, albeit along with a significant amount of HDF product (Table 1.2, entry 1). No prenylation or HDF of reagent $\mathbf{2} \mathbf{j}$ was observed. Control studies demonstrated the necessity of light, catalyst, and amine (entry 2-3). Carrying out the reaction at lower temperature increased the reaction time with no significant improvement in 3a:3a' ratio (entry 4). While decreasing the DIPEA loading slowed the reaction, increasing amine resulted in more HDF (entry 5-7); ultimately, 1.8 equivalents of DIPEA produced the optimal yield. There appeared to be a rate dependency on catalyst concentration (entries 8 and 9). Next, we investigated the effect of water on the reaction. Unexpectedly, the presence of water significantly accelerated the reaction from $18 \mathrm{~h}$ to less than 4 $\mathrm{h}$ and improved product: HDF ratio (entry 10-11). One explanation could be the increase in exothermicity of the reaction due to hydration of fluoride. ${ }^{39}$ An alternative explanation is that water acidifies the pentafluorophenol generated in situ. By doping the reaction mixture with pentafluorophenol we observed its inhibitory effect on the reaction progress. This effect was diminished upon addition of water. An alternative explanation could involve the build up of the DIPEA derived iminium, which could competitively quench the photocatalyst. The addition of water could help consume the iminium, preventing unproductive photoquenching. Recently, Wu showed that the competitive reduction product could be minimized by the addition of TEMPO. ${ }^{40}$ Therefore, we ran the reaction in the presence of TEMPO and found it initially helped, but ultimately slowed the reaction substantially. 
Table 1.2: Optimization of reactions

\begin{tabular}{|c|c|c|c|c|}
\hline & $\begin{array}{c}\text { fac-Ir(ppy })_{3}(0.3 \mathrm{~mol} \%) \\
\text { BPEA (1.2 equiv), MeCN } \\
\text { Blue LEDs, } \mathrm{Ar}, 0^{\circ} \mathrm{C}\end{array}$ & 3a & & $\begin{array}{l}H^{\prime} \\
3 a^{\prime}\end{array}$ \\
\hline Entry & Modifications & $\begin{array}{c}\text { Yield of } \\
3 a(\%)^{a}\end{array}$ & 3a:3a'd & Time (h) \\
\hline 1 & none & $31 / 62$ & $1.6: 1$ & $5 / 17$ \\
\hline 2 & no cataylst or in dark & 0 & na & $17^{b}$ \\
\hline 3 & without amine & 0 & na & $17^{b}$ \\
\hline 4 & $-10^{\circ} \mathrm{C}$ instead of $0{ }^{\circ} \mathrm{C}$ & 29/64 & $1.7: 1$ & $5 / 25$ \\
\hline 5 & DIPEA ( 1.0 equiv) & $25 / 57$ & $2: 1$ & $5 / 23^{b}$ \\
\hline 6 & DIPEA ( 1.8 equiv) & $36 / 64$ & 1.9:1 & $5 / 18$ \\
\hline 7 & DIPEA (2.5 equiv) & $38 / 57$ & 1.3:1 & $5 / 15$ \\
\hline 8 & $0.25 \mathrm{~mol} \%$ catalyst, DIPEA ( 1.8 equiv) & $31 / 58$ & $1.8: 1$ & $5 / 24$ \\
\hline 9 & $0.025 \mathrm{~mol} \%$ catalyst, DIPEA ( 1.8 equiv) & $6 / 28$ & $1.6: 1$ & $5 / 24^{b}$ \\
\hline 10 & $\mathrm{H}_{2} \mathrm{O}$ (10 equiv), DIPEA (1.8 equiv) & $57 / 65$ & $1.9: 1$ & $3 / 4$ \\
\hline 11 & $\mathrm{H}_{2} \mathrm{O}$ (15 equiv), DIPEA (1.8 equiv) & $59 / 65$ & $1.9: 1$ & $3 / 4$ \\
\hline 12 & Entry 10 with 0.4 equiv TEMPO & $39 / 68$ & 2.1:1 & $4 / 10$ \\
\hline \multicolumn{5}{|c|}{$\begin{array}{l}{ }^{a} \text { Determined by }{ }^{19} \mathrm{~F} \text { NMR analysis. Reaction complete unless otherwise } \\
\text { noted. }{ }^{b} \text { Reaction did not go to completion over extended time, observed } \\
0 \%, 0 \%, 83 \% \text { and } 44 \% \text { conversion of } 1 \text { in entries } 2,3,5 \text { and } 9 \\
\text { respectively. }{ }^{d} \text { Reported for the final time point. }\end{array}$} \\
\hline
\end{tabular}

These data were summarized after a more extensive study that included variations in several parameters and careful optimizations.

Table 1.3: Optimization of Catalyst

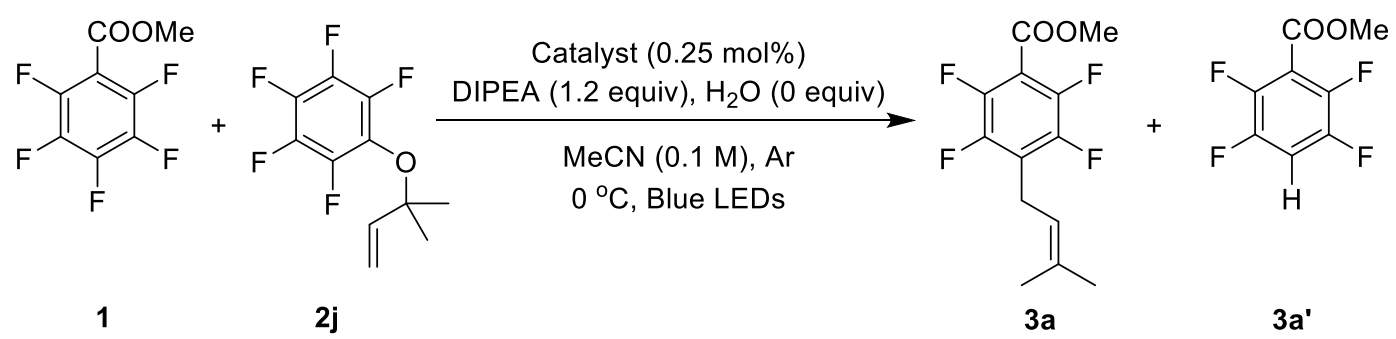




\begin{tabular}{|llrrrll|}
\hline Entry & modification & Time $(\mathbf{h})$ & $\mathbf{1}$ & $\mathbf{3 a}$ & $\mathbf{3 a}$ & (\% compound) \\
\hline 1. & no catalyst & 24 & 100 & - & - & \\
\hline 2. & Catalyst A & 21 & 12 & 58 & 30 & \\
\hline 3. & Catalyst B & 21 & 15 & 53 & 32 \\
4. & Catalyst C & 24 & 48 & 29 & 23 \\
5. & Catalyst D & 24 & 72 & 17 & 11 \\
6. & Catalyst E & 24 & 67 & 20 & 12
\end{tabular}

(Determined by 19F NMR)
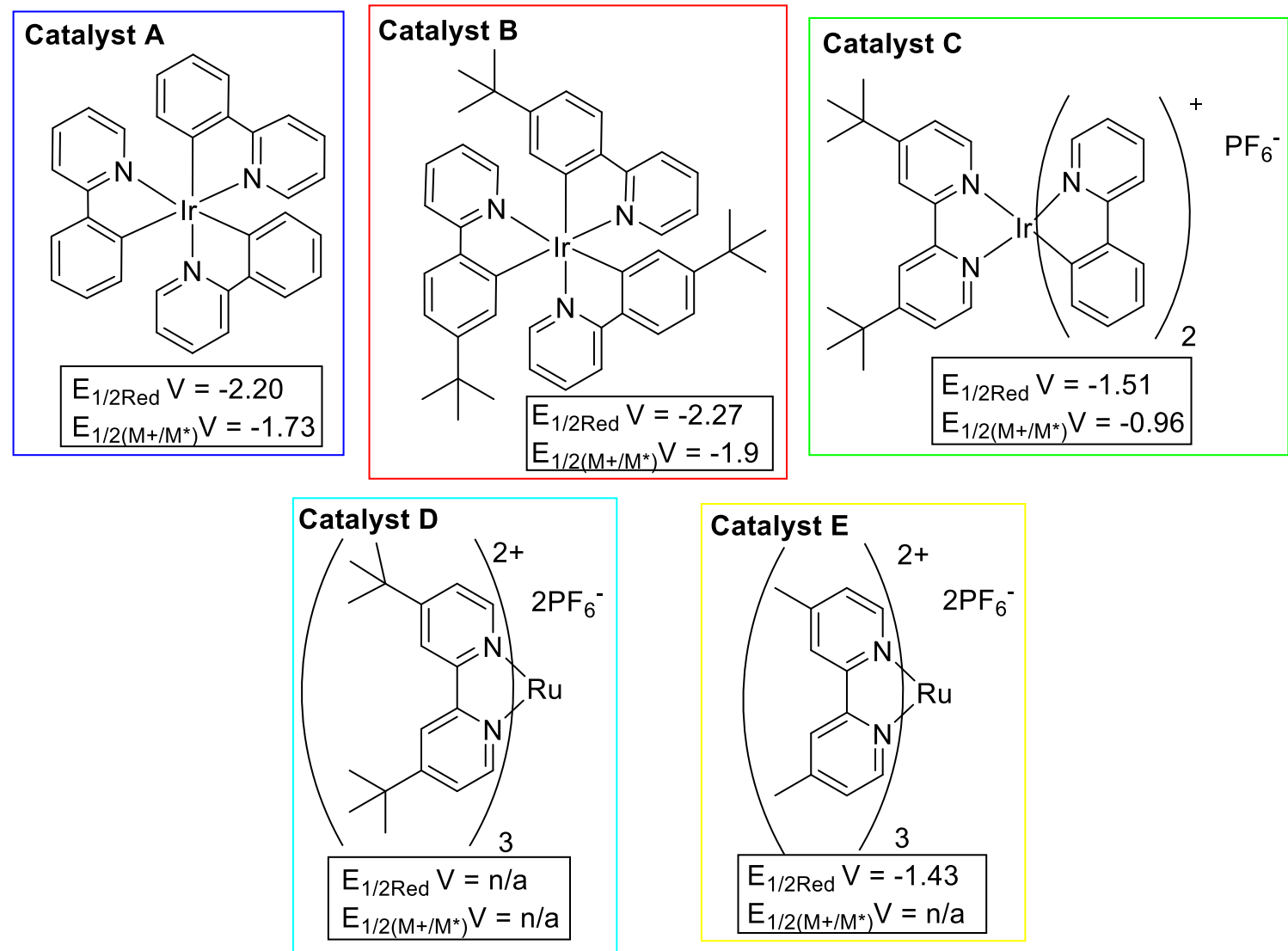

The presence of the photocatalyst was required, as indicated by the photocatalyst control reaction (Table 1.3, entry 1$)$, in which no conversion was observed. Catalyst A ( $f a c$ - $\left.\operatorname{Ir}(\text { ppy })_{3}\right)$ produced considerable amount of prenylated product (58\%) within $21 \mathrm{~h}$. Catalyst B also worked well producing $53 \%$ of the desired prenylated product within $21 \mathrm{~h}$, however the Pdt:HDF ratio was observed to be slightly better in case of Catalyst A. Less reducing Catalyst $\mathrm{C}$ also facilitated the reaction, resulting in the desired $\mathrm{C}-\mathrm{C}$ coupled product, albeit at significantly diminished rates and with diminished product selectivity. Remarkably, both Catalyst D and E also facilitated 
prenylation despite an anticipated substantial underpotential. The reaction in these cases was slow with no considerable progress after $24 \mathrm{~h}$.

Table 1.4: Catalyst loading

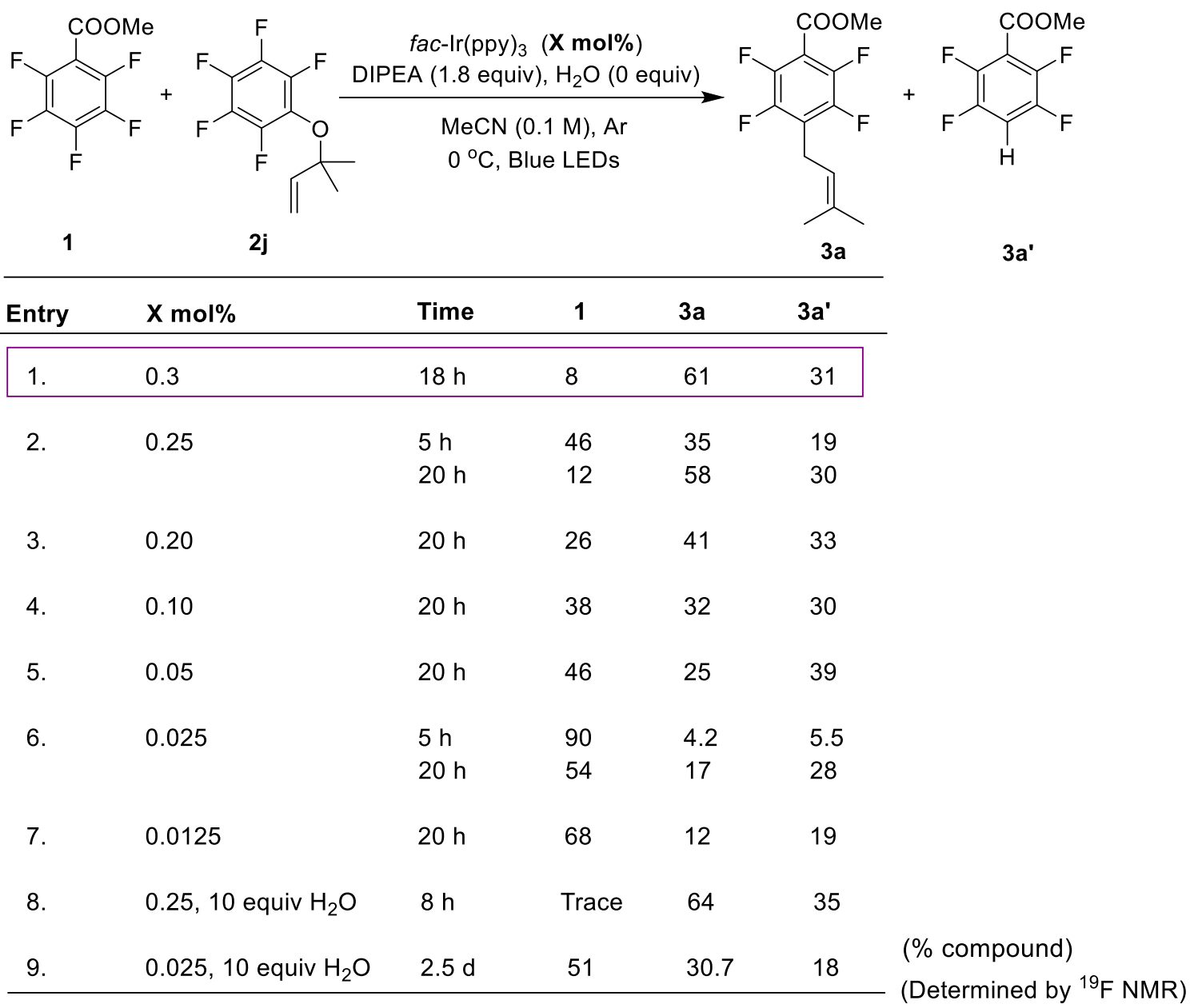

The catalyst loading experiments clearly demonstrated the rate dependency on the concentration of the catalyst. Higher concentrations of the catalyst (Table 1.4, entry 1,2 ) produced the fastest reactions with good conversions within $20 \mathrm{~h}$. The rate of reaction significantly dropped with a decrease in concentration of the catalyst. Interestingly, while water seems to accelerate the reaction at $0.25 \mathrm{~mol} \%$, this acceleration is reduced at much lower catalyst loadings (compare entries $2 \& 8$ to $6 \& 9$ ). This might be explained by a trace impurity in the reaction mixture that effectively quenches the photocatalyst when it too is present only in very trace amounts. 
Table 1.5 : Optimization of Amine
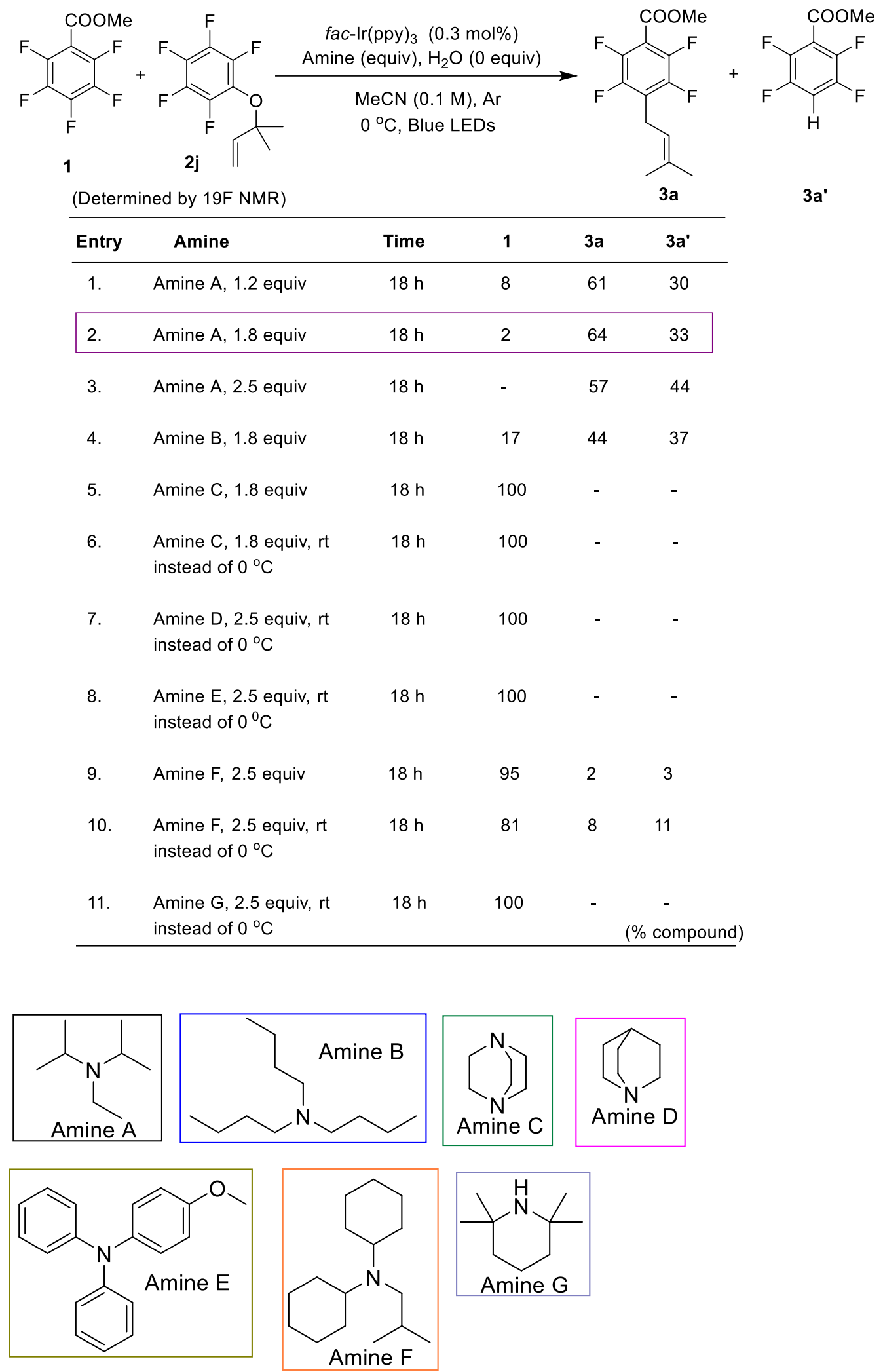
Amine A (DIPEA) produced prenylated products in moderate to high yields in $18 \mathrm{~h}$ (Table 1.5, entry 1-3). Increasing amine concentration to 1.8 equiv produced better conversion as compared to 1.2 equiv. When the amine concentration was further increased to 2.5 equiv, it resulted in complete consumption of starting material within $18 \mathrm{~h}$ but it also produced more of HDF sideproduct. Therefore, 1.8 equiv DIPEA was chosen to be the best condition. Amine B (entry 4) was also able to form desired prenylated product but in slightly lower yield. Switching the amine to Amines C-E (entry 5-8) did not result in any product formation even when the reaction was warmed to room temperature $\left(27^{\circ} \mathrm{C}\right)$ instead of running at $0{ }^{\circ} \mathrm{C}$. Compared to Amine $\mathrm{A}$, Amine $\mathrm{F}$ gave lower conversion of the starting material at $0{ }^{\circ} \mathrm{C}$, as well as at room temperature (entry 9 , 10) probably because of its lower solubility. Amine G did not result in any conversion.

Table 1.6: Temperature Screening
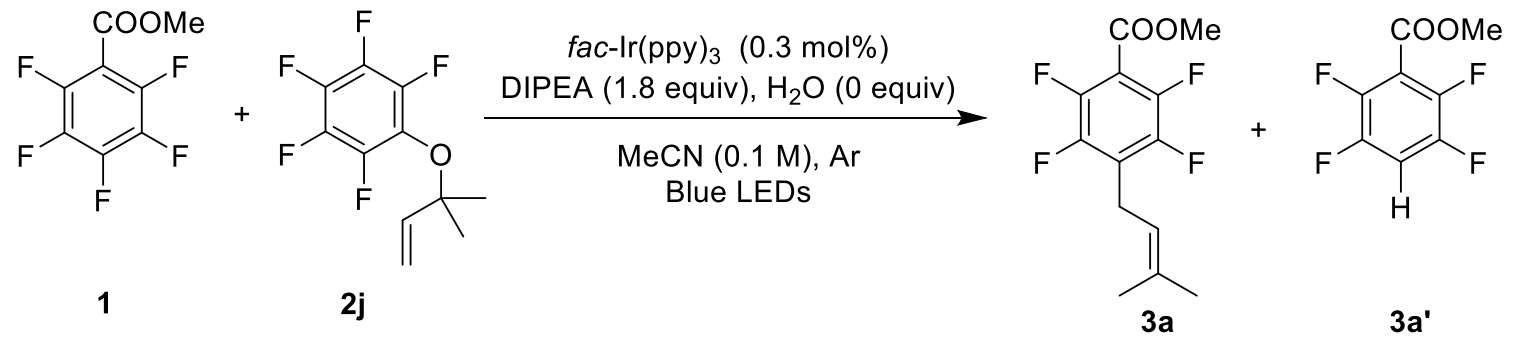

\begin{tabular}{lcccccc}
\hline Entry & Temperature $\left({ }^{\mathbf{0}} \mathbf{C}\right)$ & Time & $\mathbf{1}$ & $\mathbf{3 a}$ & $\mathbf{3 a}$ & Other \\
\hline $1 .^{\mathrm{a}}$ & -10 & $24 \mathrm{~h}$ & 19 & 55 & 26 & \\
\hline 2. & 0 & $18 \mathrm{~h}$ & 3 & 63 & 34 & \\
\hline 3. & 25 & $16 \mathrm{~h}$ & - & 55 & 36 & 8 \\
4. & 45 & $12 \mathrm{~h}$ & - & 32 & 47 & 21 \\
\hline
\end{tabular}

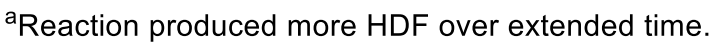

(Determined by 19F NMR)

Temperature screening revealed yet another important parameter that greatly affected the rate of reactions (Table 1.6). Reaction at $-10{ }^{\circ} \mathrm{C}$ was slow, resulting in $55 \%$ prenylated product in $24 \mathrm{~h}$. Carrying out the reaction at $0{ }^{\circ} \mathrm{C}$ produced $63 \%$ of product with reasonable Pdt:HDF ratio. As expected, at higher temperature the rate increased (entries 3-4). Though the starting material was 
fully consumed within $16 \mathrm{~h}$ (and $12 \mathrm{~h}$ ), warmer temperatures always produced relatively more HDF, in addition to another minor side product. Entry 2 was chosen to be the optimal temperature which produced the cleanest reaction within a reasonable time frame.

The inclusion of water also played a very important role in improving the reaction rate significantly (Table 1.7). The presence of 5 equiv of $\mathrm{H}_{2} \mathrm{O}$ in the reaction mixture caused the reaction to complete in $8 \mathrm{~h}$, as compared to $18 \mathrm{~h}$ when the reaction was carried out in the absence of water. As the amount of water was increased to 10 equiv (entry 3 ), the reaction completed within $4 \mathrm{~h}$. One plausible explanation could be that the pentafluorophenol (by-product that develops during the course of reaction) produces an inhibitory effect under anhydrous reaction conditions.

Table 1.7: Effect of Water<smiles>CC(=O)c1c(F)c(F)c(F)c(F)c1F</smiles>

1

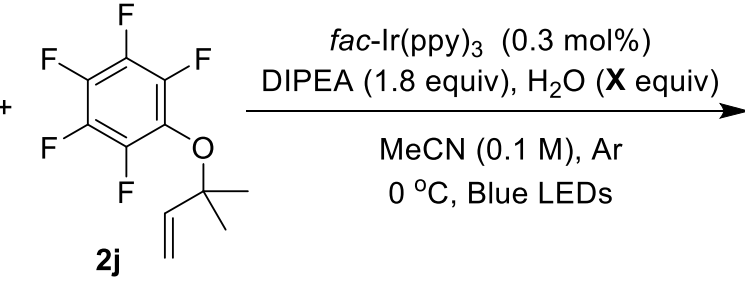

2<smiles>COC(=O)c1c(F)c(F)c(CC=C(C)C)c(F)c1C(C)=O</smiles>

\begin{tabular}{llcccc}
\hline Entry & Equiv of $\mathbf{H}_{\mathbf{2}} \mathbf{O}$ & Time & $\mathbf{1}$ & $\mathbf{3 a}$ & $\mathbf{3 a}$ \\
\hline 1. & 0 & $4 \mathrm{~h}$ & 79 & 13 & 8 \\
& & $18 \mathrm{~h}$ & - & 63 & 36 \\
2. & 5 & $4 \mathrm{~h}$ & 18 & 54 & 28 \\
& & $8 \mathrm{~h}$ & - & 63 & 35 \\
\hline 3. & 10 & $4 \mathrm{~h}$ & - & 65 & 34 \\
\hline 4. & 20 & $4 \mathrm{~h}$ & - & 65 & 35 \\
\hline
\end{tabular}

3a 3a'

By running an experiment in which pentafluorophenol was intentionally added at the beginning of the reaction, the reaction was retarded (Table 1.8). Upon addition of 10 equiv of $\mathrm{H}_{2} \mathrm{O}$ the rate was restored. Furthermore, upon addition of water an improvement can be seen from 
1.44:1 (product:HDF) in the absence of $\mathrm{H}_{2} \mathrm{O}$, to $1.8: 1$ when 10 equivalents $\mathrm{H}_{2} \mathrm{O}$ was present (entry 3). For comparison, the Pdt:HDF ratio under the standard conditions is 1.9:1.

One potential explanation is that the water acidifies pentafluorophenol facilitating deprotonation and ionization by DIPEA in the reaction, effectively removing phenol-OH by converting it to phenoxide. We suspect phenol may serve as an HAT shuttle which can facilitate HDF and can generate a problematic persistent radical, which may inhibit catalytic turnover.

Table 1.8: Experiments investigating the inhibitory effect of pentafluorophenol

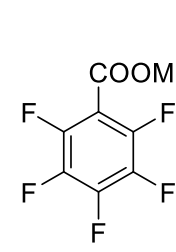

1

1 equiv

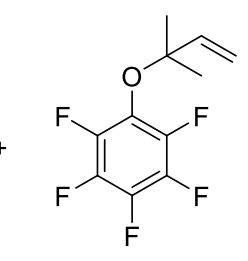

$2 \mathrm{j}$ 6 equiv

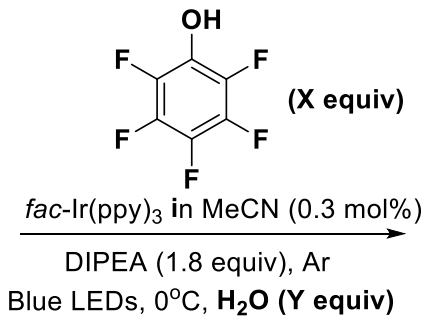

Blue LEDs, $0^{\circ} \mathrm{C}, \mathrm{H}_{\mathbf{2}} \mathrm{O}$ (Y equiv)

\begin{tabular}{cccccccc}
\hline Entry & X equiv & Y equiv & Time & $\mathbf{1}$ & $\mathbf{3 a}$ & $\mathbf{3 a}$ & $\mathbf{3 a : 3 a '}$ \\
1. & \multirow{2}{*}{0.5} & 0 & $4 \mathrm{~h}$ & 71 & 17 & 11 & $1.54: 1$ \\
& & & $10 \mathrm{~h}$ & 66 & 20 & 14 & $1.42: 1$
\end{tabular}

$2 . \quad 1.0$

0

$4 \mathrm{~h} \quad 17$

$\begin{array}{llll}10 h & 3 & 55 & 38\end{array}$

10

$4 \mathrm{~h}$

$47 \quad 26$
$1.4: 1$

1.44:1

1.8:1

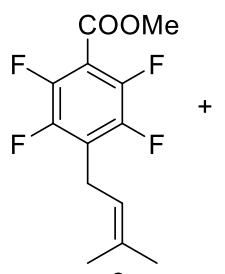

$3 a$

Other

at least 2 more pdts

+2 more pdts

+2 side pdts

We further tested the possibility of using TEMPO to minimize the formation of the competitive reduction product. ${ }^{40}$ TEMPO had a significant effect on the progress of the reaction (Table 1.9). TEMPO could abstract an $\mathrm{H}$-atom from the amine radical cation formed during the reaction forcing the aryl radical to react with the prenyl source. The Pdt:HDF ratio (3a:3a') was seen to improve during the initial time points. But as the reaction progressed, the Pdt:HDF ratio eventually returned to almost the same as observed using standard reaction conditions. Also, the presence of TEMPO slowed the overall progress of reaction (from $4 \mathrm{~h}$ to $10 \mathrm{~h}$ when 0.4 equiv was 
used) and increasing the amount of TEMPO more further decreased the rate of reaction, thus causing incomplete conversion of 1a over extended time possibly due to quenching of the necessary aryl radical intermediate.

Table 1.9: Effect of TEMPO on the rate and selectivity of the reaction
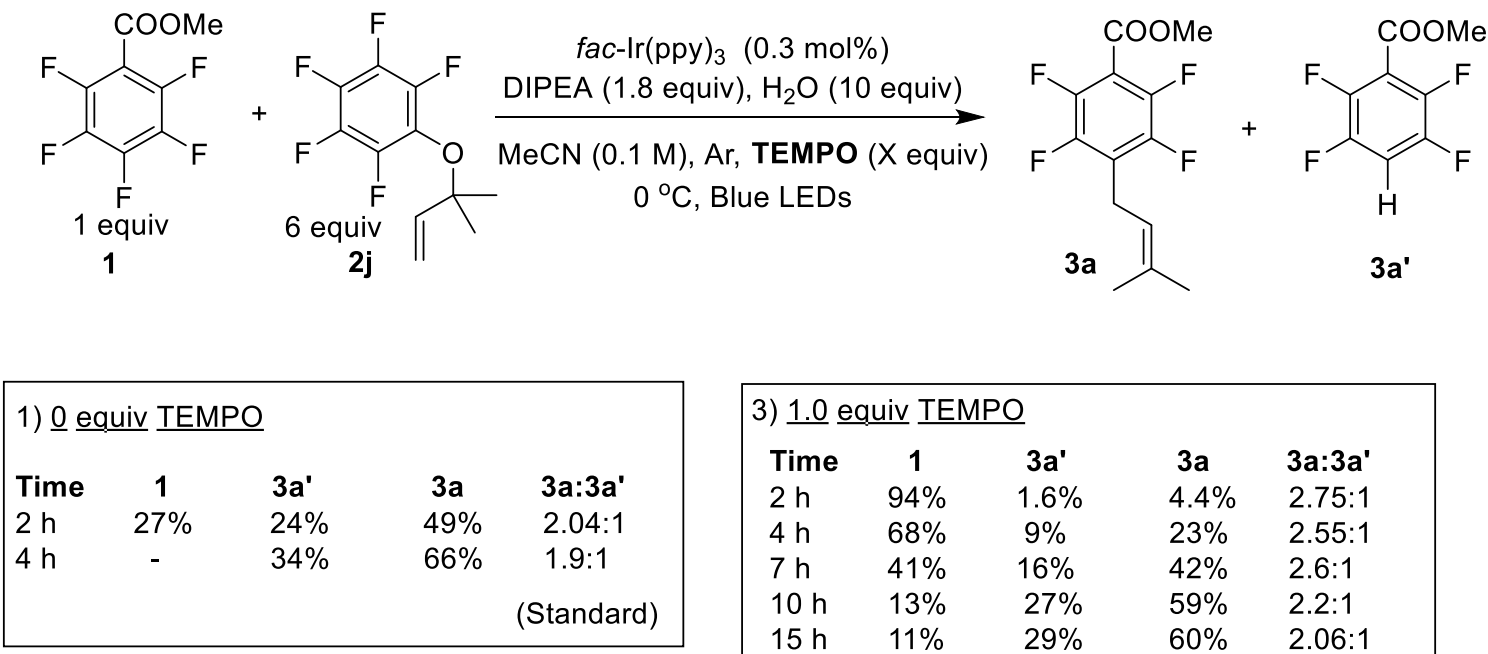

\begin{tabular}{|ccccl|}
\hline 3) 1.0 & equiv & TEMPO & & \\
Time & $\mathbf{1}$ & 3a' & 3a & 3a:3a' \\
$2 \mathrm{~h}$ & $94 \%$ & $1.6 \%$ & $4.4 \%$ & $2.75: 1$ \\
$4 \mathrm{~h}$ & $68 \%$ & $9 \%$ & $23 \%$ & $2.55: 1$ \\
$7 \mathrm{~h}$ & $41 \%$ & $16 \%$ & $42 \%$ & $2.6: 1$ \\
$10 \mathrm{~h}$ & $13 \%$ & $27 \%$ & $59 \%$ & $2.2: 1$ \\
$15 \mathrm{~h}$ & $11 \%$ & $29 \%$ & $60 \%$ & $2.06: 1$ \\
\hline
\end{tabular}

\begin{tabular}{|c|c|c|c|c|}
\hline \multicolumn{5}{|c|}{ 2) 0.4 equiv TEMPO } \\
\hline Time & 1 & $3 a^{\prime}$ & $3 a$ & 3a:3a' \\
\hline $2 \mathrm{~h}$ & $86 \%$ & $4.2 \%$ & $9.6 \%$ & $2.25: 1$ \\
\hline $4 \mathrm{~h}$ & $43 \%$ & $17 \%$ & $39 \%$ & $2.21: 1$ \\
\hline $7 \mathrm{~h}$ & $23 \%$ & $24 \%$ & $52 \%$ & 2.16:1 \\
\hline $10 \mathrm{~h}$ & - & $32 \%$ & $68 \%$ & $2.1: 1$ \\
\hline
\end{tabular}

\begin{tabular}{|lclll|}
\hline 4) 1.5 & equiv & TEMPO & & \\
Time & $\mathbf{1}$ & $\mathbf{3 a}$ & $\mathbf{3 a}$ & $\mathbf{3 a : 3 a ^ { \prime }}$ \\
$2 \mathrm{~h}$ & $97 \%$ & $0.8 \%$ & $2.2 \%$ & $2.75: 1$ \\
$4 \mathrm{~h}$ & $91 \%$ & $2.4 \%$ & $6.6 \%$ & $2.71: 1$ \\
$7 \mathrm{~h}$ & $83 \%$ & $4.6 \%$ & $12.4 \%$ & $2.69: 1$ \\
$10 \mathrm{~h}$ & $79 \%$ & $6 \%$ & $15 \%$ & $2.5: 1$ \\
$15 \mathrm{~h}$ & $77 \%$ & $7.5 \%$ & $15.6 \%$ & $2.1: 1$ \\
\hline
\end{tabular}

Ultimately, using $0.1 \mathrm{M}$ of substrate, 1.8 equiv of DIPEA, $0.3 \mathrm{~mol} \%$ of $f a c-\operatorname{Ir}(\mathrm{ppy})_{3}$ and 10 equiv of $\mathrm{H}_{2} \mathrm{O}$, we began evaluating substrate scope. Under these conditions a number of perfluoroarenes smoothly underwent $\mathrm{C}-\mathrm{F}$ defluoroprenylation in good to modest yields. The reaction tolerates a number of functional groups including esters (Table 1.10, 3a-3c), nitriles (3d), $\mathrm{CF}_{3}(\mathbf{3 e})$, and perfluoroheterocyclic arenes $(\mathbf{3 g})$. Hexafluorobenzene, devoid of any additional electron-withdrawing functional group also proceeded to form $\mathbf{3 f}$, though it required the use of 6halopyridyl prenyl source $\mathbf{2 b}$ as the prenyl source. Specifically, in the presence of prenyl transfer reagent $\mathbf{2 j}$, hexafluorobenzene remained unchanged. $3 \mathbf{h}-\mathbf{l}$ are noteworthy as they demonstrate the preference for chlorine fragmentation over that of fluorine despite the position on the ring. Given 
that many chlorofluoro-starting materials are commercially available, it provides a convenient strategy for accessing complementary regioisomers. When a chlorine was placed at the site of preferential fluorine fragmentation (4 position for pyridine), it displayed moderately shorter reaction time compared to pentafluoropyridine (i.e. $\mathbf{3 h}$ compared to $\mathbf{3 g}$ ). This could be because fragmentation of chloride ion is more exothermic than fluoride, resulting in a faster fragmentation event. Furthermore, the presence of chlorine substituents create greater steric demand than fluorine substituents, and could result in a relative increase the ground state energy. ${ }^{41}$ Likewise, steric repulsion between the substituents in the radical anion may also accelerate its breakdown, leading to faster fragmentation. Interestingly, prenylation at the meta position was also possible but required longer reaction time (3i and $\mathbf{3 j}$ vs $\mathbf{3 g})$.

Table 1.10: Scope of Prenylation

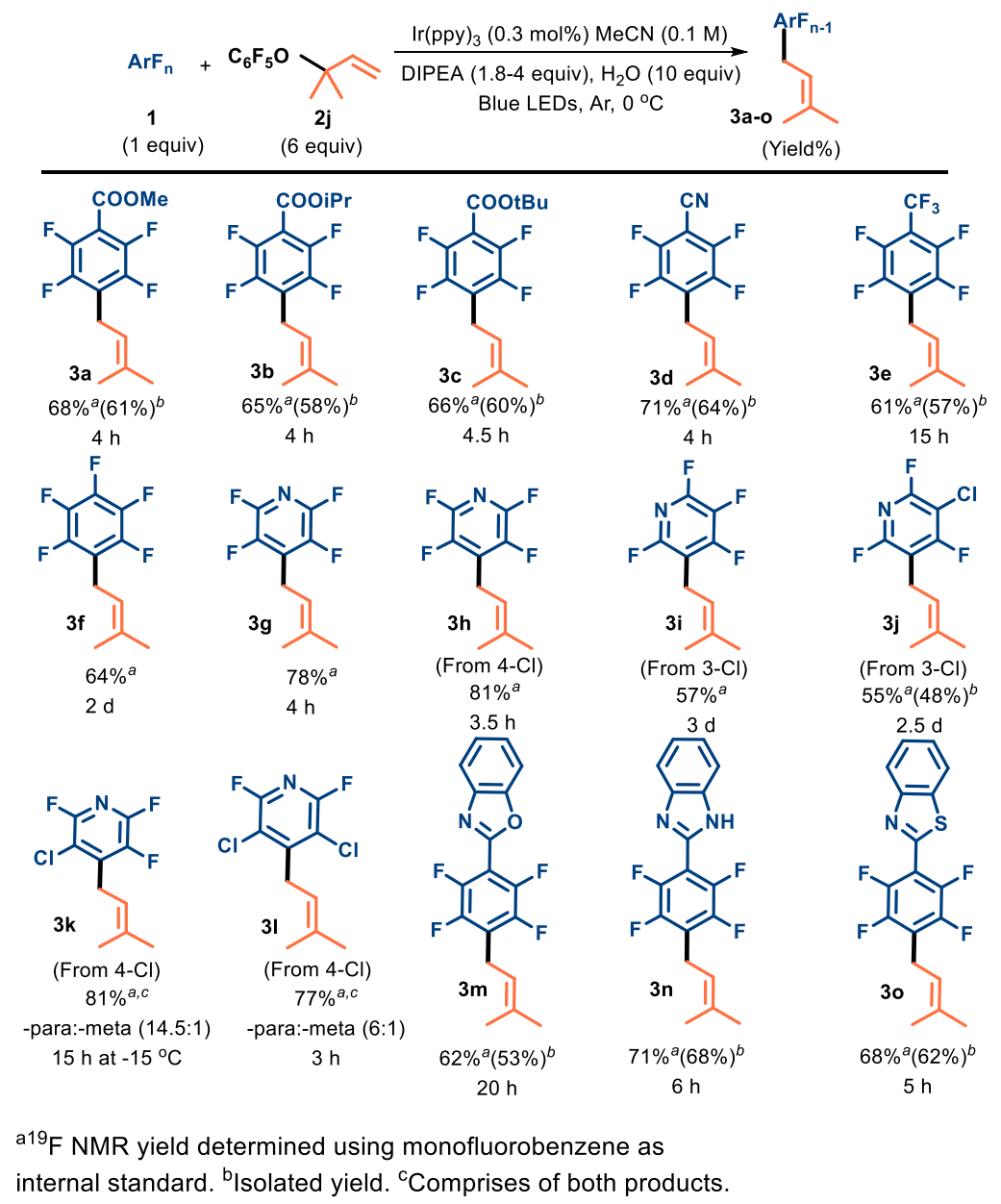


While the photocatalytically enduced mesolytic fragmentation of fluoride has been highly resgioselective, the fragmentation of chloride from multichlorinated arenes is generally less regioselective and displays a temperature dependent behavior ( $\mathbf{3 g} v s \mathbf{3 k}$ and $\mathbf{3 l})$, but still results in useful selectivities. This method can be used to access heterocyclic substituted perfluoroarenes like oxazoles $(\mathbf{3 m})$, benzoimidazoles $(\mathbf{3 n})$ and benzothiazoles (3o). In all these reactions, HDF made up the mass balance.

Looking to expand the utility of the method, we applied this strategy towards allylation of perfluoroarenes. As expected, allylation with transposition of the double bond proceeded smoothly to yield 5a-5f in good yield (Table 1.11). Substitution at both the ß-position (5c and 5d), and the $\gamma$-position were well tolerated (5e and $\mathbf{5 f}$ ). While the yield was acceptable, in the case of unsymmetric 5f, the E/Z-selectivity was very modest (1.3:1) and did not display significant temperature dependence, which may limit its use in cases where the olefin geometry is essential.

Table 1.11: Scope of Allylation

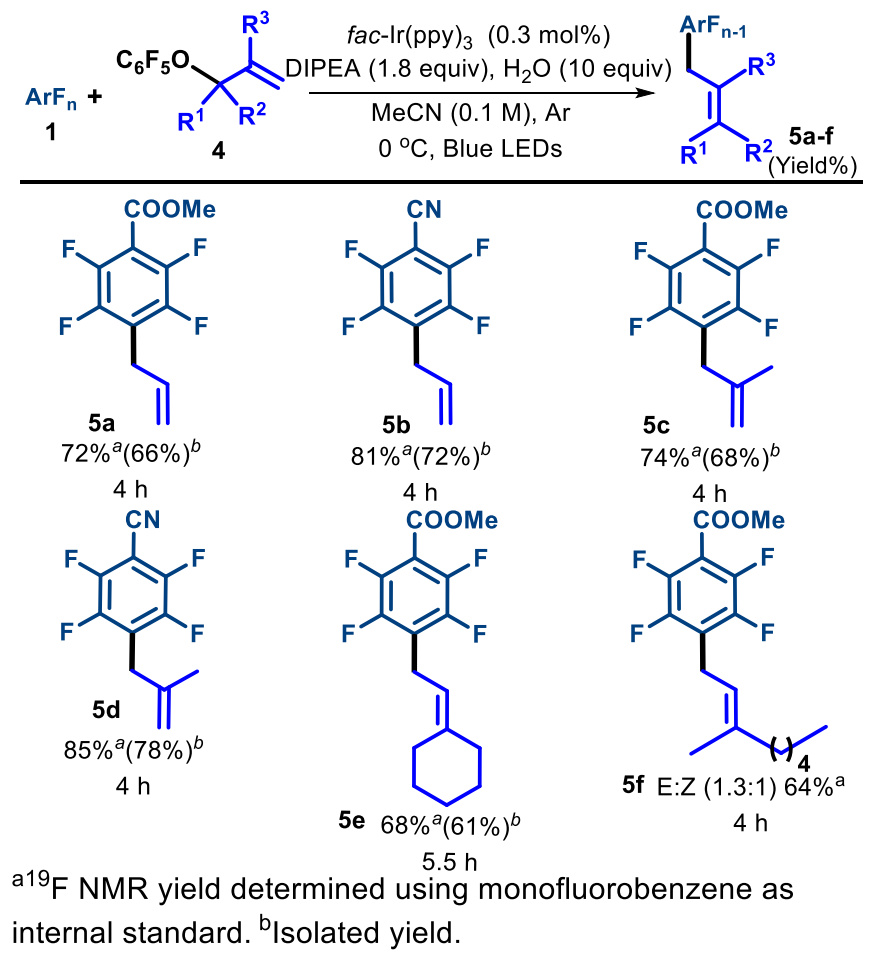


Encouraged by our success with prenyl transfer, we hoped to extend our strategy to geranyl transfer which would add a 10 carbon unit. Using the same optimized conditions, we reacted perfluoroarenes with pentafluoroisogeranyl ether $(\mathbf{6}$, Table 1.12). We were concerned that the alkyl radical formed upon addition to the alkene would undergo intramolecular addition to the additional olefin (i.e. 5-exo-trig cyclization) faster than fragmentation of the pentafluorophenoxy radical. Thus, we were pleased to obtain the geranylated product in similar yields to the prenylation reaction. A striking difference, however, was that the reaction took place preferentially at the position ortho to the substituent on the perfluoroaryl ring (c.a. ortho: para 1.6:1). This is particularly noteworthy as it is the first time that we have observed an external reagent capable of influencing the $\mathrm{C}-\mathrm{F}$ regioselectivity in a photocatalytic $\mathrm{C}-\mathrm{F}$ functionalization. While we are uncertain about the underlying cause of this change in regioselectivity, our working hypothesis is that there is an attractive interaction between $\mathbf{6}$ and the radical anion of $\mathbf{1}$. This results in an intermolecular complex which sterically perturbs the ortho $\mathrm{C}-\mathrm{F}$ bond, presumably causing deviation from planarity, and resulting in a faster fragmentation.

Table 1.12: Scope of Geranylation

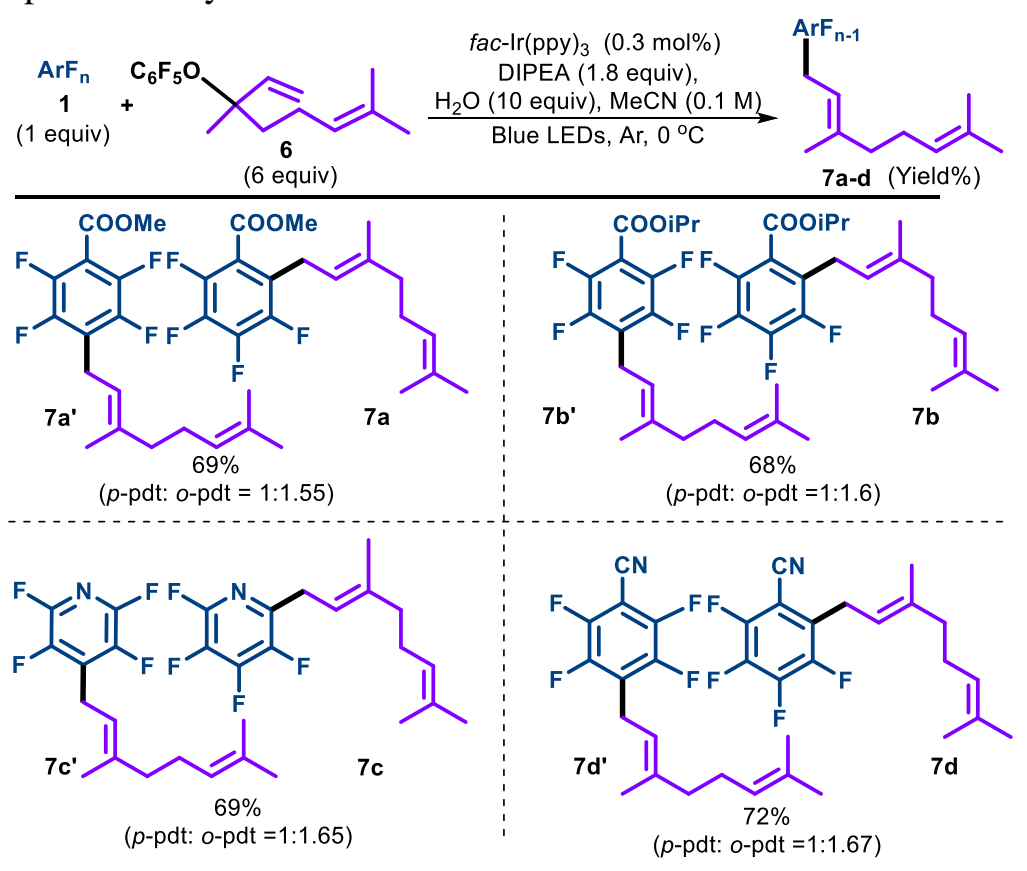

Determined by ${ }^{19} \mathrm{~F}$ NMR. Reactions completed in 6-8 $\mathrm{h}$. 
While, 7a-7d were produced as a mixture of ortho-para isomers, it demonstrated perfect diastereoselectivity, giving only the $E$-alkene. This selectivity is in stark contrast to the unsymmetric allyl derivative, $\mathbf{5 f}$, which was produced as a mixture. Again, the origin of this is not clear.

\subsection{Summary}

In conclusion, we have developed a strategy and along with reagents that enable photocatalytic defluoro-allylation, -prenylation, and -geranylation of perfluoroarenes. We observed that the addition of water leads to substantial rate enhancements. Further, as we moved from prenylation to geranylation, we observed a change in the regioselectivity of the major product from para-C-F functionalization to ortho-C-F functionalization. Our approach allows direct allyl, prenyl and geranyl substitution of C-F bonds using very mild conditions and short reaction times. This strategy should facilitate investigations involving the synthesis of hybrid fluorinated analogs of natural products. Additionally, this reaction presents a number of interesting mechanistic facets which are currently being studied, and the findings will be reported in due course.

\subsection{Experimental Section}

\section{General Experimental}

All reagents were obtained from commercial suppliers (Sigma-Aldrich, Oakwood chemicals, Alfa Aesar, Matrix Scientific) and used without further purification unless otherwise noted. Acetonitrile $\left(\mathrm{CH}_{3} \mathrm{CN}\right)$ was dried over molecular sieves. $N, N$-diisopropylethylamine was purchased from Sigma-Aldrich and stored over $\mathrm{KOH}$ pellets. Photocatalyst tris(2-phenyl pyridinato-C2, N)iridium(III)[Ir(ppy) 3 ], 99\%(purity), was synthesized according to a literature procedure. ${ }^{32 c}$ Photocatalyst tris[4,4'-bis(tert-butyl)-2,2'-bipyridine]ruthenium(II) hexafluorophosphate and tris(4,4'-dimethyl-2,2'-bipyridine)ruthenium(II) hexafluorophosphate 
were purchased from Aspira Chemical. Isopropyl 2,3,4,5,6-pentafluorobenzoate, tert-butyl 2,3,4,5,6-pentafluorobenzoate, 4-chloro-2,3,5,6-tetrafluoropyridine, 3,4-dichloro-2,5,6trifluoropyridine, 3,4,5-trichloro-2,6-difluoropyridine, 2-(perfluorophenyl)benzo[ $d]$ oxazole, 2(perfluorophenyl)-1H-benzo[d]imidazole and 2-(perfluorophenyl)benzo[ $d]$ thiazole were

synthesized according to literature procedures. ${ }^{30 \mathrm{~d}, 42}$ Reactions were monitored by ${ }^{19} \mathrm{~F}$ and GC-MS (QP 2010S, Shimadzu equipped with auto sampler). NMR spectra were obtained on a $400 \mathrm{MHz}$ Bruker Avance III spectrometer and $400 \mathrm{MHz}$ Unity Inova spectrometer. ${ }^{1} \mathrm{H}$ and ${ }^{13} \mathrm{C}$ NMR chemical shifts are reported in ppm relative to the residual protio solvent peak $\left({ }^{1} \mathrm{H},{ }^{13} \mathrm{C}\right)$ and ${ }^{19} \mathrm{~F}$ NMR shifts are reported using fluorobenzene as a standard. Melting points were determined on a Mel-Temp apparatus and are uncorrected. GC analyses were carried out using a QP 2010S Shimadzu, equipped with an auto sampler. Isolations were carried out using a Teledyne Isco Combiflash Rf 200i flash chromatograph with Sorbtech Rf normal phase silica (4 g, or $12 \mathrm{~g}$ columns). Some isolations were performed using Sorbent Technologies Silica Prep TLC Plates, w/UV254, glass backed, $1000 \mu \mathrm{m}, 20$ x $20 \mathrm{~cm}$, and were visualized with ultraviolet light. Substrate syntheses were monitored by thin layer chromatography (TLC) obtained from Sorbent Technologies; Silica XHL TLC Plates, w/UV254, glass backed, $250 \mu \mathrm{m}$, and were visualized with ultraviolet light or potassium permanganate. No attempts were made to report ${ }^{13} \mathrm{C}$ spectra of volatile compounds.

\section{Photocatalytic Reaction Set up}

Photocatalytic reactions were set up in a light bath as described below. Strips of blue LEDs (18 LEDs/ft.) were purchased from Solid Apollo. The strips ( $4.9 \mathrm{ft}$ ) were wrapped around on the walls of a glass crystallization dish, secured with masking tape and then the dish was wrapped with aluminum foil. A lid which rest on the top was fashioned from cardboard and holes were made such that NMR tubes were held firmly in the cardboard lid which was placed on the top of the bath. Isopropanol/water bath was prepared such that the tubes were submerged, and it was 
maintained at $0{ }^{\circ} \mathrm{C}$ with the aid of a chiller that circulated coolant through a coil of copper tubing placed in the bath. In some cases, the same light bath set up was used with water in it which was maintained at $45{ }^{\circ} \mathrm{C}$ with the aid of a sand bath connected to a thermostat. ${ }^{30 \mathrm{~d}}$

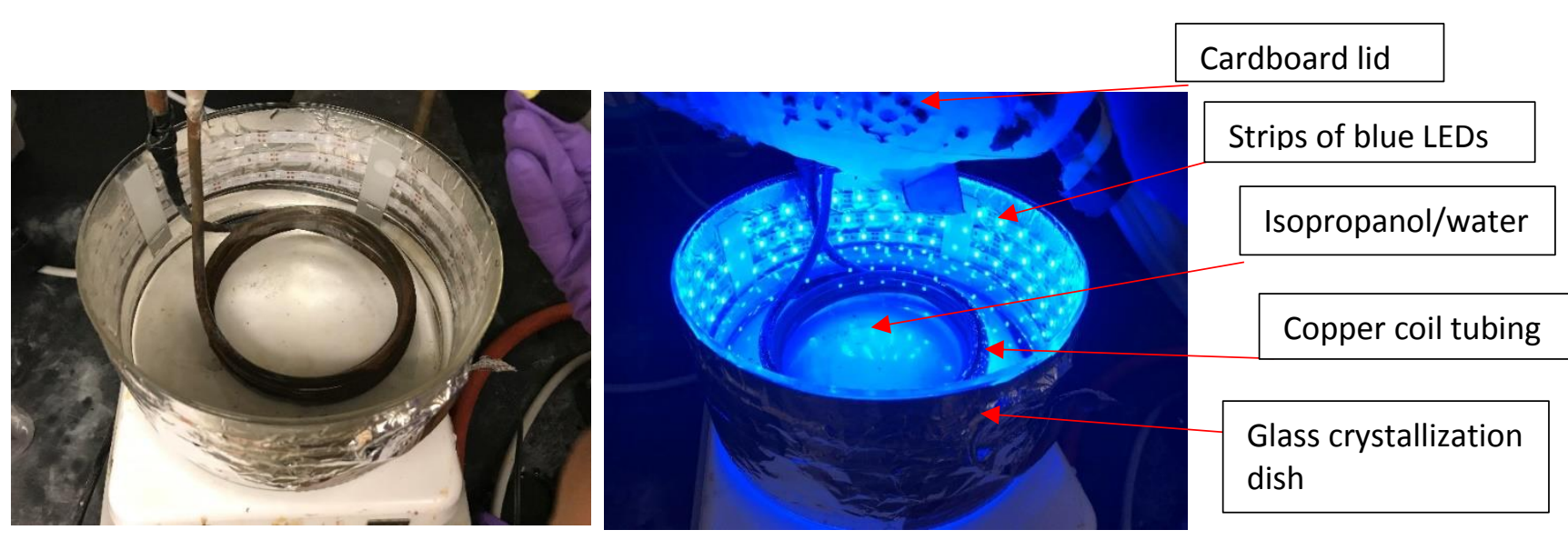

Figure 1.4: Photocatalytic reaction set up using light bath

\section{Synthesis of Substrates}

\section{General Procedure A for synthesis of aryl ethers:}

To a stirred solution of alcohol (1.0 equiv) in THF (anhyd) in a flame-dried $250 \mathrm{~mL}$ roundbottomed flask, was added $\mathrm{NaH}$ (1.3 equiv) portion wise under Ar. The resulting mixture was stirred for 20 minutes at room temperature. Hexafluorobenzene (1.3-4.0 equiv) was then added all at once and the reaction was monitored by TLC until the spot for alcohol disappeared. After completion, the reaction mixture was slowly quenched with water. The aqueous phase was extracted with diethyl ether, and the combined organic extracts were washed with brine $(3 \times 30$ $\mathrm{mL}$ ), dried over $\mathrm{MgSO}_{4}$, filtered and concentrated in vacuo. The crude material was purified by normal phase chromatography using hexane:ethyl acetate. ${ }^{43}$ 


\section{Synthesis of 1-(allyloxy)-2,3,4,5,6-pentafluorobenzene (4a)}
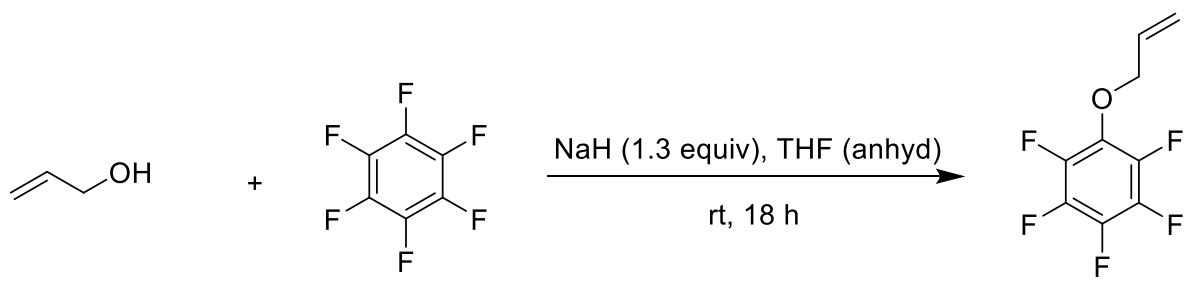

$4 a$

1-(Allyloxy)-2,3,4,5,6-pentafluorobenzene (4a) was synthesized using general procedure A. 2Propen-1-ol (3.51 mL, $51.6 \mathrm{mmol}), \mathrm{NaH}(1.61 \mathrm{~g}, 66.6 \mathrm{mmol})$ was stirred in anhyd. THF (30 mL) at room temperature for 20 minutes. Then hexafluorobenzene $(7 \mathrm{~mL}, 66.6 \mathrm{mmol})$ was added and stirred for $18 \mathrm{~h}$. The crude residue was purified by automated flash chromatography using hexane:ethyl acetate (0 \% EtOAc for 0-15 cv and ramped to $50 \%$ EtOAc for $15-25 \mathrm{cv}$ and then held at $100 \%$ EtOAc $25-35 \mathrm{cv})$ on a $24 \mathrm{~g}$ silica column to afford the product in $85 \%$ yield $(9.8 \mathrm{~g}$, $43.8 \mathrm{mmol}$ ) as a colorless liquid.

Synthesis of 1,2,3,4,5-pentafluoro-6-((2-methylallyl)oxy)benzene (4b)<smiles>C=C(C)CO</smiles><smiles>Fc1c(F)c(F)c(F)c(F)c1F</smiles>

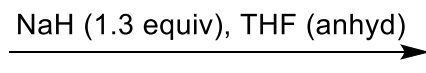

$\mathrm{rt}, 18 \mathrm{~h}$<smiles>C=C(C)COc1c(F)c(F)c(F)c(F)c1F</smiles>

4b

\section{1,2,3,4,5-Pentafluoro-6-((2-methylallyl)oxy)benzene (4b) was synthesized using general} procedure A. 2-Methylprop-2-en-1-ol (3.51 mL, $41.6 \mathrm{mmol})$, NaH (1.29 g, $54.1 \mathrm{mmol})$ was stirred in anhyd. THF $(30 \mathrm{~mL})$ at room temperature for 20 minutes. Then hexafluorobenzene (6.24 mL, $54.1 \mathrm{mmol}$ ) was added and stirred for $18 \mathrm{~h}$. The crude residue was purified by automated flash chromatography using hexane:ethyl acetate (0\% EtOAc for 0-15 cv and ramped to $50 \%$ EtOAc for $15-25 \mathrm{cv}$ and then held at $100 \%$ EtOAc $25-35 \mathrm{cv}$ ) on a $24 \mathrm{~g}$ silica column to afford the product in $86 \%$ yield $(8.52 \mathrm{~g}, 35.77 \mathrm{mmol})$ as a colorless liquid. 
Synthesis of 2-fluoro-6-((2-methylbut-3-en-2-yl)oxy)pyridine (2b)

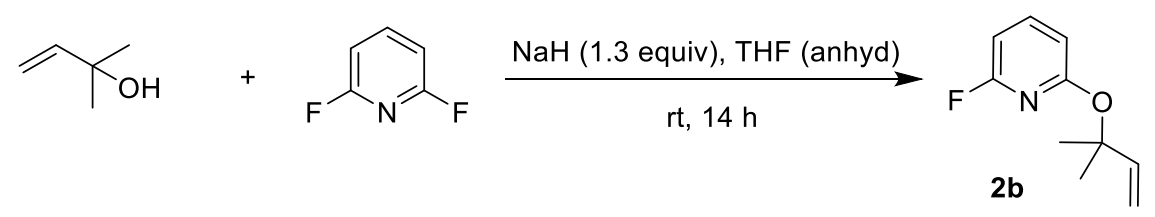

2-Fluoro-6-((2-methylbut-3-en-2-yl)oxy)pyridine (2b) was synthesized using a modified version of general procedure A. 2-Methylbut-3-en-2-ol (3 mL, 28.7 mmol), NaH (0.908 g, 37.7 mmol) was stirred in anhyd. THF (35 mL) at room temperature for 20 minutes. Then, 2,6difluoropyridine (3.12 mL, $34.4 \mathrm{mmol}$ ) (rather than $\mathrm{C}_{6} \mathrm{~F}_{6}$ ) was added and stirred for $14 \mathrm{~h}$. The crude residue was purified by automated flash chromatography using hexane:ethyl acetate $(0 \%$ EtOAc for 0-15 cv and ramped to 50\% EtOAc for 15-25 cv and then held at 100\% EtOAc 25-35 $\mathrm{cv})$ on a $24 \mathrm{~g}$ silica column to afford the product in $88 \%$ yield $(4.57 \mathrm{~g}, 25.26 \mathrm{mmol})$ as a colorless liquid.

Synthesis of 2-chloro-6-((2-methylbut-3-en-2-yl)oxy)pyridine (2c)

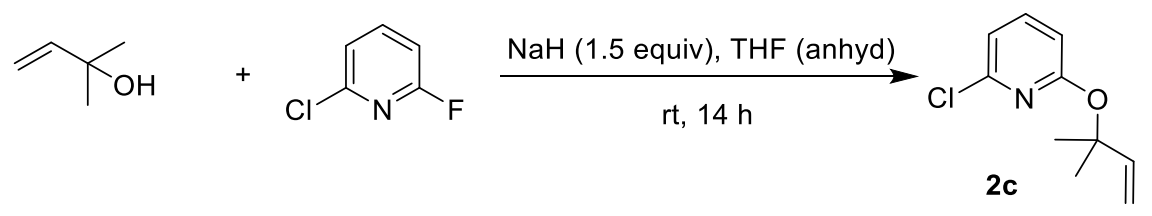

2-Chloro-6-((2-methylbut-3-en-2-yl)oxy)pyridine (2c) was synthesized using a modified version of general procedure A. 2-Methylbut-3-en-2-ol (2 mL, $19 \mathrm{mmol}), \mathrm{NaH}(0.684 \mathrm{~g}, 28.5$ mmol) was stirred in anhyd THF (35 mL) at room temperature for 20 minutes. Then 2-chloro-6fluoropyridine ( $3 \mathrm{~g}, 22.8 \mathrm{mmol}$ ) (rather than $\mathrm{C}_{6} \mathrm{~F}_{6}$ ) was added and stirred for $14 \mathrm{~h}$. The crude residue was purified by automated flash chromatography using hexane:ethyl acetate ( $0 \%$ EtOAc for $0-15 \mathrm{cv}$ and ramped to $50 \%$ EtOAc for $15-25 \mathrm{cv}$ and then held at $100 \%$ EtOAc $25-35 \mathrm{cv}$ ) on a $24 \mathrm{~g}$ silica column to afford the product in $87 \%$ yield $(3.25 \mathrm{~g}, 16.53 \mathrm{mmol})$ as a colorless liquid. 


\section{Synthesis of methyl 2-((2-methylbut-3-en-2-yl)oxy)nicotinate (2d)}

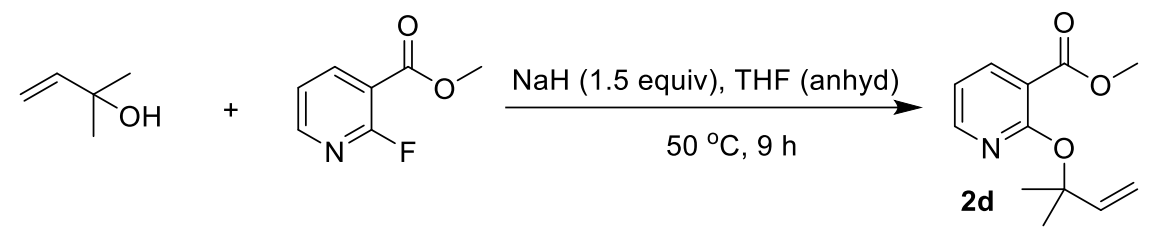

Methyl 2-((2-methylbut-3-en-2-yl)oxy)nicotinate (2d) was synthesized using a modified version of general procedure A. 2-methylbut-3-en-2-ol (1.7 mL, $16.11 \mathrm{mmol}), \mathrm{NaH}(0.58 \mathrm{~g}$, $24.16 \mathrm{mmol})$ was stirred in anhyd THF $(35 \mathrm{~mL})$ at room temperature for 20 minutes. Then methyl 2-fluoronicotinate $\left(3 \mathrm{~g}, 19.33 \mathrm{mmol}\right.$ ) (rather than $\mathrm{C}_{6} \mathrm{~F}_{6}$ ) was added, heated at $50{ }^{\circ} \mathrm{C}$ and stirred for $9 \mathrm{~h}$. The crude residue was purified by automated flash chromatography using hexane:ethyl acetate $(0 \%$ EtOAc for $0-15 \mathrm{cv}$ and ramped to $50 \%$ EtOAc for $15-25 \mathrm{cv}$ and then held at $100 \%$ EtOAc $25-35 \mathrm{cv})$ on a $24 \mathrm{~g}$ silica column to afford the product in $44 \%$ yield $(1.568 \mathrm{~g}, 7.088$ mmol) as a colorless liquid.

Synthesis of 2,3,5,6-tetrafluoro-4-((2-methylbut-3-en-2-yl)oxy)pyridine (2i)
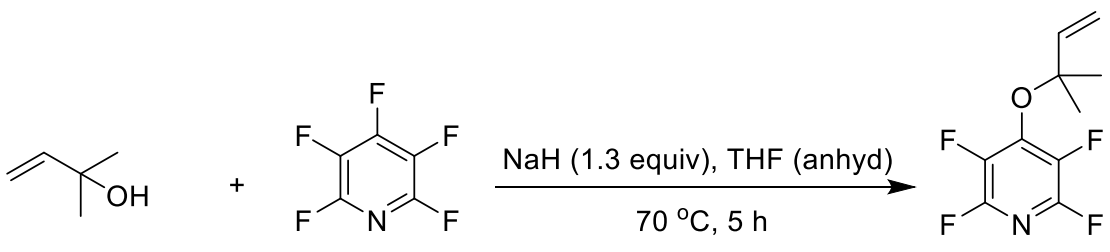

$2 \mathbf{i}$

2,3,5,6-Tetrafluoro-4-((2-methylbut-3-en-2-yl)oxy)pyridine (2i) was synthesized using a modified version of general procedure A. 2-methylbut-3-en-2-ol (3 mL, $28.7 \mathrm{mmol}), \mathrm{NaH}(0.91$ $\mathrm{g}, 37.31 \mathrm{mmol})$ was stirred in anhyd THF $(40 \mathrm{~mL})$ at room temperature for 20 minutes. Then pentafluoropyridine ( $3.8 \mathrm{~mL}, 34.44 \mathrm{mmol}$ ) (rather than $\mathrm{C}_{6} \mathrm{~F}_{6}$ ) was added, heated at $70{ }^{\circ} \mathrm{C}$ and stirred for $5 \mathrm{~h}$. The crude residue was purified by automated flash chromatography using hexane:ethyl acetate (0\% EtOAc for 0-15 cv and ramped to 50\% EtOAc for $15-25 \mathrm{cv}$ and then 
held at $100 \%$ EtOAc $25-35 \mathrm{cv})$ on a $24 \mathrm{~g}$ silica column to afford the product in $35 \%$ yield $(2.362$ $\mathrm{g}, 10.04 \mathrm{mmol}$ ) as a colorless liquid.

Synthesis of 1,2,3,4,5-pentafluoro-6-((2-methylbut-3-en-2-yl)oxy)benzene ( $2 \mathrm{j})$

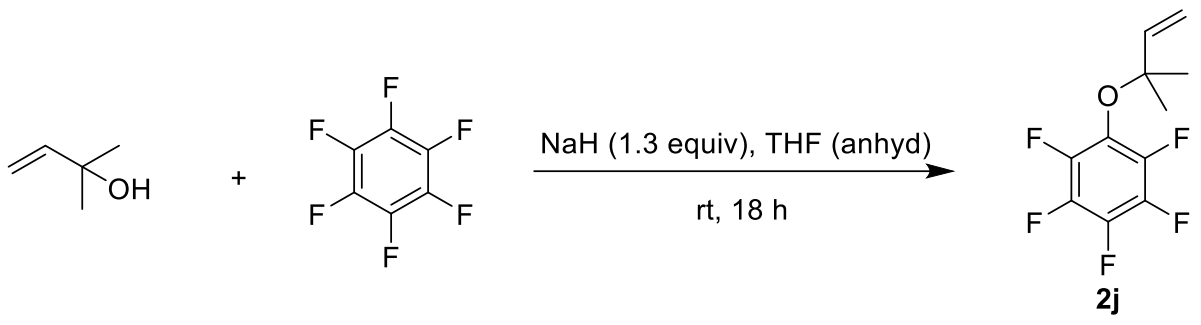

1,2,3,4,5-Pentafluoro-6-((2-methylbut-3-en-2-yl)oxy)benzene (2j) was synthesized using general procedure A. 2-Methylbut-3-en-2-ol (5.2 mL, $49.44 \mathrm{mmol})$, NaH (1.54 g, $64.2 \mathrm{mmol})$ was stirred in anhyd. THF $(40 \mathrm{~mL})$ at room temperature for 20 minutes. Then hexafluorobenzene ( $8 \mathrm{~mL}, 69.2 \mathrm{mmol}$ ) was added and stirred for $18 \mathrm{~h}$. The crude residue was purified by automated flash chromatography using hexane:ethyl acetate (0\% EtOAc for $0-15 \mathrm{cv}$ and ramped to $50 \%$ EtOAc for $15-25 \mathrm{cv}$ and then held at $100 \%$ EtOAc $25-35 \mathrm{cv}$ ) on a $24 \mathrm{~g}$ silica column to afford the product in $83 \%$ yield $(10.3 \mathrm{~g}, 41.03 \mathrm{mmol})$ as a colorless liquid.

\section{Synthesis of 1,2,4,5-tetrafluoro-3,6-bis((2-methylbut-3-en-2-yl)oxy)benzene (2k)}
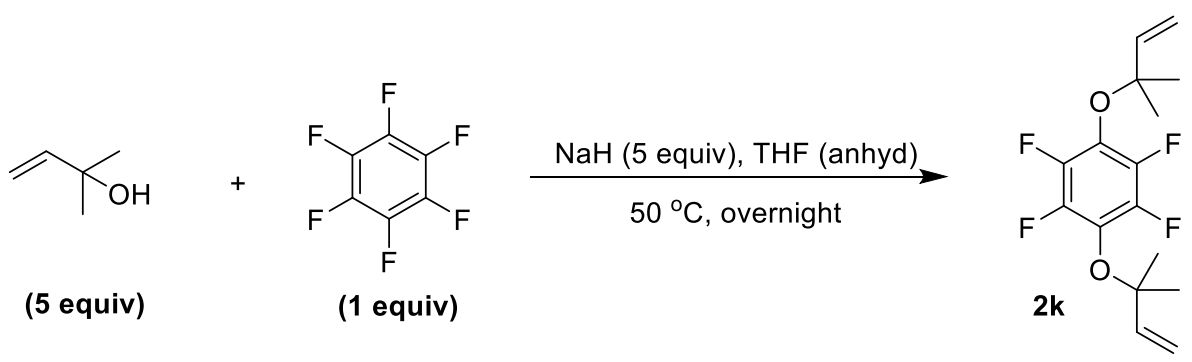

1,2,4,5-Tetrafluoro-3,6-bis((2-methylbut-3-en-2-yl)oxy)benzene (2k) was synthesized using a modified version of general procedure A. 2-Methylbut-3-en-2-ol (5.6 mL, $53.7 \mathrm{mmol}), \mathrm{NaH}$ $(1.28 \mathrm{~g}, 53.7 \mathrm{mmol})$ was stirred in anhyd. THF $(40 \mathrm{~mL})$ at room temperature for 20 minutes. Then hexafluorobenzene $(1.24 \mathrm{~mL}, 10.7 \mathrm{mmol})$ was added and stirred at $50{ }^{\circ} \mathrm{C}$ overnight. The crude residue was purified by automated flash chromatography using hexane:ethyl acetate ( $0 \%$ EtOAc 
for $0-15 \mathrm{cv}$ and ramped to $50 \%$ EtOAc for $15-25 \mathrm{cv}$ and then held at $100 \%$ EtOAc 25-35 cv) on a $24 \mathrm{~g}$ silica column to afford the product in $51 \%$ yield $(1.74 \mathrm{~g}, 5.45 \mathrm{mmol})$ as a colorless liquid.

Synthesis of 1-((3,7-dimethylocta-1,6-dien-3-yl)oxy)-2,3,4,5,6-pentafluorobenzene (6)

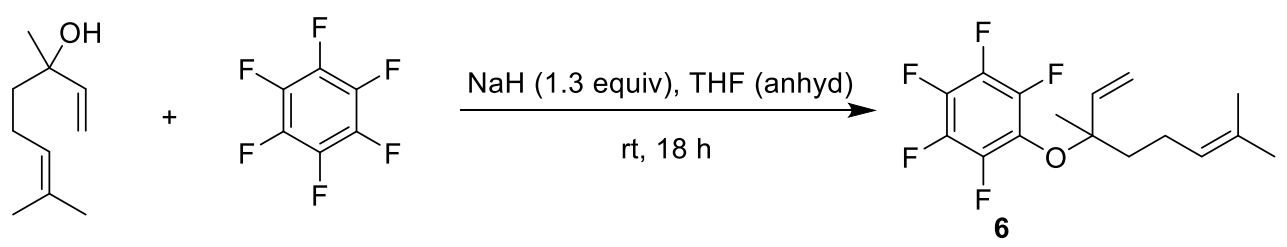

1-((3,7-Dimethylocta-1,6-dien-3-yl)oxy)-2,3,4,5,6-pentafluorobenzene (6) was synthesized using general procedure A. Linalool (1.8 mL, $9.9 \mathrm{mmol}), \mathrm{NaH}(0.31 \mathrm{~g}, 12.9 \mathrm{mmol})$ was stirred in anhyd. THF $(40 \mathrm{~mL})$ at room temperature for 20 minutes. Then hexafluorobenzene $(1.5 \mathrm{~mL}$, $12.9 \mathrm{mmol}$ ) was added and stirred for $18 \mathrm{~h}$. The crude residue was purified by automated flash chromatography using hexane:ethyl acetate (0\% EtOAc for 0-15 cv and ramped to $50 \%$ EtOAc for $15-25 \mathrm{cv}$ and then held at $100 \%$ EtOAc $25-35 \mathrm{cv}$ ) on a $24 \mathrm{~g}$ silica column to afford the product in $81 \%$ yield $(2.56 \mathrm{~g}, 8.02 \mathrm{mmol})$ as a colorless liquid.

\section{General Procedure B for synthesis of aryl ethers via Grignard reagent:}

To a suspension of fresh Mg turnings in anhydrous THF was added catalytic amount of I2. A solution of vinyl bromide (1 M in THF) was then added, and the mixture was heated to initiate the Grignard reaction. The remainder of vinyl bromide solution was added at a rate to maintain gentle reflux. After complete addition, a solution of corresponding ketone in THF was added over 15 minutes and the reaction was left to stir at room temperature overnight. The reaction was carefully quenched with saturated $\mathrm{NH} 4 \mathrm{Cl}$ solution, and then extracted with ether $(4 \mathrm{x} 40 \mathrm{~mL})$. The ether extract was washed with brine $(40 \mathrm{~mL})$, dried over $\mathrm{MgSO} 4$ and then concentrated using rotatory evaporator. The product was isolated using column chromatography. 


\section{Synthesis of 1,2,3,4,5-pentafluoro-6-((1-vinylcyclohexyl)oxy)benzene (4c)}

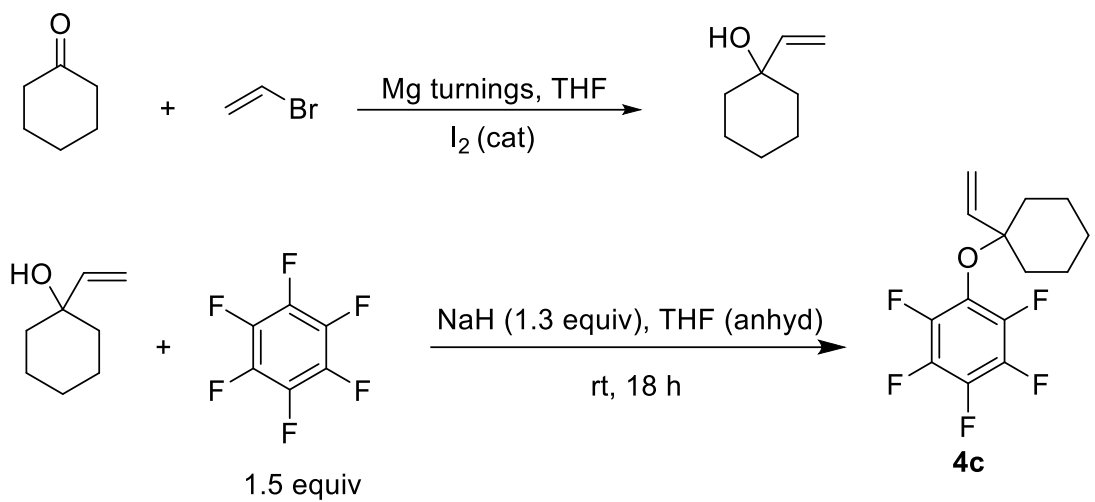

1,2,3,4,5-pentafluoro-6-((1-vinylcyclohexyl)oxy)benzene (4c) was synthesized using general procedure B followed by general procedure A. A solution of $1 \mathrm{M}$ vinyl bromide in THF (32 $\mathrm{mL}, 32 \mathrm{mmol})$ was added to $\mathrm{Mg}$ turnings $(0.77 \mathrm{~g})$ in THF $(45 \mathrm{~mL})$ and heated to initiate Grignard reaction. It was followed by addition of cyclohexanone $(2.54 \mathrm{~mL}, 24.6 \mathrm{mmol})$ over 15 minutes and left to stir overnight at room temperature. The crude residue was purified by automated flash chromatography using hexane:ethyl acetate (0\% EtOAc for 0-10 cv, ramped to $10 \%$ EtOAc for $10-25 \mathrm{cv}$, ramped again to $50 \%$ for $25-30 \mathrm{cv}$ and then held at $100 \%$ EtOAc for $30-40 \mathrm{cv}$ ) on a 24 g silica column to afford 1-vinylcyclohexan-1-ol in $29.7 \%$ yield $(0.92 \mathrm{~g}, 7.3 \mathrm{mmol})$ as a pale yellow liquid.

1-vinylcyclohexan-1-ol was then used to carry out general procedure $\mathbf{A}$ for synthesis of aryl ether. 1-vinylcyclohexan-1-ol (0.96 mL, $7.3 \mathrm{mmol})$, NaH (0.262 g, $10.94 \mathrm{mmol})$ was stirred in anhyd. THF $(40 \mathrm{~mL})$ at room temperature for 20 minutes. Then hexafluorobenzene $(1.26 \mathrm{~mL}$, $10.94 \mathrm{mmol}$ ) was added and stirred at the same temperature for $18 \mathrm{~h}$. The crude residue was purified by automated flash chromatography using hexane:ethyl acetate $(0 \%$ EtOAc for $0-15 \mathrm{cv}$ and ramped to 50\% EtOAc for 15-25 cv and then held at $100 \%$ EtOAc $25-35 \mathrm{cv}$ ) on a $24 \mathrm{~g}$ silica column to afford 1,2,3,4,5-pentafluoro-6-((1-vinylcyclohexyl)oxy)benzene (4c) in 63\% yield $(1.34 \mathrm{~g}, 4.58 \mathrm{mmol})$ as a colorless liquid. 
Synthesis of 1,2,3,4,5-pentafluoro-6-((3-methyloct-1-en-3-yl)oxy)benzene (4d)
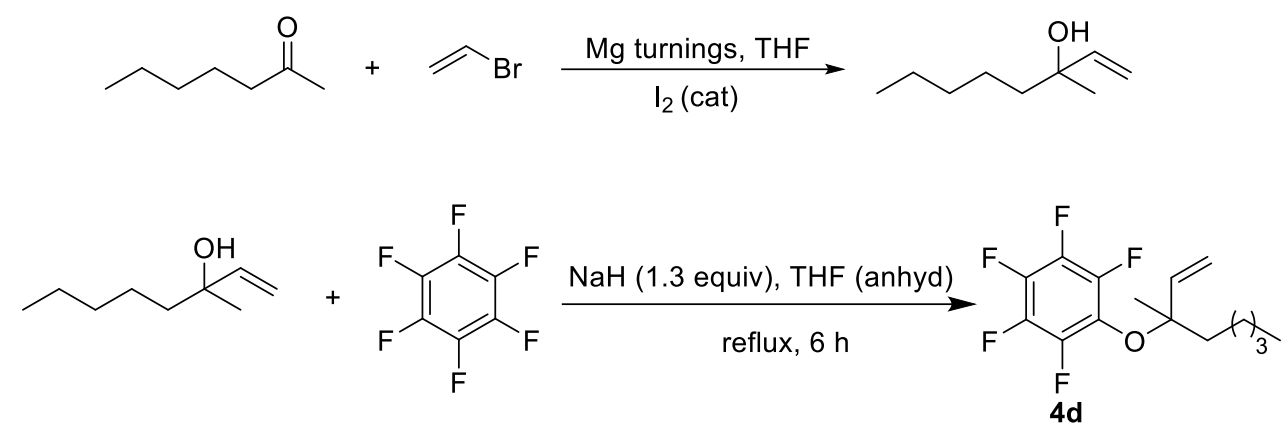

1,2,3,4,5-pentafluoro-6-((3-methyloct-1-en-3-yl)oxy)benzene (4d) was synthesized using general procedure $\mathbf{B}$ followed by general procedure $\mathbf{A}$. A solution of $1 \mathrm{M}$ vinyl bromide in THF (36 mL, $36 \mathrm{mmol})$ was added to Mg turnings $(0.864 \mathrm{~g})$ in THF (45 mL) and heated to initiate Grignard reaction. It was followed by addition of heptan-2-one (2.8 mL, $20.0 \mathrm{mmol})$ over 15 minutes and left to stir overnight at room temperature. The crude residue was purified by automated flash chromatography using hexane:ethyl acetate $(0 \%$ EtOAc for $0-10 \mathrm{cv}$, ramped to $10 \%$ EtOAc for $10-25 \mathrm{cv}$, ramped again to $50 \%$ for $25-30 \mathrm{cv}$ and then held at $100 \%$ EtOAc for $30-40 \mathrm{cv})$ on a $24 \mathrm{~g}$ silica column to afford 3-methyloct-1-en-3-ol in $44 \%$ yield $(1.25 \mathrm{~g}, 8.8$ mmol) as a colorless liquid.

3-methyloct-1-en-3-ol was then used to carry out general procedure A for synthesis of aryl ether. 3-methyloct-1-en-3-ol (1.49 mL, $8.8 \mathrm{mmol})$, NaH (0.316 g, $13.2 \mathrm{mmol})$ was stirred in anhyd. THF (40 mL) at room temperature for 20 minutes. Then hexafluorobenzene $(4.07 \mathrm{~mL}$, $35.2 \mathrm{mmol}$ ) was added and refluxed for $6 \mathrm{~h}$. The crude residue was purified by automated flash chromatography using hexane:ethyl acetate (0\% EtOAc for 0-15 cv and ramped to $50 \%$ EtOAc for $15-25 \mathrm{cv}$ and then held at $100 \%$ EtOAc $25-35 \mathrm{cv}$ ) on a $24 \mathrm{~g}$ silica column to afford $\mathbf{1 , 2 , 3 , 4 , 5 -}$ pentafluoro-6-((3-methyloct-1-en-3-yl)oxy)benzene (4d) in 66\% yield (1.78 g, $5.81 \mathrm{mmol})$ as a colorless liquid. 
Synthesis of (E)-1,2,3,4,5-pentafluoro-6-((3,7,11-trimethyldodeca-1,6,10-trien-3-

yl)oxy)benzene (7)
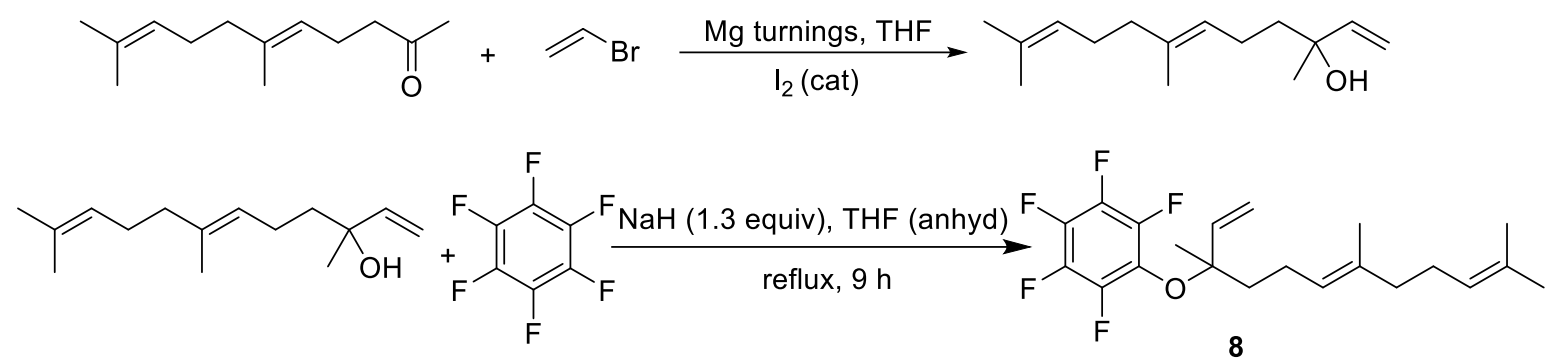

(E)-1,2,3,4,5-pentafluoro-6-((3,7,11-trimethyldodeca-1,6,10-trien-3-yl)oxy)benzene (8) was synthesized using general procedure B followed by general procedure A. A solution of $1 \mathrm{M}$ vinyl bromide in THF (25 mL, $25 \mathrm{mmol})$ was added to Mg turnings $(0.519 \mathrm{~g})$ in THF (45 mL) and heated to initiate Grignard reaction. It was followed by addition of (E)-6,10-dimethylundeca5,9-dien-2-one (3.71 mL, $16.67 \mathrm{mmol})$ over 15 minutes and left to stir overnight at room temperature. The crude residue was purified by automated flash chromatography using hexane:ethyl acetate $(0 \%$ EtOAc for 0-10 cv, ramped to $10 \%$ EtOAc for $10-25 \mathrm{cv}$, ramped again to $50 \%$ for $25-30 \mathrm{cv}$ and then held at $100 \%$ EtOAc for $30-40 \mathrm{cv}$ ) on a $24 \mathrm{~g}$ silica column to afford (E)-3,7,11-trimethyldodeca-1,6,10-trien-3-ol in 32.7\% yield $(1.21 \mathrm{~g}, 5.45 \mathrm{mmol})$ as a pale yellow liquid.

(E)-3,7,11-trimethyldodeca-1,6,10-trien-3-ol was then used to carry out general procedure A for synthesis of aryl ether. (E)-3,7,11-trimethyldodeca-1,6,10-trien-3-ol (1.38 mL, $5.45 \mathrm{mmol}$ ), $\mathrm{NaH}(0.261 \mathrm{~g}, 10.9 \mathrm{mmol})$ was stirred in anhyd. THF $(45 \mathrm{~mL})$ at room temperature for 20 minutes. Then hexafluorobenzene $(0.95 \mathrm{~mL}, 8.17 \mathrm{mmol})$ was added and refluxed for $9 \mathrm{~h}$. The crude residue was purified by automated flash chromatography using hexane:ethyl acetate ( $0 \%$ EtOAc for 0-15 cv and ramped to 50\% EtOAc for $15-25 \mathrm{cv}$ and then held at $100 \%$ EtOAc 25-35 cv) on a 24 g silica column to afford (E)-1,2,3,4,5-pentafluoro-6-((3,7,11-trimethyldodeca1,6,10-trien-3-yl)oxy)benzene (8) in $61 \%$ yield (1.29 g, $3.32 \mathrm{mmol})$ as a colorless liquid. 


\section{General procedure $\mathrm{C}$ for synthesis of aryl ether via acetylation:}

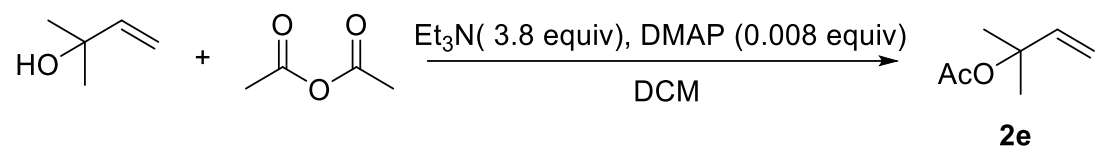

To a flame dried $250 \mathrm{~mL}$ round bottom flask was added 2-methylbut-3-en-2-ol (2.5 mL, 23 mmol), $\mathrm{Et}_{3} \mathrm{~N}(10.4 \mathrm{~mL}, 87.4 \mathrm{mmol}), \mathrm{DMAP}(0.04 \mathrm{~mL}, 0.184 \mathrm{mmol})$ and DCM (20 mL) via syringe. Flask was cooled in ice-bath and acetic anhydride $(7.2 \mathrm{~mL}, 87.4 \mathrm{mmol})$ was added dropwise with constant stirring. The resulting solution was stirred under an Ar atmosphere at room temperature and was monitored by TLC (hexane : ethyl acetate 95:5) until no alcohol was observed. The mixture was washed with $\mathrm{NaHCO}_{3}(2 \times 150 \mathrm{~mL}), 10 \% \mathrm{NaOH}(2 \times 50 \mathrm{~mL})$, brine $(50 \mathrm{~mL})$ and dried over $\mathrm{MgSO} 4$. Solvent was removed in vacuo and crude product was obtained as a yellow oil which was distilled $\left(130-150{ }^{\circ} \mathrm{C}\right.$ at $\left.760 \mathrm{~mm} \mathrm{Hg}\right)$ to yield 2-methylbut-3-en-2-yl acetate in $91 \%$ yield $(2.9 \mathrm{~mL}, 20.93 \mathrm{mmol})$ as a colorless liquid.

\section{General Procedure D for synthesis of aryl ether using dimethyl phosphorochloridate :}

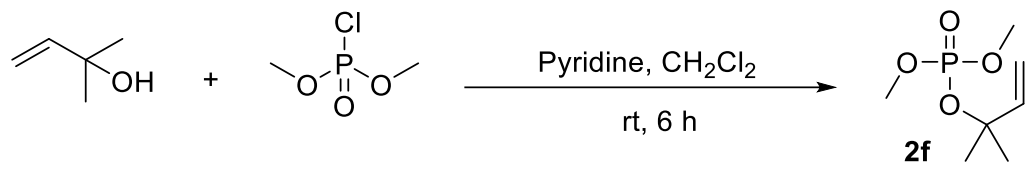

Dimethyl phosphorochloridate $(3.61 \mathrm{~g}, 25 \mathrm{mmol})$ was added to a solution of 2-methylbut-3-en-2ol ( $1.94 \mathrm{~g}, 22.5 \mathrm{mmol})$ and pyridine $(2.0 \mathrm{~mL})$ in $\mathrm{CH} 2 \mathrm{Cl} 2(30 \mathrm{~mL})$ at $0 \mathrm{oC}$ over 5 minutes. The resulting white slurry was stirred for $6 \mathrm{~h}$ at room temperature. The reaction mixture was diluted with diethyl ether and was washed successfully with a $10 \% \mathrm{HCl}$ solution, saturated $\mathrm{NaHCO}_{3}(2 \mathrm{x}$ $50 \mathrm{~mL}$ ) and brine $(3 \times 50 \mathrm{~mL})$. The organic layer was dried over anhydrous $\mathrm{MgSO}_{4}$. After removal of the solvent in vacuo, the crude product was purified by automated flash chromatography using hexane:ethyl acetate (0\% EtOAc for 0-15 cv and ramped to $50 \%$ EtOAc 
for $15-25 \mathrm{cv}$ and then held at $100 \%$ EtOAc $25-35 \mathrm{cv}$ ) on a $24 \mathrm{~g}$ silica column to afford dimethyl (2-methylbut-3-en-2-yl) phosphate in 76\% yield (3.32 g, $17.1 \mathrm{mmol})$ as a colorless liquid.

General Procedure E for synthesis of aryl ether from pyran :

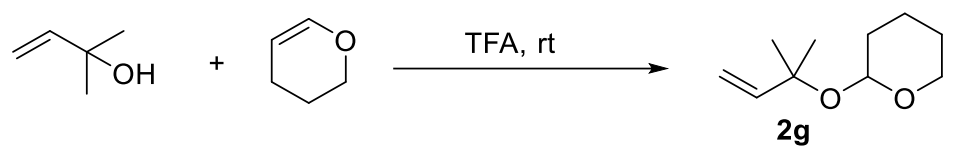

To a solution of 2-methylbut-3-en-2-ol (0.9 ml, 9 mmol) in DCM (30 mL) 2,3-dihydro-4H-pyran $(0.8 \mathrm{~mL}, 9 \mathrm{mmol})$ and trifluoroacetic acid $(0.1 \mathrm{~mL}, 1.8 \mathrm{mmol})$ were added. The reaction was stirred at room temperature and monitored by TLC. After completion of the reaction, it was quenched with $\mathrm{NaHCO} 3$ and extracted with DCM. The organic phase was then washed with water and brine, dried over MgSO4, and concentrated in vacuo. The crude product was purified by automated flash chromatography using hexane : ethyl acetate $(0 \%$ EtOAc for $0-15 \mathrm{cv}$ and ramped to $30 \%$ EtOAc for $15-25 \mathrm{cv}$ and then held at $100 \%$ EtOAc $25-35 \mathrm{cv}$ ) on a $24 \mathrm{~g}$ silica column to afford 2-((2-methylbut-3-en-2-yl)oxy)tetrahydro-2H-pyran in 70\% yield (1.07 g, 6.3 mmol) as a colorless oil.

\section{Working mechanism}

We believe that the reaction progresses with excitation of $\operatorname{Ir}(\mathrm{ppy})_{3}$ in the presence of blue LEDs to form a long lived triplet excited state. This further undergoes endothermic single electron transfer from DIPEA forming the radical anion via reductive quenching. It can then transfer an electron exothermically to the perfluoroarene (A) resulting in the formation of a perfluoroaryl radical anion (I1) that causes extrusion of fluoride ion to form a perfluoroaryl radical (I2). This perfluoroaryl radical (I2) in turn attacks the prenylating agent (B) selectively at the unsubsituted terminus of the alkene to generate a new radical (I3) followed by the loss of a phenoxy radical (I4) and results in the desired $\mathrm{C}-\mathrm{C}$ coupled prenylated product (C). 


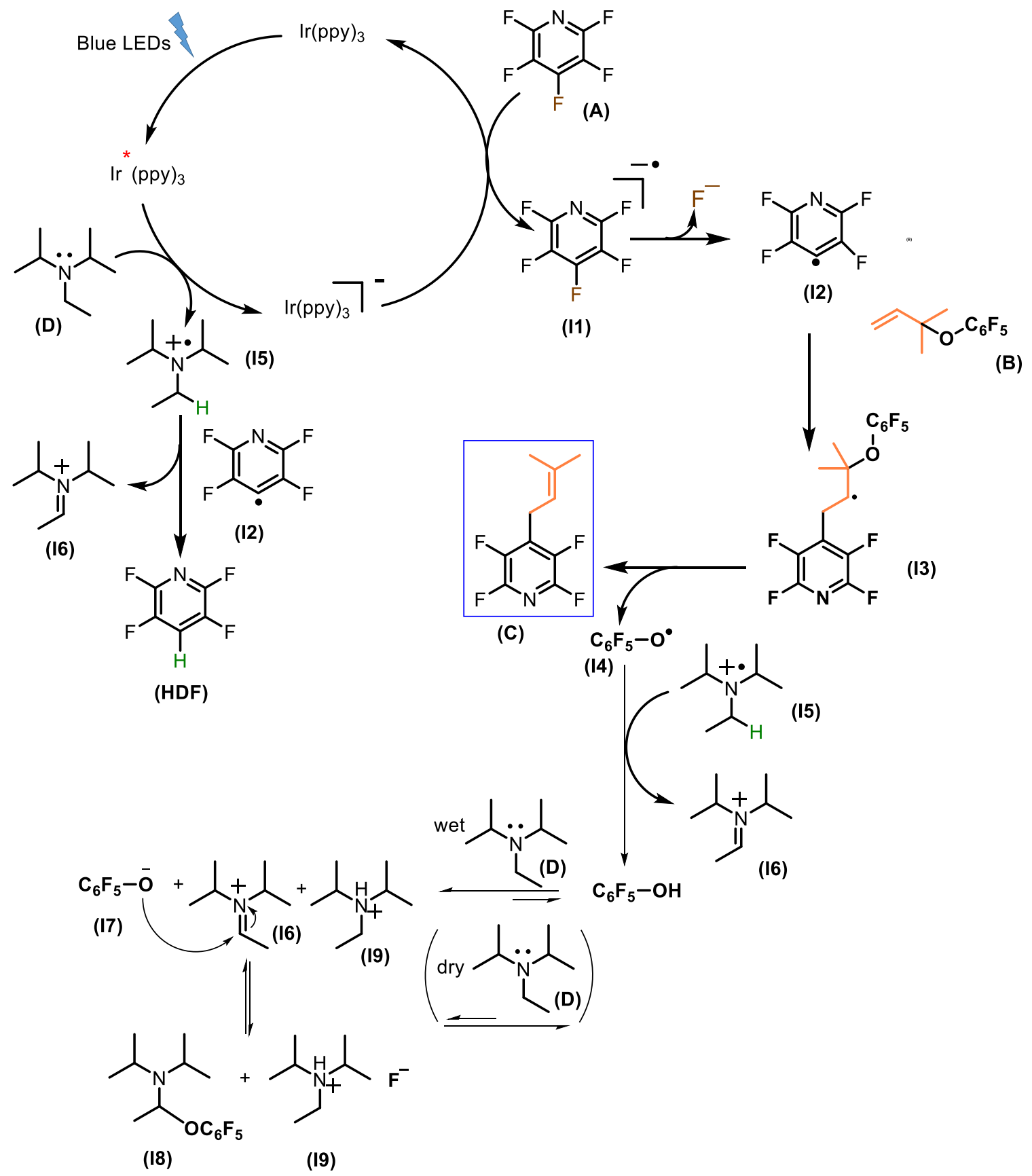

Figure 1.5: Working mechanism

\section{$\underline{\text { Photocatalytic Reactions on Perfluoroarenes }}$}

We believe that the reaction progresses with excitation of $\operatorname{Ir}(\mathrm{ppy})_{3}$ in the presence of blue LEDs to form a long lived triplet excited state. This further undergoes endothermic single electron 
transfer from DIPEA forming the radical anion via reductive quenching. It can then transfer an electron exothermically to the perfluoroarene (A) resulting in the formation of a perfluoroaryl radical anion (I1) that causes extrusion of fluoride ion to form a perfluoroaryl radical (I2). This perfluoroaryl radical (I2) in turn attacks the prenylating agent (B) selectively at the unsubsituted terminus of the alkene to generate a new radical (I3) followed by the loss of a phenoxy radical (I4) and results in the desired $\mathrm{C}-\mathrm{C}$ coupled prenylated product (C). The perfluoroaryl radical (I2) generated upon fluoride fragmentation could also undergo undesired hydrogen atom transfer from the amine radical cation (I5) (and potentially the amine $\mathrm{D}, \alpha \mathrm{C}-\mathrm{H} \mathrm{BDE}$ of $91 \mathrm{kcal} / \mathrm{mol}$ ) ${ }^{44}$ to form undesired HDF product. The phenoxy radical (I4) generated (BDE C6H5O-H is $87.6 \mathrm{kcal} / \mathrm{mol})^{45}$ during the course of reaction is capable of abstracting hydrogen atom from amine radical cation (I5, $\alpha \mathrm{C}-\mathrm{H} \mathrm{BDE} \sim 42 \mathrm{kcal} / \mathrm{mol})^{46}$ to form pentafluorophenol and generate an iminium ion (I6). We believe that in the presence of water, the equilibrium is shifted towards the ionic forms (the left). Our control studies with $\mathrm{C}_{6} \mathrm{~F}_{5} \mathrm{OH}$ demonstrate its inhibitory and deleterious effect in the absence of water (see above). This may be because it serves as a good HAT donor. We speculate that the phenolate (I7) could also have a beneficial role by attacking the iminium ion (I6) to form the Nacetal species (I8).

\section{General procedure $\mathbf{F}$ for photocatalytic allylation reaction}

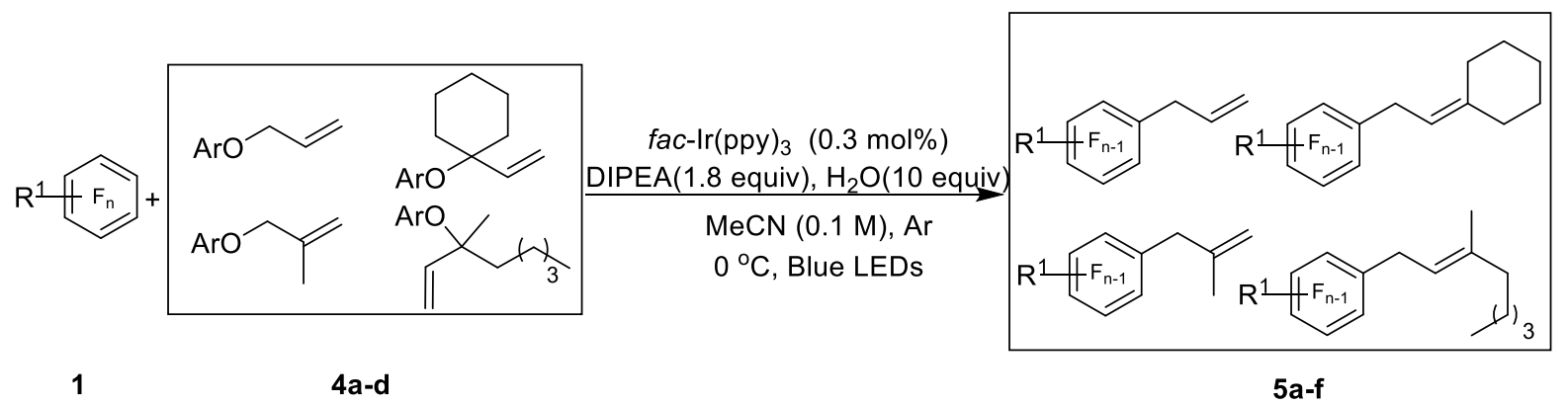

An NMR tube was charged with fluoroarene ( $0.1 \mathrm{mmol}, 1.0$ equiv), allyl-OAr ( $0.6 \mathrm{mmol}, 6$ equiv), $N, N$-diisopropylethylamine ( $0.18 \mathrm{mmol}, 1.8$ equiv), distilled water ( $1 \mathrm{mmol}, 10$ equiv), fac-tris(2- phenyl pyridinato-C2, N) Iridium(III) (Ir(ppy)3) (0.3 mM, $1 \mathrm{~mL}$ in MeCN), sealed 
glass capillary containing $\mathrm{C}_{6} \mathrm{D}_{6}$ and was capped with an NMR septum (Ace glass, part no. 909625). When reaction was run in greater than $0.1 \mathrm{mmol}$ of fluoroarene, more than one NMR tube was used to set up the reaction and each NMR tube had $1 \mathrm{~mL}$ of reaction mixture. The reaction was degassed via Ar bubbling for $15 \mathrm{~min}$ at $0{ }^{\circ} \mathrm{C}$ (to avoid evaporation of $N, N$ diisopropylethylamine and other volatile starting materials) and then placed in a light bath (vide supra) such that the lower portion of the tube was submerged under the isopropanol/water bath.

The reaction was monitored periodically by ${ }^{19} \mathrm{~F}$ NMR (care was taken to exclude light while in transit). After the complete consumption of starting material, $\mathrm{CH}_{3} \mathrm{CN}$ was removed via rotavap. The crude material was purified using prep TLC plate 10:1 hexane:ether. If the reaction did not go to completion with the first addition of $N, N$ diisopropylethylamine, an additional $0.2-1.2$ equiv of $N, N$-diisopropylethylamine was added to the reaction. Then the reaction was redegassed and returned to the light bath. This sequence was repeated until the reaction reached completion as judged by ${ }^{19} \mathrm{~F}$ NMR.

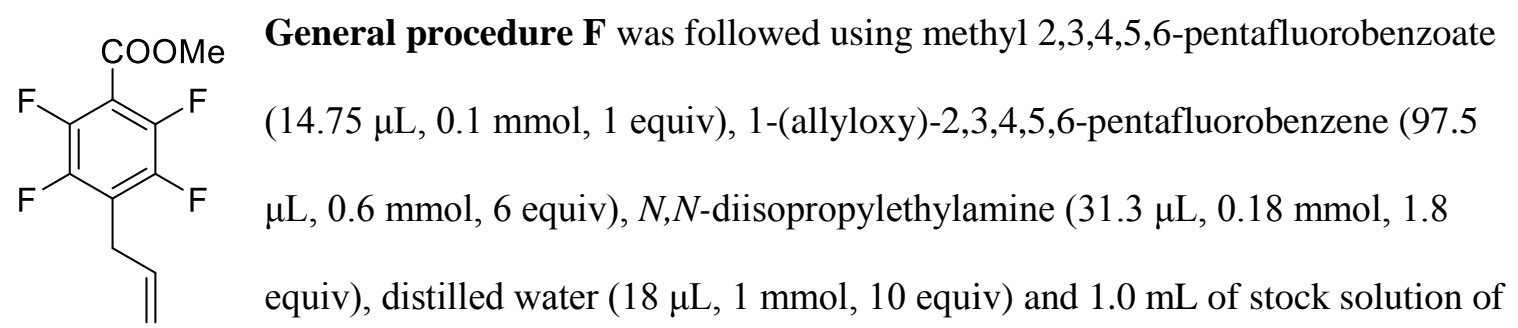
$\operatorname{Ir}(\mathrm{ppy})_{3}\left(0.16 \mathrm{mg}, 0.0003 \mathrm{mmol}, 0.003\right.$ equiv) in $\mathrm{CH}_{3} \mathrm{CN}$ was used. The crude material was purified by using Prep TLC 10:1 hexane:diethyl ether to afford methyl 4-allyl-2,3,5,6tetrafluorobenzoate (5a) as a colorless liquid in $72 \%{ }^{19} \mathrm{~F}$ NMR yield and 66\% isolated yield (14.89 mg, $0.06 \mathrm{mmol}) .{ }^{19} \mathrm{~F}$ NMR (376 MHz, $\left.\mathrm{CDCl}_{3}\right) \delta-140.04--140.19(\mathrm{~m}, 2 \mathrm{~F}),-143.12(\mathrm{td}, J$ $=15.8,4.8 \mathrm{~Hz}, 2 \mathrm{~F}) .{ }^{1} \mathrm{H}$ NMR $\left(400 \mathrm{MHz}, \mathrm{CDCl}_{3}\right) \delta 5.94-5.82(\mathrm{~m}, 1 \mathrm{H}), 5.12(\mathrm{~d}, 2 \mathrm{H}), 3.97(\mathrm{~s}$, 3H), $3.50(\mathrm{~d}, J=6.3 \mathrm{~Hz}, 2 \mathrm{H}) .{ }^{13} \mathrm{C} \mathrm{NMR}\left(101 \mathrm{MHz}, \mathrm{CDCl}_{3}\right) \delta 160.4,146.1-143.6(\mathrm{ddd}, J=12.9$, $6.4,4.8 \mathrm{~Hz}), 145.8-143.3(\mathrm{dt}, J=15.9,4.6 \mathrm{~Hz}), 132.2,121.9(\mathrm{t}, J 18.4 \mathrm{~Hz}), 117.6,110.6(\mathrm{t}, J=$ 15.7 Hz), 53.2, 27.1. GC/MS (m/z, relative intensity) 248 (M+, 48), 229 (2), 217 (100), 169 (28). 


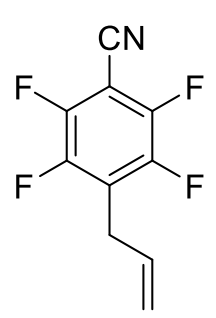

General procedure $\mathbf{F}$ was followed using methyl pentafluorobenzonitrile (12.6

$\mu \mathrm{L}, 0.1$ mmol, 1 equiv), 1-(allyloxy)-2,3,4,5,6-pentafluorobenzene (97.6 $\mu \mathrm{L}, 0.6$

mmol, 6 equiv), $N, N$-diisopropylethylamine ( $31.3 \mu \mathrm{L}, 0.18 \mathrm{mmol}, 1.8$ equiv),

distilled water (18 $\mu \mathrm{L}, 1 \mathrm{mmol}, 10$ equiv) and $1.0 \mathrm{~mL}$ of stock solution of $\operatorname{Ir}(\mathrm{ppy})_{3}$

( $0.16 \mathrm{mg}, 0.0003 \mathrm{mmol}, 0.003$ equiv) in $\mathrm{CH}_{3} \mathrm{CN}$ was used. The crude material was purified by using Prep TLC 10:1 hexane:diethyl ether to afford 4-allyl-2,3,5,6-tetrafluorobenzonitrile (5b) as a colorless liquid in $81 \%{ }^{19} \mathrm{~F}$ NMR yield and $72 \%$ isolated yield (15.48 $\left.\mathrm{mg}, 0.07 \mathrm{mmol}\right)$. Not much effort was given to evaporate the solvents due to low volatility of compound. The crude product also contained hydrodefluorinated product. ${ }^{19} \mathrm{~F}$ NMR $\left(376 \mathrm{MHz}, \mathrm{CDCl}_{3}\right) \delta-132.67--$ $133.24(\mathrm{~m}, 2 \mathrm{~F}),-133.68--134.38(\mathrm{~m}, 2 \mathrm{~F}$, minor), $-140.50(\mathrm{td}, J=15.8,4.8 \mathrm{~Hz}, 2 \mathrm{~F}),-140.94--$ $141.51\left(\mathrm{~m}, 2 \mathrm{~F}\right.$, minor). ${ }^{1} \mathrm{H}$ NMR $\left(400 \mathrm{MHz}, \mathrm{CDCl}_{3}\right) \delta 5.89-5.68(\mathrm{~m}, 1 \mathrm{H}), 5.09(\mathrm{~d}, 2 \mathrm{H}), 3.47(\mathrm{~d}$, $2 \mathrm{H})$.

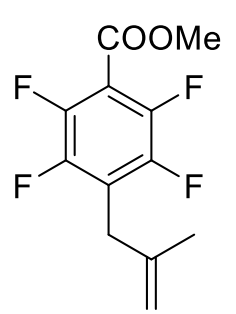

General procedure $\mathbf{F}$ was followed using methyl 2,3,4,5,6-pentafluorobenzoate (14.75 $\mu \mathrm{L}, 0.1$ mmol, 1 equiv), 1,2,3,4,5-pentafluoro-6-((2methylallyl)oxy)benzene ( $107.3 \mu \mathrm{L}, 0.6 \mathrm{mmol}, 6$ equiv), $N, N$ diisopropylethylamine (31.3 $\mu \mathrm{L}, 0.18 \mathrm{mmol}, 1.8$ equiv), distilled water $(18 \mu \mathrm{L}, 1$ mmol, 10 equiv) and $1.0 \mathrm{~mL}$ of stock solution of $\operatorname{Ir}(\mathrm{ppy})_{3}(0.16 \mathrm{mg}, 0.0003 \mathrm{mmol}, 0.003$ equiv) in $\mathrm{CH}_{3} \mathrm{CN}$ was used. The crude material was purified by using Prep TLC 10:1 hexane:diethyl ether to afford methyl 2,3,5,6-tetrafluoro-4-(2-methylallyl)benzoate (5c) as a colorless liquid in 74\% ${ }^{19} \mathrm{~F}$ NMR yield and $68 \%$ isolated yield $(18.34 \mathrm{mg}, 0.07 \mathrm{mmol}) .{ }^{19} \mathrm{~F}$ NMR $\left(376 \mathrm{MHz}, \mathrm{CDCl}_{3}\right) \delta-$ $140.02--140.44(\mathrm{~m}, 2 \mathrm{~F}),-142.50(\mathrm{td}, J=15.8,4.8 \mathrm{~Hz}, 2 \mathrm{~F}) .{ }^{1} \mathrm{H}$ NMR $\left(400 \mathrm{MHz}, \mathrm{CDCl}_{3}\right) \delta 4.85$ (s, 1H), $4.65(\mathrm{~s}, 1 \mathrm{H}), 3.98(\mathrm{~s}, 3 \mathrm{H}), 3.44(\mathrm{~s}, 2 \mathrm{H}), 1.78(\mathrm{~s}, 3 \mathrm{H}) .{ }^{13} \mathrm{C} \mathrm{NMR}\left(101 \mathrm{MHz}, \mathrm{CDCl}_{3}\right) \delta$ $160.4,146.2-143.8(\mathrm{ddd}, J=12.9,6.4,4.8 \mathrm{~Hz}), 145.8-143.2(\mathrm{dt}, J=15.9,4.6 \mathrm{~Hz}), 140.4$, $121.9(\mathrm{t}, J=18.4 \mathrm{~Hz}), 112.8,110.6(\mathrm{t}, J=15.7 \mathrm{~Hz}), 53.2,31.3-30.6(\mathrm{~m}), 22.3 . \mathrm{GC} / \mathrm{MS}(\mathrm{m} / \mathrm{z}$, relative intensity) $262(\mathrm{M}+, 64), 247(15), 231(100)$. 


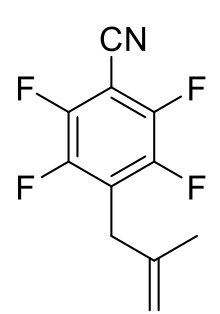

General procedure F was followed using 2,3,4,5,6-pentafluorobenzonitrile (12.6

$\mu \mathrm{L}, 0.1$ mmol, 1 equiv), 1,2,3,4,5-pentafluoro-6-((2-methylallyl)oxy)benzene

(107.3 $\mu \mathrm{L}, 0.6$ mmol, 6 equiv), $N, N$-diisopropylethylamine $(31.3 \mu \mathrm{L}, 0.18 \mathrm{mmol}$,

1.8 equiv), distilled water ( $18 \mu \mathrm{L}, 1 \mathrm{mmol}, 10$ equiv) and $1.0 \mathrm{~mL}$ of stock solution

of $\operatorname{Ir}(\mathrm{ppy})_{3}\left(0.16 \mathrm{mg}, 0.0003 \mathrm{mmol}, 0.003\right.$ equiv) in $\mathrm{CH}_{3} \mathrm{CN}$ was used. The crude material was

purified by using Prep TLC 10:1 hexane:diethyl ether to afford 2,3,5,6-tetrafluoro-4-(2-

methylallyl)benzonitrile (5d) as a colorless liquid in $85 \%{ }^{19} \mathrm{~F}$ NMR yield and $78 \%$ isolated yield (17.86 mg, $0.08 \mathrm{mmol}) .{ }^{19} \mathrm{~F} \mathrm{NMR}\left(376 \mathrm{MHz}, \mathrm{CDCl}_{3}\right) \delta-133.06(\mathrm{td}, J=17.4,7.1 \mathrm{~Hz}, 2 \mathrm{~F}),-139.86$ $(\mathrm{td}, J=16.8,7.0 \mathrm{~Hz}, 2 \mathrm{~F}) .{ }^{1} \mathrm{H} \mathrm{NMR}\left(400 \mathrm{MHz}, \mathrm{CDCl}_{3}\right) \delta 4.88(\mathrm{~s}, 1 \mathrm{H}), 4.66(\mathrm{~s}, 1 \mathrm{H}), 3.48(\mathrm{~s}, 2 \mathrm{H})$, $1.79(\mathrm{~s}, 3 \mathrm{H}) .{ }^{13} \mathrm{C} \mathrm{NMR}\left(101 \mathrm{MHz}, \mathrm{CDCl}_{3}\right) \delta 148.2-145.6(\mathrm{dt}, J=16.4,3.6 \mathrm{~Hz}), 146.3-143.4$ (m), 139.7, $125.8(\mathrm{t}, J=18.4 \mathrm{~Hz}), 113.5,107.6(\mathrm{t}, J=3.7 \mathrm{~Hz}), 92.4,31.2,22.3 . \mathrm{GC} / \mathrm{MS}(\mathrm{m} / \mathrm{z}$, relative intensity) $229(\mathrm{M}+, 55), 214(34), 194(25)$.

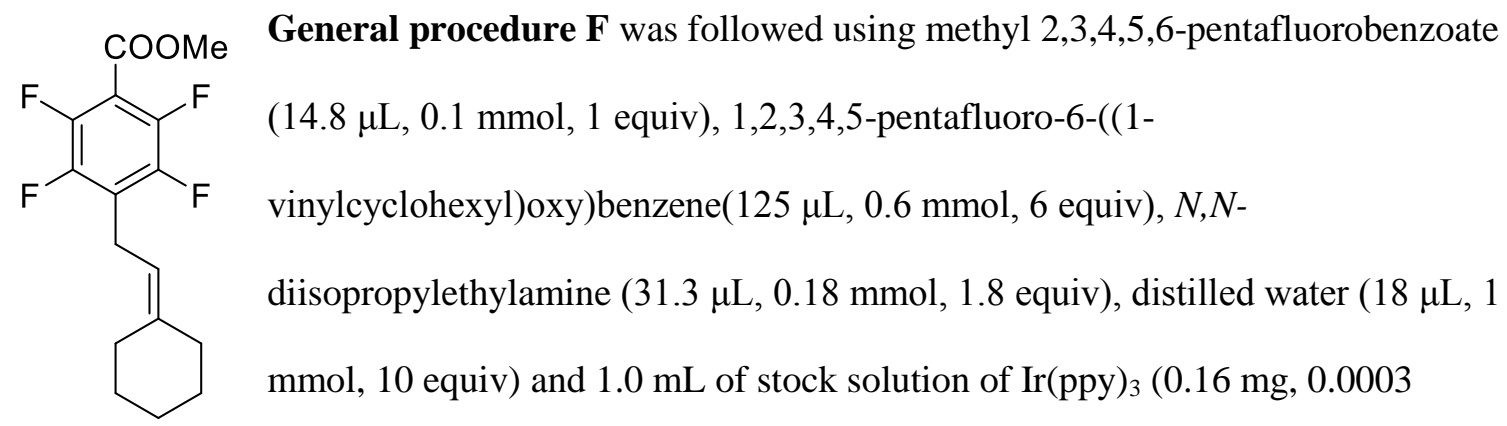

mmol, 0.003 equiv) in $\mathrm{CH}_{3} \mathrm{CN}$ was used. The crude material was purified by using Prep TLC 10:1 hexane:diethyl ether to afford methyl 4-(2-cyclohexylideneethyl)-2,3,5,6-

tetrafluorobenzoate (5e) as a colorless liquid in $68 \%{ }^{19} \mathrm{~F}$ NMR yield and $61 \%$ isolated yield (18.96 mg, $0.06 \mathrm{mmol}) .{ }^{19} \mathrm{~F} \mathrm{NMR}\left(376 \mathrm{MHz}, \mathrm{CDCl}_{3}\right) \delta-140.24--140.41(\mathrm{~m}, 2 \mathrm{~F}$, major and minor), $-143.41\left(\mathrm{td}, J=15.7,4.9 \mathrm{~Hz}, 2 \mathrm{~F}\right.$, major and minor). ${ }^{1} \mathrm{H} \mathrm{NMR}\left(400 \mathrm{MHz}, \mathrm{CDCl}_{3}\right) \delta 5.10$ (t, $J=7.5 \mathrm{~Hz}, 1 \mathrm{H}), 3.96(\mathrm{~s}, 3 \mathrm{H}), 3.45(\mathrm{~d}, J=7.5 \mathrm{~Hz}, 2 \mathrm{H}), 2.27(\mathrm{t}, J=5.5 \mathrm{~Hz}, 2 \mathrm{H}), 2.11-2.00(\mathrm{~m}$, 2H), $1.63-1.44(\mathrm{~m}, 6 \mathrm{H}) .{ }^{13} \mathrm{C} \mathrm{NMR}\left(101 \mathrm{MHz}, \mathrm{CDCl}_{3}\right) \delta 160.2,146.2-143.8$ (ddd, $J=12.9,6.4$, 
$4.8 \mathrm{~Hz}), 145.8-143.4(\mathrm{dt}, J=15.9,4.6 \mathrm{~Hz}), 143.1,123.9(\mathrm{t}, J=18.7 \mathrm{~Hz}), 114.8,109.7,53.1$, 37.0, 29.7, 28.3, 26.7, 21.3. GC/MS (m/z, relative intensity) $316(\mathrm{M}+, 15), 285(15), 235$ (58).

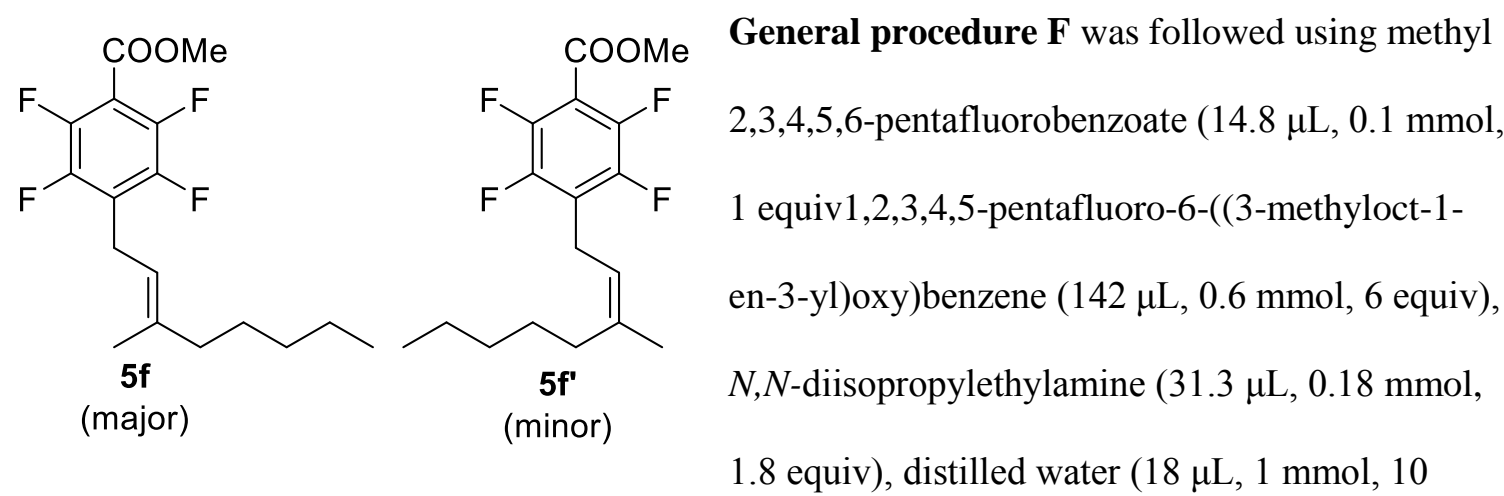

equiv) and $1.0 \mathrm{~mL}$ of stock solution of $\operatorname{Ir}(\mathrm{ppy})_{3}\left(0.16 \mathrm{mg}, 0.0003 \mathrm{mmol}, 0.003\right.$ equiv) in $\mathrm{CH}_{3} \mathrm{CN}$ was used. The crude material was purified by using Prep TLC 10:1 hexane:diethyl ether to afford methyl (E)-2,3,5,6-tetrafluoro-4-(3-methyloct-2-en-1-yl)benzoate (5f) with E:Z 1.3:1 as a colorless liquid in $64 \%{ }^{19} \mathrm{~F}$ NMR yield. Alkene geometry was assigned by NOE correlation of the allylic methylene to the cis substituent. ${ }^{19} \mathrm{~F}$ NMR $\left(376 \mathrm{MHz}, \mathrm{CDCl}_{3}\right) \delta-140.23--140.41(\mathrm{~m}, 4 \mathrm{~F}$, major and minor), $-143.13\left(\mathrm{tt}, J=15.1,6.7 \mathrm{~Hz}, 4 \mathrm{~F}\right.$, major and minor). ${ }^{1} \mathrm{H} \mathrm{NMR}(400 \mathrm{MHz}$, $\left.\mathrm{CDCl}_{3}\right) \delta 5.15(\mathrm{t}, J=7.3 \mathrm{~Hz}, 2 \mathrm{H}$, major and minor), 3.96 (s, 6H, major and minor), 3.45 (d, $J=$ $7.3 \mathrm{~Hz}, 4 \mathrm{H}$, major and minor), $2.22-2.09$ (m, 2H, minor), 1.95 (d, $J=7.8 \mathrm{~Hz}, 2 \mathrm{H}), 1.73(\mathrm{~s}, 3 \mathrm{H})$, 1.68 (s, 3H, minor), $1.45-1.14(\mathrm{~m}, 12 \mathrm{H}$, major and minor), 0.95 (t, $J=7.2 \mathrm{~Hz}, 3 \mathrm{H}$, minor) -0.83 $(\mathrm{t}, J=7.2 \mathrm{~Hz}, 3 \mathrm{H}) .{ }^{13} \mathrm{C} \mathrm{NMR}\left(101 \mathrm{MHz}, \mathrm{CDCl}_{3}\right) \delta 160.5,146.2-143.6(\mathrm{ddd}, J=12.9,6.4,4.8$ $\mathrm{Hz}), 145.8-143.1(\mathrm{dt}, J=15.9,4.6 \mathrm{~Hz}), 139.5,139.3,123.8(\mathrm{t}, J=18.7 \mathrm{~Hz}), 118.4,117.8,110.3$ $-109.3(\mathrm{~m}), 53.5-52.3(\mathrm{~m}), 39.8-39.1(\mathrm{~m}), 31.8(\mathrm{~d}, J=9.9 \mathrm{~Hz}), 31.4,27.5,22.5(\mathrm{~d}, J=9.3$ Hz), 22.2, 15.9, 14.0. GC/MS (m/z, relative intensity) 332 (M+, 18), 301 (22), 256 (30), 216 (68). 


\section{General procedure $\mathbf{G}$ for photocatalytic prenylation reaction}

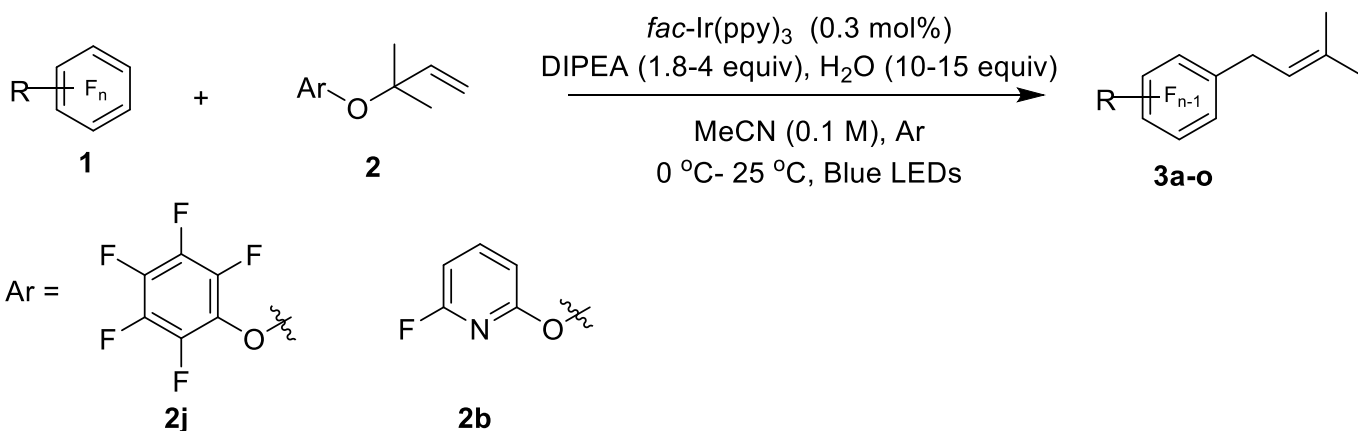

An NMR tube was charged with fluoroarene $(0.1 \mathrm{mmol}, 1.0$ equiv), prenyl-OAr (0.6-0.8 mmol, 6-8 equiv), $N, N$-diisopropylethylamine (0.18-0.4 mmol, 1.8-4 equiv), distilled water ( $1-1.5$ mmol, 10 -15 equiv), $f a c$-tris(2- phenyl pyridinato- $C 2, N) \operatorname{Iridium}(\mathrm{III})\left(\operatorname{Ir}(\mathrm{ppy})_{3}\right)(0.3 \mathrm{mM}, 1 \mathrm{~mL}$ in $\mathrm{MeCN}$ ), sealed glass capillary containing $\mathrm{C}_{6} \mathrm{D}_{6}$ and was capped with an NMR septum (Ace glass, part no. 9096-25). When reaction was run in greater than $0.1 \mathrm{mmol}$ of fluoroarene, more than one NMR tube was used to set up the reaction and each NMR tube had $1 \mathrm{~mL}$ of reaction mixture. The reaction was degassed via Ar bubbling for $15 \mathrm{~min}$ at $0{ }^{\circ} \mathrm{C}$ (to avoid evaporation of $N, N$ diisopropylethylamine and other volatile starting materials) and then placed in a light bath (vide supra) such that the lower portion of the tube was submerged under the isopropanol/water bath.

The reaction was monitored periodically by ${ }^{19} \mathrm{~F}$ NMR (care was taken to exclude light while in transit). After the complete consumption of starting material, $\mathrm{CH}_{3} \mathrm{CN}$ was removed via rotavap. The crude material was purified using prep TLC plate. If the reaction did not go to completion with the first addition of $N, N$-diisopropylethylamine, an additional 1 - 3 equiv of $N, N$ diisopropylethylamine was added to the reaction. Then the reaction was re-degassed and returned to the light bath. This sequence was repeated until the reaction reached completion as judged by ${ }^{19}$ F NMR. 


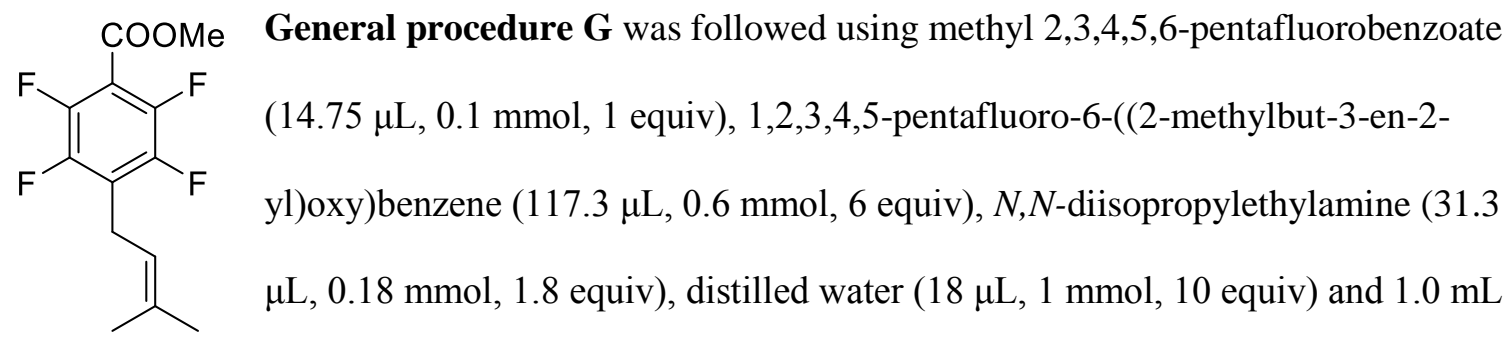
of stock solution of $\operatorname{Ir}(\mathrm{ppy})_{3}\left(0.16 \mathrm{mg}, 0.0003 \mathrm{mmol}, 0.003\right.$ equiv) in $\mathrm{CH}_{3} \mathrm{CN}$ was used. The crude material was purified by using Prep TLC 10:1 hexane:diethyl ether to afford methyl 2,3,5,6tetrafluoro-4-(3-methylbut-2-en-1-yl)benzoate (3a) as a colorless liquid in 68\% ${ }^{19} \mathrm{~F}$ NMR yield and $61 \%$ isolated yield (16.6 mg, $0.06 \mathrm{mmol}) .{ }^{19} \mathrm{~F} \mathrm{NMR}\left(376 \mathrm{MHz}, \mathrm{CDCl}_{3}\right) \delta-140.23--140.38$ (m, 2F), -143.20 (dd, $J=21.4,12.7 \mathrm{~Hz}, 2 \mathrm{~F}) .{ }^{1} \mathrm{H}$ NMR (400 MHz, $\left.\mathrm{CDCl}_{3}\right) \delta 5.15(\mathrm{t}, J=7.4 \mathrm{~Hz}$, 1H), $3.96(\mathrm{~s}, 3 \mathrm{H}), 3.43(\mathrm{~d}, J=7.4 \mathrm{~Hz}, 2 \mathrm{H}), 1.74(\mathrm{~s}, 3 \mathrm{H}), 1.69(\mathrm{~s}, 3 \mathrm{H}) .{ }^{13} \mathrm{C} \mathrm{NMR}(101 \mathrm{MHz}$ $\left.\mathrm{CDCl}_{3}\right) \delta 160.5,146.1-143.6(\mathrm{ddd}, J=12.9,6.4,4.8 \mathrm{~Hz}), 145.8-143.3(\mathrm{dt}, J=15.9,4.6 \mathrm{~Hz})$, 135.3, $123.6(\mathrm{t}, J=18.8 \mathrm{~Hz}), 118.2,110.0(\mathrm{t}, J=15.7 \mathrm{~Hz}), 53.1,25.6,22.2,17.6 . \mathrm{GC} / \mathrm{MS}(\mathrm{m} / \mathrm{z}$, relative intensity) $276(\mathrm{M}+, 20), 261(35), 245(15)$. This product was also obtained when $2-$ fluoro-6-((2-methylbut-3-en-2-yl)oxy)pyridine was used as the prenyl source. However, in this case the reaction produced a significant side-product which we assume it to be methyl 2,3,5,6tetrafluoro-4-(3-methylbut-2-enoyl)benzoate (oxidized product) based on GC/MS (m/z, relative intensity) $290(\mathrm{M}+, 40)$ which is the mass of the side product.

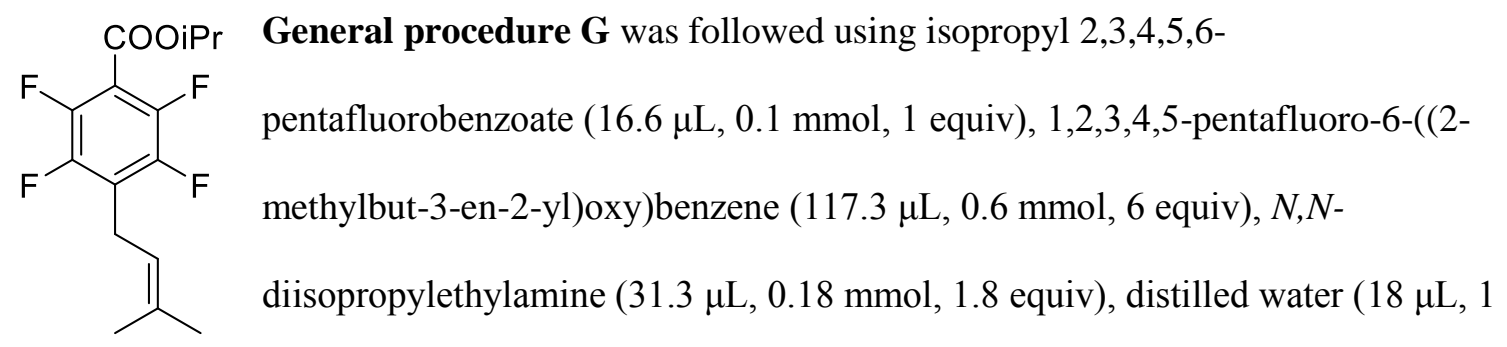
mmol, 10 equiv) and $1.0 \mathrm{~mL}$ of stock solution of $\operatorname{Ir}(\mathrm{ppy})_{3}(0.16 \mathrm{mg}, 0.0003 \mathrm{mmol}, 0.003$ equiv) in $\mathrm{CH}_{3} \mathrm{CN}$ was used. The crude material was purified by using Prep TLC 10:1 hexane:diethyl ether to afford isopropyl 2,3,5,6-tetrafluoro-4-(3-methylbut-2-en-1-yl)benzoate (3b) as a colorless 
liquid in $65 \%{ }^{19} \mathrm{~F}$ NMR yield and 58\% isolated yield ( $\left.18.24 \mathrm{mg}, 0.06 \mathrm{mmol}\right) .{ }^{19} \mathrm{~F}$ NMR (376 $\left.\mathrm{MHz}, \mathrm{CDCl}_{3}\right) \delta-141.03--141.16(\mathrm{~m}, 2 \mathrm{~F}),-143.39--143.52(\mathrm{~m}, 2 \mathrm{~F}) .{ }^{1} \mathrm{H}$ NMR $(400 \mathrm{MHz}$ $\left.\mathrm{CDCl}_{3}\right) \delta 5.34-5.25(\mathrm{~m}, 1 \mathrm{H}), 5.15(\mathrm{t}, J=7.3 \mathrm{~Hz}, 1 \mathrm{H}), 3.42(\mathrm{~d}, J=7.3 \mathrm{~Hz}, 2 \mathrm{H}), 1.74(\mathrm{~s}, 3 \mathrm{H})$, $1.69(\mathrm{~s}, 3 \mathrm{H}), 1.37(\mathrm{~d}, J=6.3 \mathrm{~Hz}, 6 \mathrm{H}) .{ }^{13} \mathrm{C} \mathrm{NMR}\left(101 \mathrm{MHz}, \mathrm{CDCl}_{3}\right) \delta 159.5,145.9-143.6$ (ddd, $J=12.9,6.4,4.8 \mathrm{~Hz}), 145.6-143.1(\mathrm{dt}, J=15.9,4.6 \mathrm{~Hz}), 135.2,123.1(\mathrm{t}, J=18.8 \mathrm{~Hz}), 118.4$, $111.0(\mathrm{t}, J=16.3 \mathrm{~Hz}), 70.6,25.6,22.2,21.7,17.6 . \mathrm{GC} / \mathrm{MS}$ (m/z, relative intensity) $304(\mathrm{M}+, 12)$, 289 (7), 247 (22).

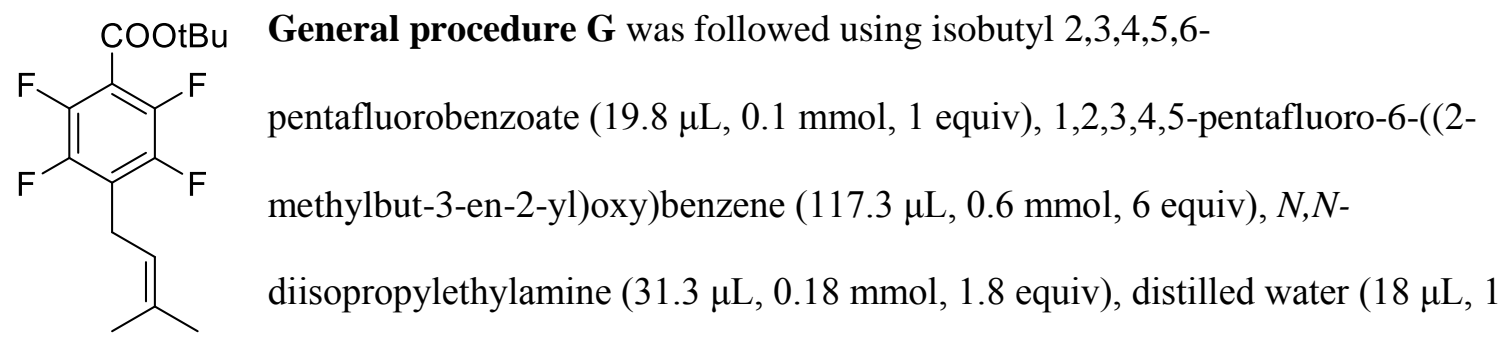
mmol, 10 equiv) and $1.0 \mathrm{~mL}$ of stock solution of $\operatorname{Ir}(\mathrm{ppy})_{3}(0.16 \mathrm{mg}, 0.0003 \mathrm{mmol}, 0.003$ equiv) in $\mathrm{CH}_{3} \mathrm{CN}$ was used. The crude material was purified by using Prep TLC 10:1 hexane:diethyl ether to afford isobutyl 2,3,5,6-tetrafluoro-4-(3-methylbut-2-en-1-yl)benzoate (3c) as a colorless liquid in $66 \%{ }^{19} \mathrm{~F}$ NMR yield and 60\% isolated yield $(19.08 \mathrm{mg}, 0.06 \mathrm{mmol}) .{ }^{19} \mathrm{~F}$ NMR (376 $\left.\mathrm{MHz}, \mathrm{CDCl}_{3}\right) \delta-137.84--137.99$ (m, minor), $-141.06--141.21$ (m, minor), $-141.87--142.00$ (m), $-143.61--143.73(\mathrm{~m}) .{ }^{1} \mathrm{H}$ NMR $\left(400 \mathrm{MHz}, \mathrm{CDCl}_{3}\right) \delta 5.15(\mathrm{t}, J=7.4 \mathrm{~Hz}, 1 \mathrm{H}), 3.41(\mathrm{~d}, J=$ $7.4 \mathrm{~Hz}, 2 \mathrm{H}), 1.74(\mathrm{~s}, 3 \mathrm{H}), 1.69(\mathrm{~s}, 3 \mathrm{H}), 1.59(\mathrm{~s}, 9 \mathrm{H}) .{ }^{13} \mathrm{C} \mathrm{NMR}\left(101 \mathrm{MHz}, \mathrm{CDCl}_{3}\right) \delta 158.9(\mathrm{t}, J=$ $3.0 \mathrm{~Hz}), 145.8-143.4(\mathrm{ddd}, J=13.0,6.8,4.5 \mathrm{~Hz}), 145.4-142.9(\mathrm{dt}, J=15.9,4.6 \mathrm{~Hz}), 135.0$, $122.5(\mathrm{t}, J=18.8 \mathrm{~Hz}), 118.5,112.1(\mathrm{t}, J=16.8 \mathrm{~Hz}), 84.3,28.1,25.6,22.1,17.6 . \mathrm{GC} / \mathrm{MS}(\mathrm{m} / \mathrm{z}$, relative intensity) $318(\mathrm{M}+, 25), 262$ (65), 247 (100).

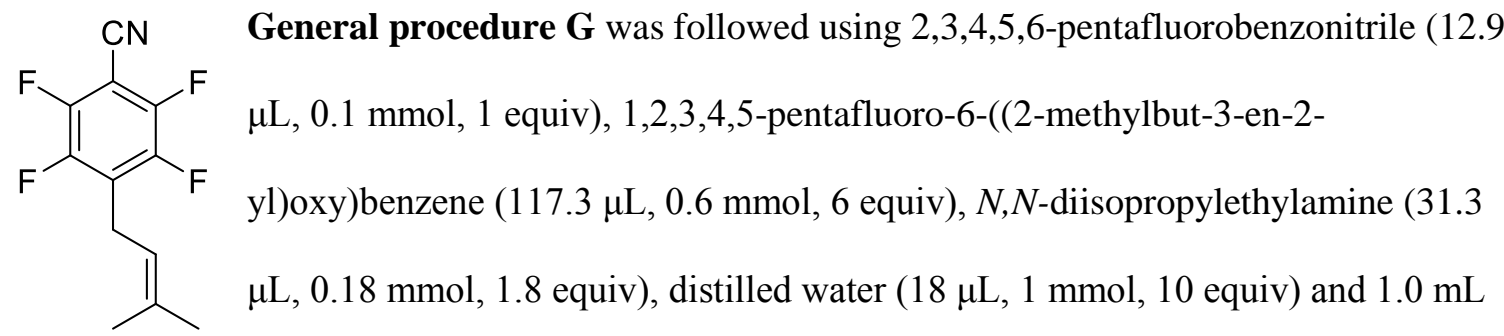


of stock solution of $\operatorname{Ir}(\mathrm{ppy})_{3}\left(0.16 \mathrm{mg}, 0.0003 \mathrm{mmol}, 0.003\right.$ equiv) in $\mathrm{CH}_{3} \mathrm{CN}$ was used. The crude material was purified by using Prep TLC 10:1 hexane:diethyl ether to afford 2,3,5,6-tetrafluoro4-(3-methylbut-2-en-1-yl)benzonitrile (3d) as a colorless liquid in $71 \%{ }^{19} \mathrm{~F}$ NMR yield and $64 \%$ isolated yield (14.58 mg, $0.06 \mathrm{mmol}) .{ }^{19} \mathrm{~F} \mathrm{NMR}\left(376 \mathrm{MHz}, \mathrm{CDCl}_{3}\right) \delta-133.13--133.26(\mathrm{~m}, 2 \mathrm{~F})$, $140.61(\mathrm{td}, J=16.4,6.9 \mathrm{~Hz}, 2 \mathrm{~F}) .{ }^{1} \mathrm{H} \mathrm{NMR}\left(400 \mathrm{MHz}, \mathrm{CDCl}_{3}\right) \delta 5.13(\mathrm{t}, J=7.2 \mathrm{~Hz}, 1 \mathrm{H}), 3.48(\mathrm{~d}$, $J=7.3 \mathrm{~Hz}, 2 \mathrm{H}), 1.75(\mathrm{~s}, 3 \mathrm{H}), 1.71(\mathrm{~s}, 3 \mathrm{H}) .{ }^{13} \mathrm{C} \mathrm{NMR}\left(101 \mathrm{MHz}, \mathrm{CDCl}_{3}\right) \delta 148.3-145.7(\mathrm{dt}, J=$ 14.3, 3.8 Hz), $145.9-143.4(\mathrm{~m}), 136.3,127.5$ (t, $J=18.6 \mathrm{~Hz}), 117.3,107.7$ (t, $J=3.7 \mathrm{~Hz}), 29.7$, 25.7, 22.7, 17.7. GC/MS (m/z, relative intensity) $243(\mathrm{M}+, 34), 228$ (40), 208 (18), 188 (35).

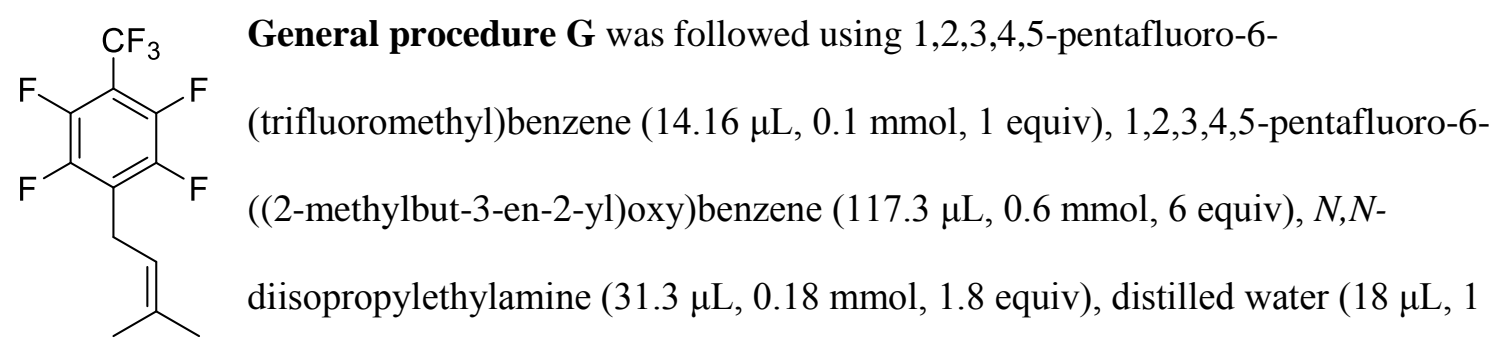
mmol, 10 equiv) and $1.0 \mathrm{~mL}$ of stock solution of $\operatorname{Ir}(\mathrm{ppy})_{3}(0.16 \mathrm{mg}, 0.0003 \mathrm{mmol}, 0.003$ equiv) in $\mathrm{CH}_{3} \mathrm{CN}$ was used. The crude material was purified by using Prep TLC 10:1 hexane:diethyl ether to afford 1,2,4,5-tetrafluoro-3-(3-methylbut-2-en-1-yl)-6-(trifluoromethyl)benzene (3e) as a colorless liquid in $61 \%{ }^{19} \mathrm{~F}$ NMR yield and $57 \%$ isolated yield $(16.3 \mathrm{mg}, 0.057 \mathrm{mmol}) .{ }^{19} \mathrm{~F} \mathrm{NMR}$ $\left(376 \mathrm{MHz}, \mathrm{CDCl}_{3}\right) \delta-56.20(\mathrm{t}, J=21.5 \mathrm{~Hz}, 3 \mathrm{~F}),-141.39--141.69(\mathrm{~m}, 2 \mathrm{~F}),-142.17(\mathrm{td}, J=16.0$, $6.5 \mathrm{~Hz}, 2 \mathrm{~F}) .{ }^{1} \mathrm{H} \mathrm{NMR}\left(400 \mathrm{MHz}, \mathrm{CDCl}_{3}\right) \delta 5.16(\mathrm{t}, J=7.5 \mathrm{~Hz}, 1 \mathrm{H}), 3.46(\mathrm{~d}, J=7.4 \mathrm{~Hz}, 2 \mathrm{H}), 1.75$ (s, 3H), $1.71(\mathrm{~s}, 3 \mathrm{H}) .{ }^{13} \mathrm{C}$ NMR (101 MHz, $\left.\mathrm{CDCl}_{3}\right) \delta 146.2-143$ (ddd, $\left.J=17.1,6.7,4.0 \mathrm{~Hz}\right)$, $145.4-142.5$ (ddd, $J=12.6,7.3,3.3 \mathrm{~Hz}), 135.7,129.0,128.2,125.3,117.8,25.7,22.2,17.7$. GC/MS (m/z, relative intensity) $286(\mathrm{M}+, 52), 271$ (64), 231 (34).

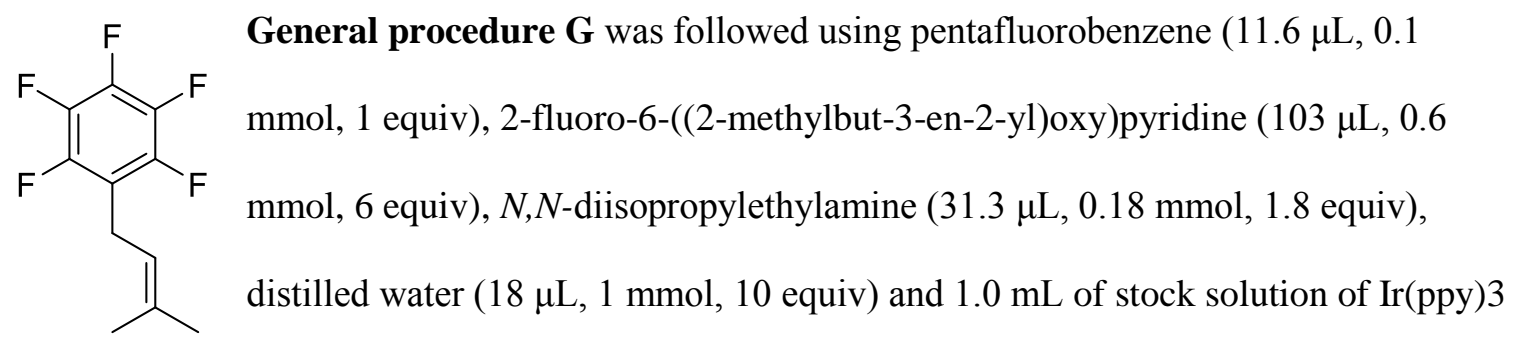


(0.16 mg, $0.0003 \mathrm{mmol}, 0.003$ equiv) in $\mathrm{CH}_{3} \mathrm{CN}$ was used. The crude material was purified by using Prep TLC 1:1 hexane : DCM to afford 1,2,3,4,5-pentafluoro-6-(3-methylbut-2-en-1yl)benzene (3f) as a colorless liquid in 64\% ${ }^{19} \mathrm{~F}$ NMR yield and 55\% isolated yield (13.9 $\mathrm{mg}$, $0.06 \mathrm{mmol})$. Due to volatile nature of compound, minimal effort was given to remove the solvents. ${ }^{19} \mathrm{~F}$ NMR $\left(376 \mathrm{MHz}, \mathrm{CDCl}_{3}\right) \delta-144.31(\mathrm{dd}, J=22.3,8.2 \mathrm{~Hz}, 2 \mathrm{~F}),-158.81(\mathrm{t}, J=20.7$ $\mathrm{Hz}, 1 \mathrm{~F}),-163.29(\mathrm{td}, J=22.3,8.1 \mathrm{~Hz}, 2 \mathrm{~F}) .{ }^{1} \mathrm{H} \mathrm{NMR}\left(400 \mathrm{MHz}, \mathrm{CDCl}_{3}\right) \delta 5.15(\mathrm{t}, J=7.3 \mathrm{~Hz}$, 1H), 3.37 (d, J=7.4 Hz, 2H), $1.74(\mathrm{~s}, 3 \mathrm{H}), 1.69$ (s, 3H). GC/MS (m/z, relative intensity) 236 $(\mathrm{M}+, 70), 221(85), 201(20)$. The compound produced a thermally generated impurity under GC conditions that was otherwise not observed in ${ }^{1} \mathrm{H}$ or ${ }^{19} \mathrm{~F}$ NMR.

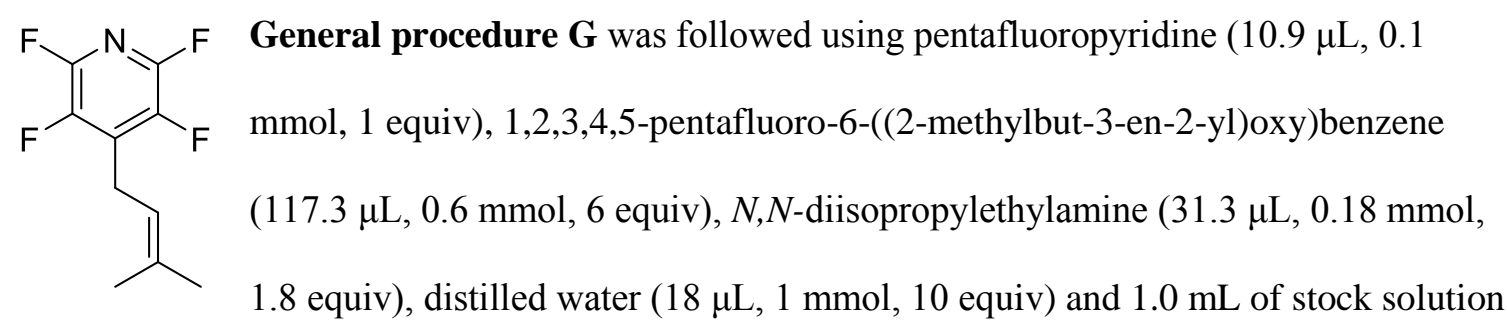
of $\operatorname{Ir}(\mathrm{ppy})_{3}\left(0.16 \mathrm{mg}, 0.0003 \mathrm{mmol}, 0.003\right.$ equiv) in $\mathrm{CH}_{3} \mathrm{CN}$ was used. The crude material was purified by using Prep TLC with 100\% hexanes to afford 2,3,5,6-tetrafluoro-4-(3-methylbut-2en-1-yl)pyridine (3g) as a colorless liquid in $78 \%{ }^{19} \mathrm{~F}$ NMR yield and $74 \%$ isolated yield (15.33 $\mathrm{mg}, 0.07 \mathrm{mmol}$ ). Minimal effort was given to evaporate the solvent due to volatile nature of the product. ${ }^{19} \mathrm{~F}$ NMR $\left(376 \mathrm{MHz}, \mathrm{CDCl}_{3}\right) \delta-91.72--91.93(\mathrm{~m}, 2 \mathrm{~F}),-145.20--145.42(\mathrm{~m}, 2 \mathrm{~F}) .{ }^{1} \mathrm{H}$ $\operatorname{NMR}\left(400 \mathrm{MHz}, \mathrm{CDCl}_{3}\right) \delta 5.10(\mathrm{t}, J=7.5 \mathrm{~Hz}, 1 \mathrm{H}), 3.42(\mathrm{~d}, J=7.5 \mathrm{~Hz}, 2 \mathrm{H}), 1.69(\mathrm{~s}, 3 \mathrm{H}), 1.65$ $(\mathrm{s}, 3 \mathrm{H}) .{ }^{13} \mathrm{C} \mathrm{NMR}\left(101 \mathrm{MHz}, \mathrm{CDCl}_{3}\right) \delta 144.7-141.3(\mathrm{~m}), 141.5-138.7(\mathrm{~m}), 136.4,134.3(\mathrm{t}, J=$ 17.3 Hz), 116.9, 25.7, 22.9, 17.7. GC/MS (m/z, relative intensity) $219(\mathrm{M}+, 100), 204(84), 184$ (62), $177(40)$.<smiles>CC(C)=CCc1c(F)nc(F)c(F)c1F</smiles>

General procedure $\mathbf{G}$ was followed using 3-chloro-2,4,5,6tetrafluoropyridine $(12.44 \mu \mathrm{L}, 0.1 \mathrm{mmol}, 1$ equiv), 1,2,3,4,5-pentafluoro6-((2-methylbut-3-en-2-yl)oxy)benzene (117.3 $\mu \mathrm{L}, 0.6 \mathrm{mmol}, 6$ equiv), 
$N, N$-diisopropylethylamine $(31.3 \mu \mathrm{L}, 0.18 \mathrm{mmol}, 1.8$ equiv), distilled water $(18 \mu \mathrm{L}, 1 \mathrm{mmol}, 10$ equiv) and $1.0 \mathrm{~mL}$ of stock solution of $\operatorname{Ir}(\mathrm{ppy})_{3}\left(0.16 \mathrm{mg}, 0.0003 \mathrm{mmol}, 0.003\right.$ equiv) in $\mathrm{CH}_{3} \mathrm{CN}$ was used. The crude material was purified by using Prep TLC with $100 \%$ hexanes to $\mathbf{2 , 3 , 4 , 6 -}$ tetrafluoro-5-(3-methylbut-2-en-1-yl)pyridine (3i) as a colorless liquid in 57\% ${ }^{19} \mathrm{~F}$ NMR yield and $41 \%$ isolated yield $(8.97 \mathrm{mg}, 0.04 \mathrm{mmol})$. Minimal effort was given to evaporate the solvent due to volatile nature of the product. ${ }^{19} \mathrm{~F}$ NMR $\left(376 \mathrm{MHz}, \mathrm{CDCl}_{3}\right) \delta-73.43--73.64(\mathrm{~m}, 1 \mathrm{~F})$, $88.22--88.43(\mathrm{~m}, 1 \mathrm{~F}),-118.20(\mathrm{q}, J=17.3 \mathrm{~Hz}, 1 \mathrm{~F}),-167.39(\mathrm{ddd}, J=24.1,21.7,19.6 \mathrm{~Hz}, 1 \mathrm{~F})$. ${ }^{1} \mathrm{H}$ NMR (400 MHz, $\left.\mathrm{CDCl}_{3}\right) \delta 5.15(\mathrm{t}, J=7.9 \mathrm{~Hz}, 1 \mathrm{H}), 3.32(\mathrm{~d}, J=7.2 \mathrm{~Hz}, 2 \mathrm{H}), 1.74(\mathrm{~s}, 3 \mathrm{H})$, $1.70(\mathrm{~s}, 3 \mathrm{H}) . \mathrm{GC} / \mathrm{MS}$ (m/z, relative intensity) $219(\mathrm{M}+, 95), 204(80), 184$ (60).<smiles>CC(C)=CCc1c(F)nc(F)c(Cl)c1F</smiles>

General procedure $\mathbf{G}$ was followed using 3,5-dichloro-2,4,6trifluoropyridine (12.44 $\mu \mathrm{L}, 0.1 \mathrm{mmol}, 1$ equiv), 1,2,3,4,5-pentafluoro-6((2-methylbut-3-en-2-yl)oxy)benzene (117.3 $\mu \mathrm{L}, 0.6 \mathrm{mmol}, 6$ equiv), $N, N$-diisopropylethylamine $(31.3 \mu \mathrm{L}, 0.18 \mathrm{mmol}, 1.8$ equiv), distilled water $(18 \mu \mathrm{L}, 1 \mathrm{mmol}, 10$ equiv) and $1.0 \mathrm{~mL}$ of stock solution of $\operatorname{Ir}(\mathrm{ppy})_{3}\left(0.16 \mathrm{mg}, 0.0003 \mathrm{mmol}, 0.003\right.$ equiv) in $\mathrm{CH}_{3} \mathrm{CN}$ was used. The crude material was purified by using Prep TLC with $100 \%$ hexanes to afford 3chloro-2,4,6-trifluoro-5-(3-methylbut-2-en-1-yl)pyridine $\left(\mathbf{3 j}\right.$ ) as a colorless liquid in $55 \%{ }^{19} \mathrm{~F}$ NMR yield and $48 \%$ isolated yield $(11.5 \mathrm{mg}, 0.05 \mathrm{mmol})$. Minimal effort was given to evaporate the solvent due to volatile nature of the product. ${ }^{19} \mathrm{~F} \mathrm{NMR}\left(376 \mathrm{MHz}, \mathrm{CDCl}_{3}\right) \delta-71.52--71.67$ (m, 1F), -72.44 (t, $J=13.6 \mathrm{~Hz}, 1 \mathrm{~F}),-97.91(\mathrm{dd}, J=19.5,13.8 \mathrm{~Hz}, 1 \mathrm{~F}) .{ }^{1} \mathrm{H}$ NMR $(400 \mathrm{MHz}$, $\left.\mathrm{CDCl}_{3}\right) \delta 5.14(\mathrm{t}, J=7.4 \mathrm{~Hz}, 1 \mathrm{H}), 3.32(\mathrm{~d}, J=7.4 \mathrm{~Hz}, 2 \mathrm{H}), 1.74(\mathrm{~s}, 3 \mathrm{H}), 1.70(\mathrm{~s}, 3 \mathrm{H}) .{ }^{13} \mathrm{C} \mathrm{NMR}$ $\left(101 \mathrm{MHz}, \mathrm{CDCl}_{3}\right) \delta 167.4-164.8(\mathrm{dd}, J=10.5,4.9 \mathrm{~Hz}), 158.7-156.3(\mathrm{~m}), 156.5-154.1(\mathrm{~m})$, 135.2, 118.3, 115.4, $110.4(\mathrm{ddd}, J=35.5,20.0,7.2 \mathrm{~Hz}), 25.6,21.5,17.7 . \mathrm{GC} / \mathrm{MS}$ (m/z, relative intensity) $235(\mathrm{M}+, 50), 220$ (100), $180(70)$. 


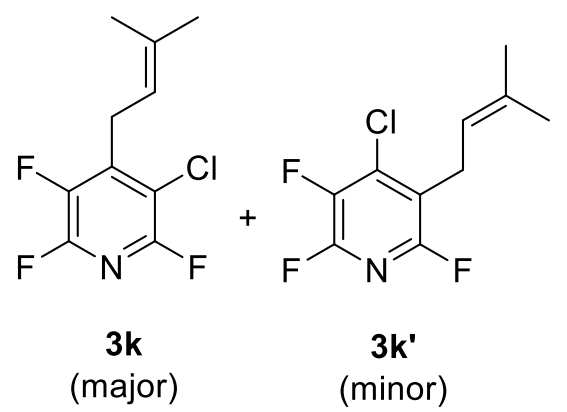

General procedure G was followed using 3,4-dichloro-

2,5,6-trifluoropyridine (12.4 $\mu \mathrm{L}, 0.1 \mathrm{mmol}, 1$ equiv), 1,2,3,4,5-pentafluoro-6-((2-methylbut-3-en-2yl)oxy)benzene (117.3 $\mu \mathrm{L}, 0.6 \mathrm{mmol}, 6$ equiv), $N, N$ diisopropylethylamine (31.3 $\mu \mathrm{L}, 0.18 \mathrm{mmol}, 1.8$ equiv),

distilled water $(18 \mu \mathrm{L}, 1 \mathrm{mmol}, 10$ equiv $)$ and $1.0 \mathrm{~mL}$ of stock solution of $\operatorname{Ir}(\mathrm{ppy})_{3}(0.16 \mathrm{mg}$, 0.0003 mmol, 0.003 equiv) in $\mathrm{CH}_{3} \mathrm{CN}$ was used. The reaction was run at $-15{ }^{\circ} \mathrm{C}$ instead of $0{ }^{\circ} \mathrm{C}$ to control the selectivity, delivering more para substituted product. The crude material was purified by using Prep TLC with 100\% hexanes to afford 3-chloro-2,5,6-trifluoro-4-(3-methylbut-2-en1-yl)pyridine (major, 3k) as a colorless liquid in $81 \%{ }^{19} \mathrm{~F}$ NMR yield and $73 \%$ isolated yield (16.51 mg, $0.06 \mathrm{mmol})$. It comprised of a mixture of para substituted product and meta prenylated product in the ratio 14.5:1 (para:meta). Looking at the ${ }^{19} \mathrm{~F}$ NMR of both isomers we see that these signals shift very closely to one another. Unfortunately, they shift too close to use recently developed 19F NMR prediction method (JOC, 2018, 83, 3220). We unsuccessfully attempted to derivatize the mixture, which might have allowed us to distinguish the molecules so the assignment is unfortunately made based on analogy with $\mathbf{3 l} / \mathbf{3 l}$ '. In the substrate $\mathbf{3 k}$, which has one fewer meta chlorines, we assume it follows the same pattern. Minimal effort was given to evaporate the solvent due to volatile nature of the product. ${ }^{19} \mathrm{~F}$ NMR $\left(376 \mathrm{MHz}, \mathrm{CDCl}_{3}\right) \delta-73.85$ (dd, $J=26.9,12.3 \mathrm{~Hz}, 1 \mathrm{~F}$, minor ), $-74.15(\mathrm{dd}, J=27.8,12.8 \mathrm{~Hz}, 1 \mathrm{~F}),-89.54(\mathrm{dd}, J=20.9,14.1$ Hz, 1F, minor), -89.91 (dd, $J=21.5,12.8 \mathrm{~Hz}),-145.00$ (dd, $J=25.7,21.3 \mathrm{~Hz}, 1 \mathrm{~F}$, minor), $145.33(\mathrm{dd}, J=27.8,21.7 \mathrm{~Hz}) .{ }^{1} \mathrm{H} \mathrm{NMR}\left(400 \mathrm{MHz}, \mathrm{CDCl}_{3}\right) \delta 5.15(\mathrm{~m}, 2 \mathrm{H}$, major and minor), $3.58(\mathrm{~d}, J=7.2 \mathrm{~Hz}, 2 \mathrm{H}), 3.43(\mathrm{~d}, J=7.6 \mathrm{~Hz}, 2 \mathrm{H}$, minor), 1.77 (s, 6H, major and minor), 1.70 (s, 6H, major and minor). GC/MS (m/z, relative intensity) $235(\mathrm{M}+, 52), 220(100), 180(90)$. 
<smiles>CC(C)=CCc1c(F)nc(F)c(Cl)c1Cl</smiles>

General procedure $\mathbf{G}$ was followed using 3,4,5trichloro-2,6-difluoropyridine $(12.44 \mu \mathrm{L}, 0.1 \mathrm{mmol}, 1$ equiv), 1,2,3,4,5-pentafluoro-6-((2-methylbut-3-en-2yl)oxy)benzene ( $117.3 \mu \mathrm{L}, 0.6 \mathrm{mmol}, 6$ equiv), $N, N$ diisopropylethylamine ( $31.3 \mu \mathrm{L}, 0.18 \mathrm{mmol}, 1.8$ equiv),

distilled water $\left(18 \mu \mathrm{L}, 1 \mathrm{mmol}, 10\right.$ equiv) and $1.0 \mathrm{~mL}$ of stock solution of $\operatorname{Ir}(\mathrm{ppy})_{3}(0.16 \mathrm{mg}$, 0.0003 mmol, 0.003 equiv) in $\mathrm{CH}_{3} \mathrm{CN}$ was used. The crude material was purified by using Prep TLC with 100\% hexanes to afford 3,5-dichloro-2,6-difluoro-4-(3-methylbut-2-en-1-yl)pyridine (major, 3l) as a colorless liquid in 77\% ${ }^{19} \mathrm{~F}$ NMR yield and 69\% isolated yield (16.56 mg, 0.06 mmol). It comprised of a mixture of para substituted product (single peak for symmetrical Fatoms at $-71.67 \mathrm{ppm}$ ) and meta prenylated product in the ratio $6: 1$ (para:meta), determined by ${ }^{19} \mathrm{~F}$ NMR Pdt1:Pdt2 peak integrations. ${ }^{19} \mathrm{~F}$ NMR $\left(376 \mathrm{MHz}, \mathrm{CDCl}_{3}\right) \delta-70.67(\mathrm{~d}, J=16.4 \mathrm{~Hz}, 1 \mathrm{~F}$, minor), $-71.67(\mathrm{~s}, 2 \mathrm{~F}),-71.77\left(\mathrm{~d}, J=12.3 \mathrm{~Hz}, 1 \mathrm{~F}\right.$, minor). ${ }^{1} \mathrm{H} \mathrm{NMR}\left(400 \mathrm{MHz}, \mathrm{CDCl}_{3}\right) \delta 5.07(\mathrm{~m}$, 1H), 4.99 (m, 1H, minor), 3.73 (d, $J=7.0 \mathrm{~Hz}, 2 \mathrm{H}), 3.49$ (d, $J=7.1 \mathrm{~Hz}, 2 \mathrm{H}$, minor), $1.84(\mathrm{~s}, 3 \mathrm{H})$, 1.79 (s, 3H, minor), $1.74(\mathrm{~s}, 3 \mathrm{H}), 1.72$ (s, 3H, minor). GC/MS (m/z, relative intensity) 251 (M+, 45), 216 (35), 200 (37).<smiles>CC(C)=CCc1c(F)c(F)c(-c2nc3ccccc3o2)c(F)c1F</smiles>

General procedure $\mathbf{G}$ was followed using 2-(perfluorophenyl)benzo[d]oxazole (18.6 $\mu \mathrm{L}, 0.1$ mmol, 1 equiv), 1,2,3,4,5-pentafluoro-6-((2-methylbut-3-en-2yl)oxy)benzene (117.3 $\mu \mathrm{L}, 0.6 \mathrm{mmol}, 6$ equiv), $N, N$-diisopropylethylamine (31.3 $\mu \mathrm{L}, 0.18 \mathrm{mmol}, 1.8$ equiv), distilled water (18 $\mu \mathrm{L}, 1 \mathrm{mmol}, 10$ equiv) and $1.0 \mathrm{~mL}$ of stock solution of $\operatorname{Ir}(\mathrm{ppy})_{3}\left(0.16 \mathrm{mg}, 0.0003 \mathrm{mmol}, 0.003\right.$ equiv) in $\mathrm{CH}_{3} \mathrm{CN}$ was used. The crude material was purified by using Prep TLC with 1\% AcOH in hexanes to afford 2$(2,3,5,6$-tetrafluoro-4-(3-methylbut-2-en-1-yl)phenyl)benzo[d]oxazole (3m) as a pale yellow solid in $62 \%{ }^{19} \mathrm{~F}$ NMR yield and $53 \%$ isolated yield $(17.75 \mathrm{mg}, 0.05 \mathrm{mmol})$, which includes $20 \%$ 
HDF. ${ }^{19} \mathrm{~F} \mathrm{NMR}\left(376 \mathrm{MHz}, \mathrm{CDCl}_{3}\right) \delta-137.11--137.33$ (m, 2F, minor), $-137.68(\mathrm{tt}, J=16.9,5.2$ $\mathrm{Hz}, 2 \mathrm{~F}$, minor), $-138.79--138.93(\mathrm{~m}, 2 \mathrm{~F}),-143.04(\mathrm{td}, J=15.1,4.8 \mathrm{~Hz}, 2 \mathrm{~F}) .{ }^{1} \mathrm{H}$ NMR (400 $\left.\mathrm{MHz}, \mathrm{CDCl}_{3}\right) \delta 7.89(\mathrm{td}, J=7.7,1.1 \mathrm{~Hz}, 1 \mathrm{H}), 7.65(\mathrm{td}, J=7.8,1.1 \mathrm{~Hz} 1 \mathrm{H}), 7.48-7.40(\mathrm{~m}, 2 \mathrm{H})$ $5.22(\mathrm{t}, J=7.4 \mathrm{~Hz}, 1 \mathrm{H}), 3.51(\mathrm{~d}, J=7.4 \mathrm{~Hz}, 2 \mathrm{H}), 1.78(\mathrm{~s}, 3 \mathrm{H}), 1.73(\mathrm{~s}, 3 \mathrm{H}) .{ }^{13} \mathrm{C} \mathrm{NMR}(101 \mathrm{MHz}$, $\left.\mathrm{CDCl}_{3}\right) \delta 153.9-153.2(\mathrm{~m}), 150.8-150.1(\mathrm{~m}), 146.6-146.0(\mathrm{~m}), 143.9(\mathrm{dd}, J=21.2,11.8 \mathrm{~Hz})$, 141.2, 135.4, 126.6, 126.3, 125.2, 125.0, 123.5, 118.2, 111.0, 25.7, 22.4, 17.7. GC/MS (m/z, relative intensity) $335(\mathrm{M}+, 100), 320$ (80), 300 (42), 280 (70).

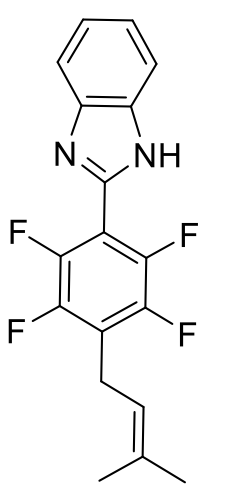

General procedure G was followed using 2-(perfluorophenyl)-1Hbenzo[d]imidazole (28.4 mg, $0.1 \mathrm{mmol}, 1$ equiv), 1,2,3,4,5-pentafluoro-6-((2methylbut-3-en-2-yl)oxy)benzene (117.3 $\mu \mathrm{L}, 0.6 \mathrm{mmol}, 6$ equiv), $N, N$ diisopropylethylamine ( $31.3 \mu \mathrm{L}, 0.18 \mathrm{mmol}, 1.8$ equiv), distilled water $(18 \mu \mathrm{L}, 1$ mmol, 10 equiv) and $1.0 \mathrm{~mL}$ of stock solution of $\operatorname{Ir}(\mathrm{ppy})_{3}(0.16 \mathrm{mg}, 0.0003$ mmol, 0.003 equiv) in $\mathrm{CH}_{3} \mathrm{CN}$ was used. Due to lower solubility of the perfluoroarene starting material, another $1 \mathrm{~mL}$ of dry $\mathrm{CH}_{3} \mathrm{CN}$ was added and the reaction mixture $(0.05 \mathrm{M})$ was subjected to sonication after regular intervals. The crude material was purified by using Prep TLC with 100\% hexanes followed by re-dipping the plate in 10:1 hexane:ether to afford 2-(2,3,5,6-tetrafluoro-4-(3-methylbut-2-en-1-yl)phenyl)-1H-benzo[d]imidazole (3n) as a pale yellow solid in $71 \%{ }^{19} \mathrm{~F}$ NMR yield and $68 \%$ isolated yield $(22.7 \mathrm{mg}, 0.068 \mathrm{mmol})$, which includes $12 \% \mathrm{HDF} .{ }^{19} \mathrm{~F}$ NMR $\left(376 \mathrm{MHz}, \mathrm{CD}_{3} \mathrm{CN}\right) \delta-140.04--140.35$ (m, 2F, minor), -141.66 -141.84 (m, 2F, minor), $-142.27--142.43$ (m, 2F), -145.11 - -145.28 (m, 2F). ${ }^{1} \mathrm{H}$ NMR (400 $\left.\mathrm{MHz}, \mathrm{CD}_{3} \mathrm{CN}\right) \delta 7.75(\mathrm{dd}, J=6.1,3.2 \mathrm{~Hz}, 2 \mathrm{H}), 7.38(\mathrm{dd}, J=6.1,3.2 \mathrm{~Hz}, 2 \mathrm{H}), 5.25(\mathrm{t}, J=7.4 \mathrm{~Hz}$, 1H), $3.53(\mathrm{~d}, J=7.3 \mathrm{~Hz}, 2 \mathrm{H}), 1.79(\mathrm{~s}, 3 \mathrm{H}), 1.72(\mathrm{~s}, 3 \mathrm{H}) .{ }^{13} \mathrm{C} \mathrm{NMR}\left(101 \mathrm{MHz}, \mathrm{CDCl}_{3}\right) \delta 146.9$ (m), 146.6 - $144.1(\mathrm{ddt}, J=17.1,12.7,6.6 \mathrm{~Hz}), 145.7-143.2(\mathrm{~m}), 140.3,135.3,124.0,122.1(\mathrm{t}$, $J=18.8 \mathrm{~Hz}), 118.3,115.5(\mathrm{dd}, J=33.9,24.7 \mathrm{~Hz}), 107.0,25.7,22.3,17.7$. GC/MS (m/z, relative intensity) $334(\mathrm{M}+, 75), 319$ (68), 291 (100), 278 (60). 


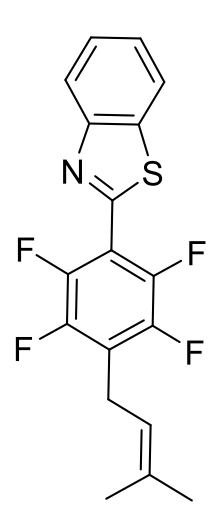

General procedure $\mathbf{G}$ was followed using 2-(perfluorophenyl)benzo[d]thiazole (31.76 mg, 0.1 mmol, 1 equiv), 1,2,3,4,5-pentafluoro-6-((2-methylbut-3-en-2yl)oxy)benzene (117.3 $\mu \mathrm{L}, 0.6$ mmol, 6 equiv), $N, N$-diisopropylethylamine (31.3 $\mu \mathrm{L}, 0.18 \mathrm{mmol}, 1.8$ equiv), distilled water (18 $\mu \mathrm{L}, 1 \mathrm{mmol}, 10$ equiv) and $1.0 \mathrm{~mL}$ of stock solution of $\operatorname{Ir}(\text { ppy })_{3}\left(0.16 \mathrm{mg}, 0.0003 \mathrm{mmol}, 0.003\right.$ equiv) in $\mathrm{CH}_{3} \mathrm{CN}$ was used. The crude material was purified by using Prep TLC with $100 \%$ hexanes

followed by re-dipping the plate in 10:1 hexane:ether to afford $\mathbf{2 - ( 2 , 3 , 5 , 6 - t e t r a f l u o r o - 4 - ( 3 -}$ methylbut-2-en-1-yl)phenyl)benzo[d]thiazole (3o) as a white solid in $68 \%{ }^{19} \mathrm{~F}$ NMR yield and $62 \%$ isolated yield $(21.76 \mathrm{mg}, 0.06 \mathrm{mmol}) .{ }^{19} \mathrm{~F}$ NMR $\left(376 \mathrm{MHz}, \mathrm{CDCl}_{3}\right) \delta-140.17--140.29(\mathrm{~m}$, 2F), $-143.38--143.51(\mathrm{~m}, 2 \mathrm{~F}) .{ }^{1} \mathrm{H}$ NMR $\left(400 \mathrm{MHz}, \mathrm{CDCl}_{3}\right) \delta 8.20(\mathrm{~d}, J=8.1 \mathrm{~Hz}, 1 \mathrm{H}), 7.98(\mathrm{~d}, J$ $=8.0 \mathrm{~Hz}, 1 \mathrm{H}), 7.57(\mathrm{td}, J=7.6,1.2 \mathrm{~Hz} 1 \mathrm{H}), 7.48(\mathrm{td}, J=7.7,1.1 \mathrm{~Hz}, 1 \mathrm{H}), 5.23(\mathrm{t}, J=7.4 \mathrm{~Hz}$, $1 \mathrm{H}), 3.50(\mathrm{~d}, J=7.4 \mathrm{~Hz}, 2 \mathrm{H}), 1.78(\mathrm{~s}, 3 \mathrm{H}), 1.72(\mathrm{~s}, 3 \mathrm{H}) .{ }^{13} \mathrm{C} \mathrm{NMR}\left(101 \mathrm{MHz}, \mathrm{CDCl}_{3}\right) \delta 154.1$, $152.9,146.6-144.1(\mathrm{ddd}, J=13.0,6.8,4.5 \mathrm{~Hz}), 145.4-142.9(\mathrm{dt}, J=15.9,4.6 \mathrm{~Hz}), 135.6(\mathrm{t}, J$ $=2.5 \mathrm{~Hz}), 135.2,126.6,126.1,125.2,124.1,122.3(\mathrm{t}, J=18.9 \mathrm{~Hz}), 121.4,118.5,25.7,22.3,17.7$. GC/MS (m/z, relative intensity) 351 (M+, 100), 336 (70), 316 (46), 296 (73). 
Table 1.13: Scope of perfluoroarenes for prenylation reactions

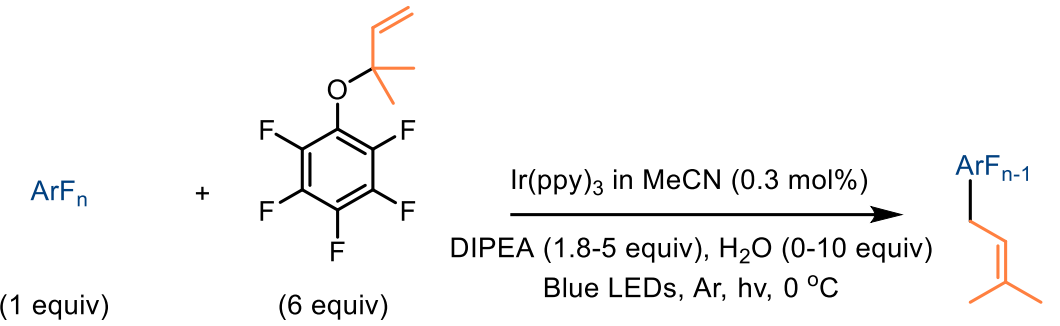

\begin{tabular}{|l|l|l|l|}
\hline Entry & Nosult \\
\hline 4 & & & \\
\hline
\end{tabular}

\begin{tabular}{|l|l|}
\hline Result \\
\hline 10
\end{tabular}




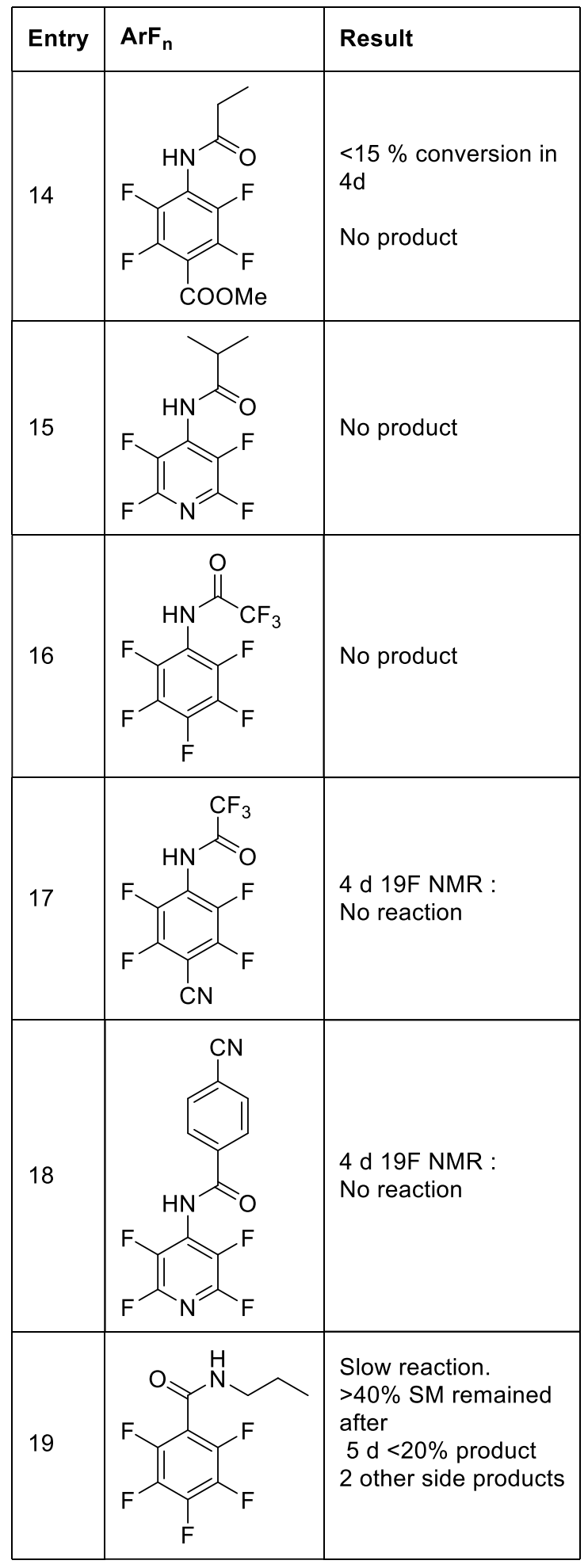

\begin{tabular}{|l|l|l|}
\hline Result \\
\hline $\begin{array}{l}\text { 19F NMR yield : } \\
\text { Pdt1 =27\% } \\
\text { Pdt3 }=35 \% \\
\text { HDF =24\% }\end{array}$ \\
\hline 20
\end{tabular}




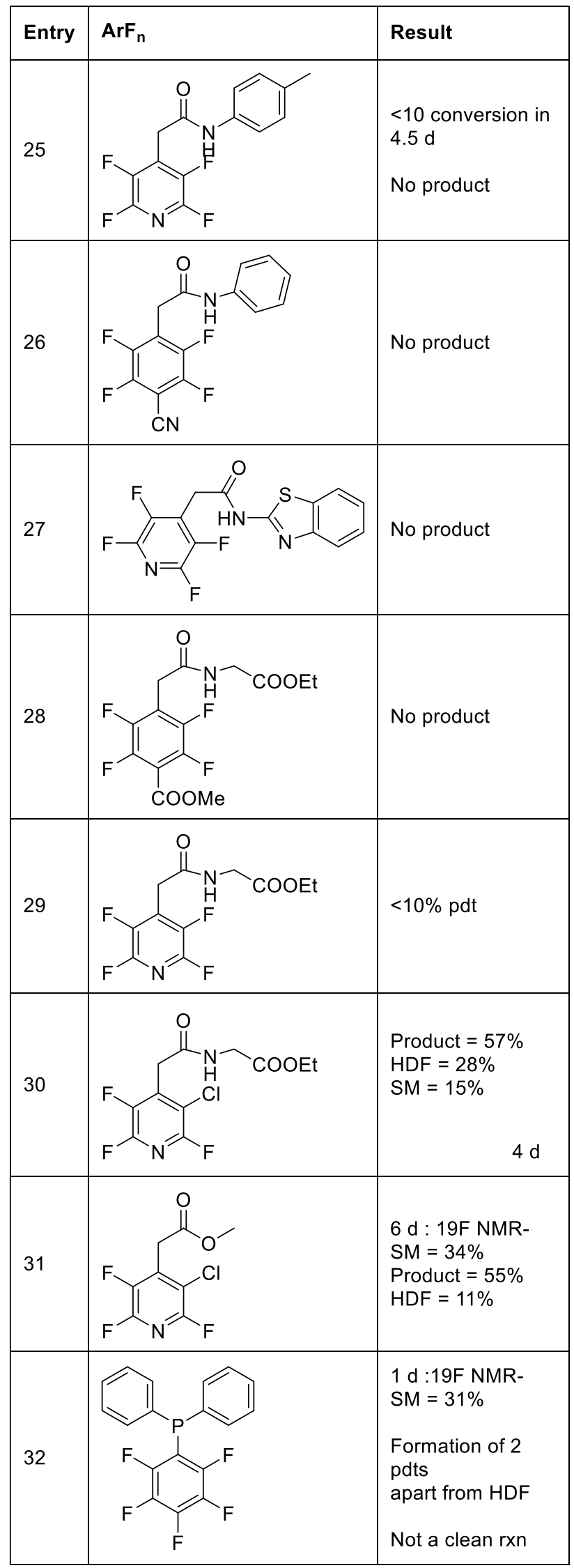

\begin{tabular}{|l|l|l|}
\hline Entry & Nesult \\
\hline 36 & Not a clean reaction \\
\hline along with many side \\
products
\end{tabular}


Table 1.14: Scope of prenylating agents

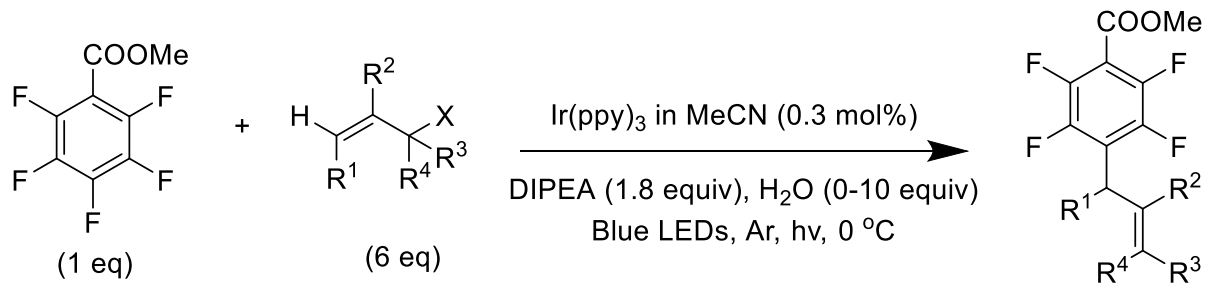

\begin{tabular}{|c|c|c|c|c|c|c|}
\hline \multirow{3}{*}{$\leftarrow$} & $\mathbf{R}^{1}$ & $\mathrm{R}^{2}$ & $\mathbf{R}^{3}$ & $\mathbf{R}^{4}$ & $x$ & Result \\
\hline & $\mathrm{H}$ & $\mathrm{Me}$ & $\mathrm{H}$ & $\mathrm{H}$ & $\mathrm{Cl}$ & $\begin{array}{l}41 \% \text { product with PFP } \\
41 \% \text { product with MPB }(3 d)\end{array}$ \\
\hline & & $\mathrm{H}$ & $\mathrm{Me}$ & $\mathrm{H}$ & OAc & $\begin{array}{l}\text { No product } \\
\text { Multiple sideproducts }\end{array}$ \\
\hline \multirow{8}{*}{$\begin{array}{l}\text { With } \\
\text { PFP }\end{array}$} & & $\mathrm{H}$ & $\mathrm{Me}$ & $\mathrm{H}$ & OAc & $\begin{array}{l}\text { No product } \\
\text { Not a clean reaction }\end{array}$ \\
\hline & $\mathrm{H}$ & $\mathrm{H}$ & $\mathrm{Me}$ & $\mathrm{Me}$ & OAC & Multiple products \\
\hline & $\mathrm{H}$ & $\mathrm{H}$ & $\mathrm{Me}$ & $\mathrm{Me}$ & $\mathrm{OH}$ & $\begin{array}{l}\text { 19F NMR: Could see the product, } \\
\text { reduction,C-O coupling, amine addition } \\
\text { GC: Observed peaks for amine addition } \\
\text { and product. }\end{array}$ \\
\hline & $\mathrm{H}$ & $\mathrm{H}$ & $\mathrm{i}-\mathrm{Pr}$ & $\mathrm{H}$ & & $\begin{array}{l}21 \% \text { product } \\
66 \% \mathrm{HDF}\end{array}$ \\
\hline & $\mathrm{H}$ & $\mathrm{H}$ & $\mathrm{i}-\mathrm{Pr}$ & $\mathrm{H}$ & & $\begin{array}{l}13 \% \text { product } \\
69 \% \text { HDF }\end{array}$ \\
\hline & $\mathrm{H}$ & $\mathrm{Me}$ & $\mathrm{H}$ & $\mathrm{H}$ & & $4 \%$ product \\
\hline & $\mathrm{H}$ & $\mathrm{Me}$ & $\mathrm{H}$ & $\mathrm{H}$ & & $\begin{array}{l}10 \% \text { product } \\
\text { Slow reaction }\end{array}$ \\
\hline & $\mathrm{H}$ & $\mathrm{H}$ & $\mathrm{H}$ & $\mathrm{H}$ & & $\begin{array}{l}48 \% \text { product } \\
47 \% \text { HDF }\end{array}$ \\
\hline
\end{tabular}



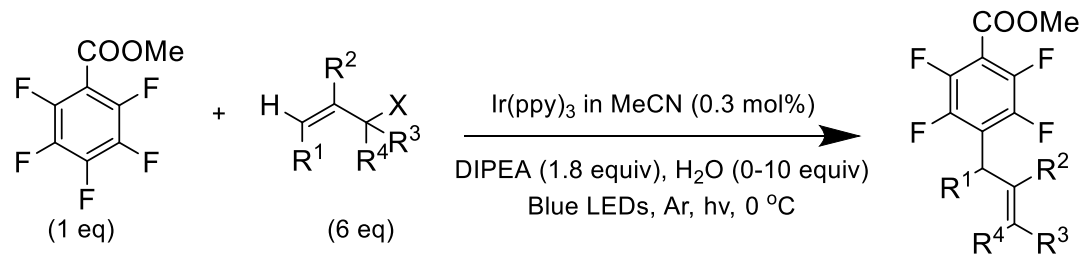

\begin{tabular}{|c|c|c|c|c|c|c|}
\hline Entry & $\mathbf{R}^{1}$ & $\mathbf{R}^{2}$ & $\mathbf{R}^{\mathbf{3}}$ & $\mathbf{R}^{4}$ & $\mathbf{x}$ & Result \\
\hline 11 & $\mathrm{H}$ & $\mathrm{H}$ & $\mathrm{Me}$ & $\mathrm{Me}$ & $\underbrace{\mathrm{O}}_{0}$ & $\begin{array}{l}36 \% \mathrm{pdt} \\
51 \% \mathrm{HDF}+\text { other } \\
\end{array}$ \\
\hline 12 & $\mathrm{H}$ & $\mathrm{Me}$ & Me & $\mathrm{Me}$ & $\sqrt{11} \mathrm{~S}_{0}^{\mathrm{O}} \mathrm{O}$ & $\begin{array}{l}23 \% \text { product } \\
43 \% \text { HDF } \\
\end{array}$ \\
\hline 13 & $\mathrm{H}$ & $\mathrm{H}$ & & $\mathrm{H}$ & 0 & $\begin{array}{l}\text { 19F NMR: } 2 d-\text { Observed } \\
\text { SM, reduction, C-C coupled } \\
\text { product with multiple side } \\
\text { products }\end{array}$ \\
\hline 14 & $\mathrm{H}$ & $\mathrm{Me}$ & $\mathrm{H}$ & $\mathrm{H}$ & $\mathrm{O}_{\substack{11 \\
0}}$ & $\begin{array}{l}\text { Very slow reaction } \\
\text { Good Pdt:HDF ratio }\end{array}$ \\
\hline 15 & $\mathrm{H}$ & $\mathrm{H}$ & $\mathrm{H}$ & $\mathrm{H}$ & $-S_{0}^{11}$ & $\begin{array}{l}4 \mathrm{~d}-19 \mathrm{~F} \text { NMR: } \\
\mathrm{SM}=52 \%, \text { Product }=36 \%, \mathrm{HDF}=10 \%\end{array}$ \\
\hline 16 & $\mathrm{H}$ & $\mathrm{Me}$ & & & $\begin{array}{l}0 \\
-S_{11}^{11} \\
0\end{array}$ & No Product \\
\hline 17 & $\mathrm{H}$ & $\mathrm{Me}$ & $\mathrm{H}$ & $\mathrm{H}$ & O & $\begin{array}{l}\text { Clean but slow rxn, pdt more } \\
\text { than reduction. }\end{array}$ \\
\hline 18 & $\mathrm{H}$ & $\mathrm{H}$ & $\mathrm{Me}$ & $\mathrm{Me}$ & $>S_{0}^{11} m$ & $\begin{array}{l}4 \mathrm{~d}-19 \mathrm{~F} \text { NMR: } \\
\text { SM }=61 \%, \text { Product }=24 \%, \mathrm{HDF}=15 \%\end{array}$ \\
\hline 19 & $\mathrm{H}$ & $\mathrm{H}$ & $\mathrm{H}$ & $\mathrm{H}$ & $\begin{array}{l}-S m \\
0\end{array}$ & 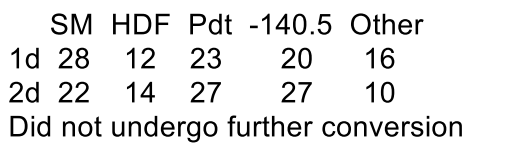 \\
\hline 20 & $\mathrm{H}$ & $\mathrm{H}$ & $\mathrm{Me}$ & $\mathrm{Me}$ & $-S_{0}^{\|} m$ & 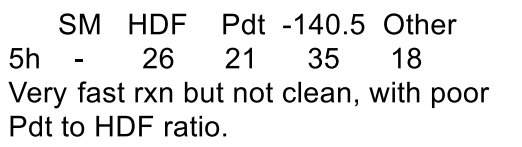 \\
\hline
\end{tabular}




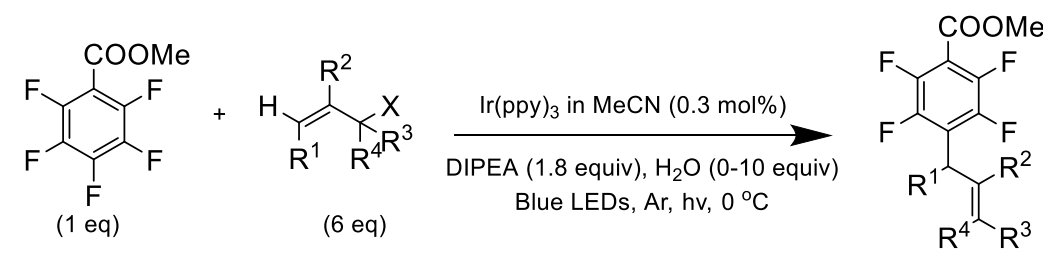

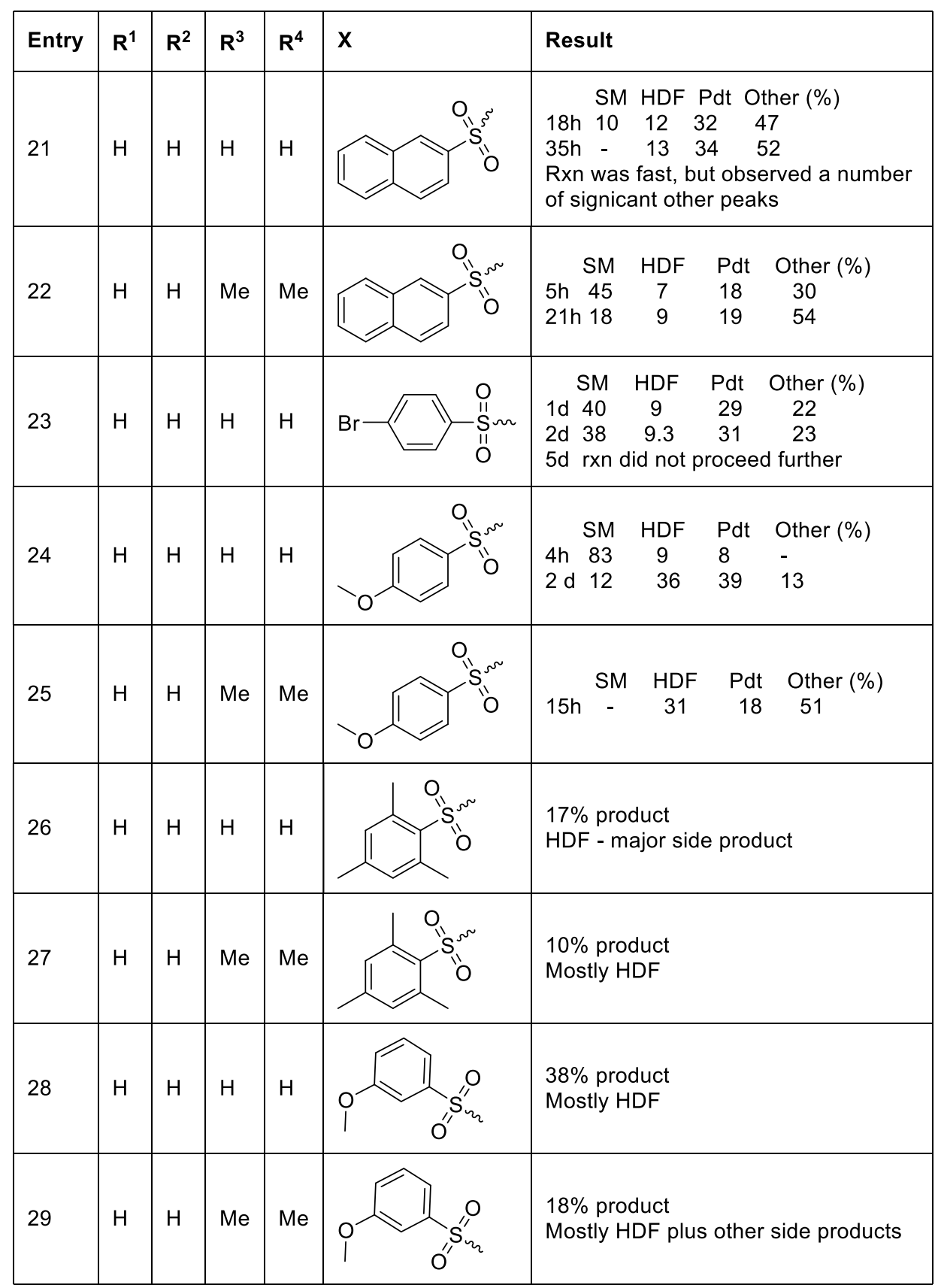




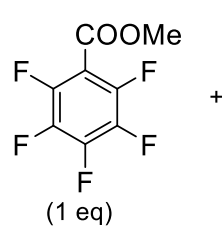

${ }_{(6 \mathrm{eq})}^{\mathrm{R}^{2}}$

$\operatorname{Ir}(\mathrm{ppy})_{3}$ in $\mathrm{MeCN}(0.3 \mathrm{~mol} \%)$

DIPEA ( 1.8 equiv), $\mathrm{H}_{2} \mathrm{O}$ ( $0-10$ equiv)

Blue LEDs, Ar, hv, $0^{\circ} \mathrm{C}$

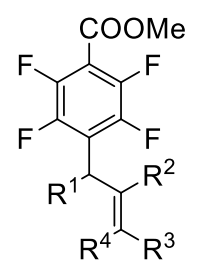

\begin{tabular}{|c|c|c|c|c|c|c|}
\hline Entry & $R^{1}$ & $\mathbf{R}^{2}$ & $\mathbf{R}^{3}$ & $R^{4}$ & $x$ & Result \\
\hline 30 & $\mathrm{H}$ & $\mathrm{H}$ & $\mathrm{H}$ & $\mathrm{H}$ & & $\begin{array}{l}31 \% \text { product } \\
\text { Not a clean reaction }\end{array}$ \\
\hline 31 & $\mathrm{H}$ & $\mathrm{H}$ & $\mathrm{Me}$ & $\mathrm{Me}$ & & $\begin{array}{l}17 \% \text { product } \\
\text { Multiple side products }\end{array}$ \\
\hline 32 & $\mathrm{H}$ & $\mathrm{H}$ & $\mathrm{H}$ & $\mathrm{H}$ & & No product \\
\hline 33 & $\mathrm{H}$ & $\mathrm{H}$ & $\mathrm{Me}$ & $\mathrm{Me}$ & & No product \\
\hline 34 & $\mathrm{H}$ & $\mathrm{H}$ & $\mathrm{Me}$ & $\mathrm{Me}$ & & $\begin{array}{l}7 \% \text { product } \\
4 \text { sets of peaks in C-C range with } \\
\text { reduction being the major pdt }\end{array}$ \\
\hline 35 & $\mathrm{H}$ & $\mathrm{H}$ & $\mathrm{Me}$ & $\mathrm{Me}$ & & No product \\
\hline 36 & $\mathrm{H}$ & $\mathrm{H}$ & $\mathrm{Me}$ & $\mathrm{Me}$ & & $\begin{array}{l}\text { No product } \\
\text { Major product }=\mathrm{HDF}\end{array}$ \\
\hline 37 & $\mathrm{H}$ & $\mathrm{H}$ & $\mathrm{Me}$ & $\mathrm{Me}$ & & $\begin{array}{l}4 \% \text { product } \\
\text { Mostly HDF }\end{array}$ \\
\hline
\end{tabular}




\section{General procedure $\mathrm{H}$ for photocatalytic geranylation reaction}

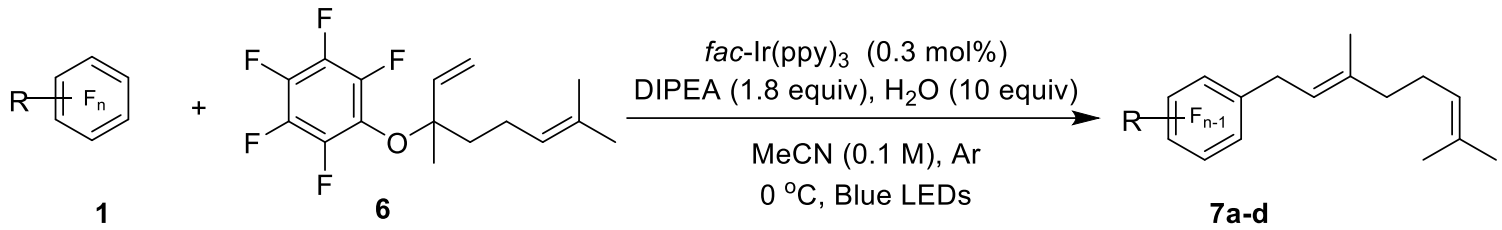

An NMR tube was charged with fluoroarene (0.1 mmol, 1.0 equiv), 1-((3,7-dimethylocta-1,6dien-3-yl)oxy)-2,3,4,5,6-pentafluorobenzene ( $0.6 \mathrm{mmol}, 6$ equiv), $N, N$-diisopropylethylamine ( 0.18 mmol, 1.8 equiv), distilled water ( $1 \mathrm{mmol}, 10$ equiv), $f a c$-tris $(2$ - phenyl pyridinato- $C 2, N)$ Iridium(III) (Ir(ppy) $\left.)_{3}\right)(0.3 \mathrm{mM}, 1 \mathrm{~mL}$ in $\mathrm{MeCN})$, sealed glass capillary containing $\mathrm{C}_{6} \mathrm{D}_{6}$ and was capped with an NMR septum (Ace glass, part no. 9096-25). When reaction was run in greater than $0.1 \mathrm{mmol}$ of fluoroarene, more than one NMR tube was used to set up the reaction and each NMR tube had $1 \mathrm{~mL}$ of reaction mixture. The reaction was degassed via Ar bubbling for $15 \mathrm{~min}$ at $0{ }^{\circ} \mathrm{C}$ (to avoid evaporation of $N, N$-diisopropylethylamine and other volatile starting materials) and then placed in a light bath (vide supra) such that the lower portion of the tube was submerged under the isopropanol/water bath.

The reaction was monitored periodically by ${ }^{19} \mathrm{~F}$ NMR (care was taken to exclude light while in transit). After the complete consumption of starting material, $\mathrm{CH}_{3} \mathrm{CN}$ was removed via rotavap. The crude material was purified using prep TLC plate. If the reaction did not go to completion with the first addition of $N, N$-diisopropylethylamine, an additional 1-3 equiv of $N, N$ diisopropylethylamine was added to the reaction. Then the reaction was re-degassed and returned to the light bath. This sequence was repeated until the reaction reached completion as judged by ${ }^{19} \mathrm{~F}$ NMR. 

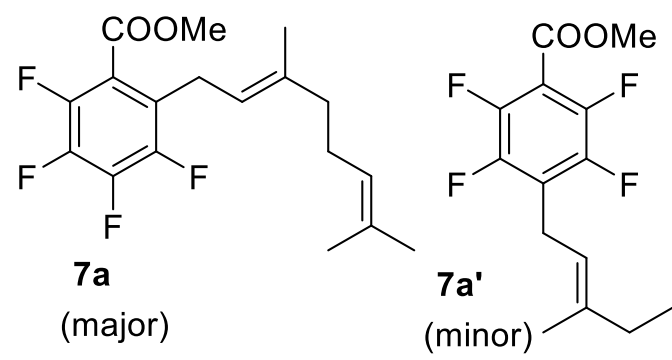

General procedure $\mathbf{H}$ was followed using methyl 2,3,4,5,6-pentafluorobenzoate (14.75 $\mu \mathrm{L}, 0.1$ mmol, 1 equiv), $1-((3,7-$ dimethylocta-1,6-dien-3-yl)oxy)-2,3,4,5,6pentafluorobenzene $(147 \mu \mathrm{L}, 0.6 \mathrm{mmol}, 6$

equiv), $N, N$-diisopropylethylamine $(31.3 \mu \mathrm{L}, 0.18 \mathrm{mmol}, 1.8$ equiv), distilled water ( $18 \mu \mathrm{L}, 1$ mmol, 10 equiv) and $1.0 \mathrm{~mL}$ of stock solution of $\operatorname{Ir}(\mathrm{ppy})_{3}(0.16 \mathrm{mg}, 0.0003 \mathrm{mmol}, 0.003$ equiv) in $\mathrm{CH}_{3} \mathrm{CN}$ was used. The crude material was purified by using Prep TLC 10:1 hexane:diethyl ether to afford methyl (E)-2-(3,7-dimethylocta-2,6-dien-1-yl)-3,4,5,6-tetrafluorobenzoate (7a) and methyl (E)-4-(3,7-dimethylocta-2,6-dien-1-yl)-2,3,5,6-tetrafluorobenzoate (7a') as a colorless liquid in $42 \%$ and $27 \%{ }^{19} \mathrm{~F}$ NMR yield respectively $(o-G e r: p$-Ger $=1.55: 1)$. This was determined using ${ }^{19} \mathrm{~F}$ NMR peak integrations (four $-\mathrm{F}$ peaks as a result of ortho-substitution and two peaks arising from para-substitution. ${ }^{19} \mathrm{~F}$ NMR $\left(376 \mathrm{MHz}, \mathrm{CDCl}_{3}\right) \delta-134.34--134.51$ (m, 1F), -138.07 (dd, $J=22.8,12.4 \mathrm{~Hz}, 1 \mathrm{~F}),-140.14(\mathrm{ddd}, J=21.6,12.4,5.2 \mathrm{~Hz}, 1 \mathrm{~F}),-140.21--$ $140.38(\mathrm{~m}, 2 \mathrm{~F}$, minor), $-140.44(\mathrm{ddd}, J=21.8,12.4,5.2 \mathrm{~Hz}, 1 \mathrm{~F}),-142.99--143.15(\mathrm{~m}, 2 \mathrm{~F}$, minor). ${ }^{1} \mathrm{H}$ NMR (400 MHz, $\left.\mathrm{CDCl}_{3}\right) \delta 5.44(\mathrm{t}, J=7.0 \mathrm{~Hz}, 1 \mathrm{H}), 5.16(\mathrm{t}, J=14.6 \mathrm{~Hz}, 2 \mathrm{H}$, major and minor), 5.03 (t, $J=7.5 \mathrm{~Hz}, 1 \mathrm{H}$, minor), 3.97 (s, 3H), 3.96 (s, 3H, minor), 3.45 (d, $J=7.3 \mathrm{~Hz}$, 2H), $3.19(\mathrm{~d}, J=10.7 \mathrm{~Hz}, 2 \mathrm{H}$, minor), $2.34-1.96$ (m, 8H, major and minor), 1.77 (d, $J=1.5 \mathrm{~Hz}$, 3H), $1.74\left(\mathrm{~s}, 3 \mathrm{H}\right.$, minor), $1.70(\mathrm{~s}, 3 \mathrm{H}), 1.69$ (s, 3H, minor), $1.64(\mathrm{~s}, 3 \mathrm{H}), 1.63\left(\mathrm{~s}, 3 \mathrm{H}\right.$, minor) ${ }^{13} \mathrm{C}$ $\operatorname{NMR}\left(101 \mathrm{MHz}, \mathrm{CDCl}_{3}\right) \delta 160.5,160.2,147.1$ - $145.4(\mathrm{~m}), 146.4-143.5(\mathrm{~m}), 145.9-143.6$ (m), $145.5-142.8(\mathrm{~m}), 140.2,138.8(\mathrm{~d}, J=13.0 \mathrm{~Hz}), 132.1,131.7,127.4(\mathrm{t}, J=17.2 \mathrm{~Hz}), 123.9$, 123.7, 121.8, 118.7, 118.3, $110.1(\mathrm{t}, J=15.7 \mathrm{~Hz}), 53.1,49.2,41.8,39.5,37.2,34.3,31.8,30.4$, 26.4, 26.3, 26.1, 25.7, 25.6, 25.2, 22.2, 17.6, 16.1. GC/MS (m/z, relative intensity) 344 (M+, 15), 313 (10), $301(20)$. 


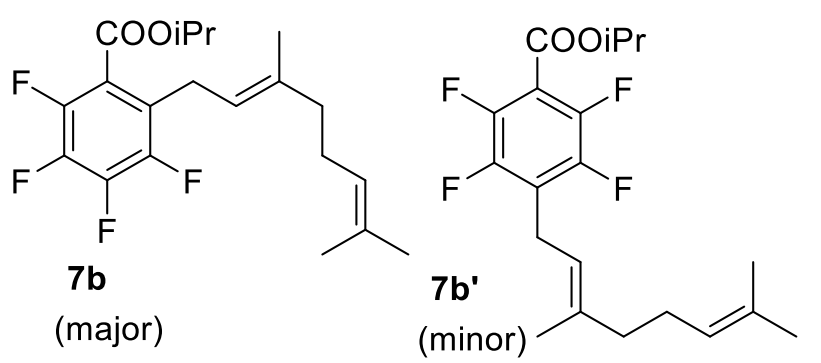

equiv), $N, N$-diisopropylethylamine $(31.3 \mu \mathrm{L}, 0.18 \mathrm{mmol}, 1.8$ equiv), distilled water (18 $\mu \mathrm{L}, 1$ mmol, 10 equiv) and $1.0 \mathrm{~mL}$ of stock solution of $\operatorname{Ir}(\mathrm{ppy})_{3}(0.16 \mathrm{mg}, 0.0003 \mathrm{mmol}, 0.003$ equiv) in $\mathrm{CH}_{3} \mathrm{CN}$ was used. The crude material was purified by using Prep TLC 10:1 hexane:diethyl ether to afford isopropyl (E)-2-(3,7-dimethylocta-2,6-dien-1-yl)-3,4,5,6-tetrafluorobenzoate (7b) and isopropyl (E)-4-(3,7-dimethylocta-2,6-dien-1-yl)-2,3,5,6- tetrafluorobenzoate (7b') as a colorless liquid in $42 \%$ and $26 \%{ }^{19} \mathrm{~F}$ NMR yield respectively $(o$-Ger $: p$-Ger $=1.6: 1)$. This was determined using ${ }^{19} \mathrm{~F}$ NMR peak integrations (assignment was made based on the analogy with 7a). ${ }^{19} \mathrm{~F}$ NMR $\left(376 \mathrm{MHz}, \mathrm{CDCl}_{3}\right) \delta-134.55--134.77(\mathrm{~m}, 1 \mathrm{~F}),-138.32(\mathrm{dd}, J=22.8,12.4 \mathrm{~Hz}$, 1F), $-140.82--140.97(\mathrm{~m}, 1 \mathrm{~F}),-140.99--141.17(\mathrm{~m}, 2 \mathrm{~F}$, minor), $-141.17--141.27(\mathrm{~m}, 1 \mathrm{~F}),-$ $143.22--143.44$ (m, 2F, minor). ${ }^{1} \mathrm{H}$ NMR $\left(400 \mathrm{MHz}, \mathrm{CDCl}_{3}\right) \delta 5.44(\mathrm{t}, J=7.0 \mathrm{~Hz}, 2 \mathrm{H}), 5.30$ (hept, 2H, major and minor), $5.15(\mathrm{t}, J=9.2 \mathrm{~Hz}, 2 \mathrm{H}$, major and minor), $5.05-5.00(\mathrm{~m}, 1 \mathrm{H}$, minor), $3.44(\mathrm{~d}, J=7.3 \mathrm{~Hz}, 3 \mathrm{H}), 3.18(\mathrm{~d}, J=10.7 \mathrm{~Hz}, 3 \mathrm{H}$, minor), $2.33-2.01(\mathrm{~m}, 8 \mathrm{H}$, major and minor), $1.76(\mathrm{~s}, 3 \mathrm{H}), 1.73(\mathrm{~s}, 3 \mathrm{H}$, minor), $1.70(\mathrm{~d}, J=2.3 \mathrm{~Hz}, 3 \mathrm{H}$, minor), $1.65(\mathrm{~s}, 3 \mathrm{H}), 1.63(\mathrm{~d}$, $3 \mathrm{H}$, minor), $1.57(\mathrm{~s}, 3 \mathrm{H}), 1.39(\mathrm{~d}, 3 \mathrm{H}), 1.38(\mathrm{~d}, 3 \mathrm{H}$, minor $), 1.37(\mathrm{~d}, 3 \mathrm{H}), 1.36(\mathrm{~d}, 3 \mathrm{H}$, minor $) .{ }^{13} \mathrm{C}$ $\operatorname{NMR}\left(101 \mathrm{MHz}, \mathrm{CDCl}_{3}\right) \delta 159.5,159.2,147.9-146.4(\mathrm{~m}), 147.2-145.8(\mathrm{~m}), 147.1-143.0$ (m), $144.8-142.6$ (m), 140.2, 138.8, 138.7, 132.1, 131.7, 127.0, 126.6, 123.8, 123.7, 123.1, $121.9,119.8,118.9,118.3,111.3-110.8(\mathrm{~m}), 70.7,70.6,53.4,49.2,41.9,39.5,37.2,34.3,30.4$ $26.3(\mathrm{~d}, J=9.9 \mathrm{~Hz}), 26.1(\mathrm{~d}, J=6.7 \mathrm{~Hz}), 25.7(\mathrm{~d}, J=8.6 \mathrm{~Hz}), 25.3,22.1(\mathrm{~d}, J=5.9 \mathrm{~Hz}), 21.7$, 17.6, 16.0. GC/MS (m/z, relative intensity) $372(\mathrm{M}+, 20), 329(25), 313(20)$. 


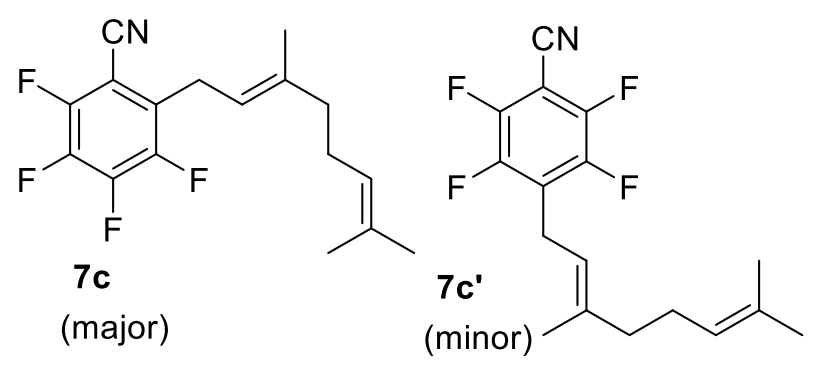

equiv), $N, N$-diisopropylethylamine
General procedure $\mathbf{H}$ was followed using Pentafluorobenzonitrile $(12.6 \mu \mathrm{L}, 0.1$ mmol, 1 equiv), 1-((3,7-dimethylocta-1,6dien-3-yl)oxy)-2,3,4,5,6pentafluorobenzene $(147 \mu \mathrm{L}, 0.6 \mathrm{mmol}, 6$

(31.3 $\mu \mathrm{L}, 0.18 \mathrm{mmol}, 1.8$ equiv), distilled water (18 $\mu \mathrm{L}, 1 \mathrm{mmol}, 10$ equiv) and $1.0 \mathrm{~mL}$ of stock solution of $\operatorname{Ir}(\mathrm{ppy})_{3}\left(0.16 \mathrm{mg}, 0.0003 \mathrm{mmol}, 0.003\right.$ equiv) in $\mathrm{CH}_{3} \mathrm{CN}$ was used. The crude material was purified by using Prep TLC 10:1 hexane:diethyl ether to afford (E)-2-(3,7-dimethylocta-2,6dien-1-yl)-3,4,5,6-tetrafluorobenzonitrile (7c) and (E)-4-(3,7-dimethylocta-2,6-dien-1-yl)-

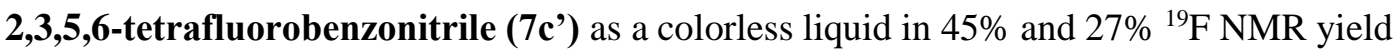
respectively $(o$-Ger $: p$-Ger $=1.65: 1)$. This was determined using ${ }^{19} \mathrm{~F}$ NMR peak integrations (four $-\mathrm{F}$ peaks as a result of ortho-substitution and two peaks arising from para-substitution). Assignment was made based on the analogy with 7a. ${ }^{19} \mathrm{~F} \mathrm{NMR}\left(376 \mathrm{MHz}, \mathrm{CDCl}_{3}\right) \delta-132.13$ (ddt, $J=16.9,11.2,5.6 \mathrm{~Hz}, 1 \mathrm{~F}),-133.01(\mathrm{ddd}, J=20.6,12.1,7.4 \mathrm{~Hz}, 1 \mathrm{~F}),-133.22(\mathrm{tt}, J=16.6,8.4 \mathrm{~Hz}$, 2F, minor), -133.47 (ddd, $J=22.0,12.0,7.3 \mathrm{~Hz}, 1 \mathrm{~F}),-135.40(\mathrm{dd}, J=22.1,12.1 \mathrm{~Hz}, 1 \mathrm{~F}),-140.50$ (tt, $J=16.5,8.5 \mathrm{~Hz}, 2 \mathrm{~F}$, minor). ${ }^{1} \mathrm{H} \mathrm{NMR}\left(400 \mathrm{MHz}, \mathrm{CDCl}_{3}\right) \delta 5.44(\mathrm{t}, J=7.0 \mathrm{~Hz}, 2 \mathrm{H}$, major and minor), 5.13 (t, $J=7.4 \mathrm{~Hz}, 1 \mathrm{H}), 5.01$ (t, $J=7.5 \mathrm{~Hz}, 1 \mathrm{H}$, minor), 3.49 (d, $J=1.8 \mathrm{~Hz}, 2 \mathrm{H}), 3.23$ (d, 2H, minor), $2.36-1.92(\mathrm{~m}, 8 \mathrm{H}$, major and minor), $1.77(\mathrm{~s}, 3 \mathrm{H}), 1.74(\mathrm{~s}, 3 \mathrm{H}$, minor), $1.69(\mathrm{~s}, 3 \mathrm{H})$, $1.64\left(\mathrm{~s}, 3 \mathrm{H}\right.$, minor), $1.62\left(\mathrm{~s}, 3 \mathrm{H}\right.$, minor), $1.57(\mathrm{~s}, 3 \mathrm{H}) .{ }^{13} \mathrm{C} \mathrm{NMR}\left(101 \mathrm{MHz}, \mathrm{CDCl}_{3}\right) \delta 148.1(\mathrm{~d}, J$ $=6.4 \mathrm{~Hz}), 147.9(\mathrm{~d}, J=6.6 \mathrm{~Hz}), 148.8-146.2(\mathrm{~m}), 148.1-145.8(\mathrm{~m}), 144.6(\mathrm{dt}, J=15.9,4.6$ Hz), $143.8-142.6(\mathrm{dt}, J=15.9,4.6 \mathrm{~Hz}), 140.1,139.8,132.2,131.8,131.1,127.7,127.5,123.6$, 121.7, 117.1, 107.7, 91.8, 49.5, 39.5, 37.4, 34.2, 30.2, 26.2, 25.9 (d, $J=6.8 \mathrm{~Hz}), 25.7,25.2,23.2$, 
22.6, $22.2(\mathrm{~d}, J=6.2 \mathrm{~Hz}), 17.6(\mathrm{~d}, J=2.9 \mathrm{~Hz}), 16.1 . \mathrm{GC} / \mathrm{MS}$ (m/z, relative intensity) $311(\mathrm{M}+$, 15), $296(5), 268$ (35), 255 (10).

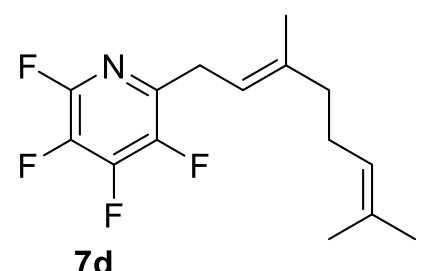

(major)

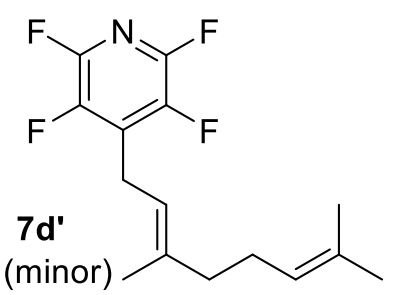

General procedure $\mathbf{H}$ was followed using Pentafluoropyridine $(10.9 \mu \mathrm{L}, 0.1 \mathrm{mmol}, 1$ equiv), 1-((3,7-dimethylocta-1,6-dien-3yl)oxy)-2,3,4,5,6-pentafluorobenzene (147

$\mu \mathrm{L}, 0.6 \mathrm{mmol}, 6$ equiv), $N, N$-diisopropylethylamine ( $31.3 \mu \mathrm{L}, 0.18 \mathrm{mmol}, 1.8$ equiv), distilled water $(18 \mu \mathrm{L}, 1 \mathrm{mmol}, 10$ equiv) and $1.0 \mathrm{~mL}$ of stock solution of $\operatorname{Ir}(\mathrm{ppy}) 3(0.16 \mathrm{mg}, 0.0003$ mmol, 0.003 equiv) in $\mathrm{CH}_{3} \mathrm{CN}$ was used. The crude material was purified by using Prep TLC 10:1 hexane:diethyl ether to afford (E)-2-(3,7-dimethylocta-2,6-dien-1-yl)-3,4,5,6-

\section{tetrafluoropyridine (7d) and (E)-4-(3,7-dimethylocta-2,6-dien-1-yl)-2,3,5,6-}

tetrafluoropyridine (7d') as a colorless liquid in $43 \%$ and $26 \%{ }^{19} \mathrm{~F}$ NMR yield respectively (o-

Ger : $p$-Ger $=1.67: 1)$. Assignment was made based on the analogy with 7a. ${ }^{19} \mathrm{~F}$ NMR $(376 \mathrm{MHz}$, $\left.\mathrm{CDCl}_{3}\right) \delta-91.62--92.13(\mathrm{~m}, 3 \mathrm{~F}$, major and minor), $-92.39(\mathrm{ddd}, J=28.6,21.8,14.0 \mathrm{~Hz}, 1 \mathrm{~F}),-$ $136.75--136.99(\mathrm{~m}, 1 \mathrm{~F}),-140.61--140.98(\mathrm{~m}, 1 \mathrm{~F}),-145.00--145.32$ (m, 2F, minor). ${ }^{1} \mathrm{H}$ NMR $\left(400 \mathrm{MHz}, \mathrm{CDCl}_{3}\right) \delta 5.48-5.39(\mathrm{~m}, 1 \mathrm{H}), 5.22-5.14(\mathrm{~m}, 1 \mathrm{H}), 5.14-5.08(\mathrm{~m}, 1 \mathrm{H}$, minor), 5.02 (dt, $J=6.8,4.1 \mathrm{~Hz}, 1 \mathrm{H}$, minor), $3.50(\mathrm{~d}, J=7.4 \mathrm{~Hz}, 2 \mathrm{H}), 3.23(\mathrm{~d}, J=10.9 \mathrm{~Hz}, 2 \mathrm{H}$, minor), $2.38-$ $1.96(\mathrm{~m}, 8 \mathrm{H}$, major and minor), $1.77(\mathrm{~s}, 3 \mathrm{H}), 1.75(\mathrm{~s}, 3 \mathrm{H}$, minor), $1.69(\mathrm{~s}, 3 \mathrm{H}), 1.64(\mathrm{~s}, 3 \mathrm{H}$, minor), $1.62(\mathrm{~s}, 3 \mathrm{H}), 1.57$ (s, 3H, minor). ${ }^{13} \mathrm{C} \mathrm{NMR}\left(101 \mathrm{MHz}, \mathrm{CDCl}_{3}\right) \delta 149.5-148.9(\mathrm{~m})$, 148.6 - $147.9(\mathrm{~m}), 147.6-147.1(\mathrm{~m}), 146.9$ - $146.2(\mathrm{~m}), 145.7$ - $142.7(\mathrm{~m}), 144.9-142.1(\mathrm{~m})$, $140.2,139.9,139.8,139.1(\mathrm{~d}, J=9.0 \mathrm{~Hz}), 131.8,123.6,123.5,121.7,117.5,116.8,49.7,41.8$, $39.5,37.1,34.1,26.3,25.7-25.4(\mathrm{~m}), 25.2,22.9-22.7(\mathrm{~m}), 22.6,22.1(\mathrm{~d}, J=6.0 \mathrm{~Hz}), 17.6$, 16.1. GC/MS (m/z, relative intensity) $287(\mathrm{M}+, 30), 272(10), 258(8), 244$ (35). 


\section{General procedure I for the attempted photocatalytic farnesylation reaction}

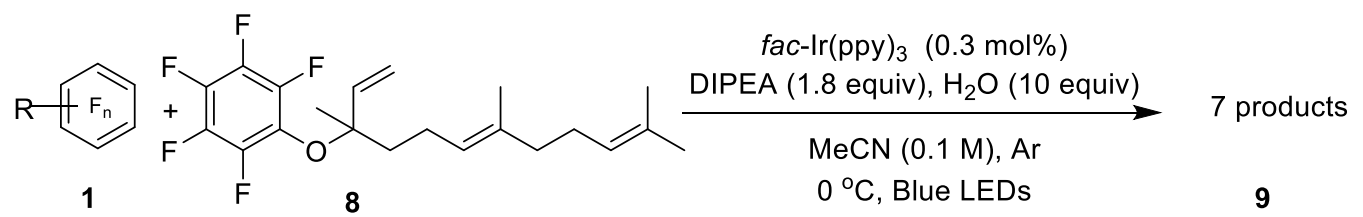

An NMR tube was charged with fluoroarene (0.1 mmol, 1.0 equiv), 1-((3,7-dimethylocta-1,6dien-3-yl)oxy)-2,3,4,5,6-pentafluorobenzene ( $0.6 \mathrm{mmol}, 6$ equiv), $N, N$-diisopropylethylamine ( $0.18 \mathrm{mmol}, 1.8$ equiv), distilled water ( $1 \mathrm{mmol}, 10$ equiv), $f a c$-tris $(2$ - phenyl pyridinato- $C 2, N)$ Iridium(III) (Ir(ppy)3) (0.3 mM, $1 \mathrm{~mL}$ in $\mathrm{MeCN})$, sealed glass capillary containing $\mathrm{C}_{6} \mathrm{D}_{6}$ and was capped with an NMR septum (Ace glass, part no. 9096-25). When reaction was run in greater than $0.1 \mathrm{mmol}$ of fluoroarene, more than one NMR tube was used to set up the reaction and each NMR tube had $1 \mathrm{~mL}$ of reaction mixture. The reaction was degassed via Ar bubbling for $15 \mathrm{~min}$ at $0{ }^{\circ} \mathrm{C}$ (to avoid evaporation of $N, N$ diisopropylethylamine and other volatile starting materials) and then placed in a light bath (vide supra) such that the lower portion of the tube was submerged under the isopropanol/water bath.

The reaction was monitored periodically by ${ }^{19} \mathrm{~F}$ NMR (care was taken to exclude light while in transit). After the complete consumption of starting material, $\mathrm{CH}_{3} \mathrm{CN}$ was removed via rotavap. The crude material was purified using prep TLC plate. If the reaction did not go to completion with the first addition of $N, N$-diisopropylethylamine, an additional 1 - 3 equiv of $N, N$ diisopropylethylamine was added to the reaction. Then the reaction was re-degassed and returned to the light bath. This sequence was repeated until the reaction reached completion as judged by ${ }^{19} \mathrm{~F}$ NMR.

General procedure I was followed using methyl 2,3,4,5,6-pentafluorobenzoate $(14.7 \mu \mathrm{L}, 0.1$ mmol, 1 equiv), (E)-1,2,3,4,5-pentafluoro-6-((3,7,11-trimethyldodeca-1,6,10-trien-3yl)oxy)benzene (154 $\mu \mathrm{L}, 0.6 \mathrm{mmol}, 6$ equiv), $N$,Ndiisopropylethylamine $(31.3 \mu \mathrm{L}, 0.18 \mathrm{mmol}, 1.8$ equiv), distilled water (18 $\mu \mathrm{L}, 1 \mathrm{mmol}, 10$ equiv) and $1.0 \mathrm{~mL}$ of stock solution of $\operatorname{Ir}(\mathrm{ppy})_{3}(0.16$ 
$\mathrm{mg}, 0.0003 \mathrm{mmol}, 0.003$ equiv) in $\mathrm{CH}_{3} \mathrm{CN}$ was used. The reaction produced 7 products (determined by GC/MS). An attempt was made to improve the selectivity by lowering the temperature to $-20{ }^{\circ} \mathrm{C}$ and/or varying the amount of farnesyl ether in the reaction but these multiple products were still observed at those conditions.

Table 1.15: Optimization of attempted farnesylation reaction at $-20{ }^{\circ} \mathrm{C}$

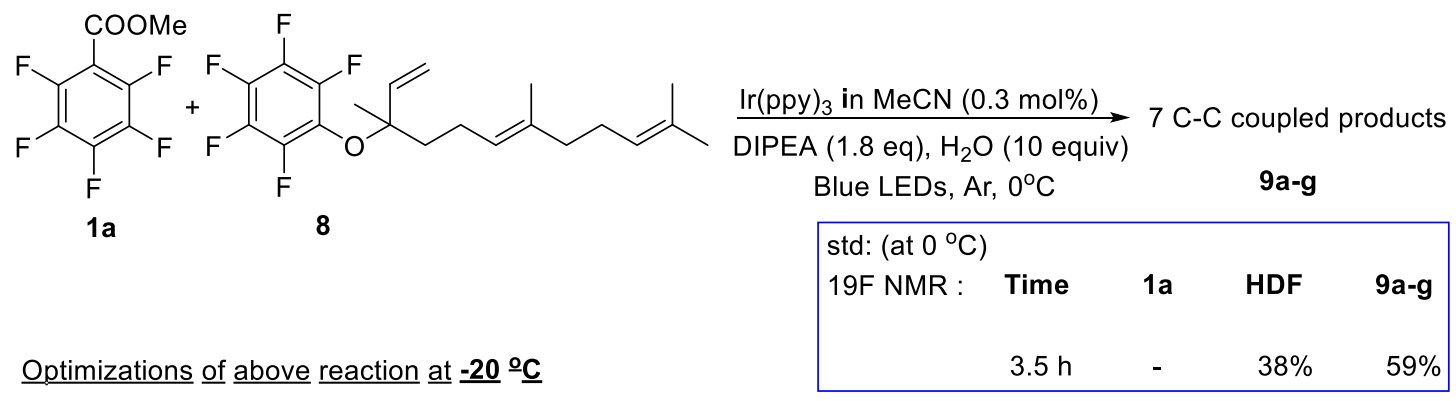

$\begin{array}{llllll}\text { Entry } & \text { Conditions } & \text { Time } & \text { 1a } & \text { HDF } & \text { 9a-g } \\ \text { 1. } & \text { 6 equiv ether } & 5 \mathrm{~h} & 56 \% & 17 \% & 26.7 \% \\ \text { 2. } & 3 \text { equiv ether } & 5 \mathrm{~h} & 24 \% & 56 \% & 21 \% \\ \text { 3. } & \text { 1 equiv ether } & 5 \mathrm{~h} & 9 \% & 83 \% & 8 \% \\ \text { 4. } & \text { 6 equiv ether, no water } & 5 \mathrm{~h} & 62 \% & 22 \% & 16 \%\end{array}$

Multiple C-C coupled product formations observed from the initial stage of reaction.

Table 1.16: Change in product ratios on varying conditions

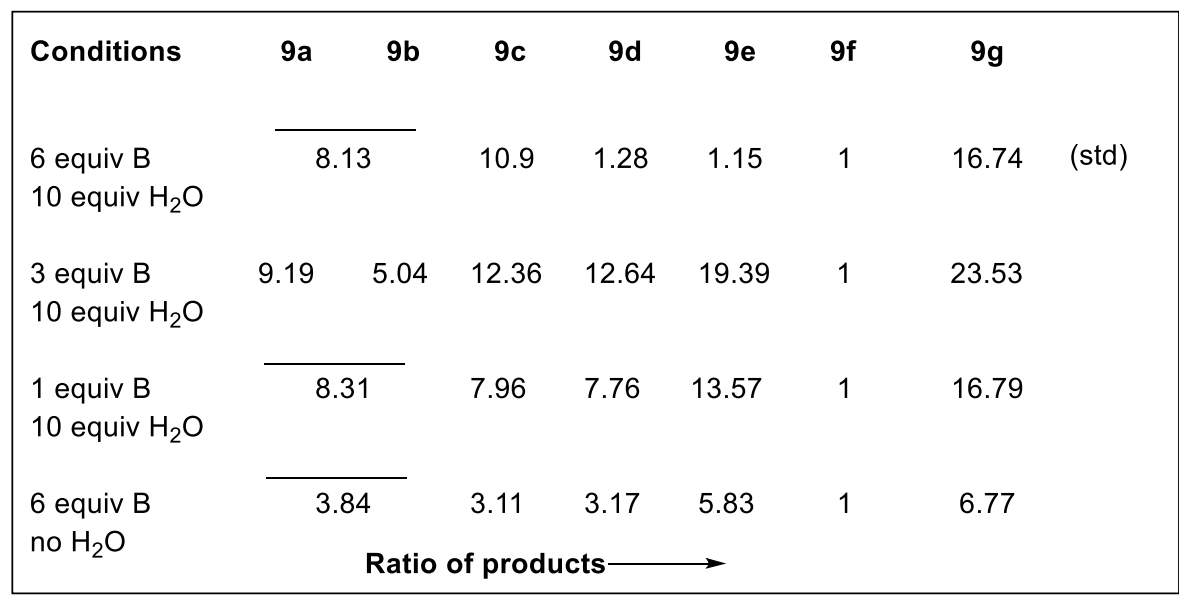

In some cases $\mathbf{9 a}$ and $\mathbf{9 b}$ did not resolve completely on GCMS and have been represented by a - to show a combined peak appearing at a specific retention time.

(Determined by calculating peak areas in GC/MS) 


\section{Evidence for ortho C-F Functionalization}
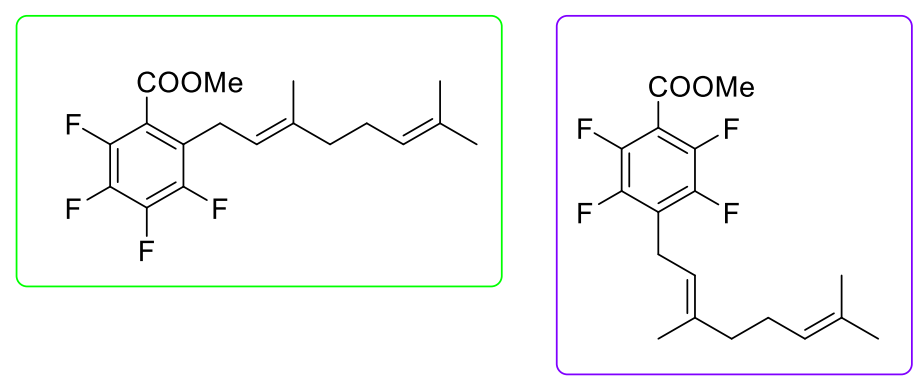

One interesting feature of this project was the observed change in regioselectivity of the major product upon moving from prenylation to geranylation. This is the first report of preferential ortho fragmentation based on reagent (we have shown that an intramolecular hydrogen bond can cause the ortho fragmentation to occur preferentially). Thus, we approached this with a healthy skepticism. We based the proposed structure on the basis of several arguments which are outlined below. First, we observed 6 peaks in the ${ }^{19} \mathrm{~F}$ NMR which could arise from 3 parasubstituted products in which 2 of them were produced in the same ratio, or alternatively the reaction produces two products in total, i.e., expected para-geranylated product that accounts for two 1:1 -F signals and an ortho-geranylated product which accounts for four $-\mathrm{F}$ signals in a 1:1:1:1 relationship with one another. We ruled out the possibility of formation of 3 parasubstituted products as the four -F signals were found to be present in the same spin system as confirmed by ${ }^{19} \mathrm{~F}-{ }^{19} \mathrm{~F}$ TOCSY. Another major evidence that supported ortho-geranylation was that upon running a $\mathrm{AgNO}_{3}$ impregnated silica column chromatography in an attempt to separate the $\mathrm{C}-\mathrm{C}$ coupled products from one another, we observed that the compound eluted in such a way that each and every fraction (from very early to late fractions) produced four $1: 1: 1: 1$ peaks in ${ }^{19} \mathrm{~F}$ NMR, suggesting either perfect co-elution of two compounds or that this was a single compound. Other evidences included appropriate and distinct vinyl protons, methyl ester, methylene and methyl peaks in ${ }^{1} \mathrm{H}$ NMR, two separate peaks of same m/z determined by GCMS, genuine 4-bond $\mathrm{F}-\mathrm{F}$ couplings observed in ${ }^{19} \mathrm{~F}-{ }^{19} \mathrm{~F} \mathrm{COSY}^{47}$. Another very important study to validate ortho $\mathrm{C}-\mathrm{C}$ coupled product was to calculate predicted ${ }^{19} \mathrm{~F}$ NMR shifts for ortho-geranylated product. We 
observed that the actual ${ }^{19} \mathrm{~F}$ NMR shifts fell in the acceptable range of error. ${ }^{48}$ Apart from that, we determined that all the F-atoms were attached to distinct $\mathrm{C}$-atoms by ${ }^{19} \mathrm{~F}_{-}{ }^{13} \mathrm{C}$ HSQC and ${ }^{1} \mathrm{H}_{-}-{ }^{13} \mathrm{C}$ HSQC further confirmed our assignment of vinyl, methyl ester, benzylic methylene, methylene from geranyl chain and methyl protons on ${ }^{1} \mathrm{H}$ NMR. Alkene geometry was assigned by NOE correlations.

\section{1. ${ }^{19}$ F NMR}

Observation:

- Four distinct 1:1:1:1 peaks with similar splitting pattern supported o-Geranylated pdt $(-134.4,-138.2,-140,-140.4)$

- Two 1:1 peaks confirmed p-Geranylated pdt (-140.3 and -143.1)

\section{2. ${ }^{1} \mathrm{H} \mathrm{NMR}$}

- 4 vinyl protons (5.01-5.5 ppm)

- Methylene (3.2-3.4 ppm and 1.95-2.35 ppm) and methyl peaks (1.55-2.78 ppm) from both compounds

\section{3. $\underline{\mathrm{GC} / \mathrm{MS}}$}

- 2 peaks each of M+ 344 (at 17.4 and 17.6 mins retention time)

4. Isolation using $\mathrm{AgNO}_{3}$ impregnated silica column

- ${ }^{19} \mathrm{~F}$ NMR of various fractions contained either 1:1:1:1 peaks for o-Geranylated product or 1:1 peaks for $\mathrm{p}$-Geranylated product

\section{5. ${ }^{19} \mathrm{~F}^{19} \mathrm{~F}$ TOCSY}


- $\quad 4-\mathrm{F}$ peaks in the same spin-system

- $\quad 2-$ F peaks within another spin-system

6. ${ }^{19} \mathrm{~F}^{19} \mathrm{~F} \operatorname{COSY}$

- 4-bond coupling stronger than 3-bond coupling

- F-1 and F-3 showed strong correlation

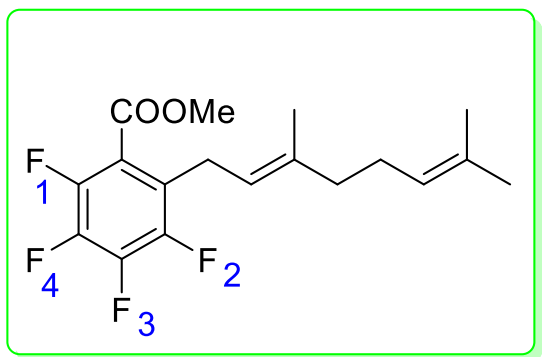

- F-2 showed strong correlation with F-4

- Weak interaction observed between F-1 and F-4

7. Structure prediction using NMR calculations

\begin{tabular}{|ccccc|}
\hline Experimental Shift & Isotropic & Calculated Shift & Error & \\
\cline { 1 - 4 }-135.11 & 312.5896 & -127.3452 & 8 & $(\mathrm{ppm})$ \\
-138.88 & 315.2231 & -129.9849 & 8.02 & 0.63 \\
-141.34 & 327.1844 & -141.9751 & 7.8 \\
-141.76 & 334.8345 & -149.6436 & \\
\hline \multicolumn{6}{l}{} \\
Calculated isotropic values, and shifts of compounds \\
Geometry optimizations and NMR calculations run using the B3LYP/6-31+G(d,p) method in gas phase using \\
Gaussian09. The shifts were scaled based on the equation $\mathrm{y}=-0.9968 \mathrm{x}+184.92$.
\end{tabular}

- The actual NMR shifts lie within the acceptable error range. 


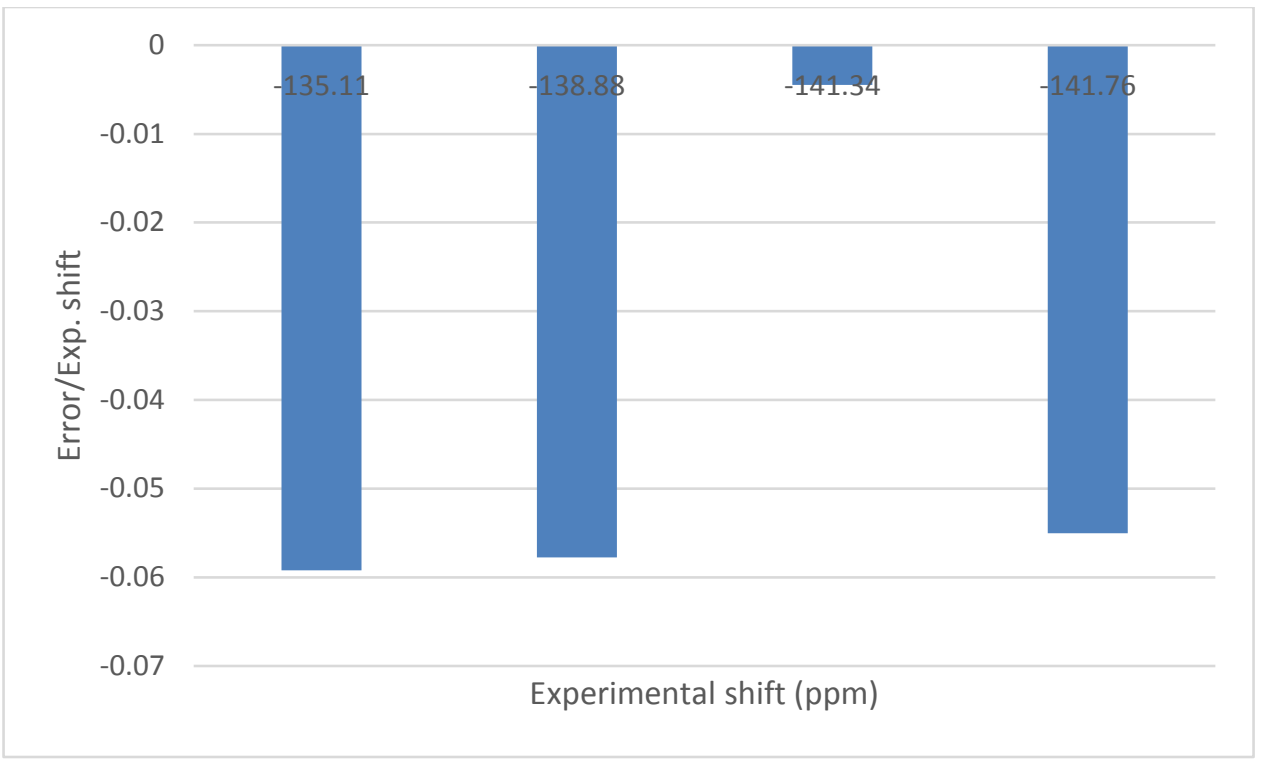

8. $\underline{{ }^{19} \mathrm{~F}-{ }^{13} \mathrm{C} \mathrm{HSQC}}$

- The four $-\mathrm{F}$ peaks are attached to four different $\mathrm{C}$-atoms

9. ${ }^{1} \mathrm{H}_{-}{ }^{13} \mathrm{C}$ HSQC

- A total of 4 vinyl protons from both molecules $5.0-5.5 \mathrm{ppm}$

- 2 separate methyl ester peaks (3.94-4.0 ppm)

- 2 benzylic methylene signals (3.2 and $3.4 \mathrm{ppm})$

- Presence of 4 types of alkyl methylene signals (1.95-2.35 ppm)

[This region includes peaks from minor side-products]

- Both products produces a total of 6 different methyl signals in the alkyl region (1.55-2.78 ppm) [This region also includes peaks from minor side-products] 


\section{UV-Vis Experiments:}

In order to gain a better insight on the interactions between substrates, we carried out UV-Vis experiments. We did not see any interaction between perfluoroarene and prenylating source, but there was a formation of exciplex observed between prenylating source and DIPEA.

Prenyl ether and Methylpentafluoro benzoate in $\underline{\operatorname{MeCN}} \underline{(0.1} \underline{\mathrm{M})}$
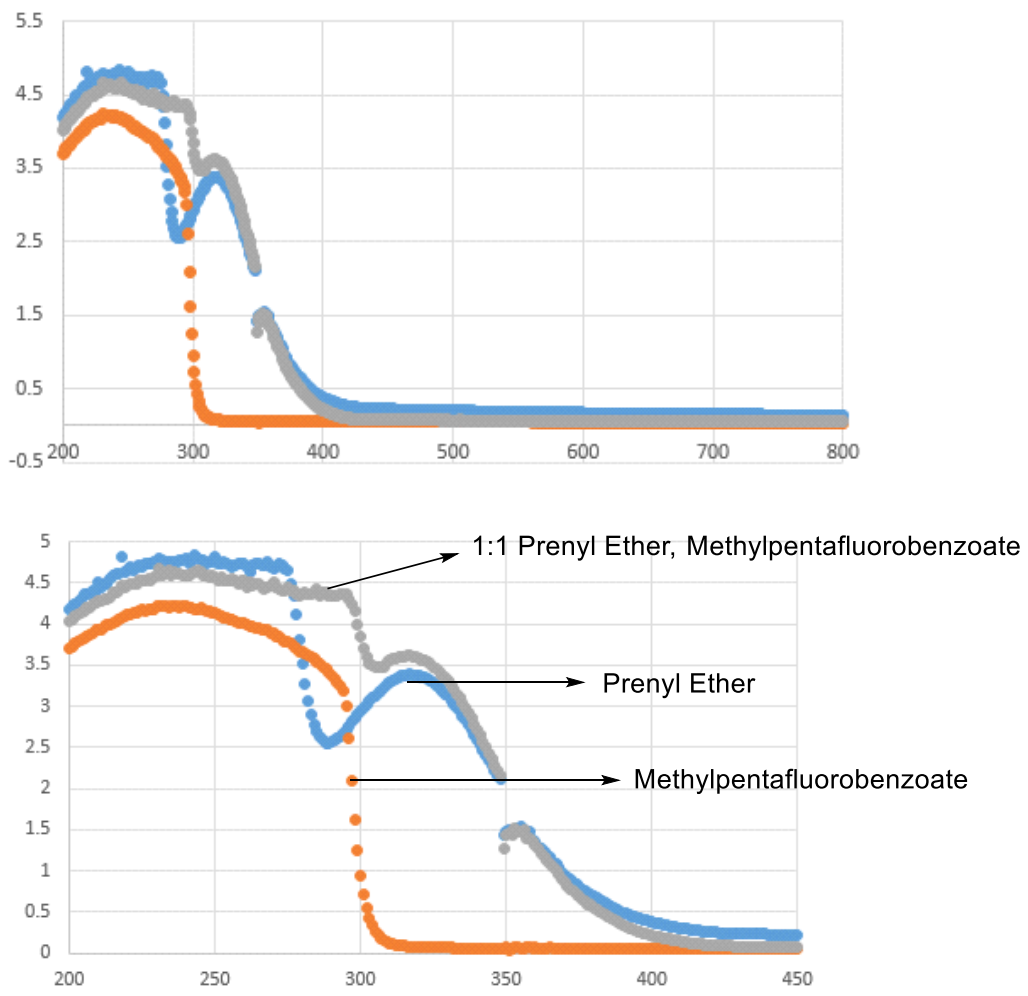

Prenvl Ether Methvl Pentafluorobenzoate DIPEA in $\underline{\mathrm{MeCN}} \underline{(0.1} \underline{\mathrm{M})}$

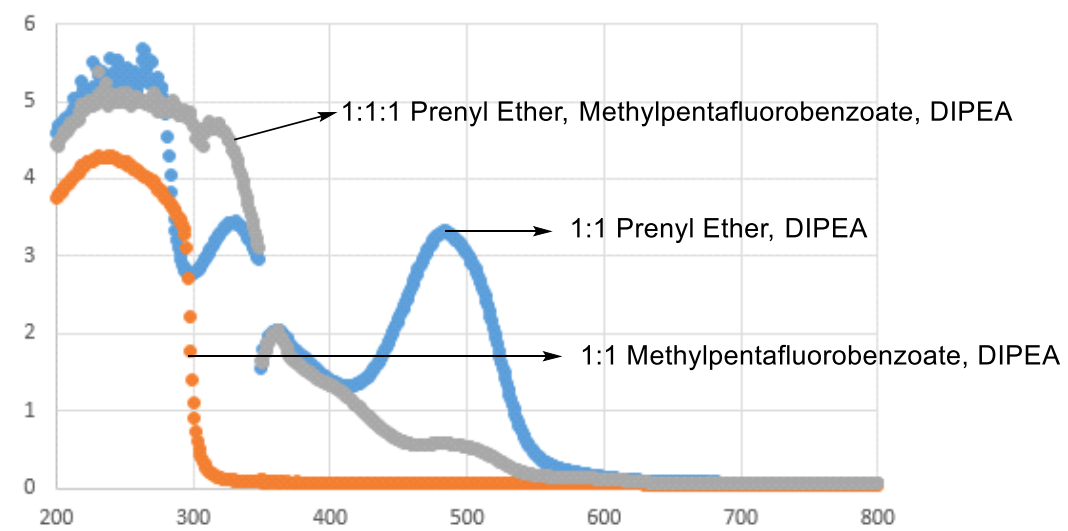


Geranyl ether and methylpentafluoro benzoate $(0.1 \mathrm{M})$ in $\mathrm{MeCN}$
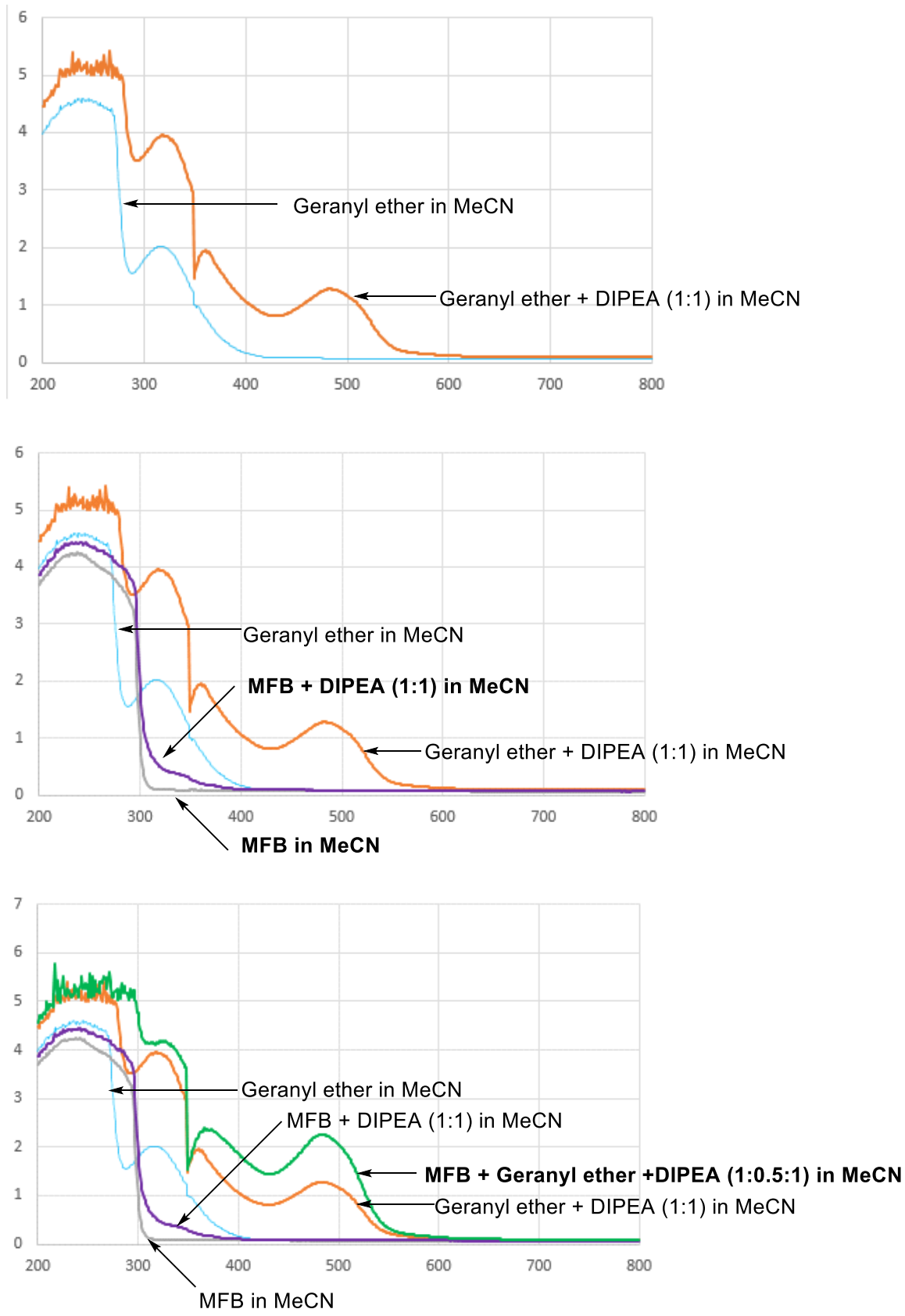

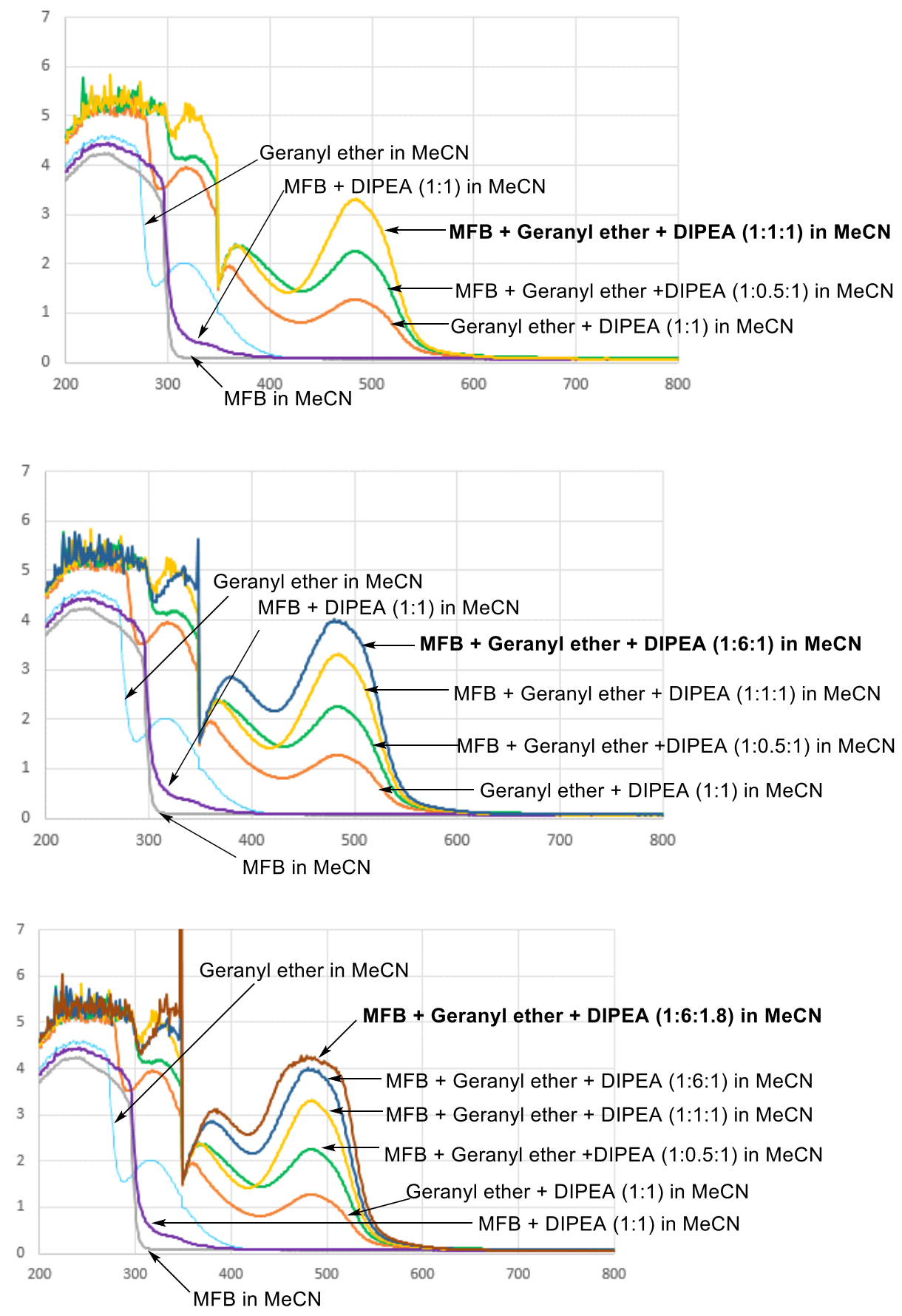

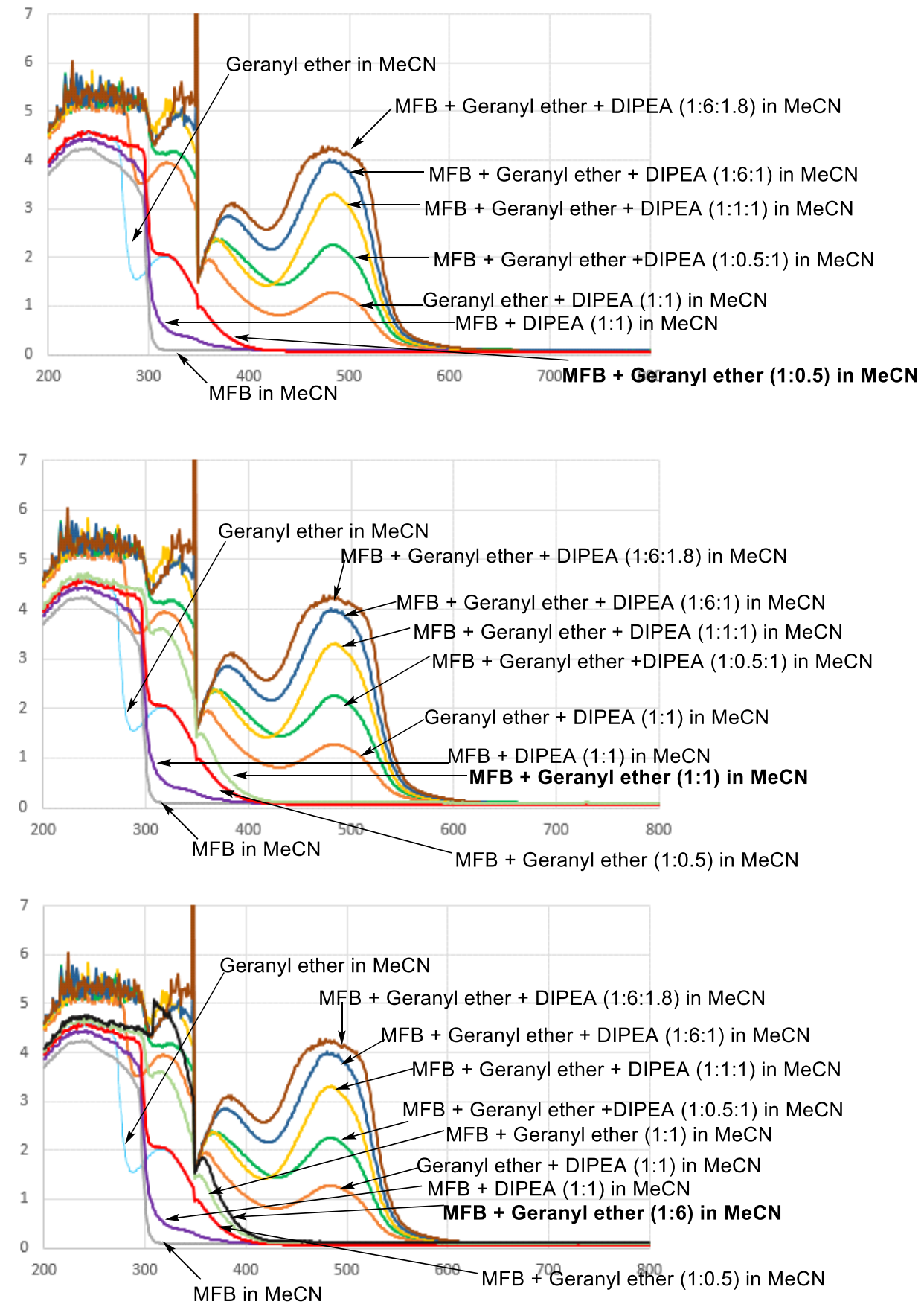

Figure 1.6: UV-Vis experiments 


\section{NMR Titration experiments:}

Several combinations of ${ }^{19} \mathrm{~F}$ NMR titrations were also carried out that in turn demonstrated no significant interactions between perfluoroarene and prenylating agent at ground state.
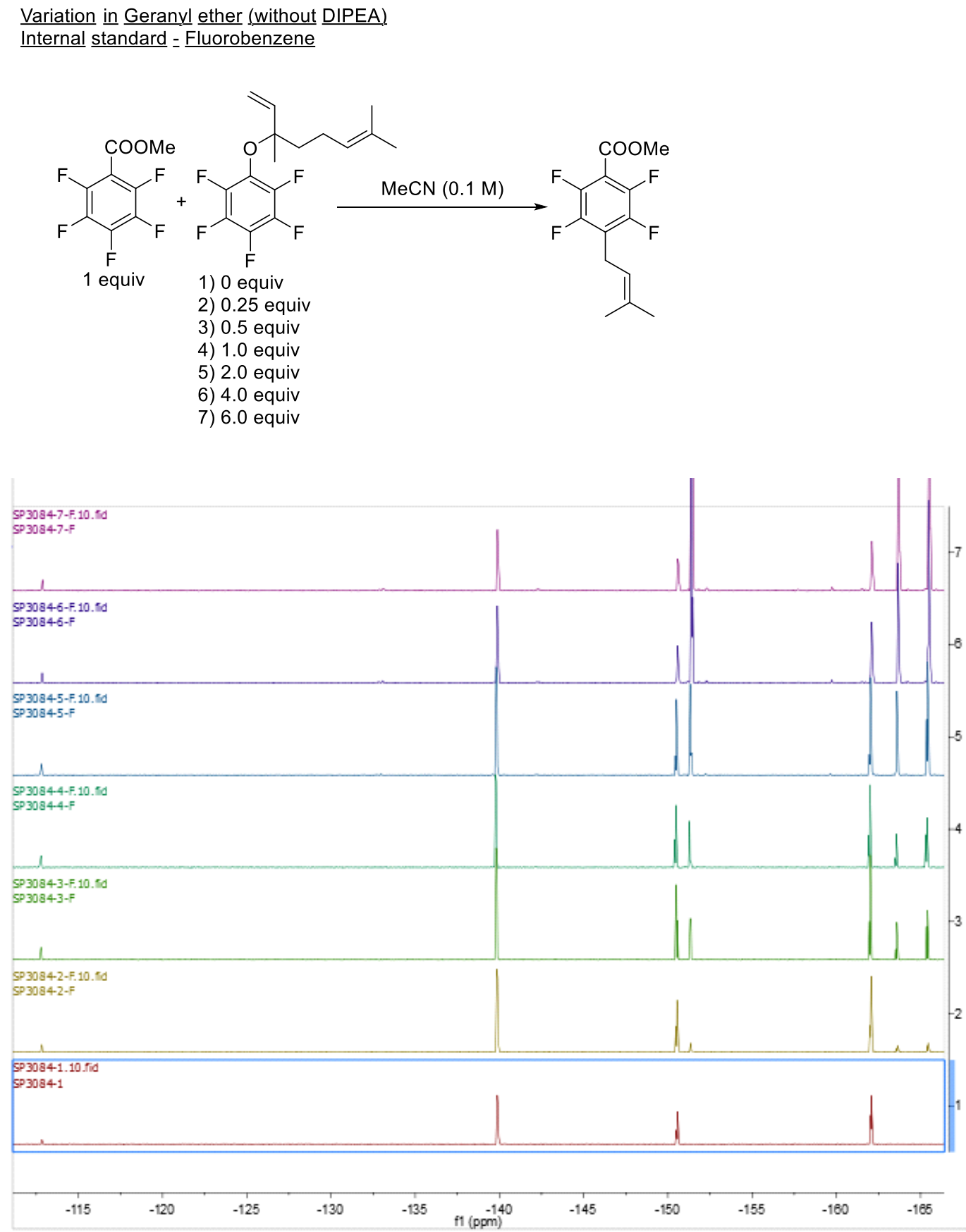

Figure 1.7: NMR titration experiments: variations in geranyl ether (without DIPEA) 
$\underline{\text { NMR }}$ Titrations $=$ Variation in Geranyl ether (with $\underline{\text { DIPEA) }}$

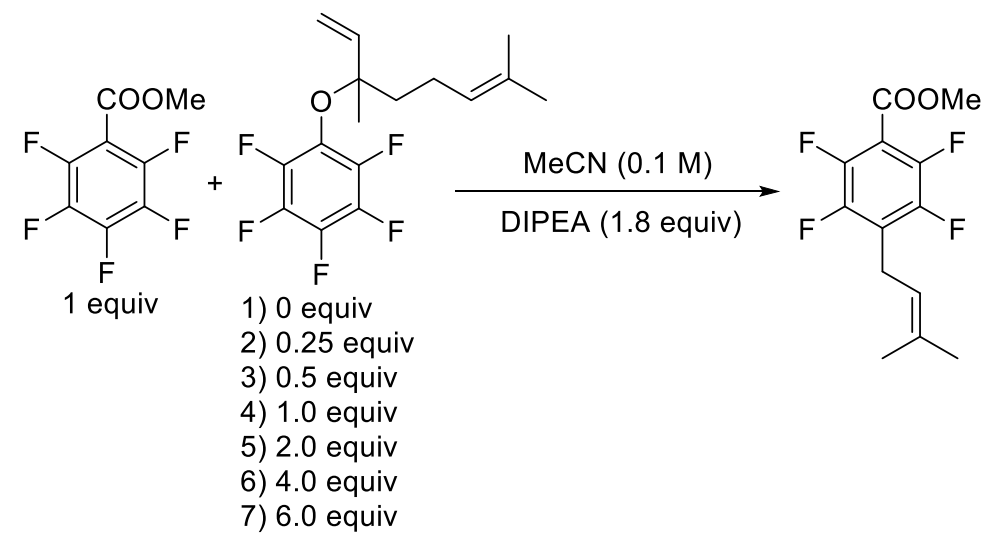

Internal standard - Monofluorobenzene

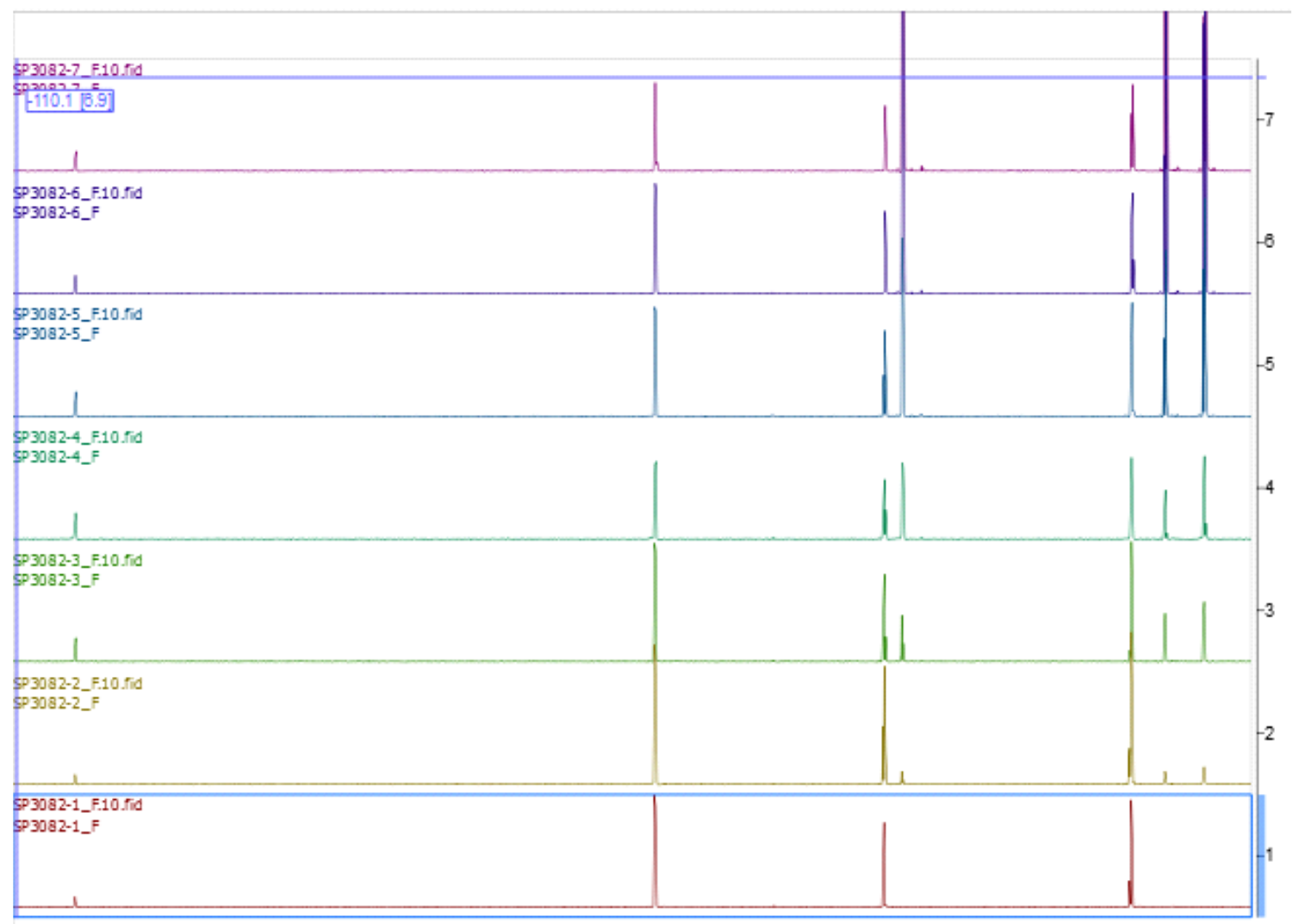

$10-112-114-116-118-120-122-124-128-128-130-132-134-138-138-140-142-144-148-148-150-152-154-158-158-180-182-184 \quad-168$

Figure 1.8: NMR titration experiments: variations in geranyl ether (with DIPEA) 
Variation in DIPEA

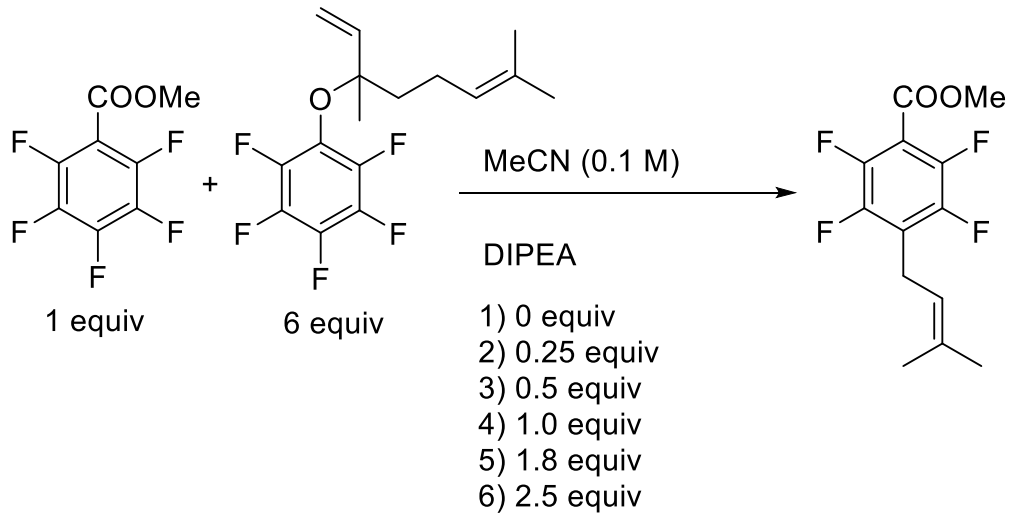

Internal standard - Monofluorobenzene

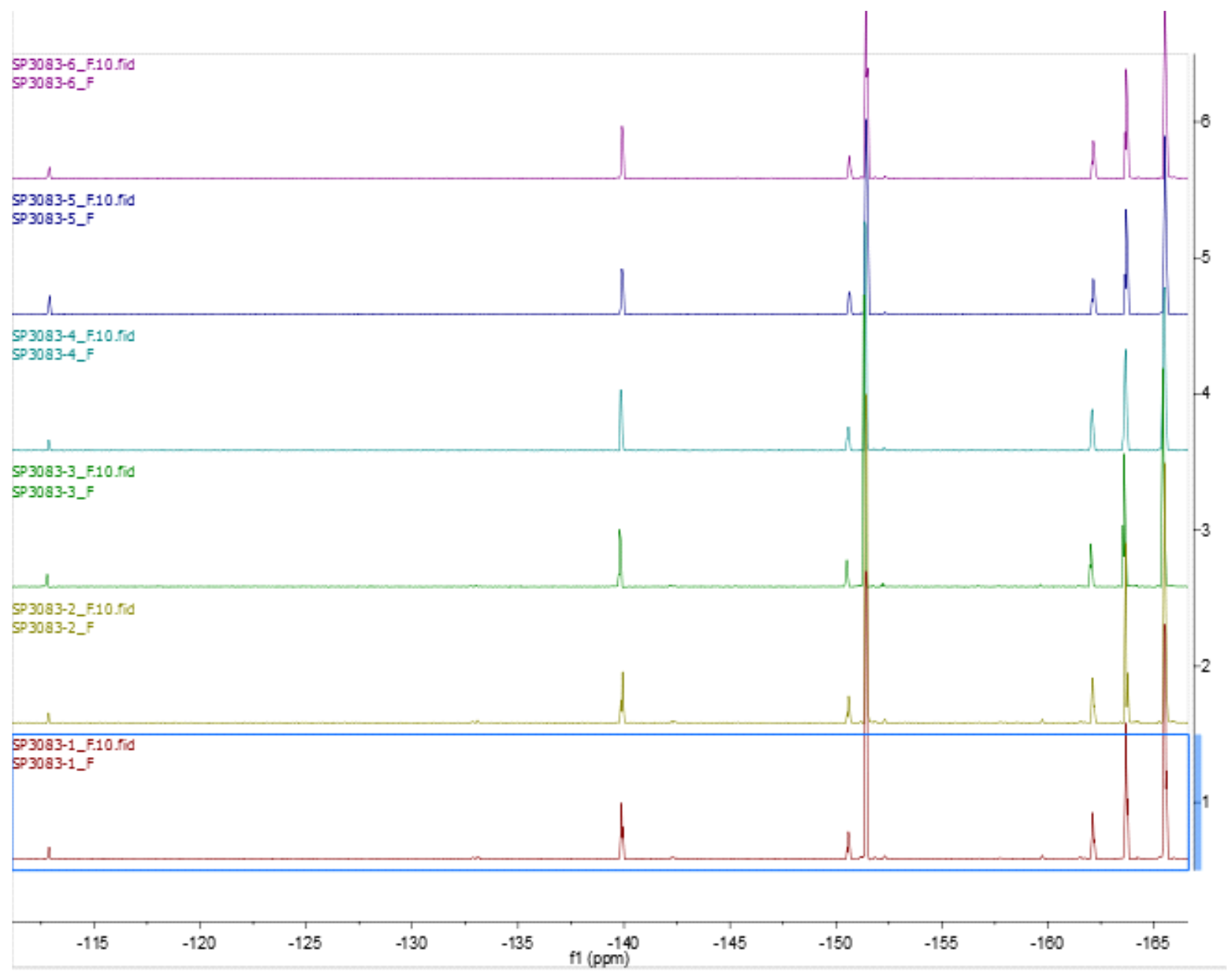

Figure 1.9: NMR titration experiments: variations in DIPEA 
Evidence for no post-reaction isomerization in geranylated products:

Table 1.17: Evidence for no post-reaction isomerization in geranylated products:

\begin{tabular}{|c|c|c|c|}
\hline Entry & $\begin{array}{l}\text { Conditions } \\
0.025 \mathrm{M} \mathrm{MeCN}\end{array}$ & $\begin{array}{l}\text { ortho-Ger enriched mixture } \\
\text { ortho:para ratio }{ }^{a}\end{array}$ & $\begin{array}{l}\text { para-Ger enriched mixture } \\
\text { ortho-para ratio }^{\mathrm{a}}\end{array}$ \\
\hline 1 & Mixtures at $22{ }^{\circ} \mathrm{C}, 3 \mathrm{~h}$ & $1: 0.65$ & $1: 0.96$ \\
\hline 2. & Mixtures heated to $45^{\circ} \mathrm{C}, 3 \mathrm{~h}$ & $1: 0.645$ & $1: 0.96$ \\
\hline 3. & $\begin{array}{l}\text { Mixtures, } 0.3 \mathrm{~mol} \% \text { fac- }-\operatorname{lr}(\mathrm{ppy})_{3} \\
\text { blue LEDs, } 3 \mathrm{~h} \text { in } 0{ }^{\circ} \mathrm{C}\end{array}$ & $1: 0.64$ & $1: 0.96$ \\
\hline 4. & $\begin{array}{l}\text { Mixtures, } 0.3 \mathrm{~mol} \% \text { fac-Ir(ppy })_{3} \\
\text { blue LEDs, } 3 \mathrm{~h} \text { in } 22^{\circ} \mathrm{C}\end{array}$ & 1:0.65 & 1:0.955 \\
\hline 5. & $\begin{array}{l}\text { Mixtures, } 0.3 \mathrm{~mol} \% \text { fac- }-\mathrm{Ir}(\mathrm{ppy})_{3} \\
\text { blue LEDs, } 3 \mathrm{~h} \text { in } 45^{\circ} \mathrm{C}\end{array}$ & $1: 0.645$ & 1:0.965 \\
\hline \multicolumn{4}{|c|}{ ( ${ }^{\mathrm{a} D e t e r m i n e d}$ by integration of the ${ }^{19} \mathrm{~F}$ NMR signal at -134.4 and $-143.1 \mathrm{ppm}$ after normalization) } \\
\hline \multicolumn{4}{|c|}{ In order to check for post-reaction isomerization of geranylated products, while we were not able } \\
\hline \multicolumn{4}{|c|}{ to completely resolve these isomers, we were able to collect samples enriched in one or the other } \\
\hline \multicolumn{4}{|c|}{ isomers after chromatography by taking early and late fractions. When we re-subjected the } \\
\hline \multicolumn{4}{|c|}{ enriched mixtures to a number of conditions (see above), we saw that the ratio never } \\
\hline chang & ed. This is clear evidence that th & he selectivity is a kinetic ph & henon and not subj \\
\hline
\end{tabular}




\section{1. ortho-Ger enriched mixture}

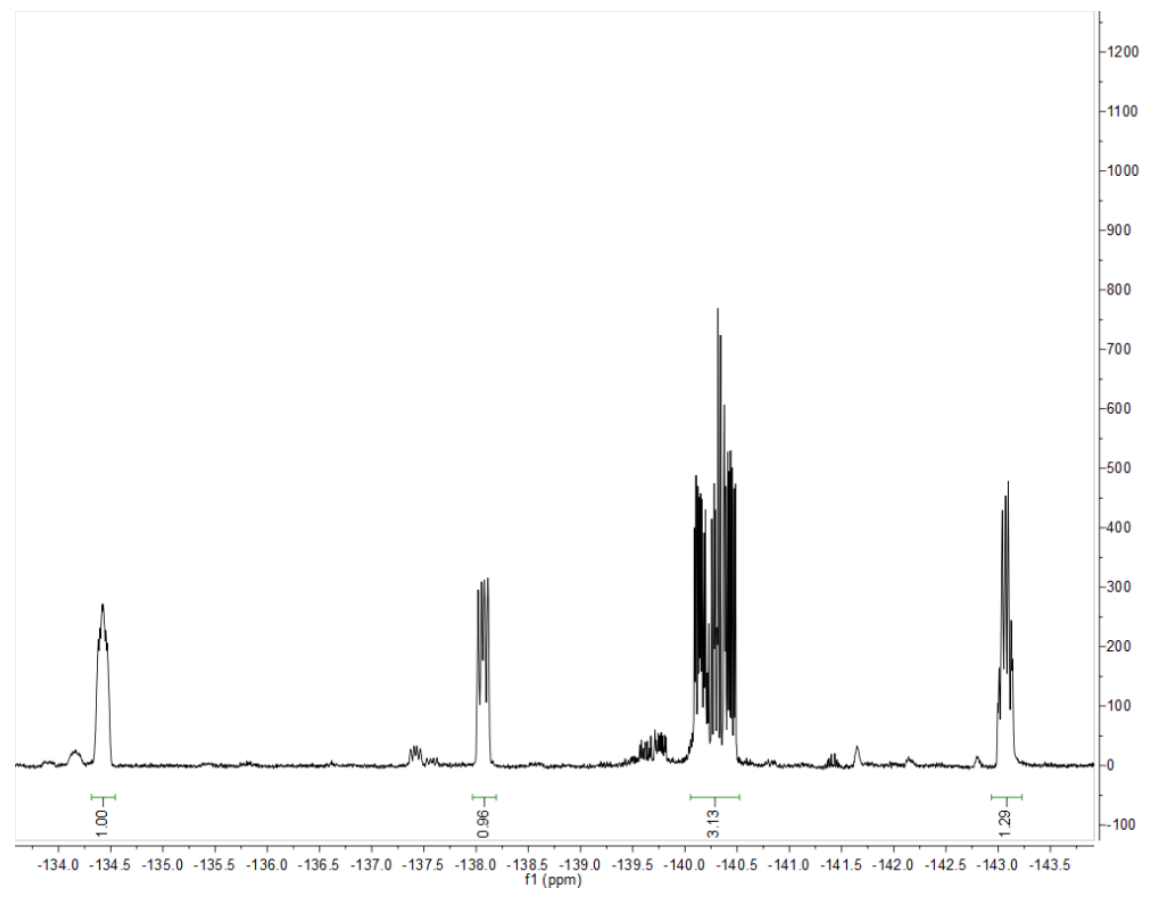

2.

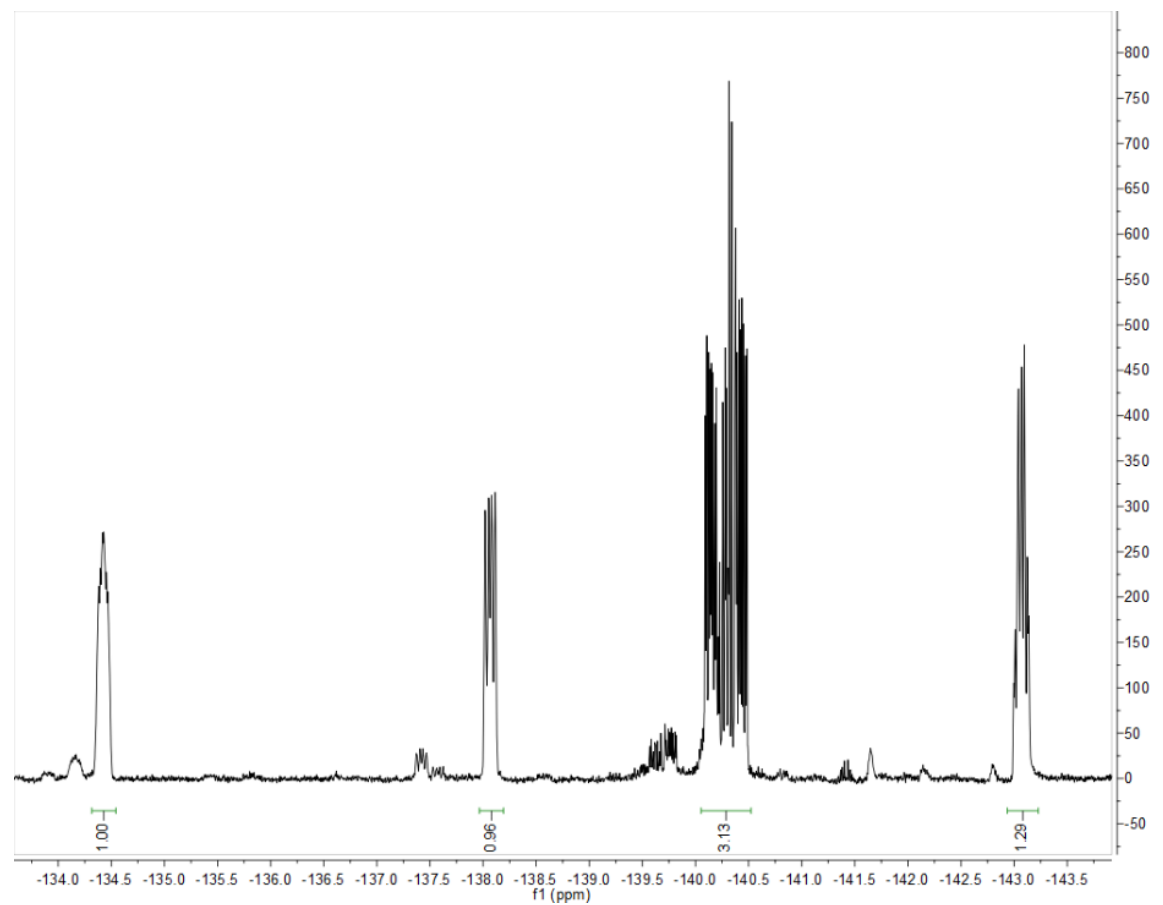


3.

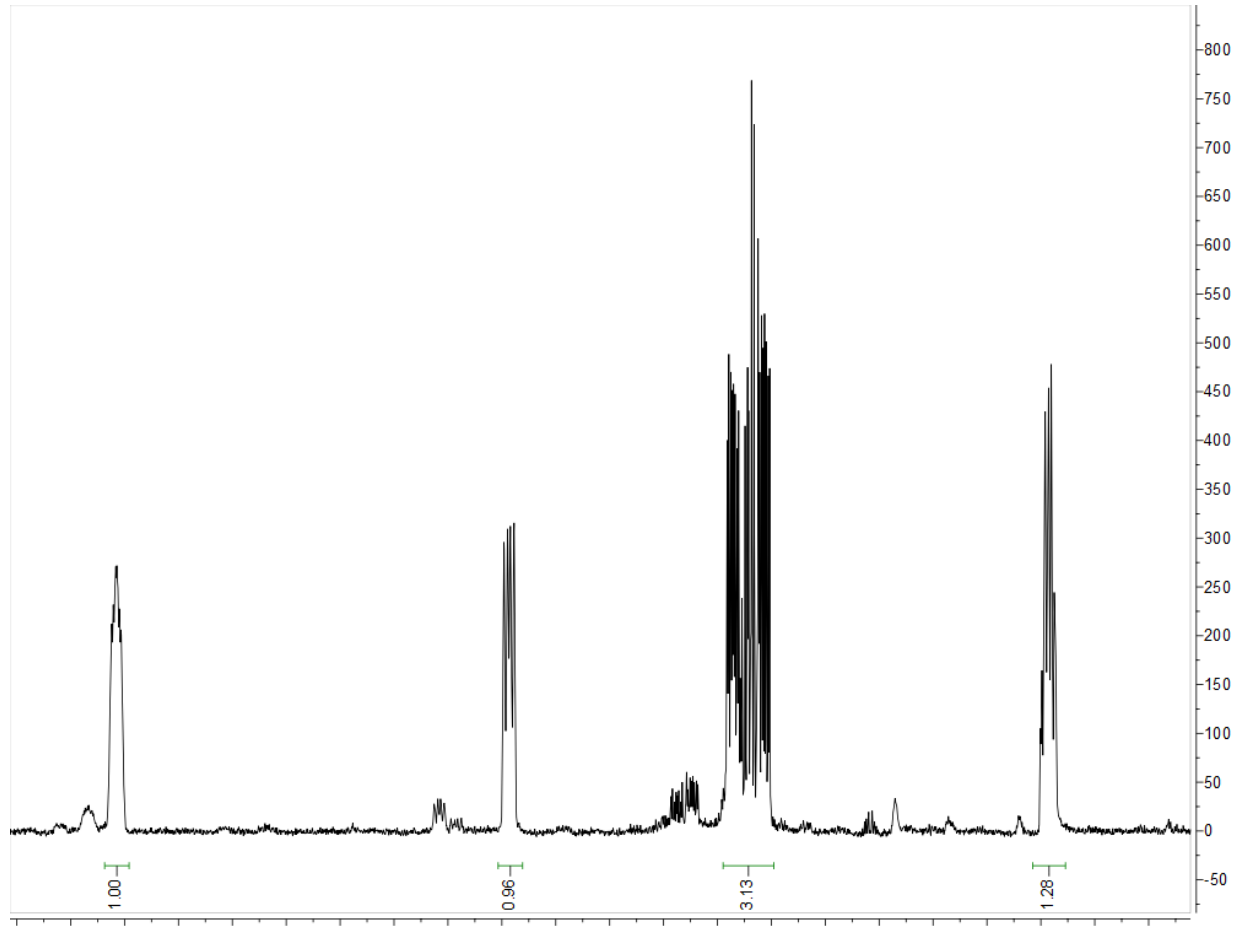

$33.5-134.0-134.5-135.0-135.5-136.0-136.5-137.0-137.5-138.0-138 .+11$ (ppm)

4.

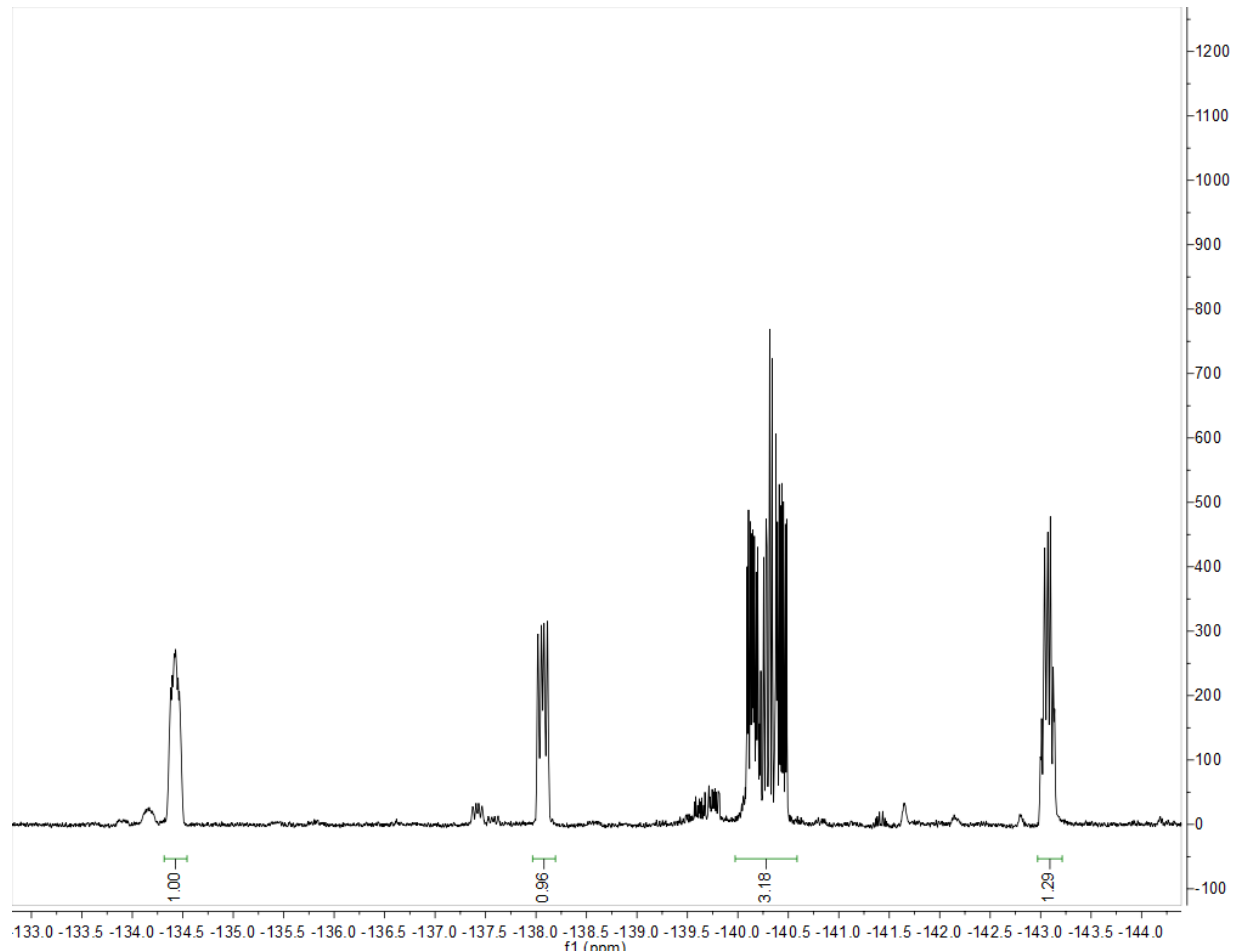


5.

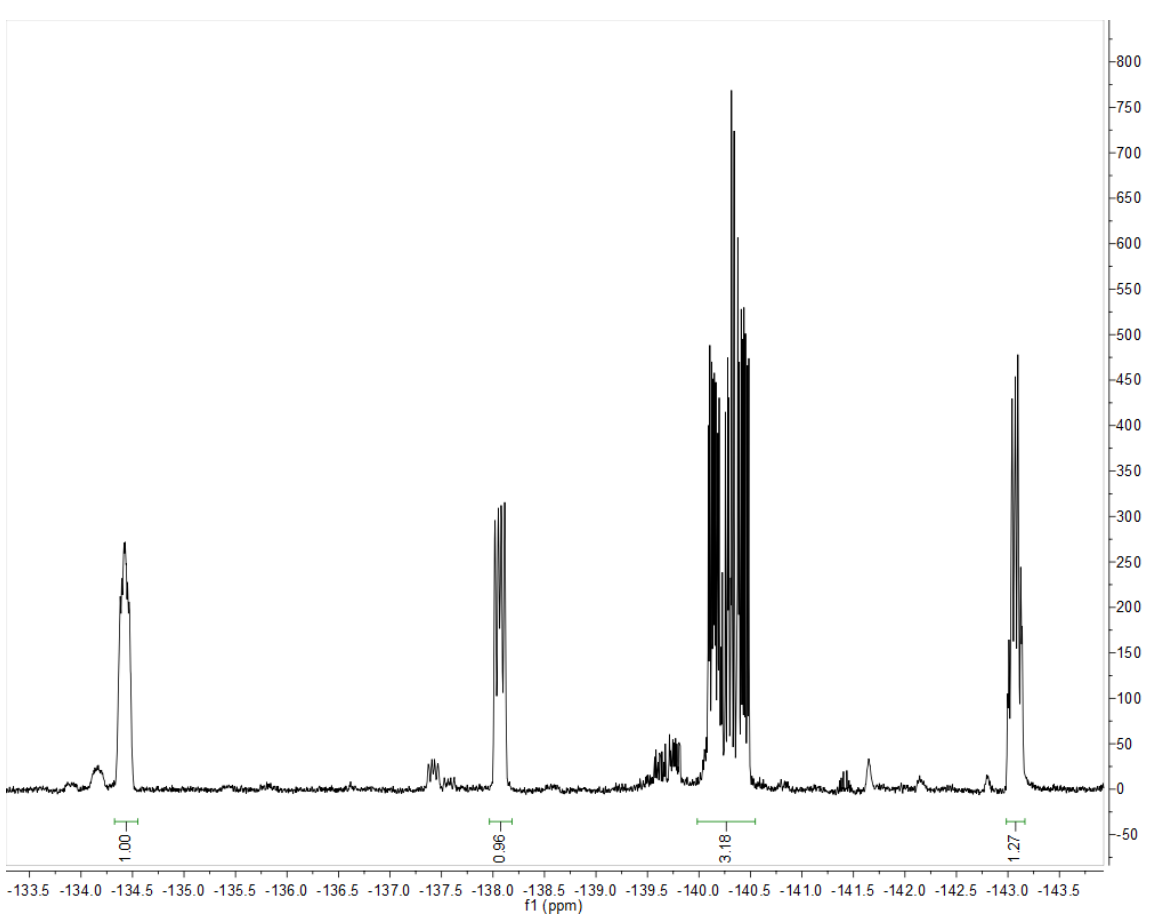

Figure 1.10: ortho-Ger enriched mixture

\section{1. para-Ger enriched mixture}

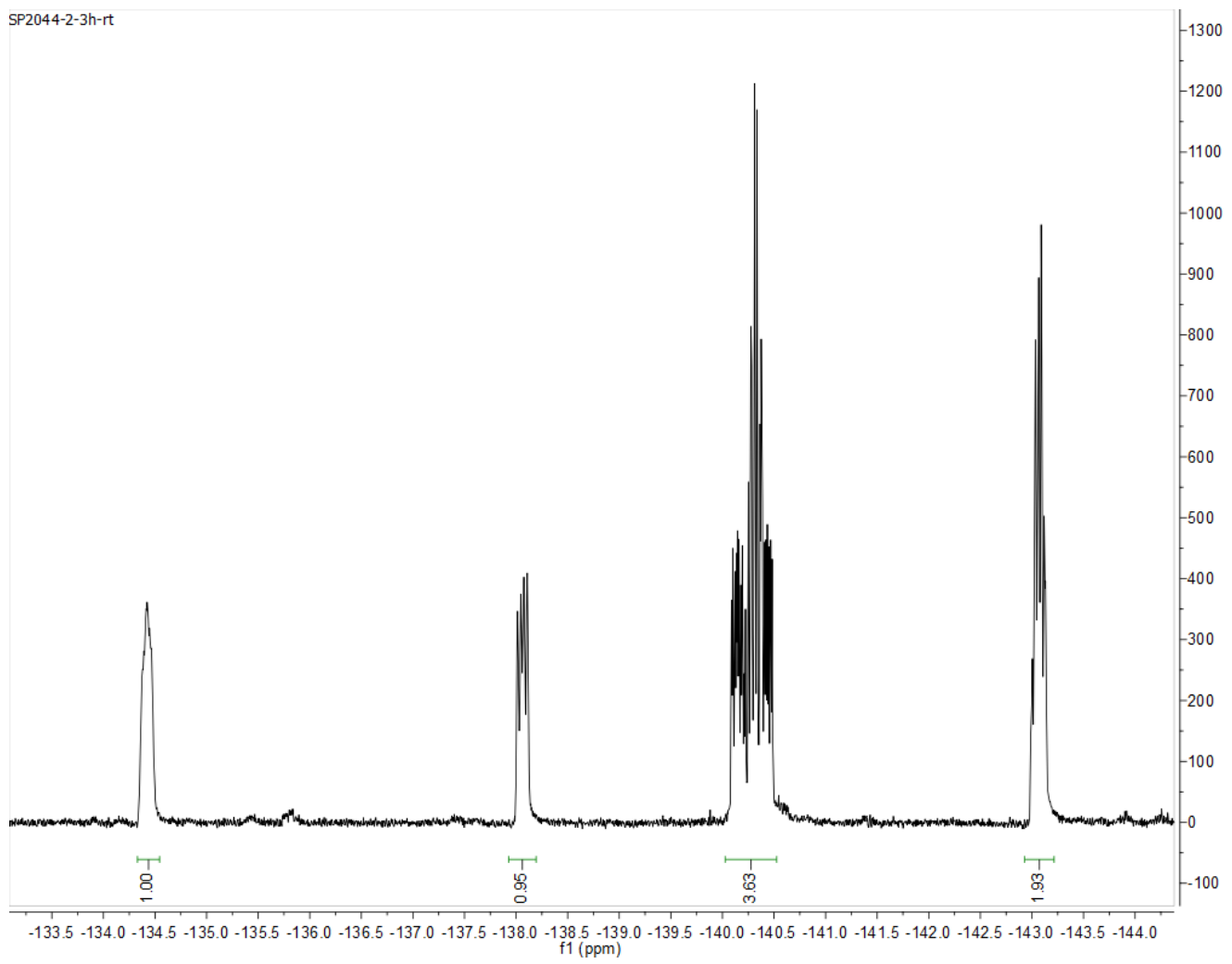


2.

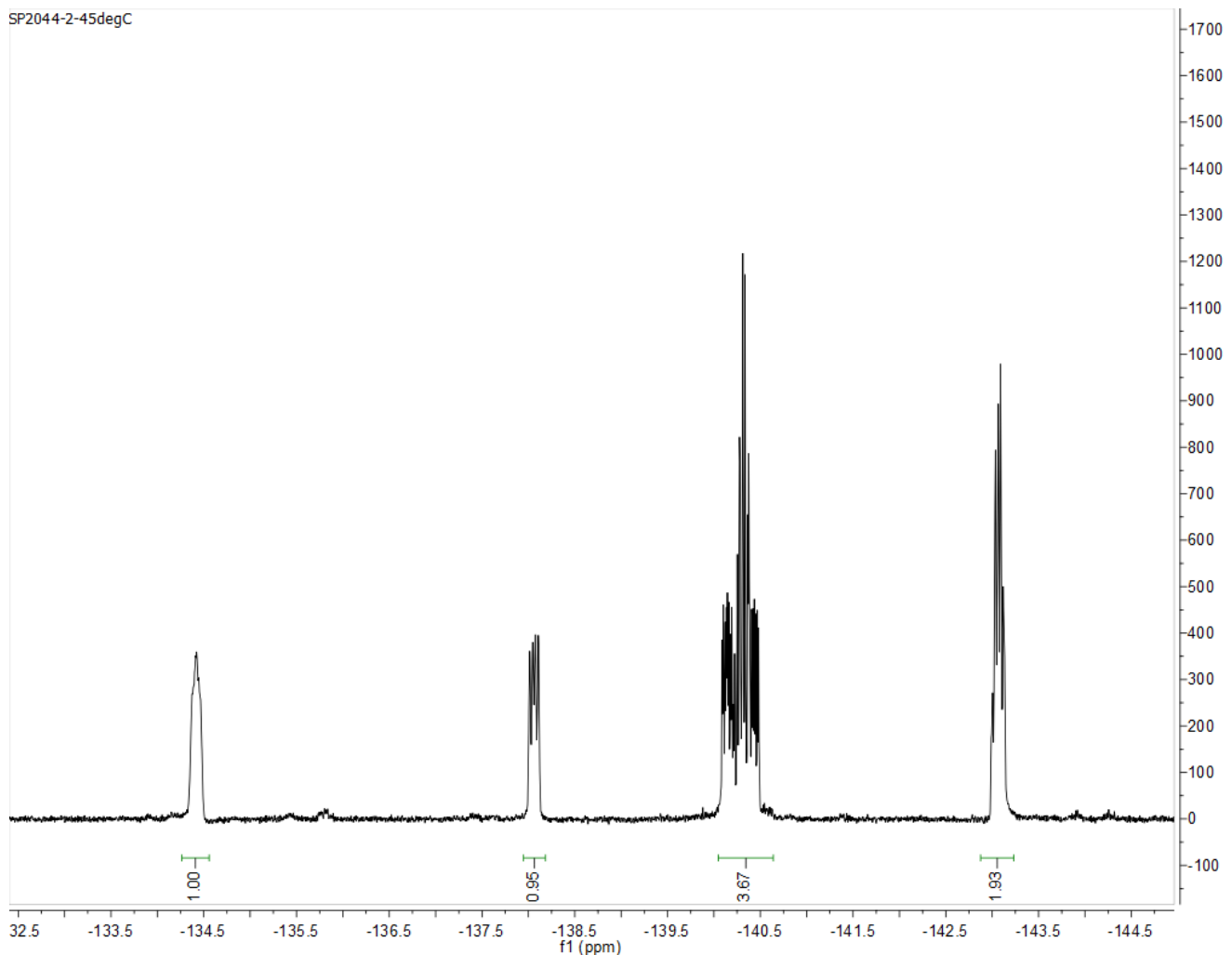

3.

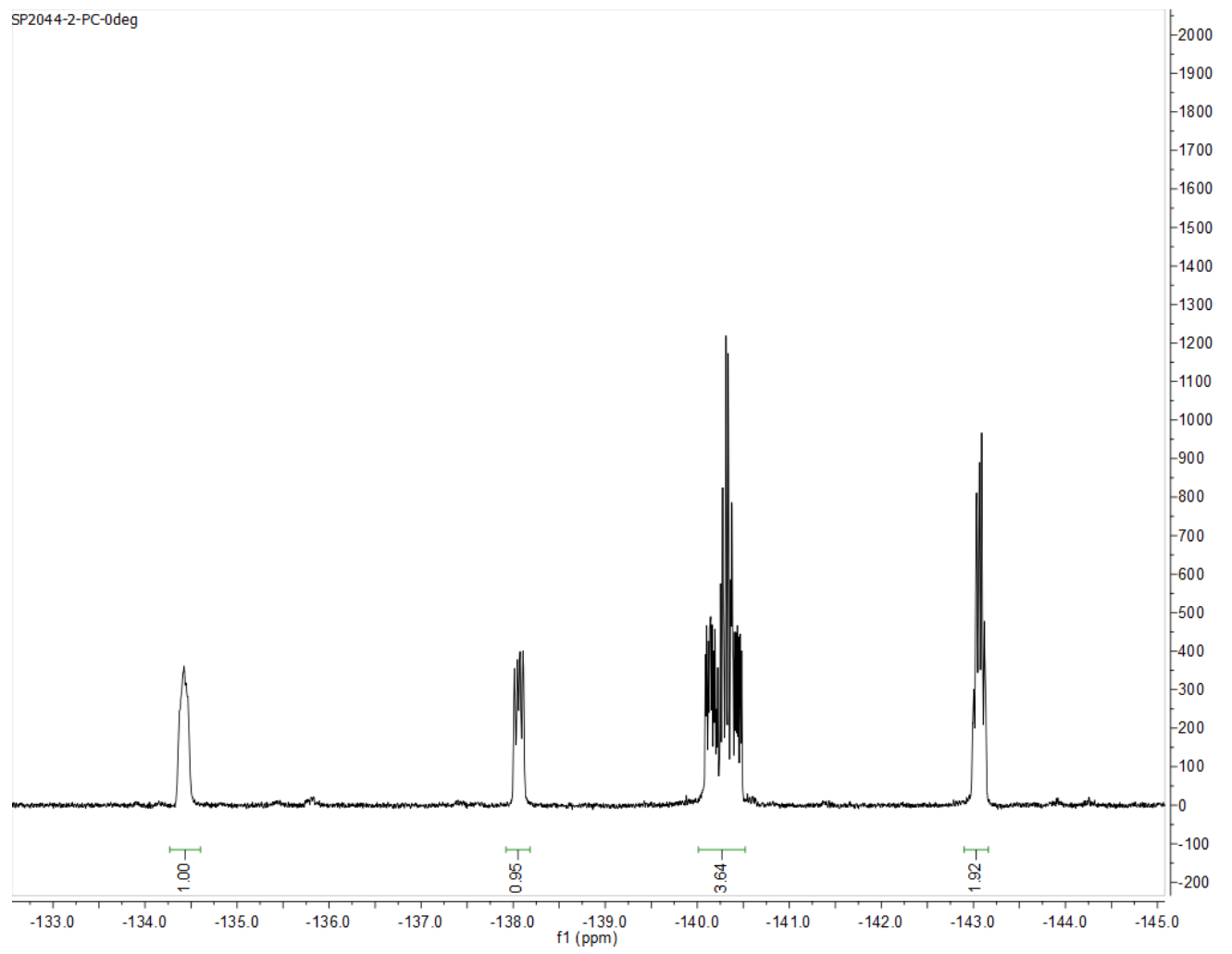


4.

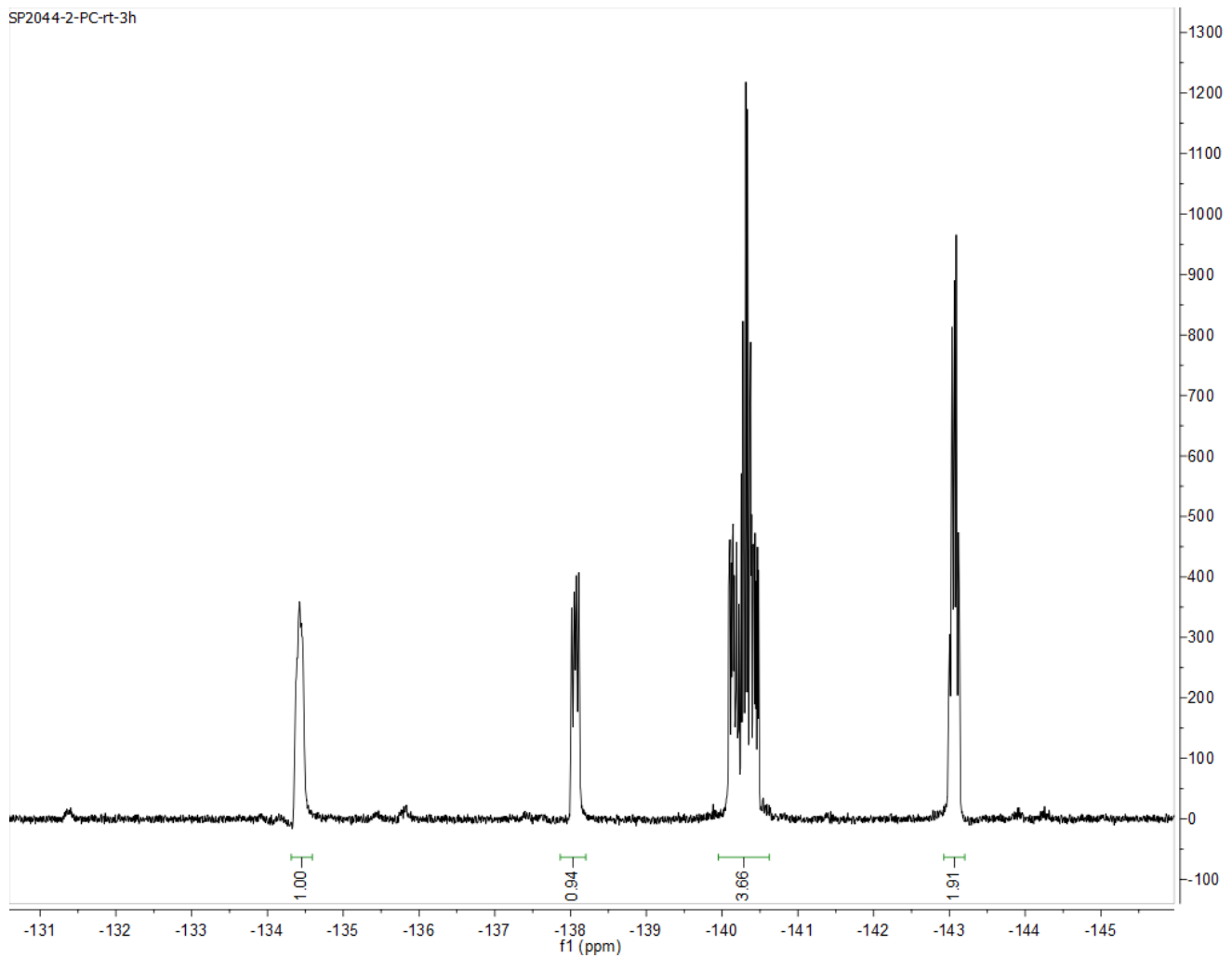

5.

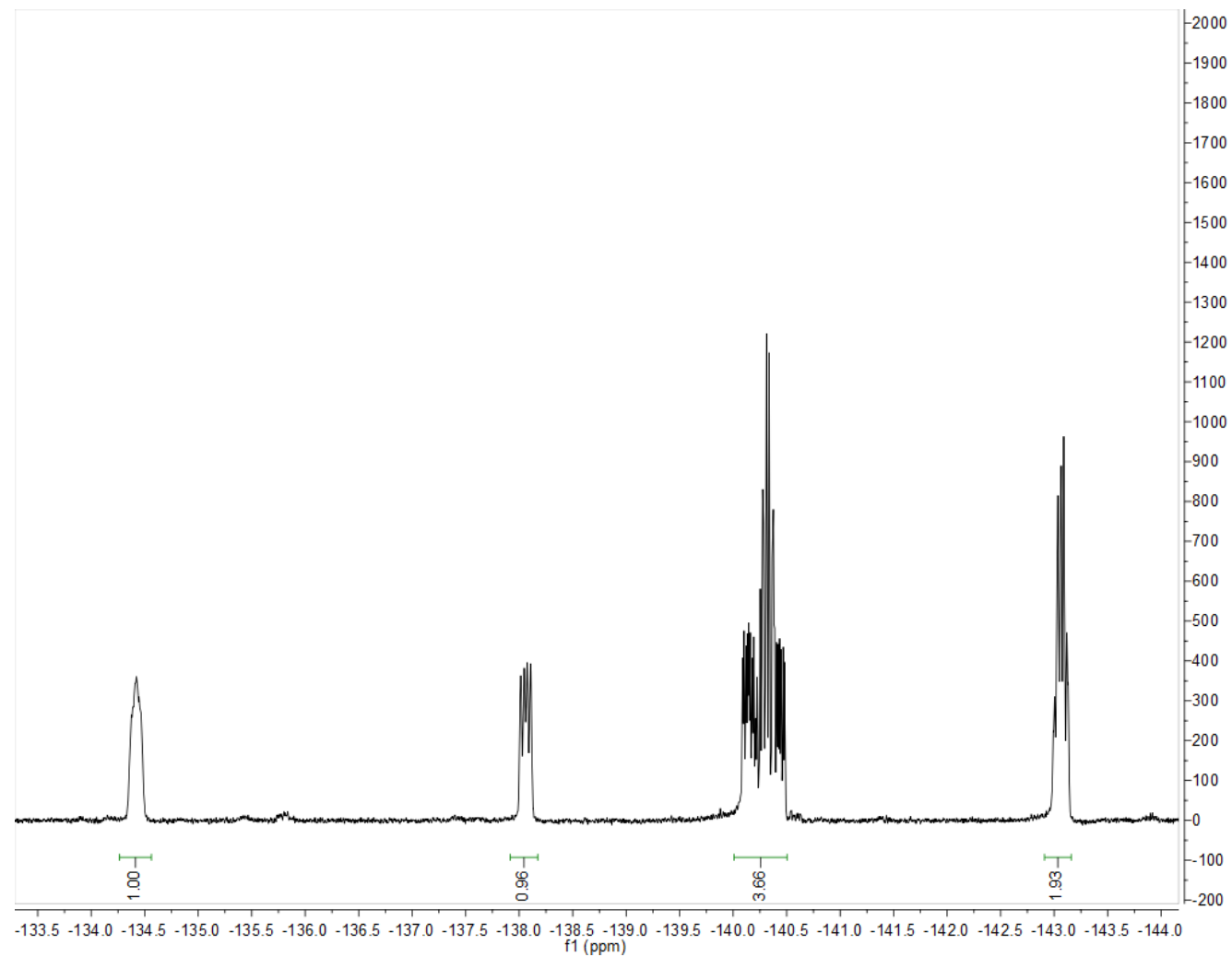

Figure 1.11: para-Ger enriched mixture 
${ }^{19} \mathrm{~F}$ NMR (376 MHz, CDCl3, at rt) spectrum of methyl 4-allyl-2,3,5,6-tetrafluorobenzoate (5a)

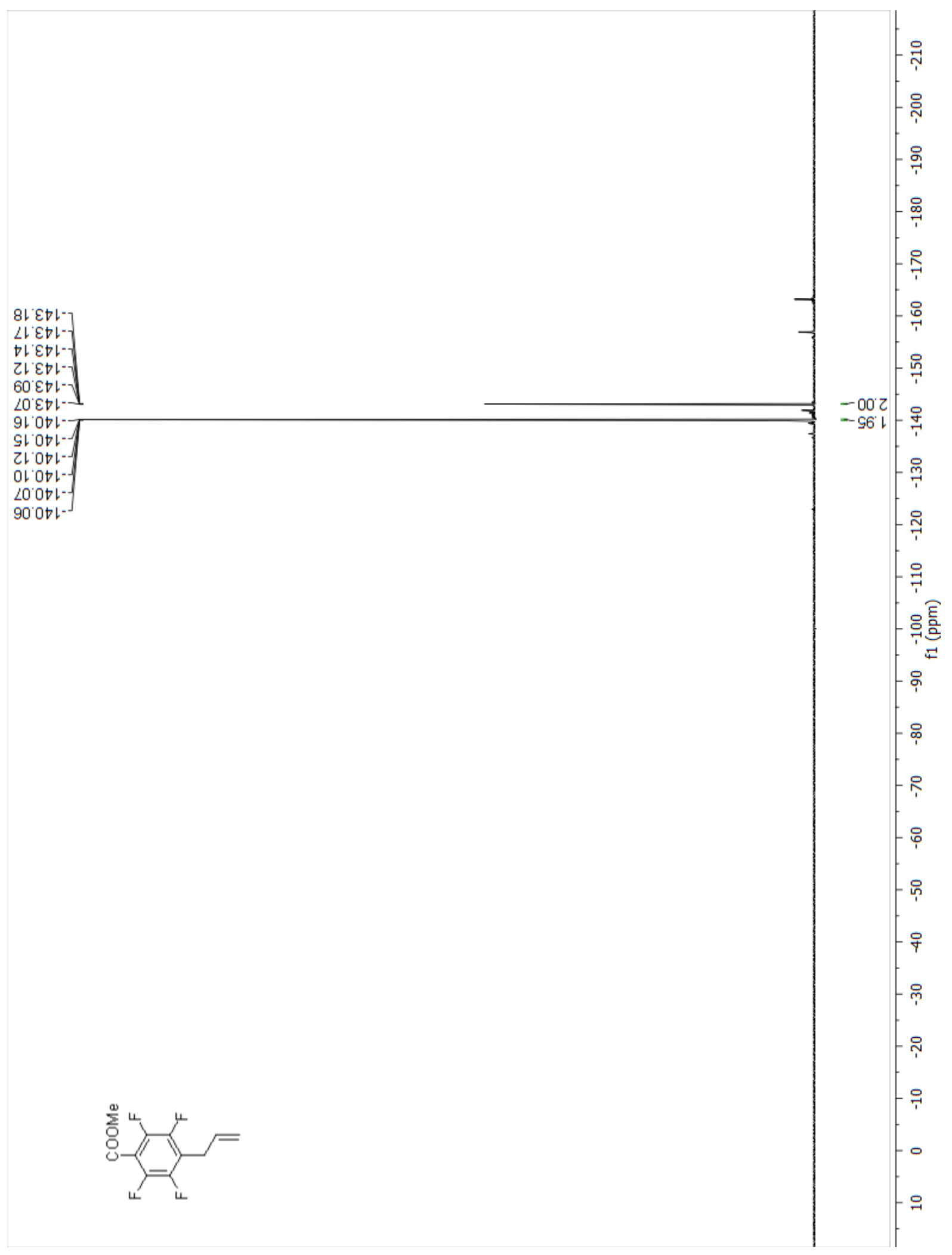


${ }^{1} \mathrm{H}$ NMR (400 MHz, CDCl3, at rt) spectrum of methyl 4-allyl-2,3,5,6-tetrafluorobenzoate (5a)

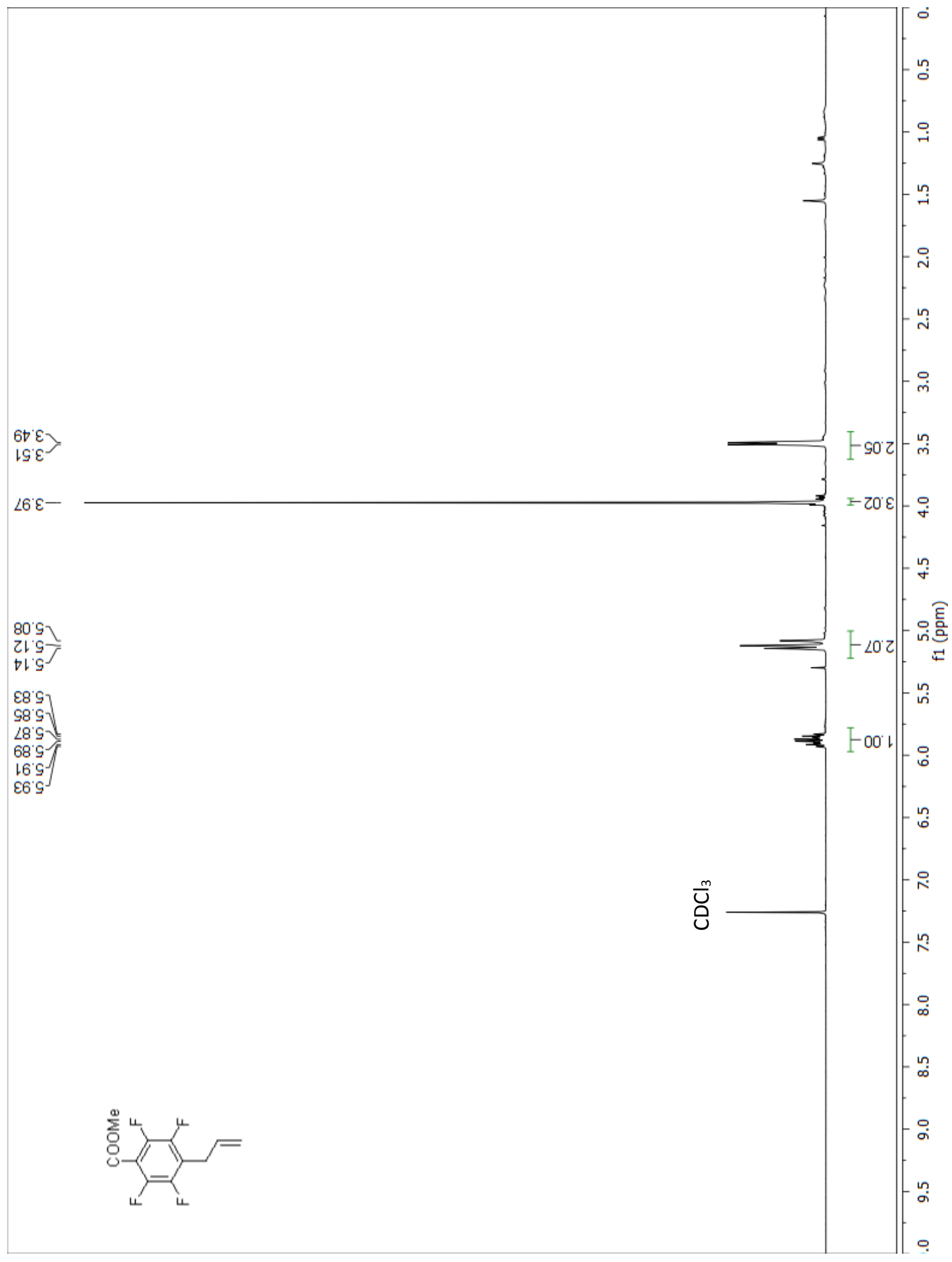


${ }^{13} \mathrm{C}$ NMR (101 MHz, CDCl3, at rt) spectrum of methyl 4-allyl-2,3,5,6-tetrafluorobenzoate (5a)

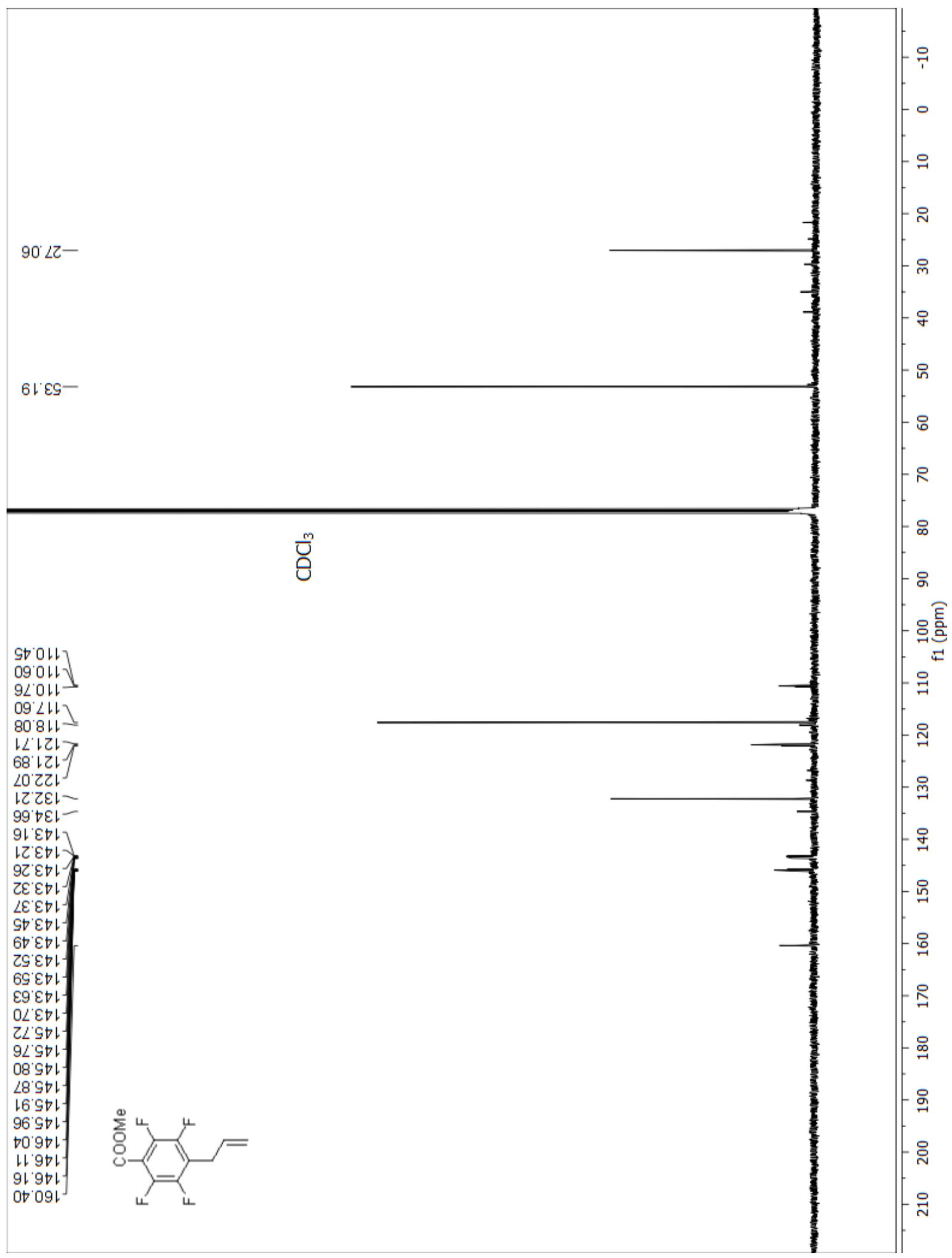


GC and MS of methyl 4-allyl-2,3,5,6-tetrafluorobenzoate (5a)
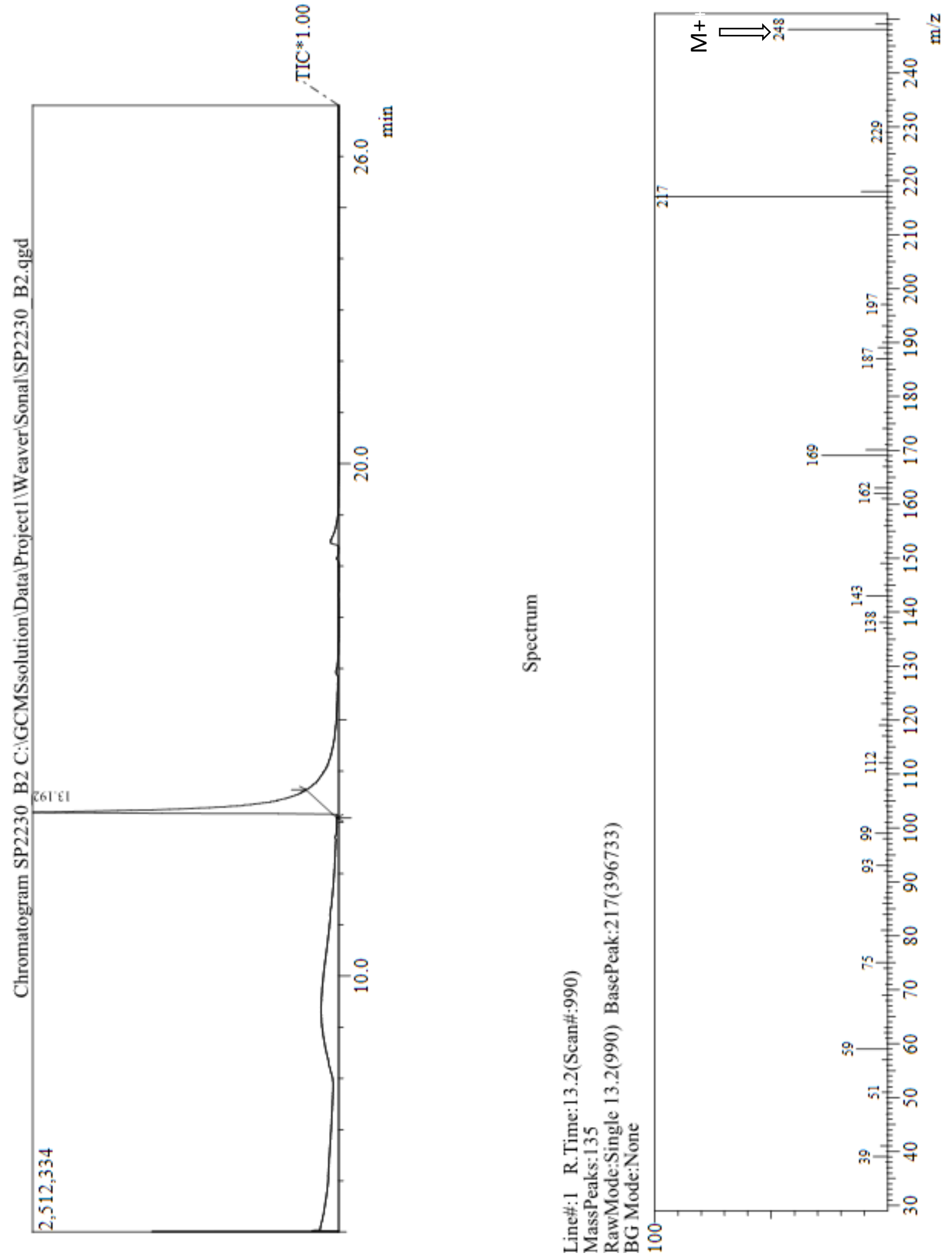
${ }^{19} \mathrm{~F}$ NMR $(376 \mathrm{MHz}, \mathrm{CDCl} 3$, at rt) spectrum of 4-allyl-2,3,5,6-tetrafluorobenzonitrile (5b)

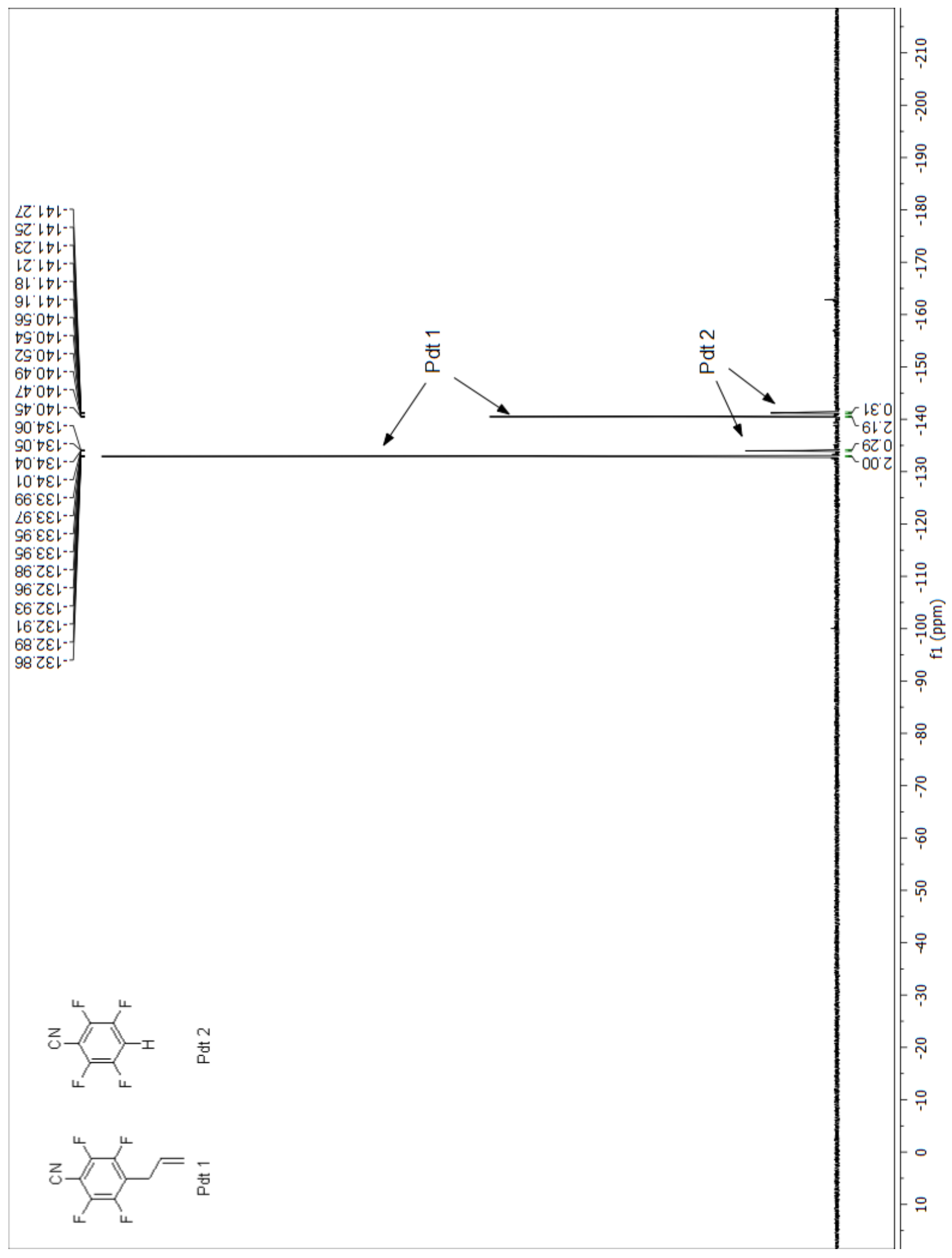


${ }^{1} \mathrm{H}$ NMR (400 MHz, $\mathrm{CDCl} 3$, at rt) spectrum of 4-allyl-2,3,5,6-tetrafluorobenzonitrile (5b)

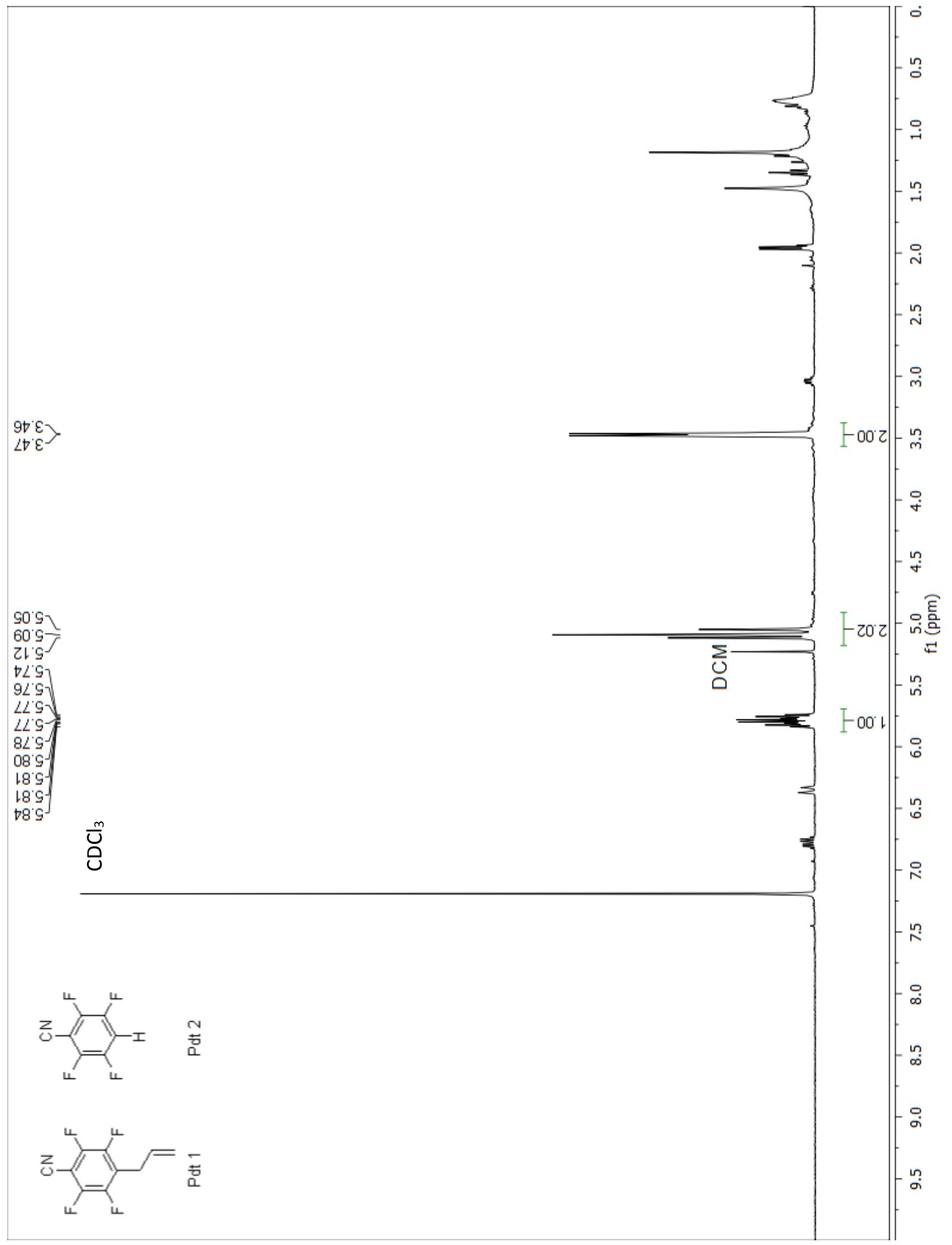


GC and MS of 4-allyl-2,3,5,6-tetrafluorobenzonitrile (5b)
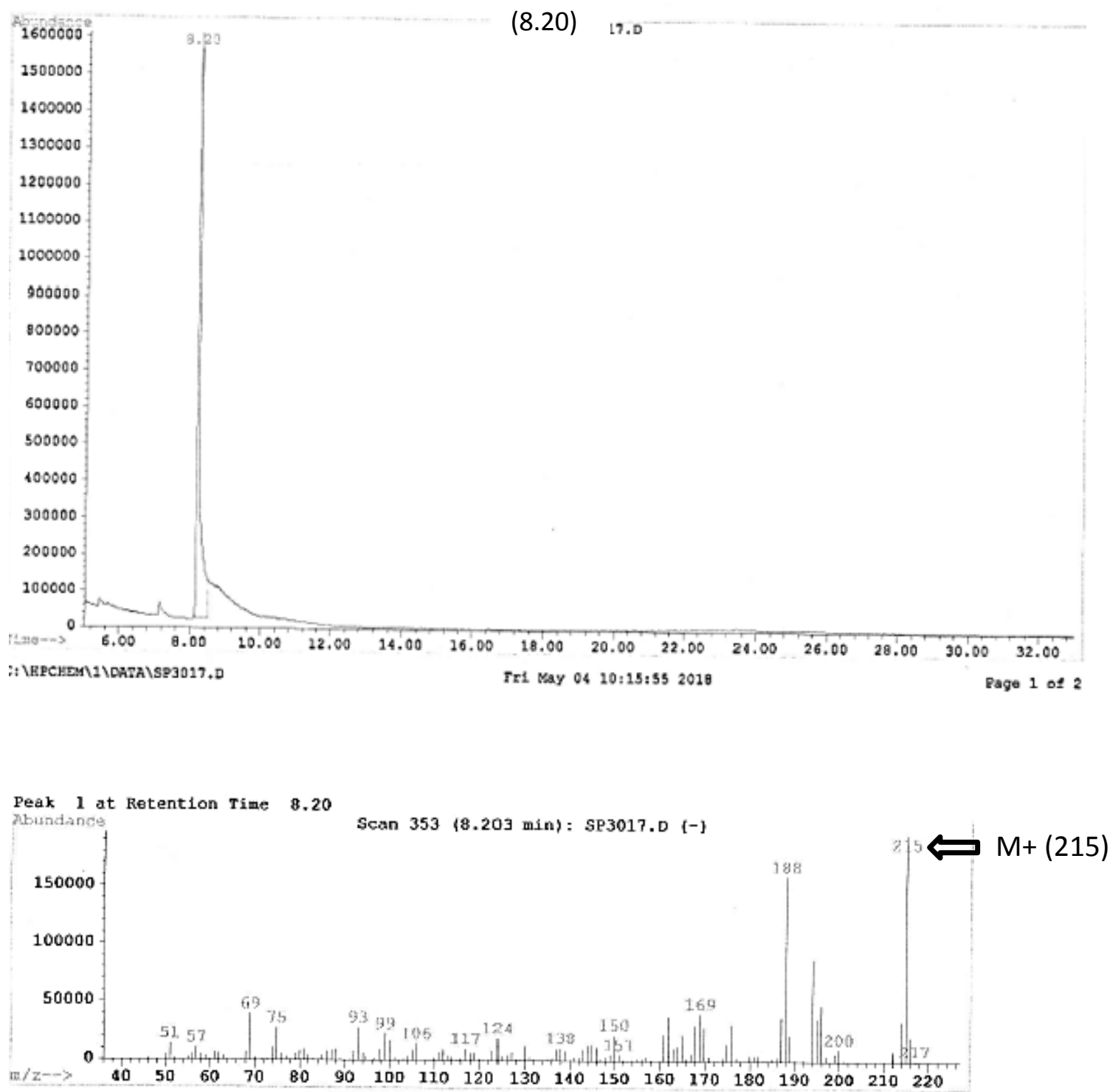
${ }^{19} \mathrm{~F}$ NMR (376 MHz, CDCl3, at rt) spectrum of methyl 2,3,5,6-tetrafluoro-4-(2-

methylallyl)benzoate (5c)

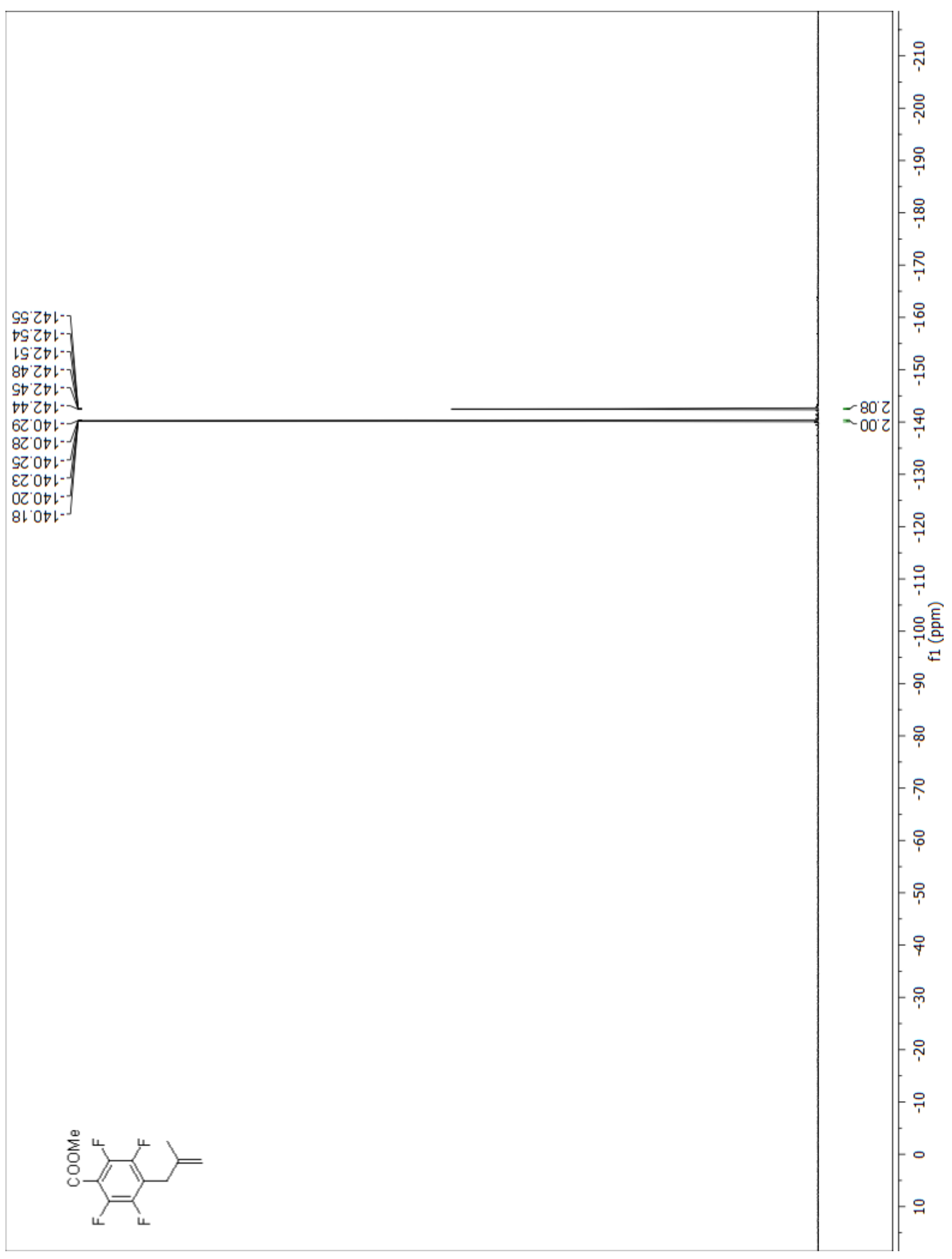


${ }^{1} \mathrm{H}$ NMR (400 MHz, CDCl3, at rt) spectrum of methyl 2,3,5,6-tetrafluoro-4-(2-

methylallyl)benzoate (5c)

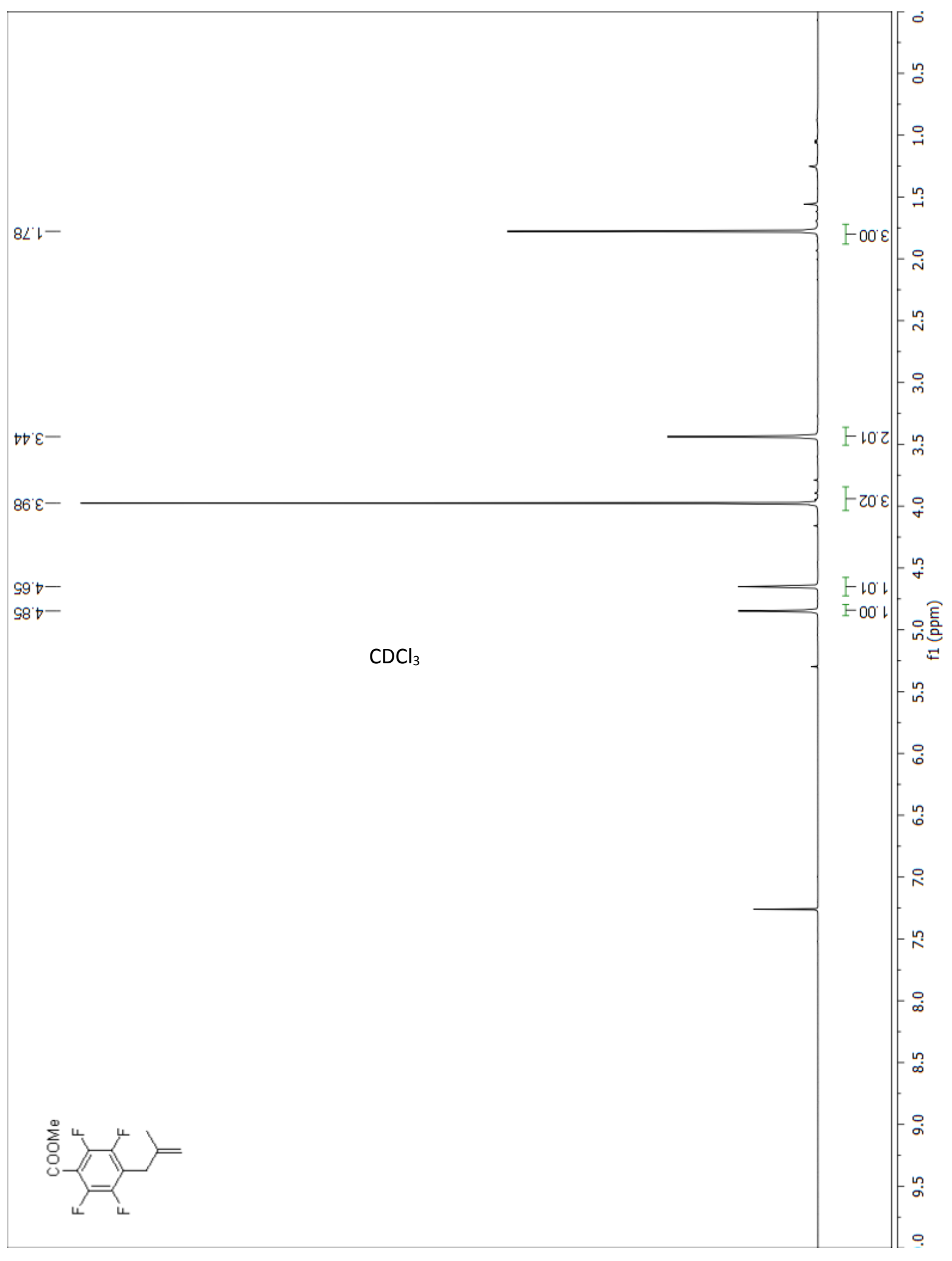


${ }^{13} \mathrm{C}$ NMR (101 MHz, CDCl3, at rt) spectrum of methyl 2,3,5,6-tetrafluoro-4-(2-

methylallyl)benzoate (5c)

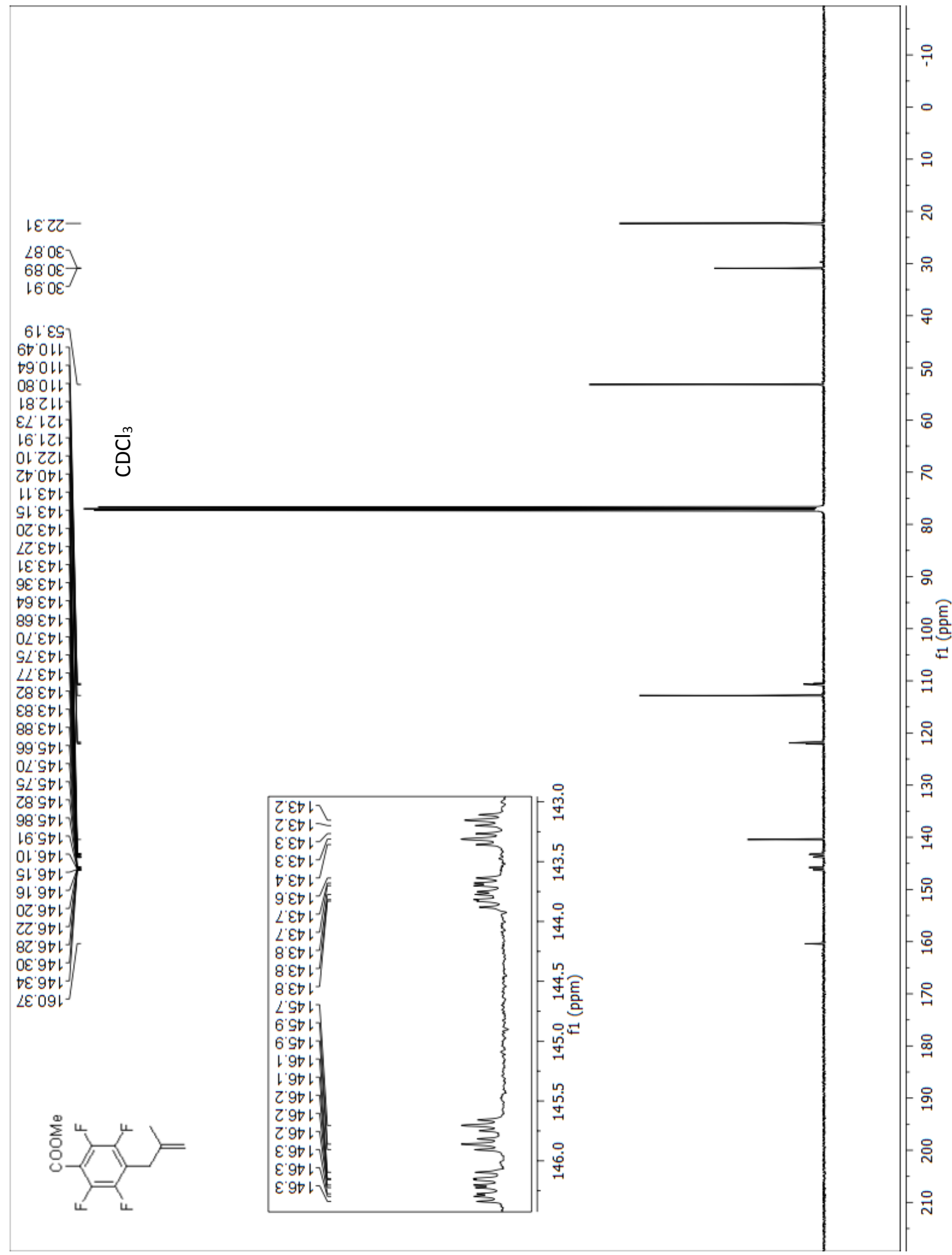


GC and MS of methyl 2,3,5,6-tetrafluoro-4-(2-methylallyl)benzoate (5c)

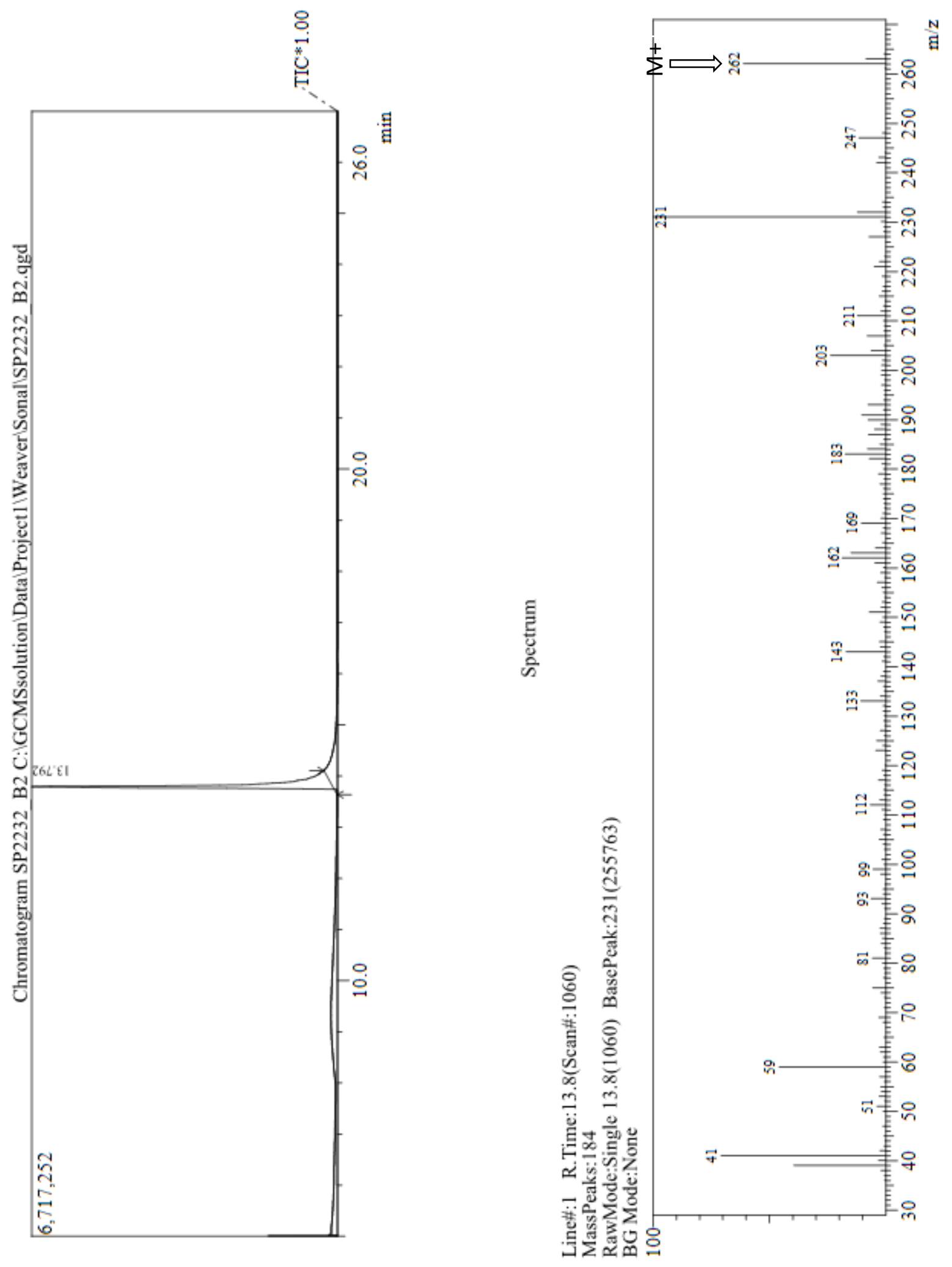


${ }^{19}$ F NMR (376 MHz, CDCl3, at rt) spectrum of 2,3,5,6-tetrafluoro-4-(2methylallyl)benzonitrile (5d)

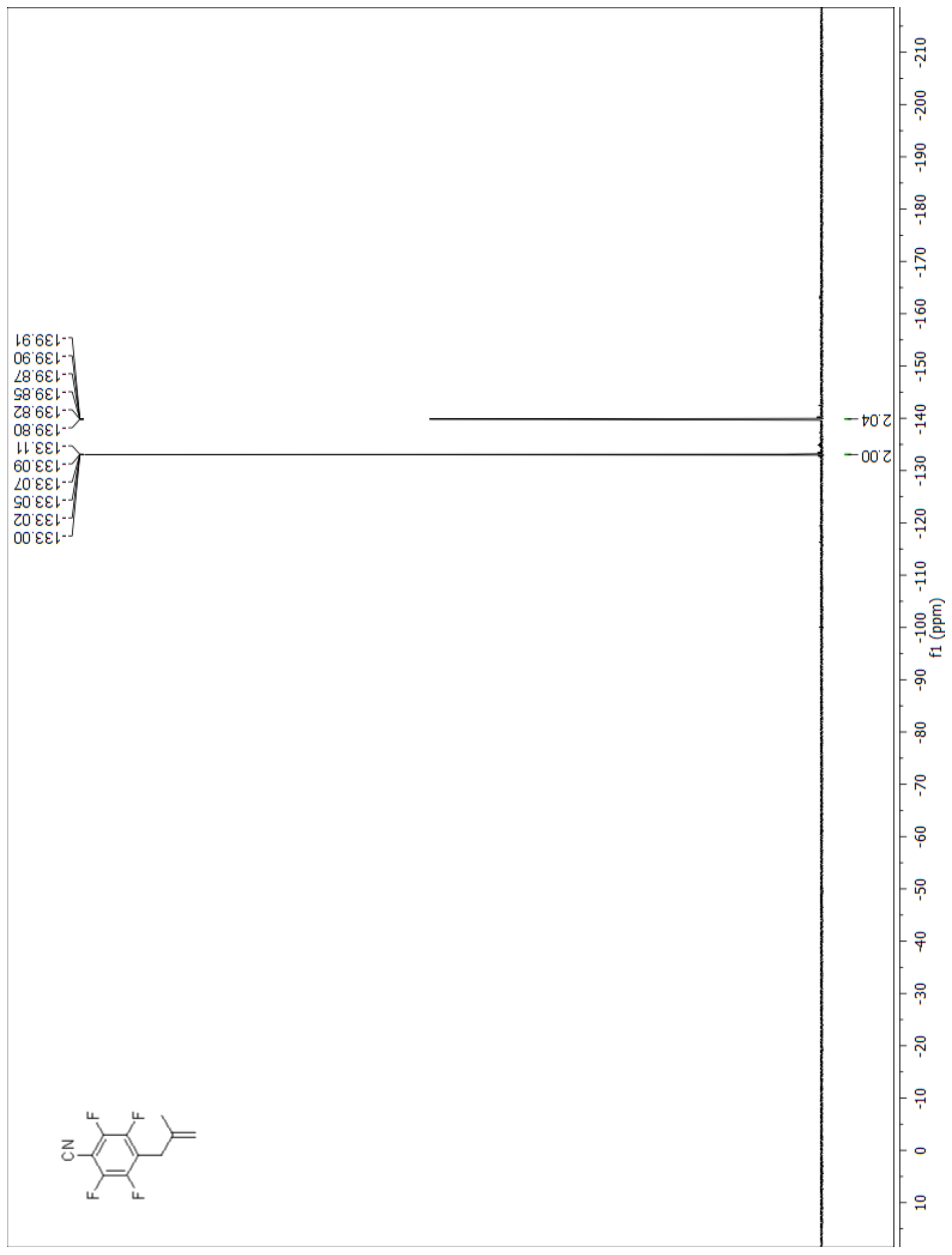


${ }^{1} \mathrm{H}$ NMR (400 MHz, CDCl3, at rt) spectrum of 2,3,5,6-tetrafluoro-4-(2-

methylallyl)benzonitrile (5d)

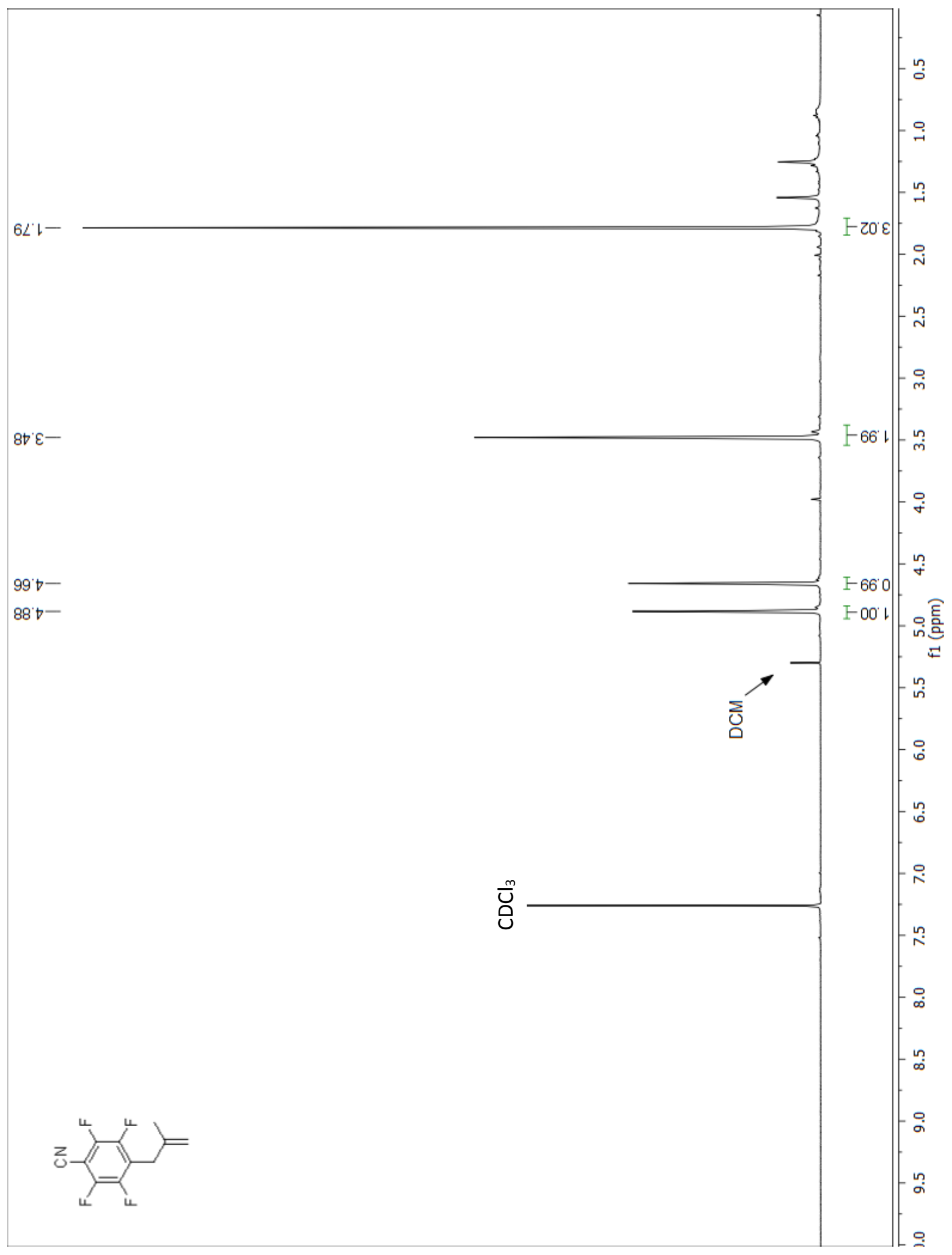


${ }^{13}$ C NMR (101 MHz, CDCl3, at rt) spectrum of 2,3,5,6-tetrafluoro-4-(2-

methylallyl)benzonitrile (5d)

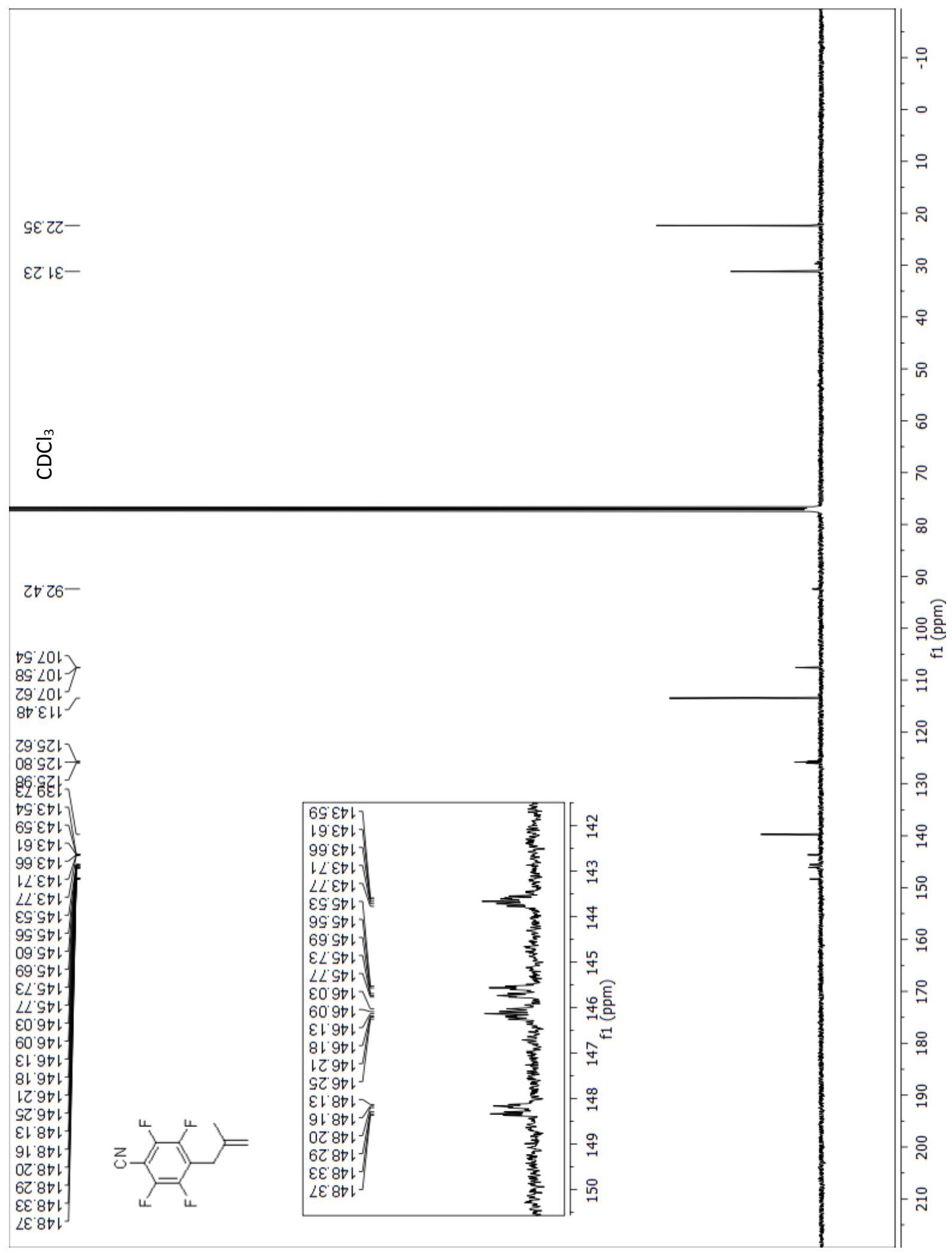


GC and MS of 2,3,5,6-tetrafluoro-4-(2-methylallyl)benzonitrile (5d)
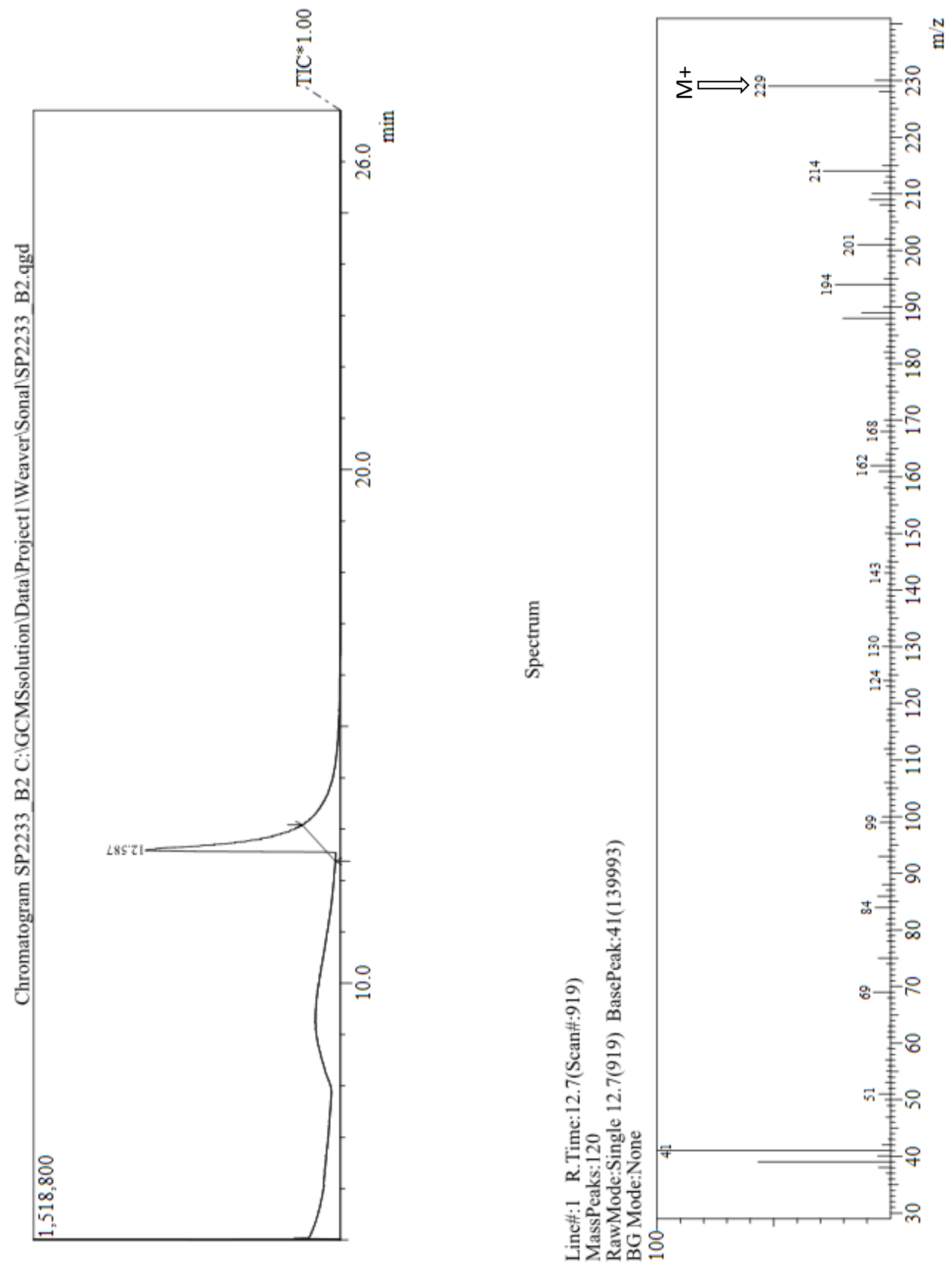
${ }^{19} \mathrm{~F}$ NMR (376 MHz, CDCl3, at rt) spectrum of methyl 4-(2-cyclohexylideneethyl)-2,3,5,6-

tetrafluorobenzoate (5e)

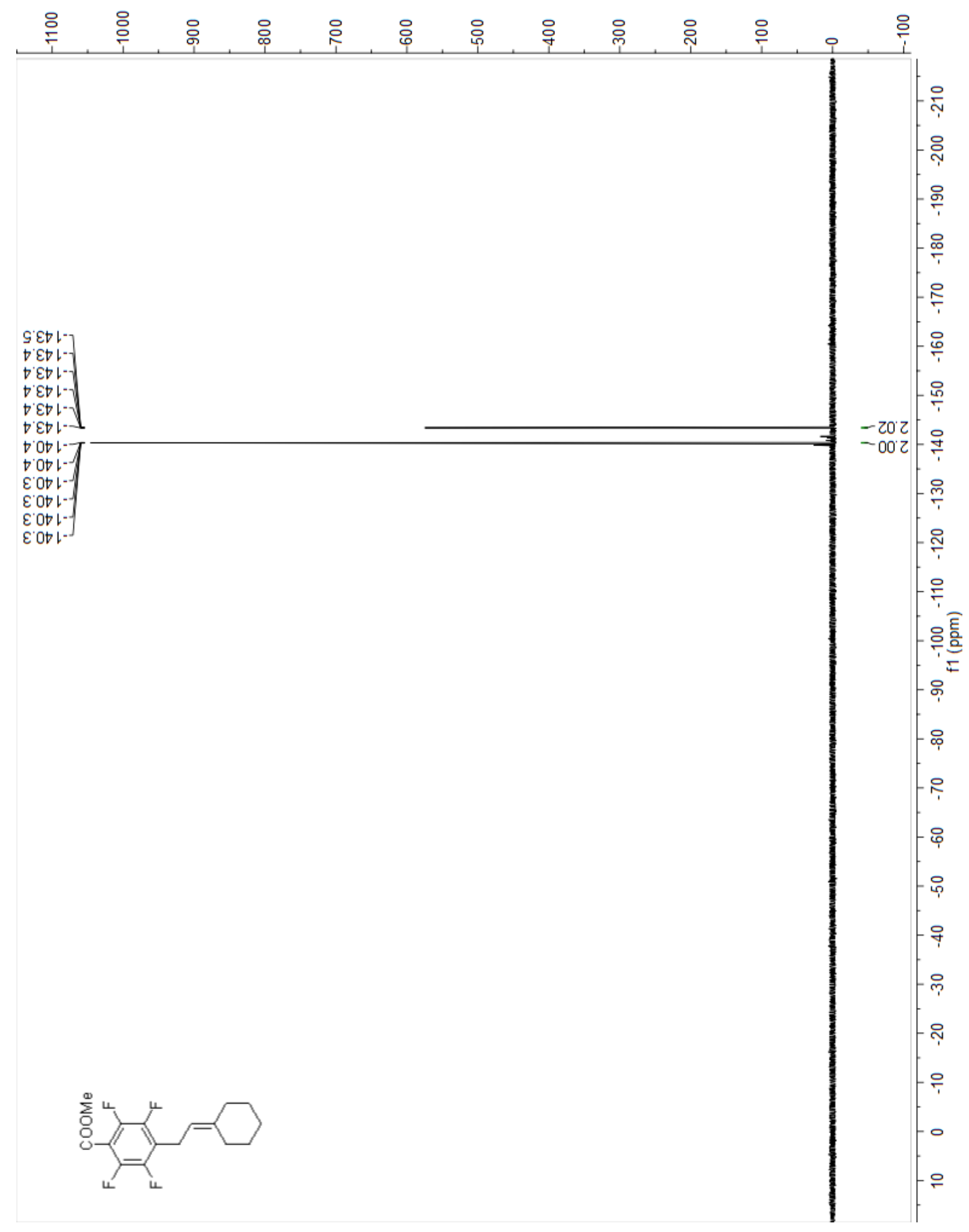


${ }^{1} \mathrm{H}$ NMR (400 MHz, CDCl3, at rt) spectrum of methyl 4-(2-cyclohexylideneethyl)-2,3,5,6-

tetrafluorobenzoate $(5 \mathrm{e})$

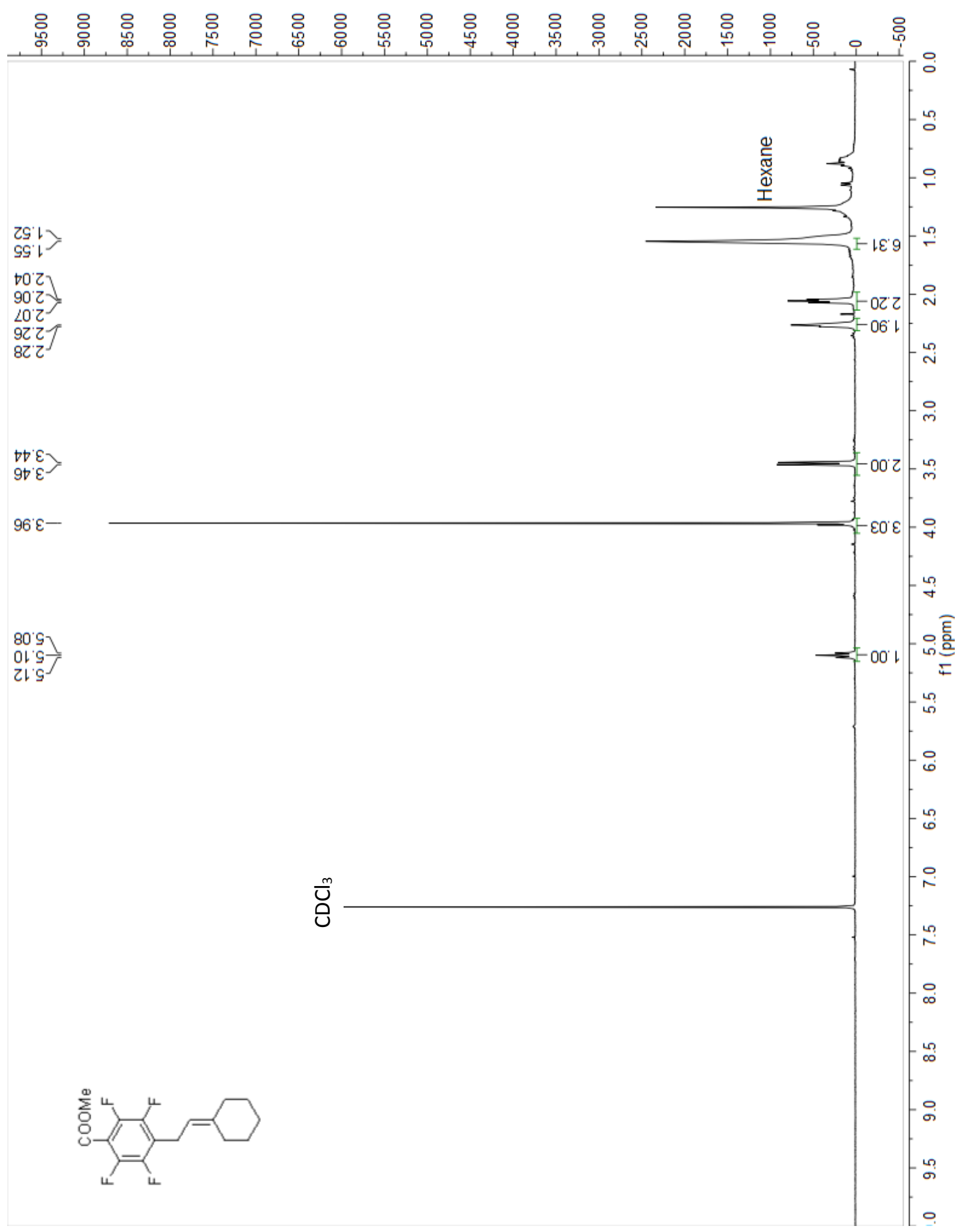


${ }^{13} \mathrm{C}$ NMR (101 MHz, CDCl3, at rt) spectrum of methyl 4-(2-cyclohexylideneethyl)-2,3,5,6-

tetrafluorobenzoate (5e)

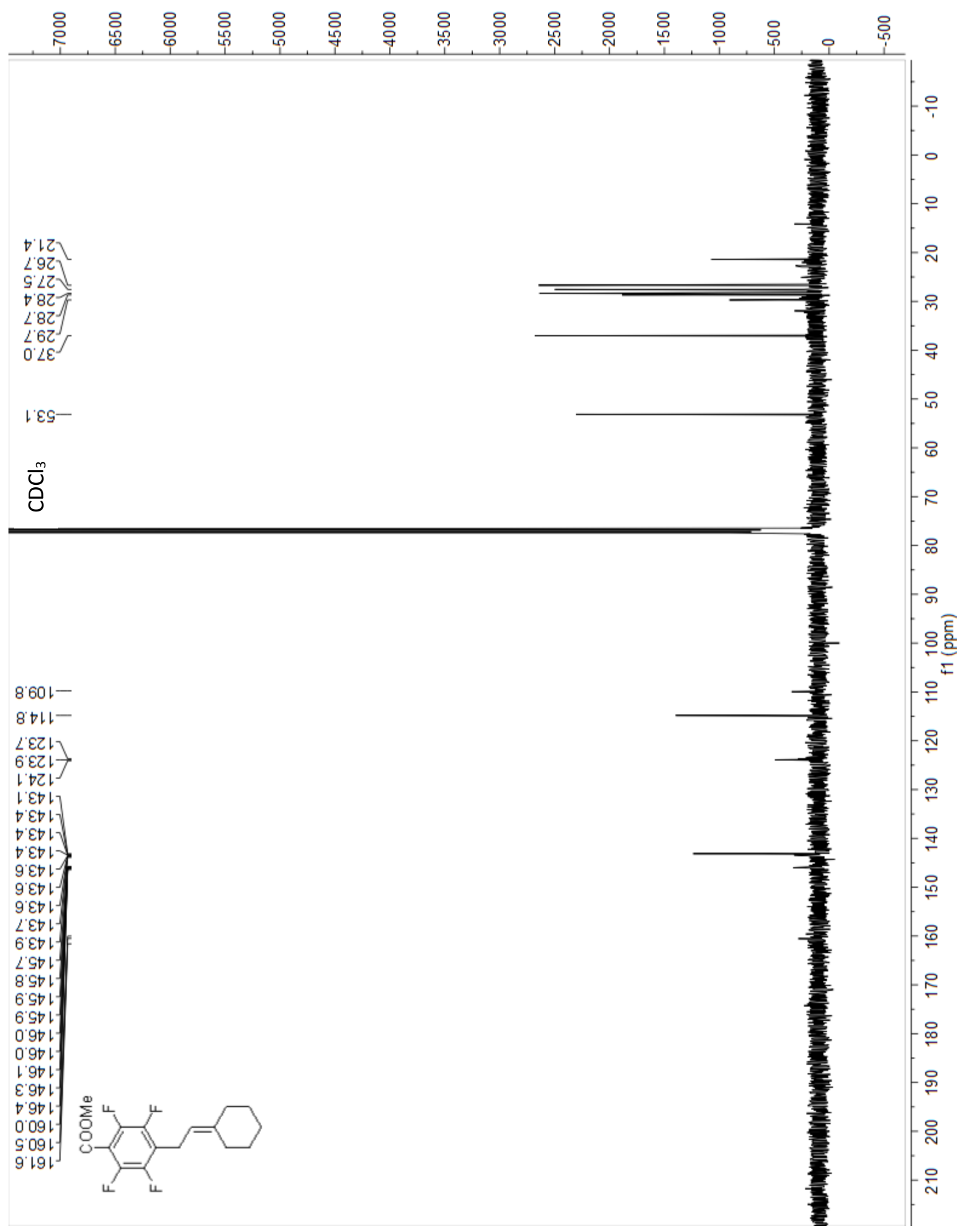




\section{GC and MS of methyl 4-(2-cyclohexylideneethyl)-2,3,5,6-tetrafluorobenzoate (5e)}

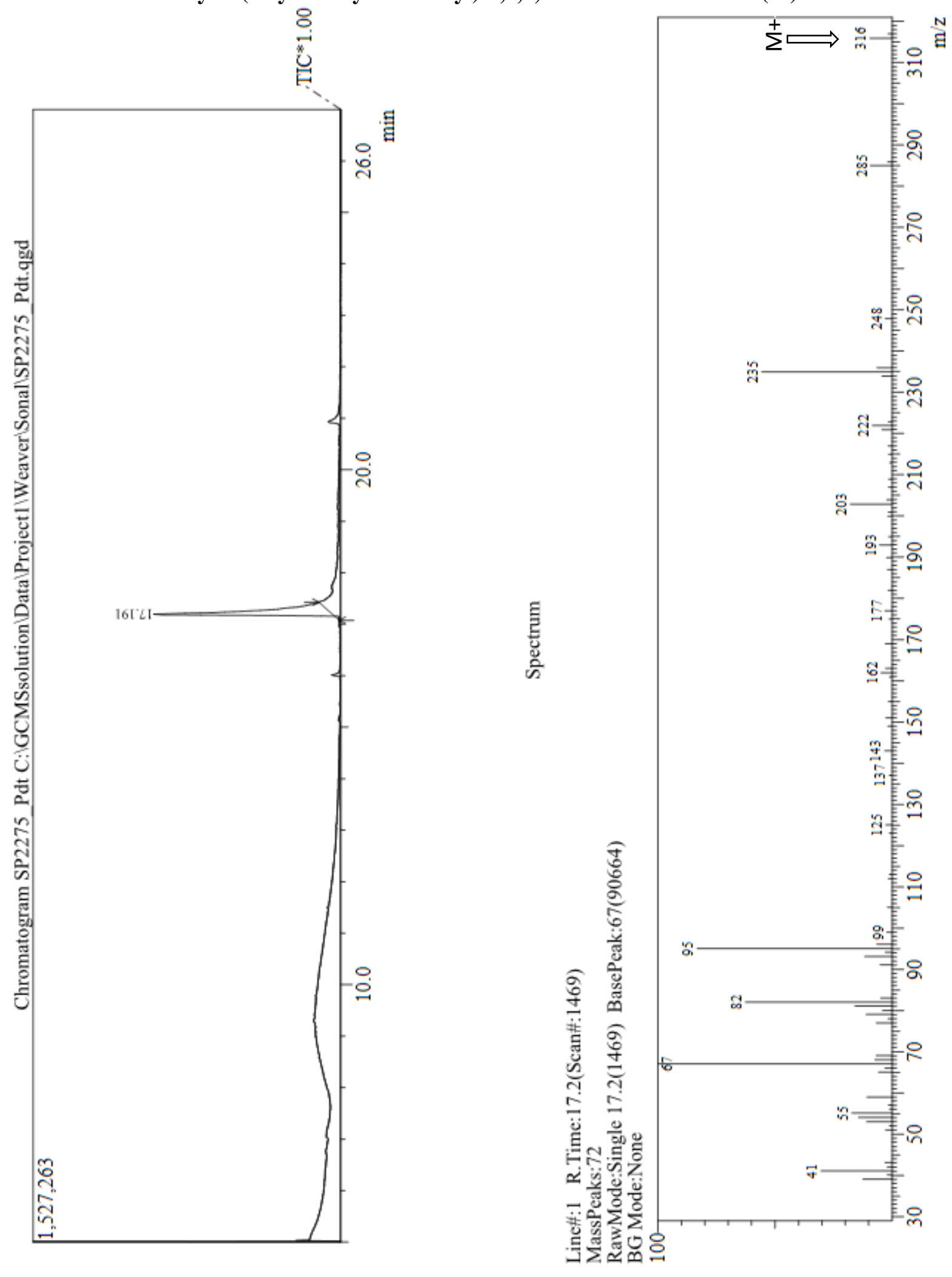


${ }^{19} \mathrm{~F}$ NMR (376 MHz, CDCl3, at rt) spectrum of methyl (E)-2,3,5,6-tetrafluoro-4-(3-methyloct-

2-en-1-yl)benzoate (5f)

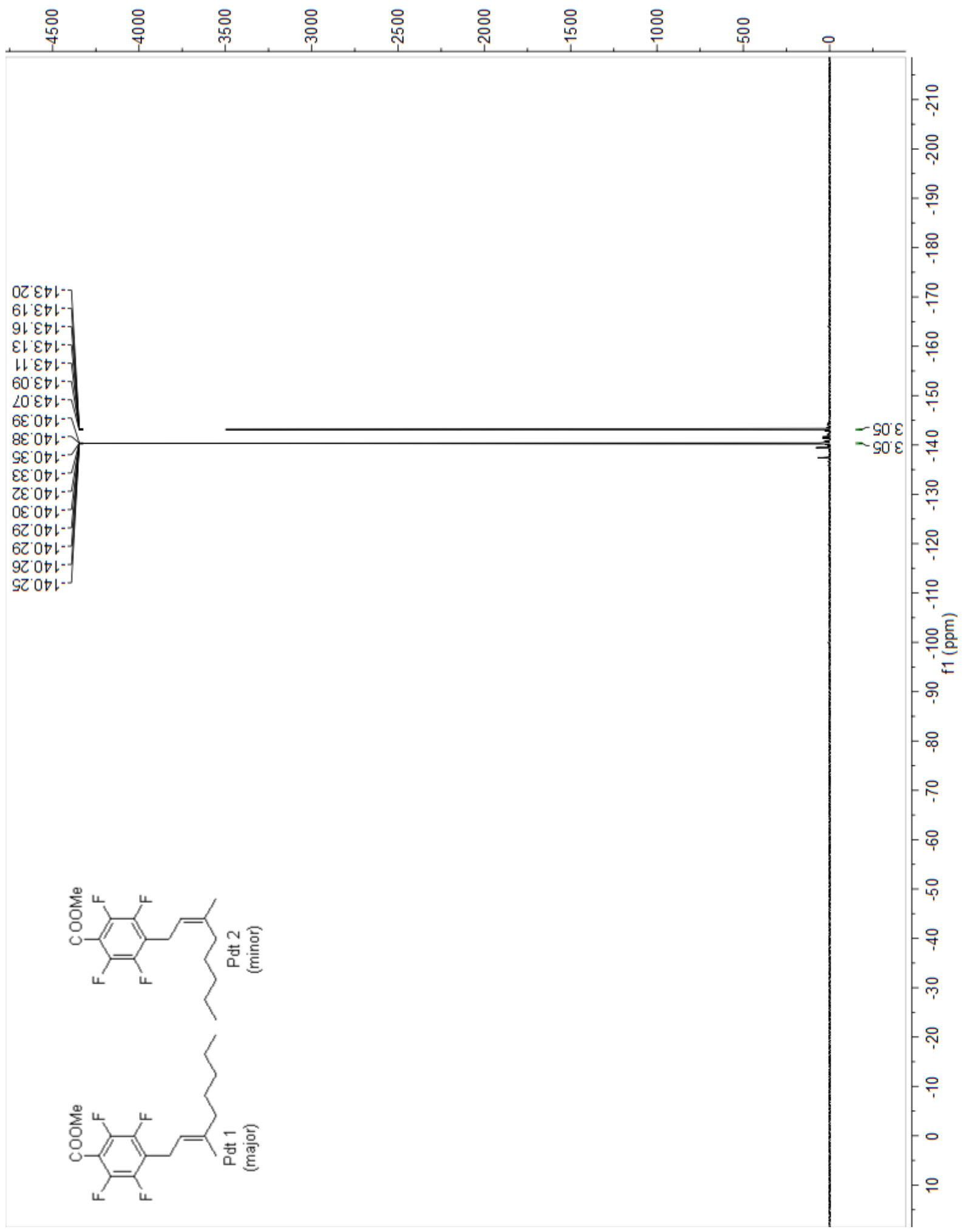


${ }^{1} \mathrm{H}$ NMR (400 MHz, CDCl3, at rt) spectrum of methyl methyl (E)-2,3,5,6-tetrafluoro-4-(3methyloct-2-en-1-yl)benzoate (5f)

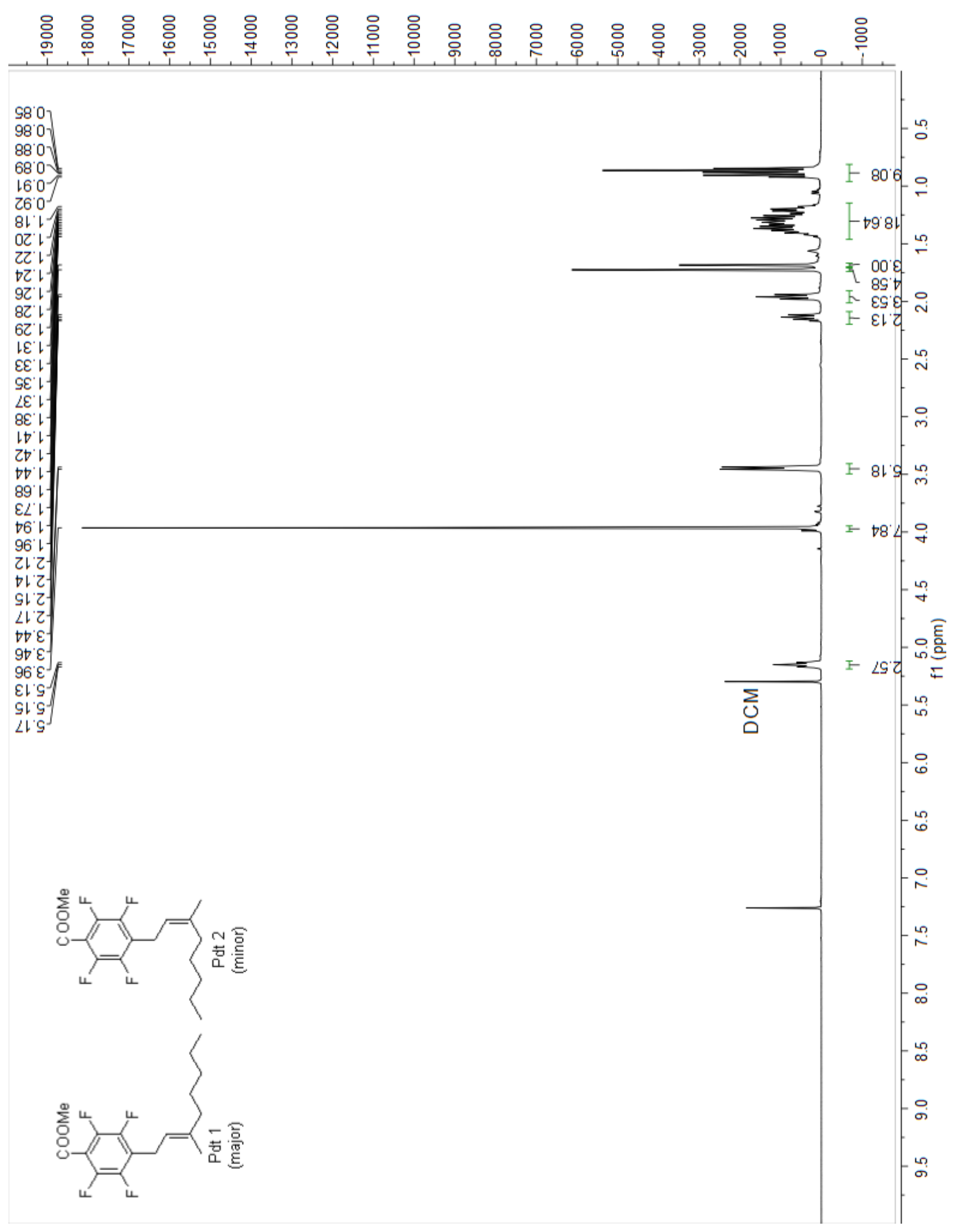


${ }^{13} \mathrm{C}$ NMR (101 MHz, CDCl3, at rt) spectrum of methyl (E)-2,3,5,6-tetrafluoro-4-(3-methyloct-

2-en-1-yl)benzoate (5f)

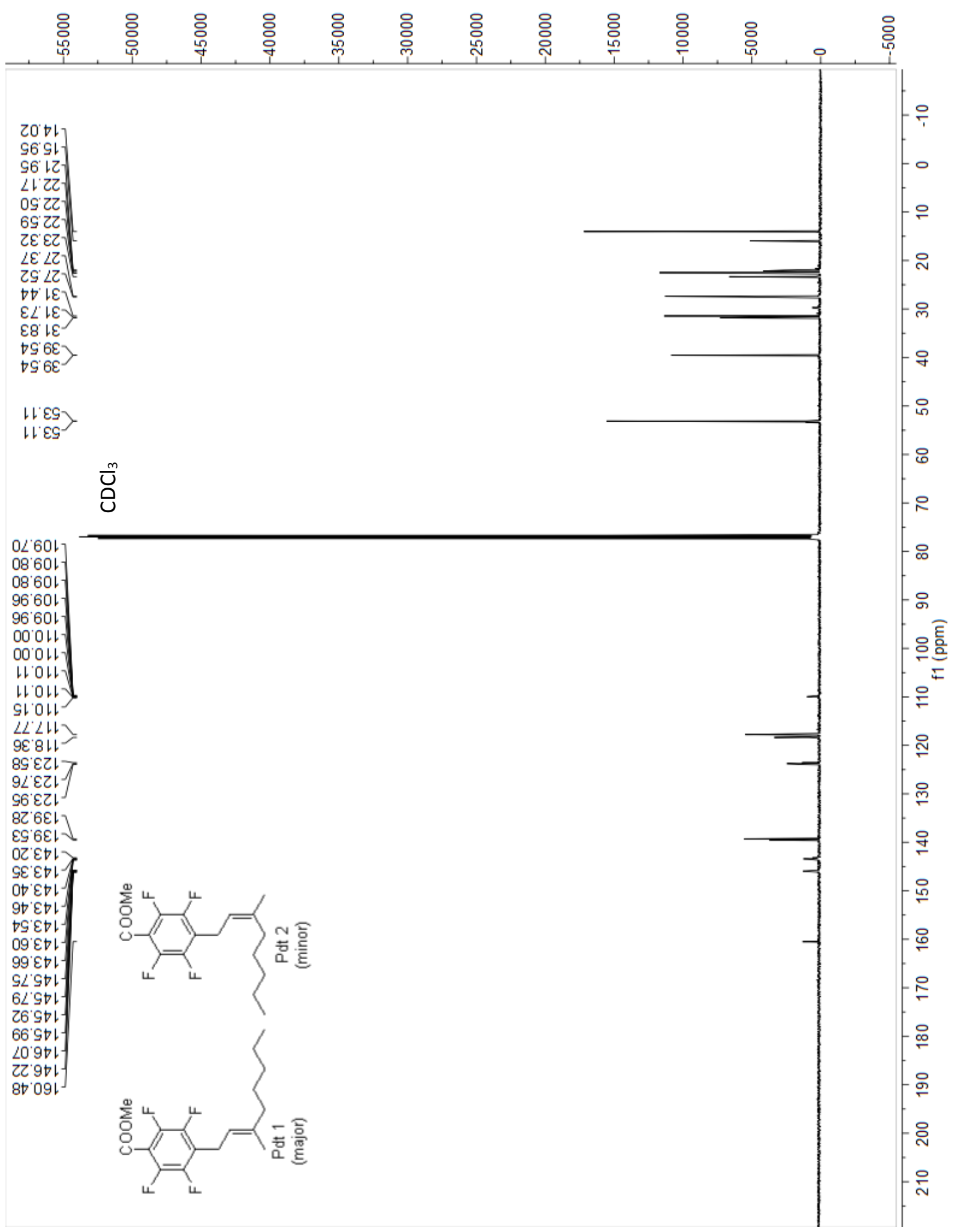


GC and MS of methyl (E)-2,3,5,6-tetrafluoro-4-(3-methyloct-2-en-1-yl)benzoate (5f)
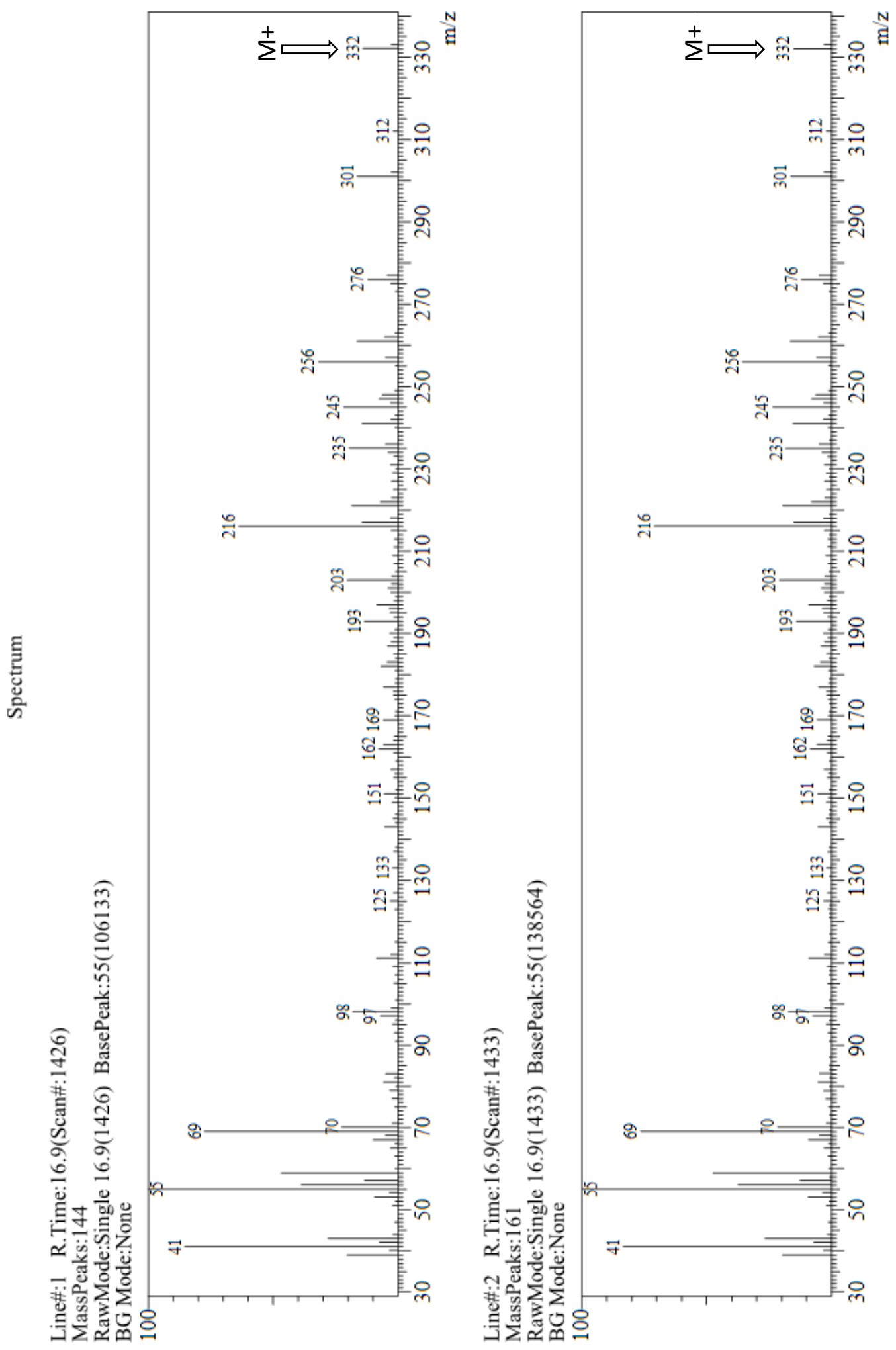
NOESY of methyl (E)-2,3,5,6-tetrafluoro-4-(3-methyloct-2-en-1-yl)benzoate (5f)

(udd) if

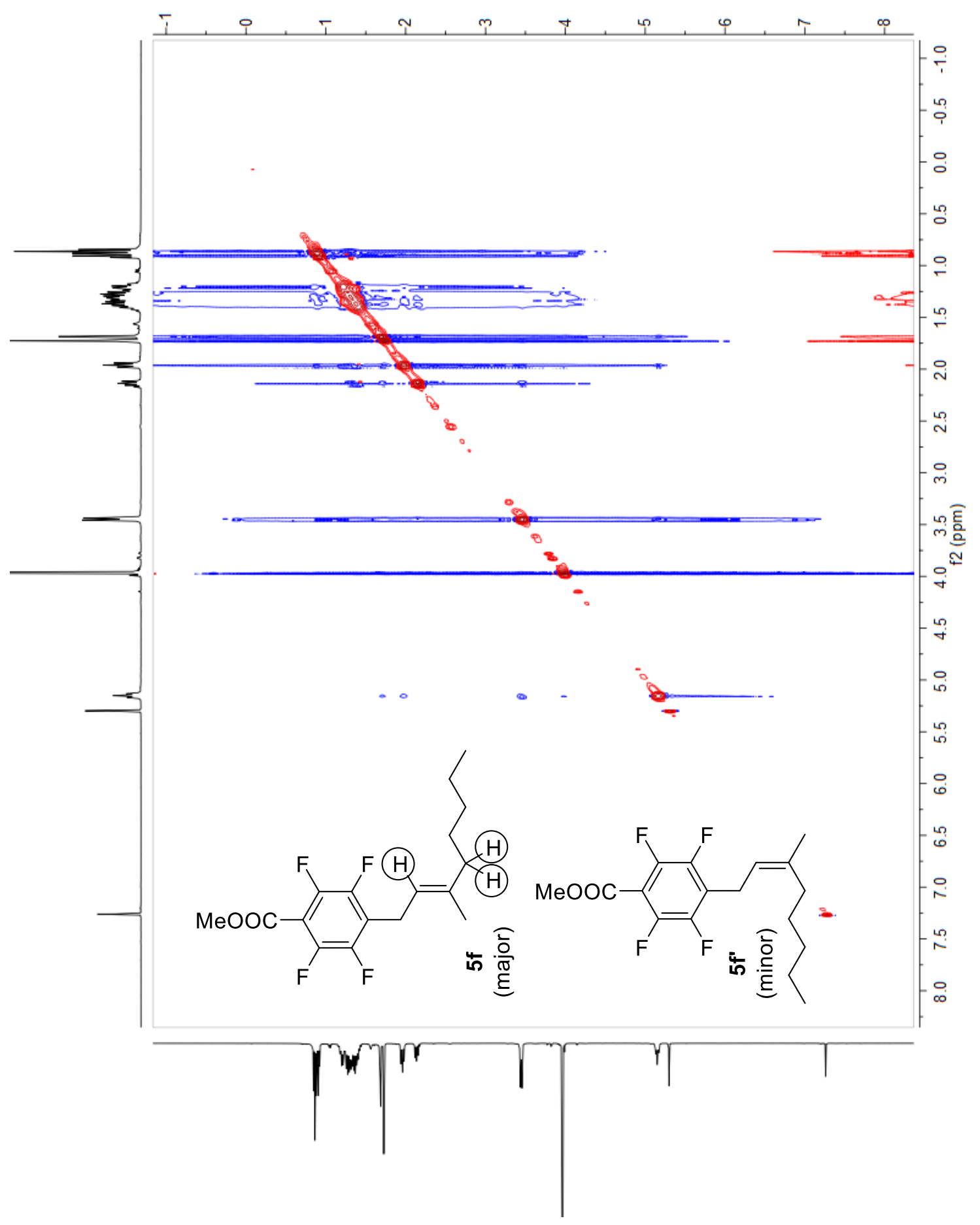


${ }^{19} \mathrm{~F}$ NMR (376 MHz, CDCl3, at rt) spectrum of methyl 2,3,5,6-tetrafluoro-4-(3-methylbut-2-

en-1-yl)benzoate (3a)

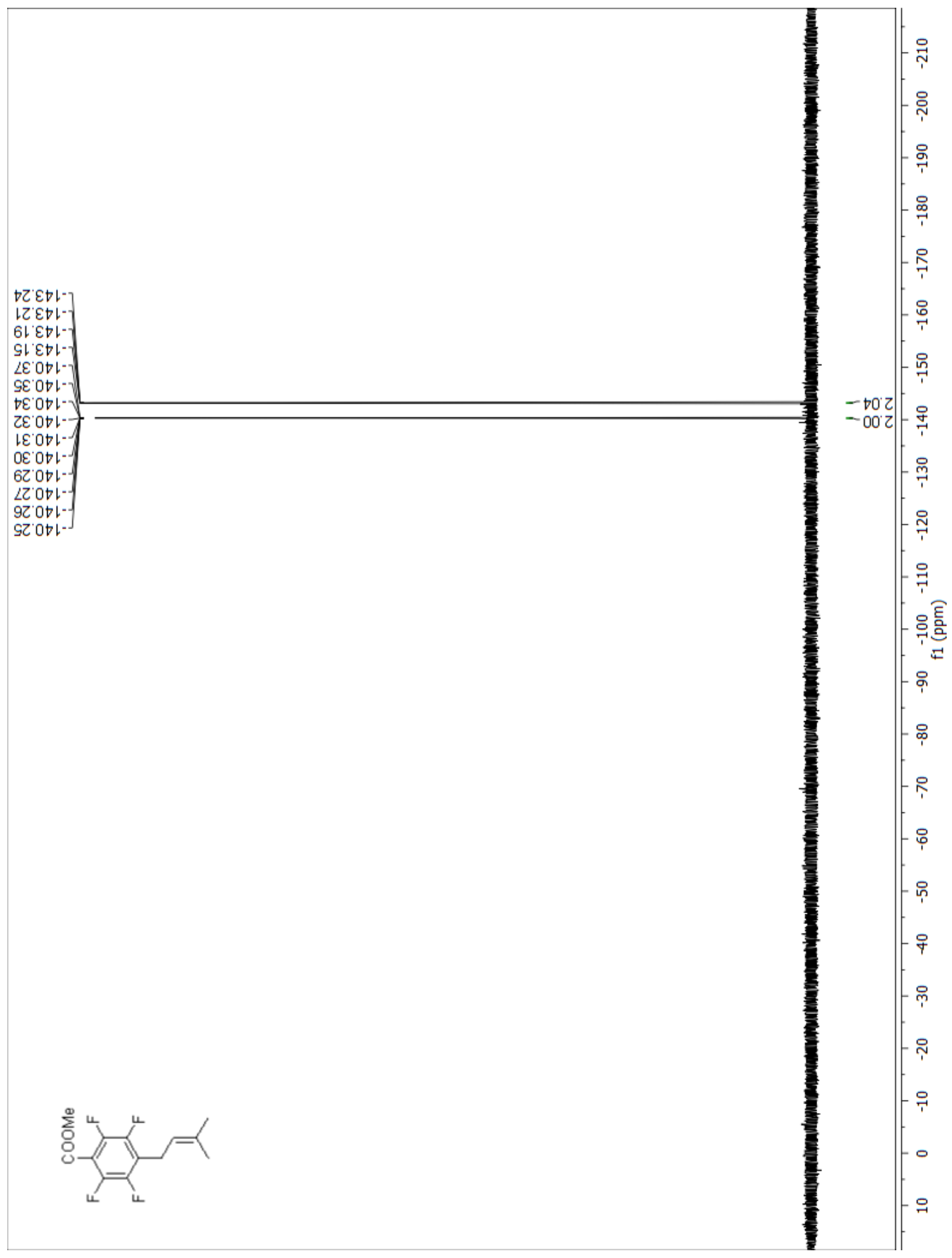


${ }^{1} \mathrm{H}$ NMR (400 MHz, CDCl3, at rt) spectrum of methyl 2,3,5,6-tetrafluoro-4-(3-methylbut-2-en-

\section{1-yl)benzoate (3a)}

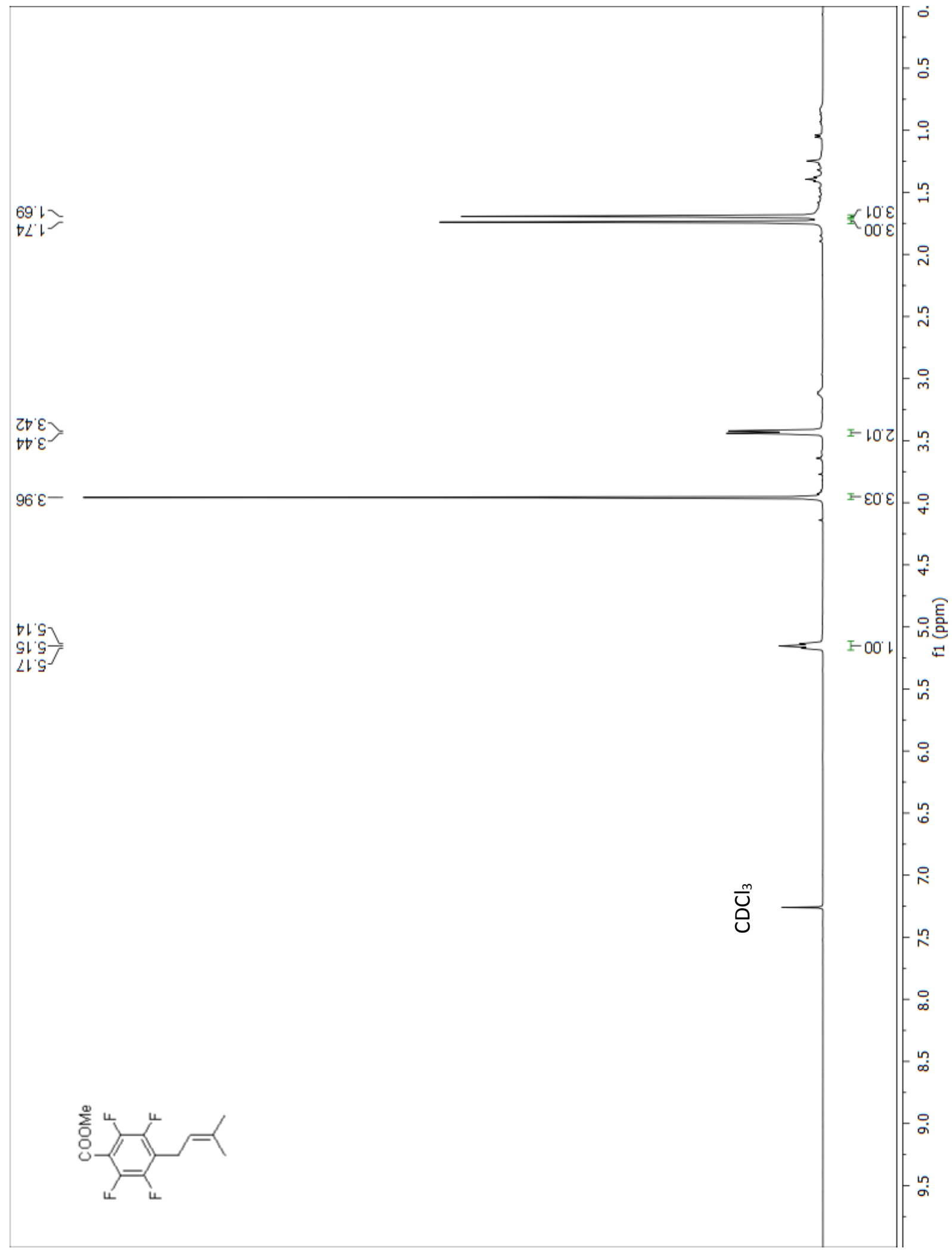


${ }^{13} \mathrm{C}$ NMR (101 MHz, CDCl3, at rt) spectrum of methyl 2,3,5,6-tetrafluoro-4-(3-methylbut-2-

en-1-yl)benzoate (3a)

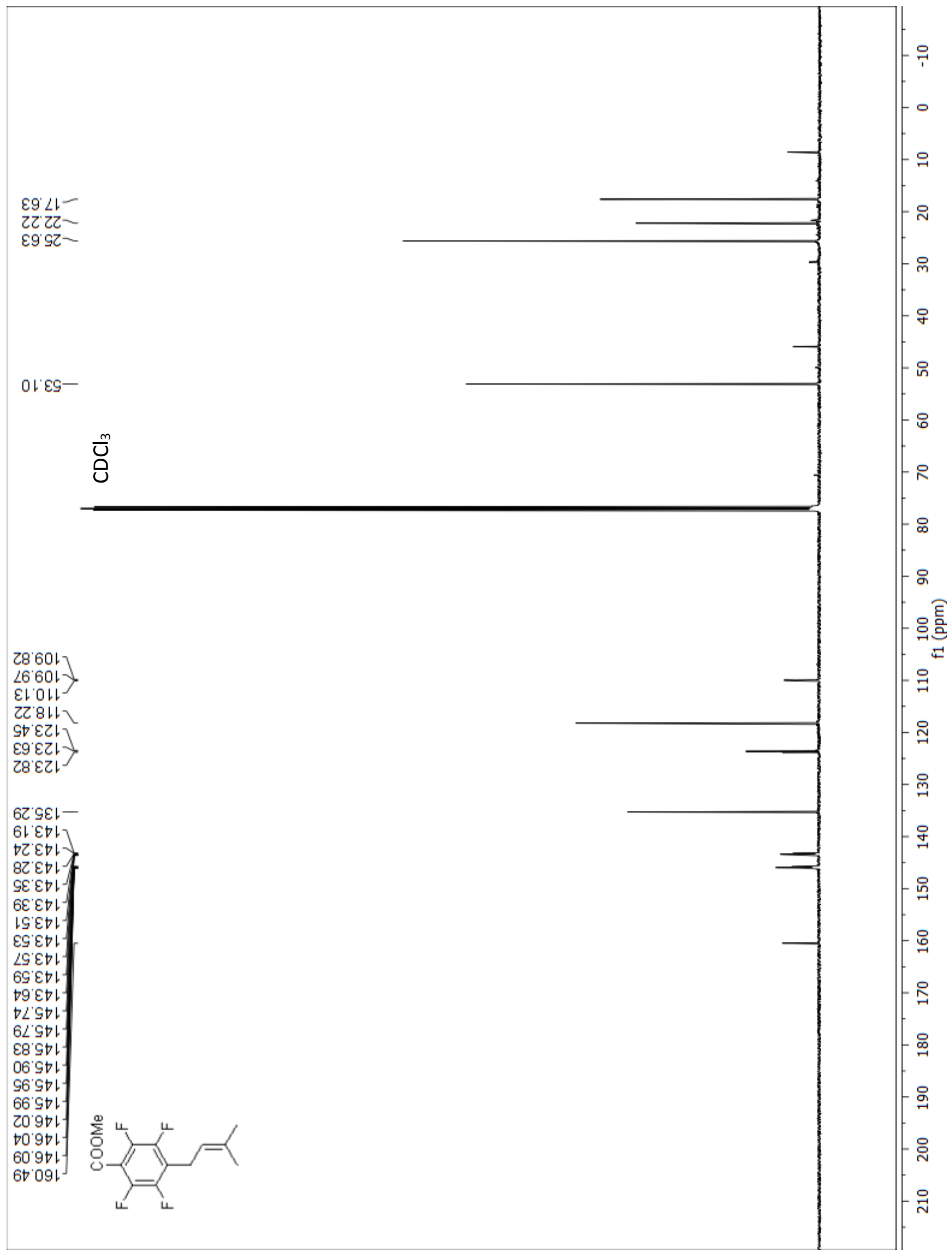


GC and MS of methyl 2,3,5,6-tetrafluoro-4-(3-methylbut-2-en-1-yl)benzoate (3a)
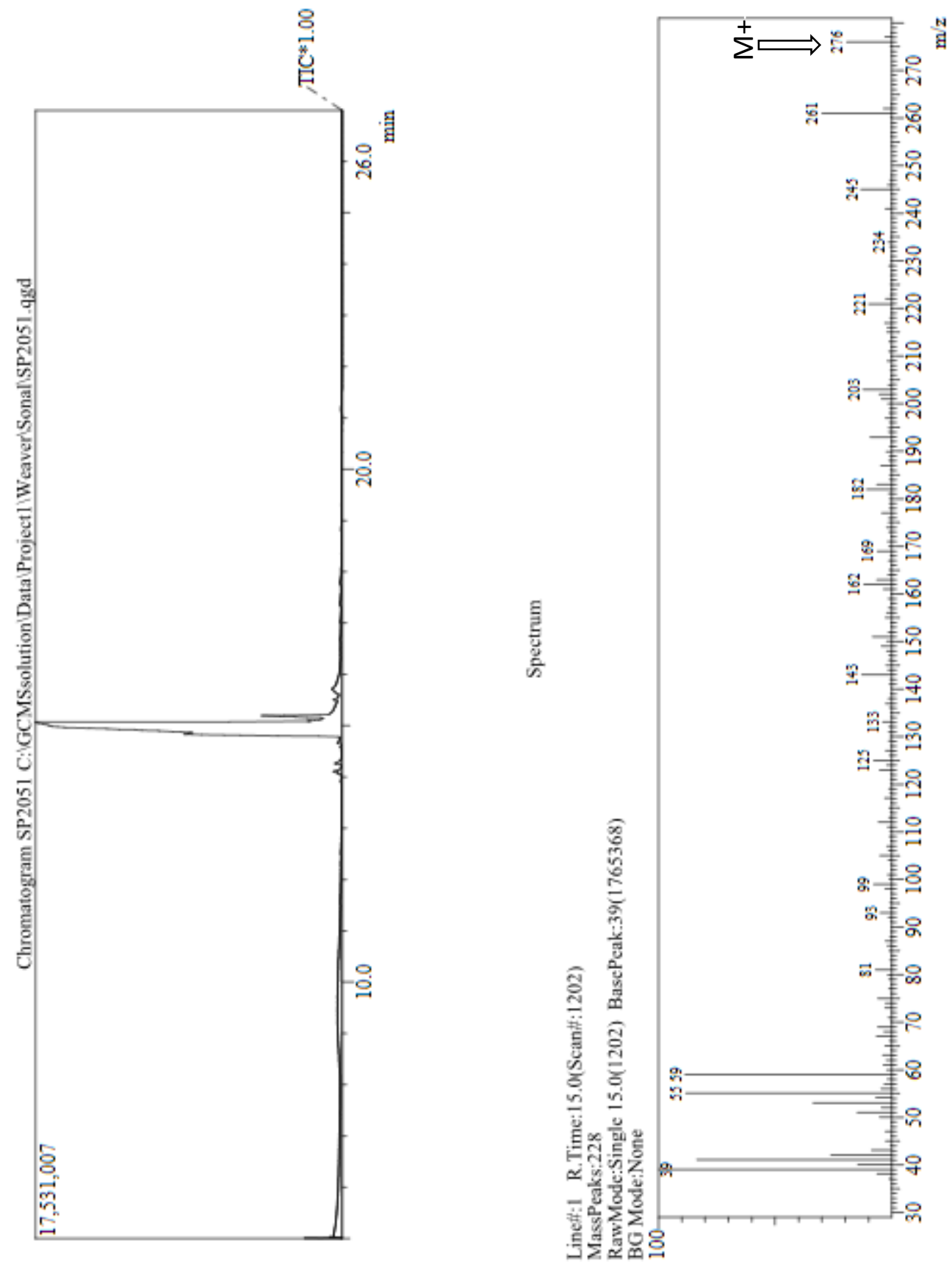
${ }^{19} \mathrm{~F} \mathrm{NMR}(376 \mathrm{MHz}, \mathrm{CDCl} 3$, at $\mathrm{rt}$ ) spectrum of isopropyl 2,3,5,6-tetrafluoro-4-(3-methylbut-2-

en-1-yl)benzoate (3b)

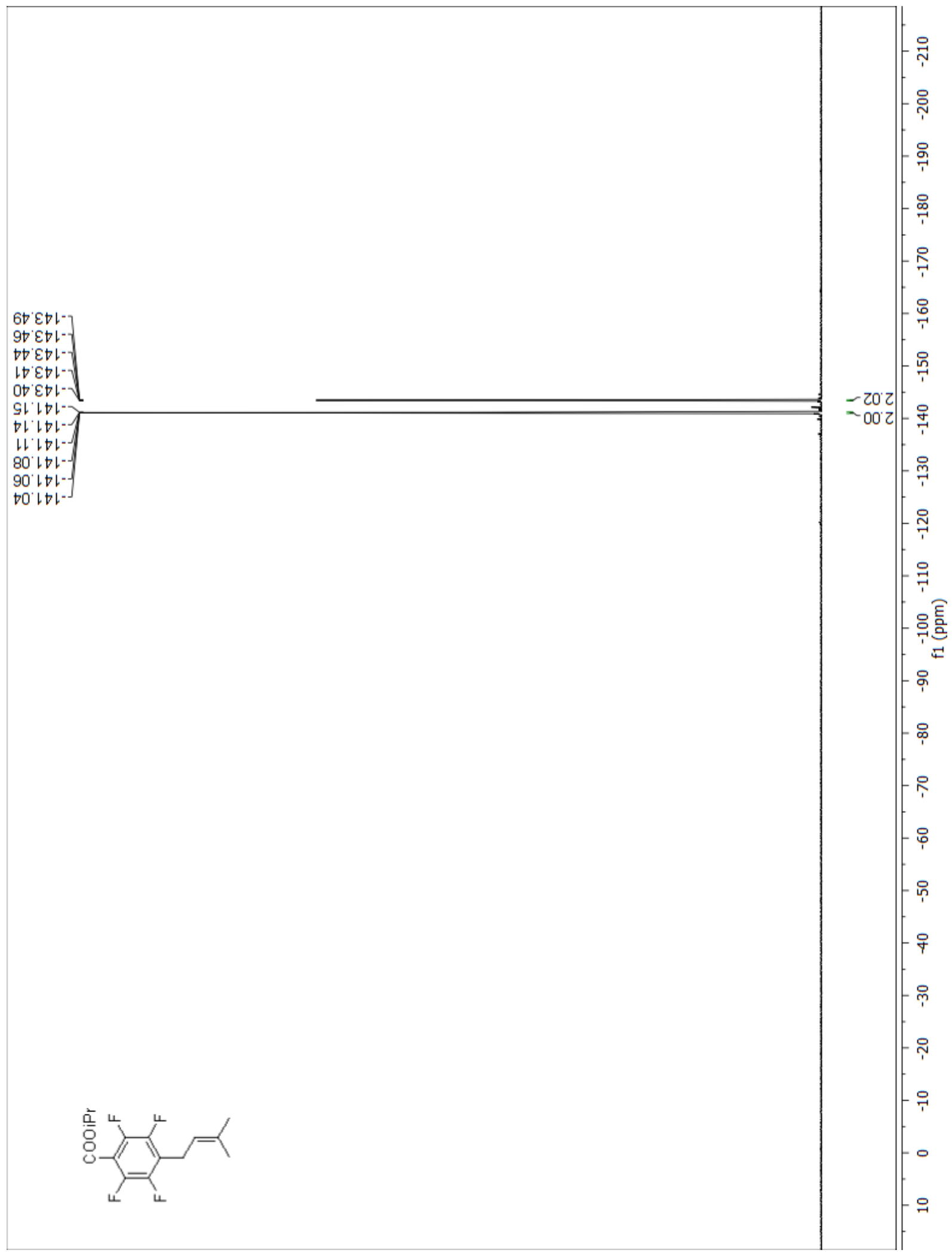


${ }^{1} \mathrm{H}$ NMR (400 MHz, CDCl3, at rt) spectrum of isopropyl 2,3,5,6-tetrafluoro-4-(3-methylbut-2-

en-1-yl)benzoate (3b)

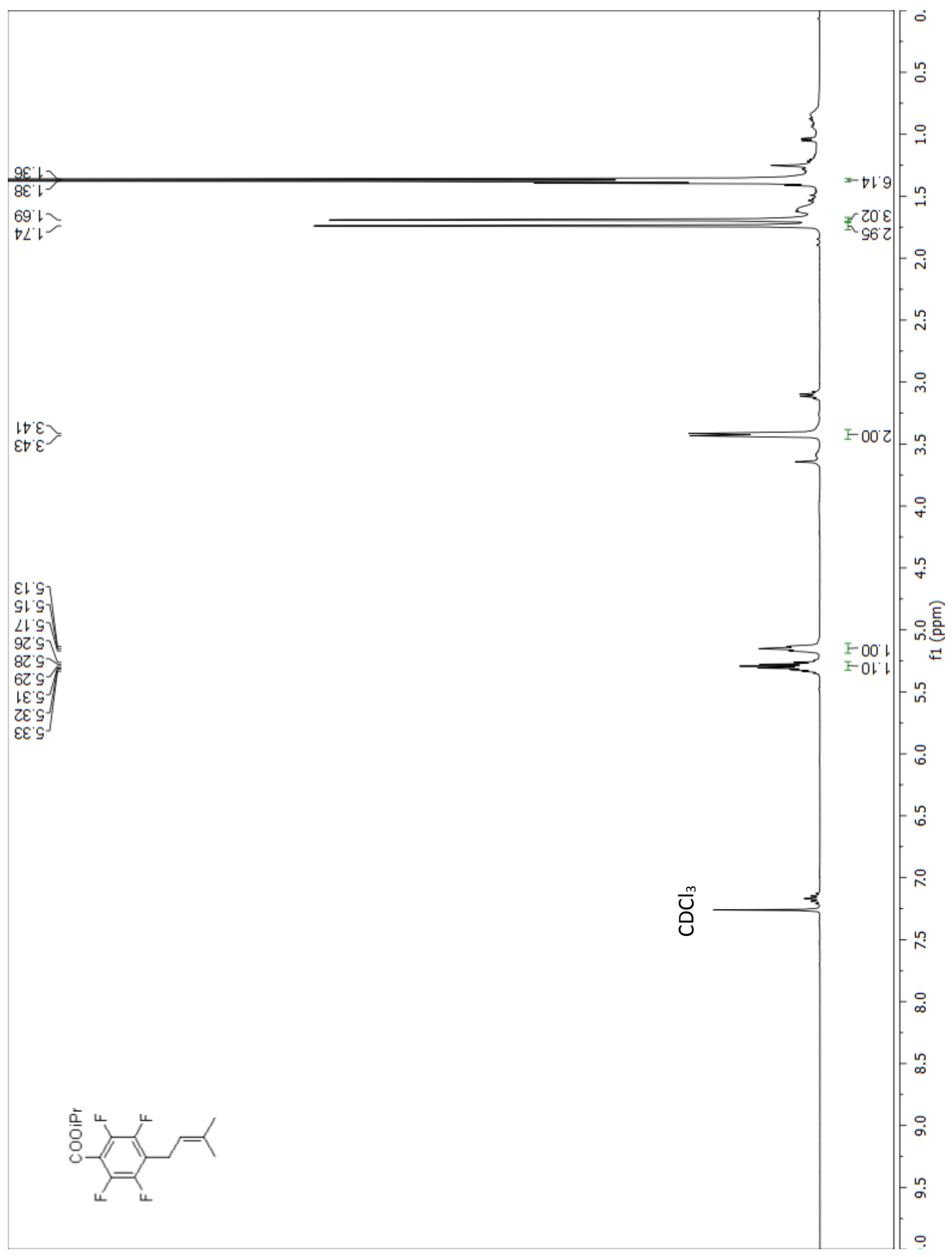


${ }^{13} \mathrm{C}$ NMR (101 MHz, CDCl3, at rt) spectrum of isopropyl 2,3,5,6-tetrafluoro-4-(3-methylbut-2-

en-1-yl)benzoate (3b)

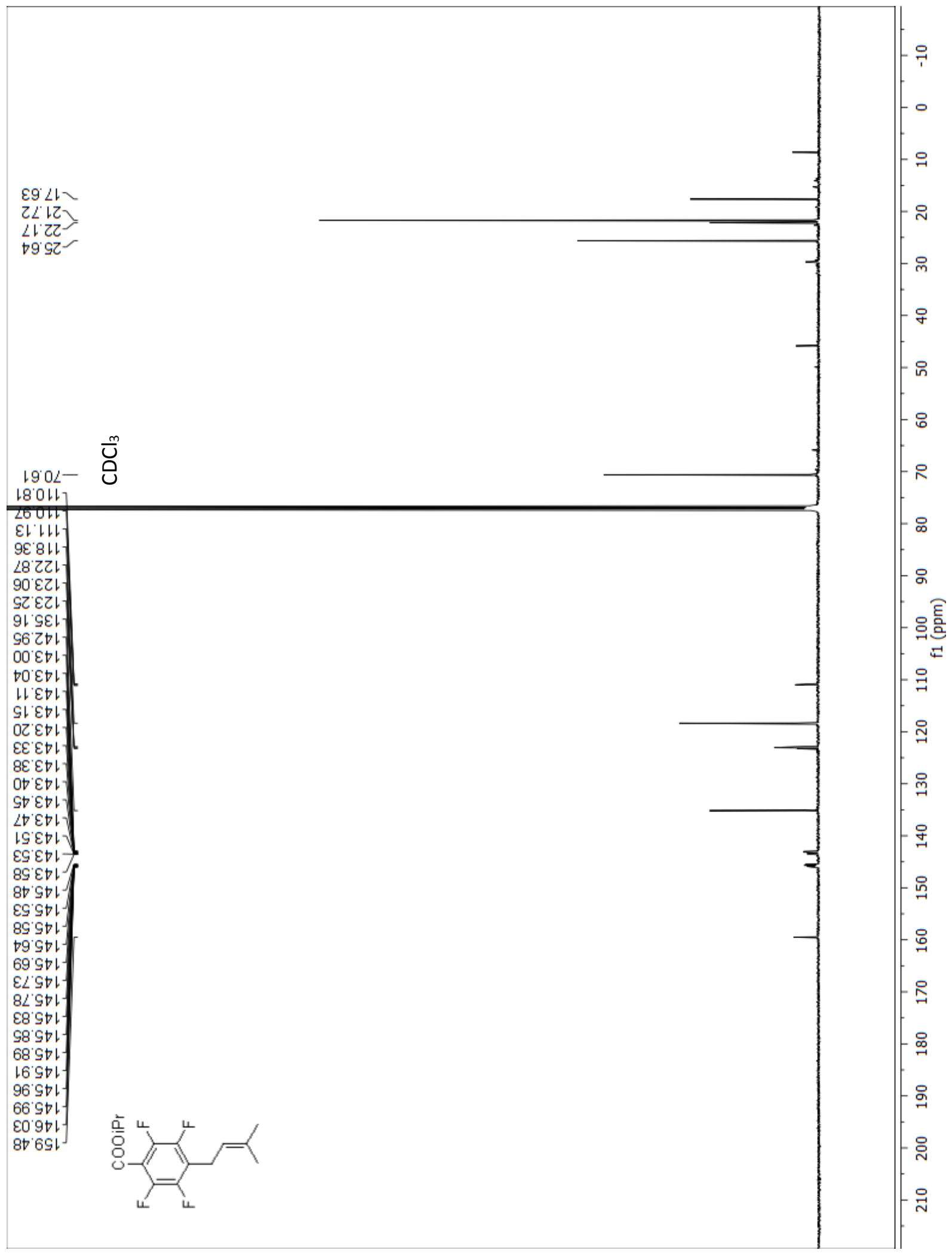


GC and MS of isopropyl 2,3,5,6-tetrafluoro-4-(3-methylbut-2-en-1-yl)benzoate (3b)
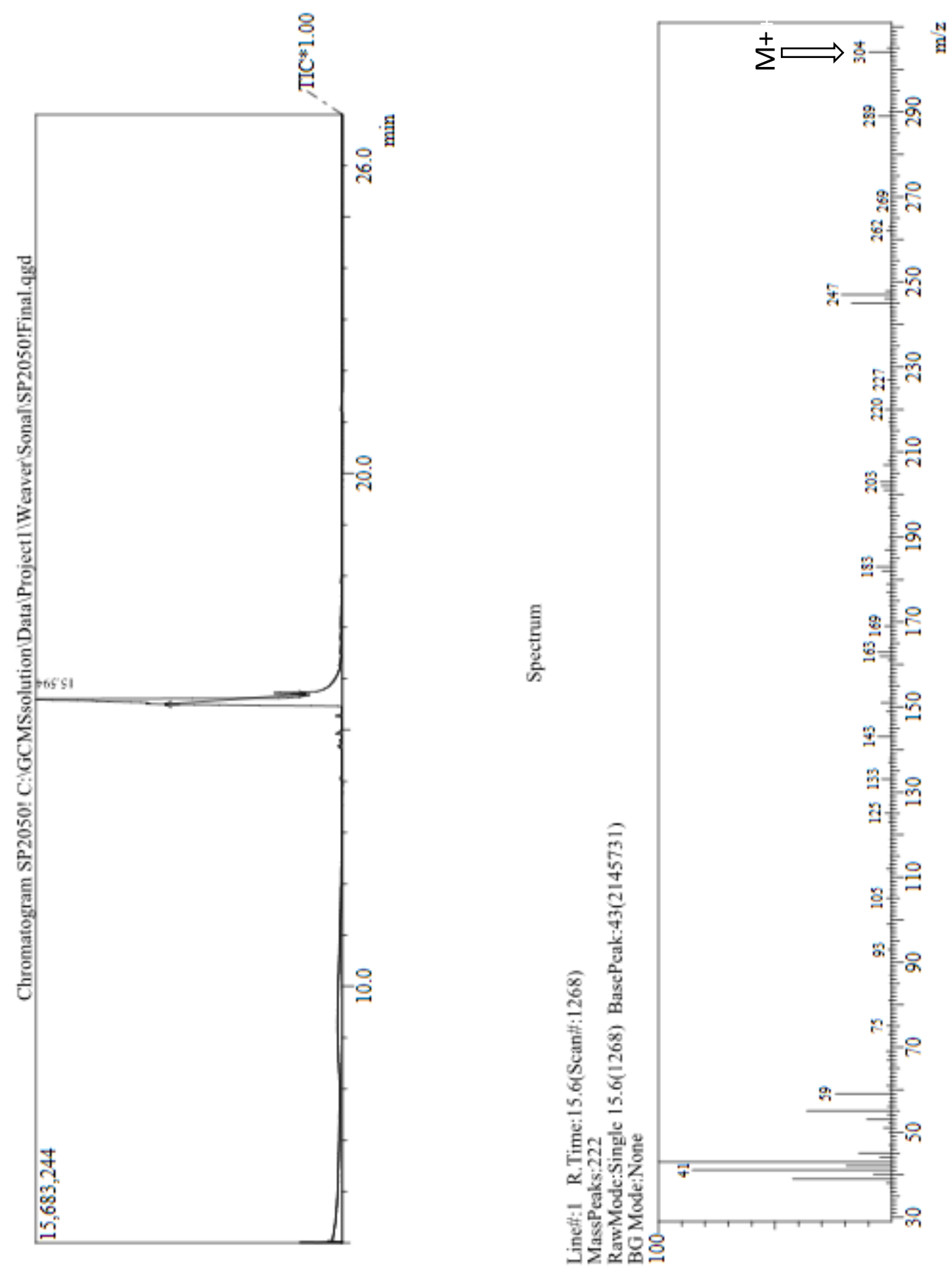
${ }^{19} \mathrm{~F}$ NMR (376 MHz, CDCl3, at rt) spectrum of isobutyl 2,3,5,6-tetrafluoro-4-(3-methylbut-2-

en-1-yl)benzoate (3c)

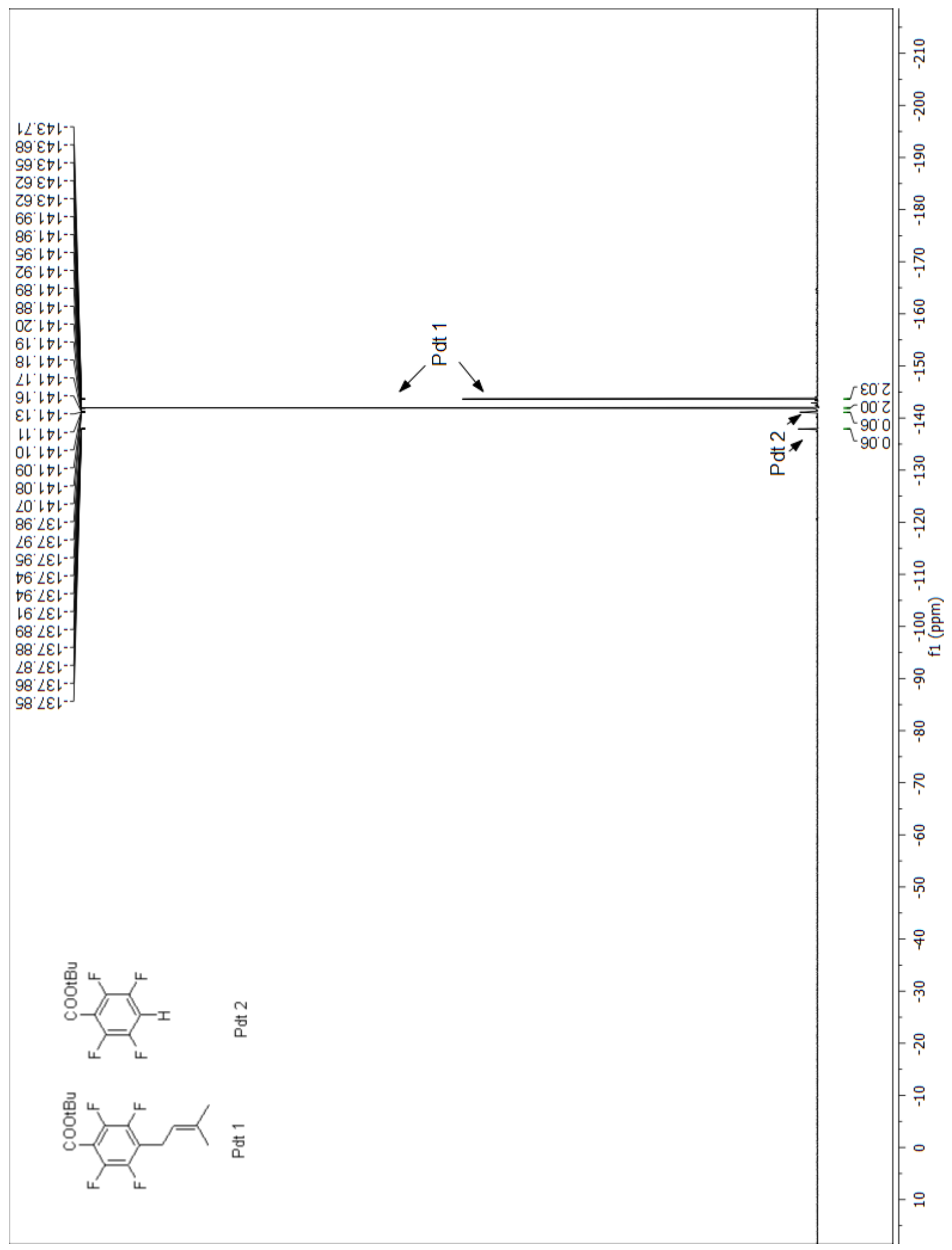


${ }^{1} \mathrm{H}$ NMR (400 MHz, CDCl3, at rt) spectrum of isobutyl 2,3,5,6-tetrafluoro-4-(3-methylbut-2-

en-1-yl)benzoate (3c)

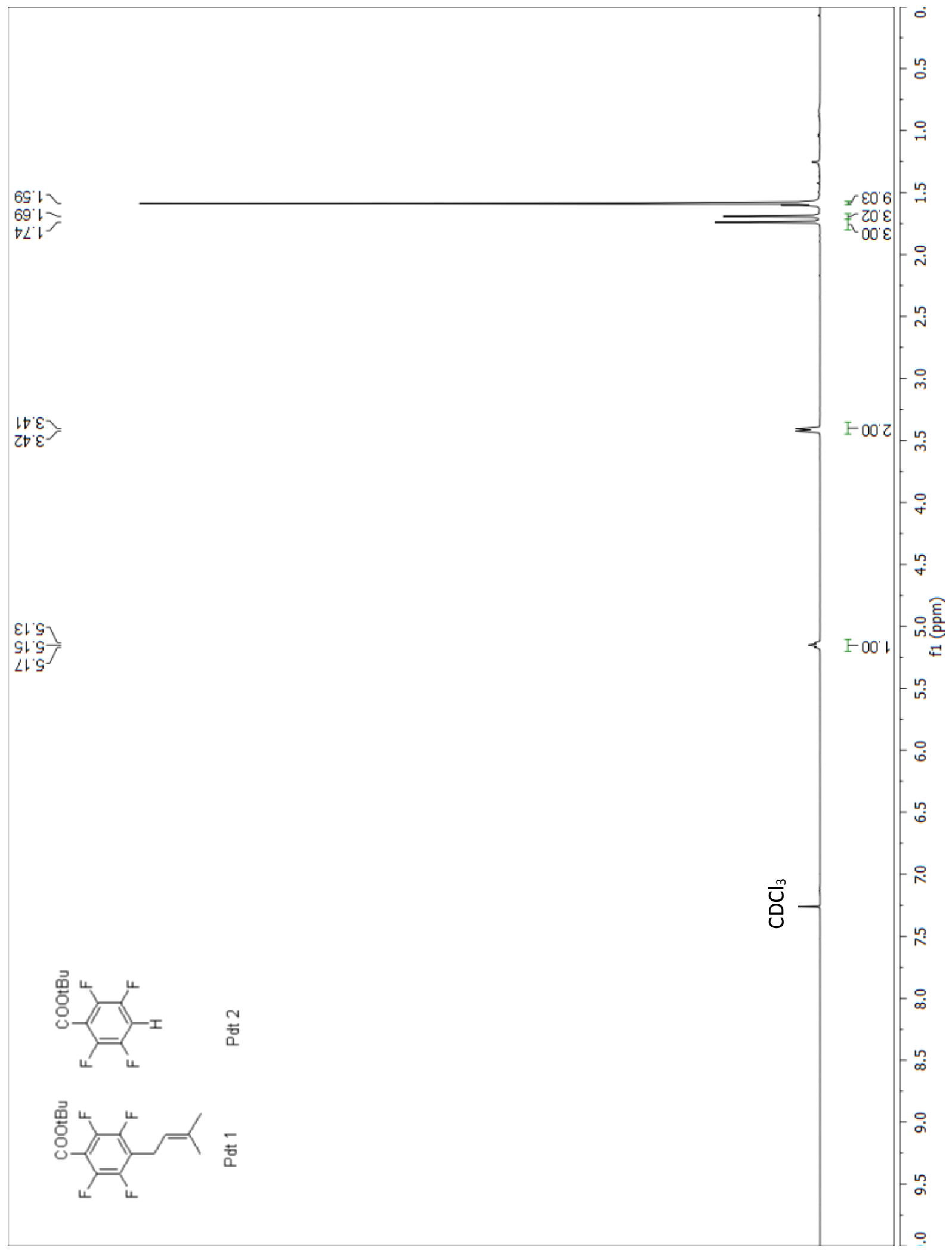


${ }^{13} \mathrm{C}$ NMR (101 MHz, CDCl3, at rt) spectrum of isobutyl 2,3,5,6-tetrafluoro-4-(3-methylbut-2-

en-1-yl)benzoate (3c)

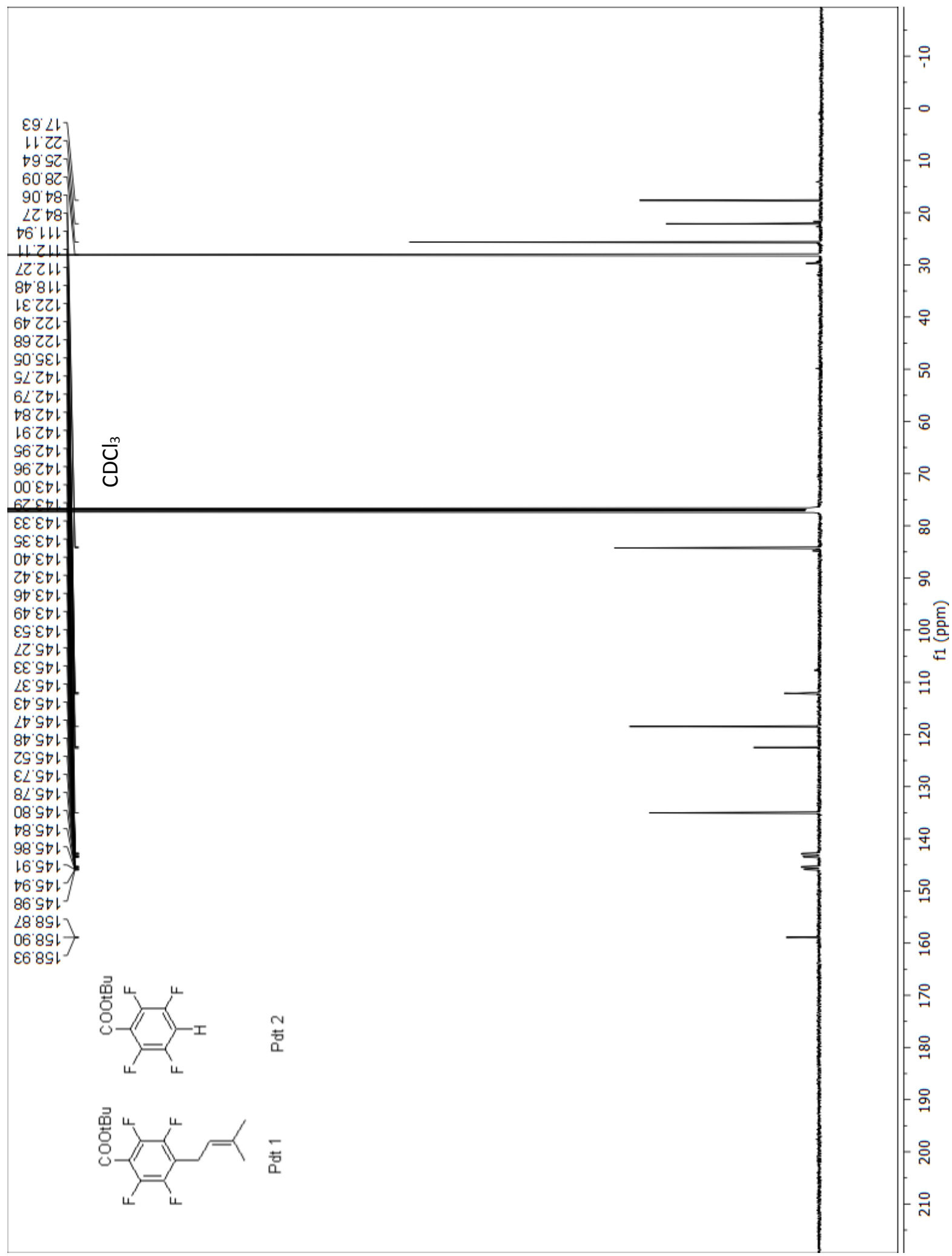


GC and MS of isobutyl 2,3,5,6-tetrafluoro-4-(3-methylbut-2-en-1-yl)benzoate (3c)
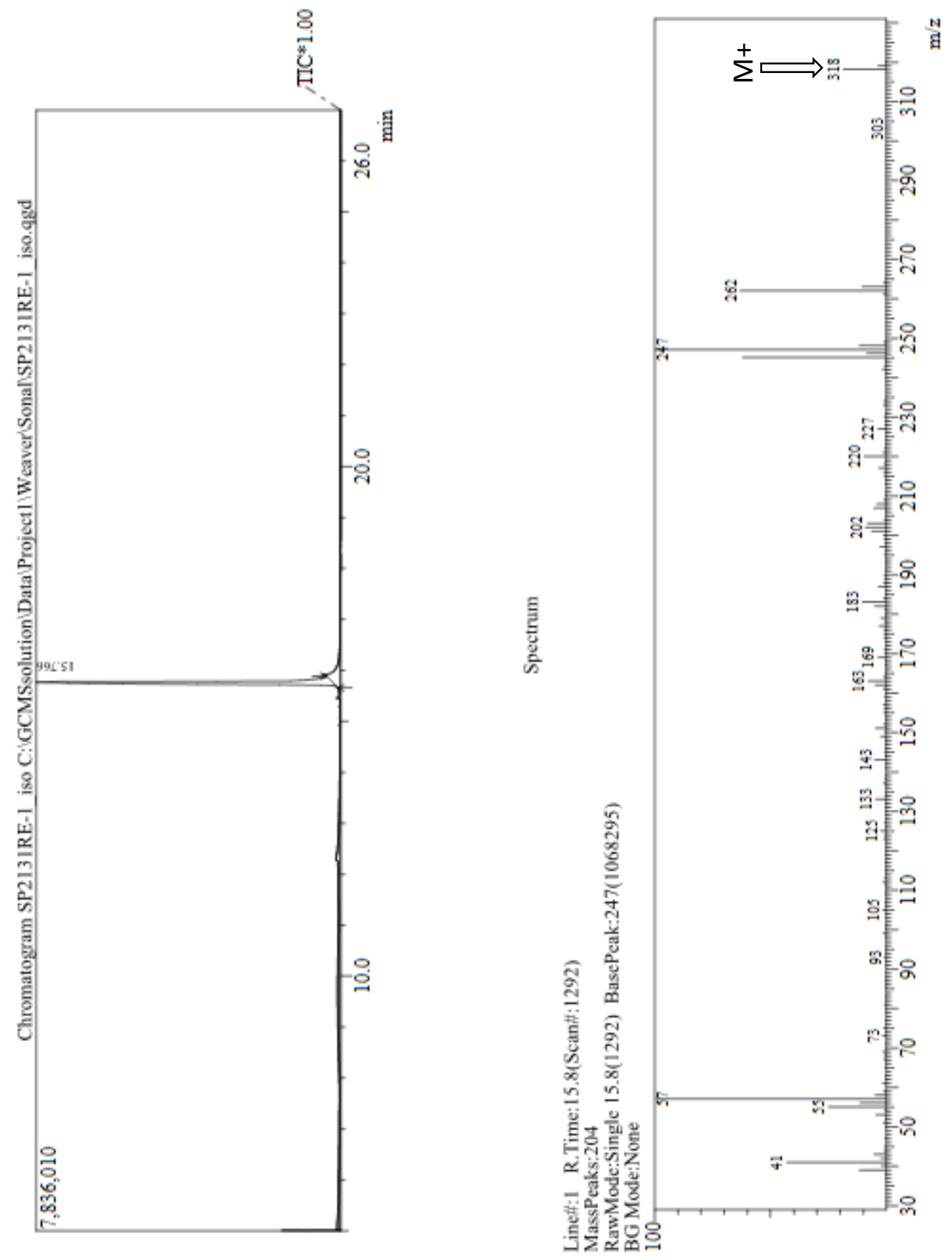
${ }^{19} \mathrm{~F}$ NMR $(376 \mathrm{MHz}, \mathrm{CDCl} 3$, at rt) spectrum of 2,3,5,6-tetrafluoro-4-(3-methylbut-2-en-1-

\section{yl)benzonitrile (3d)}

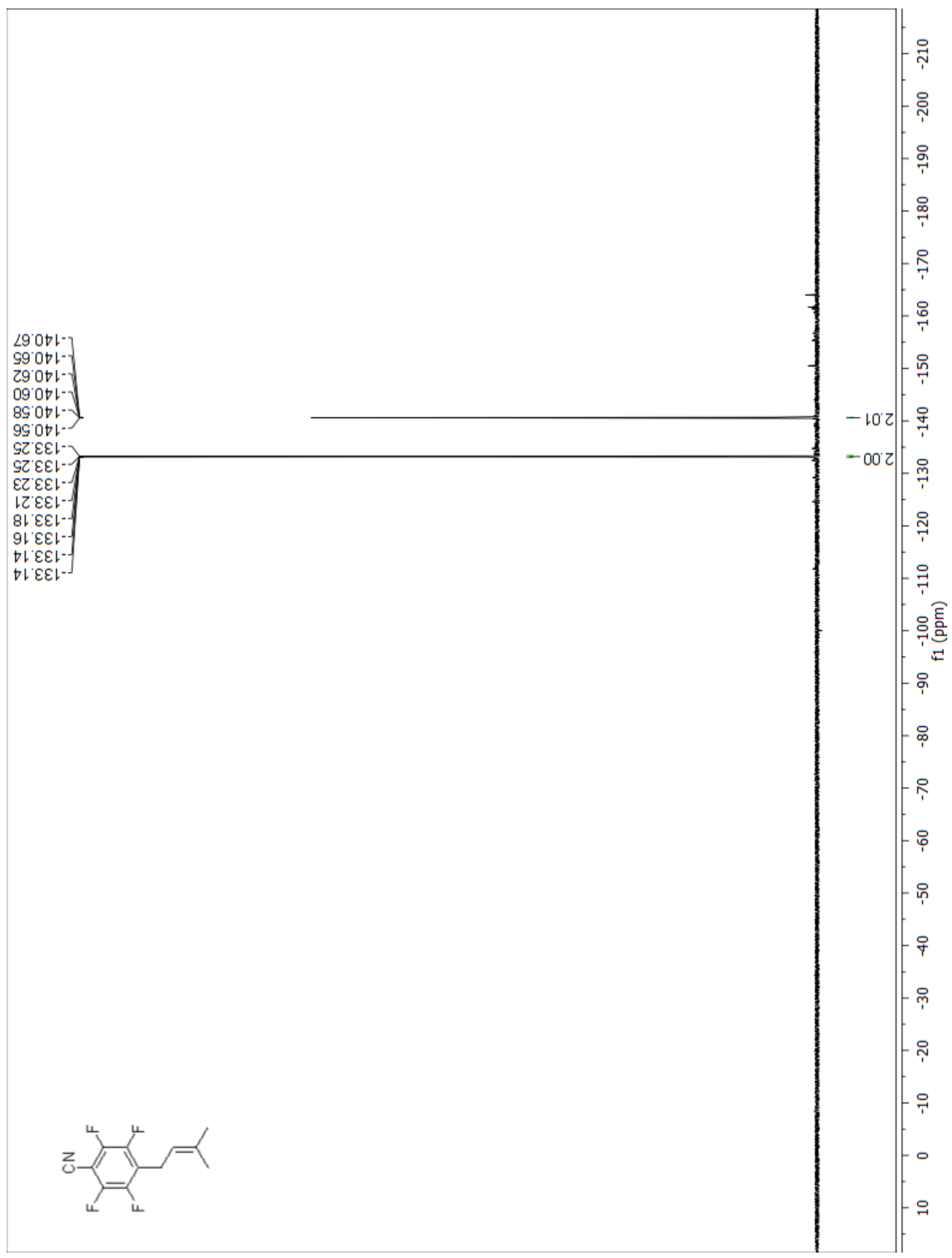


${ }^{1} \mathrm{H}$ NMR (400 MHz, CDCl3, at rt) spectrum of 2,3,5,6-tetrafluoro-4-(3-methylbut-2-en-1-

yl)benzonitrile (3d)

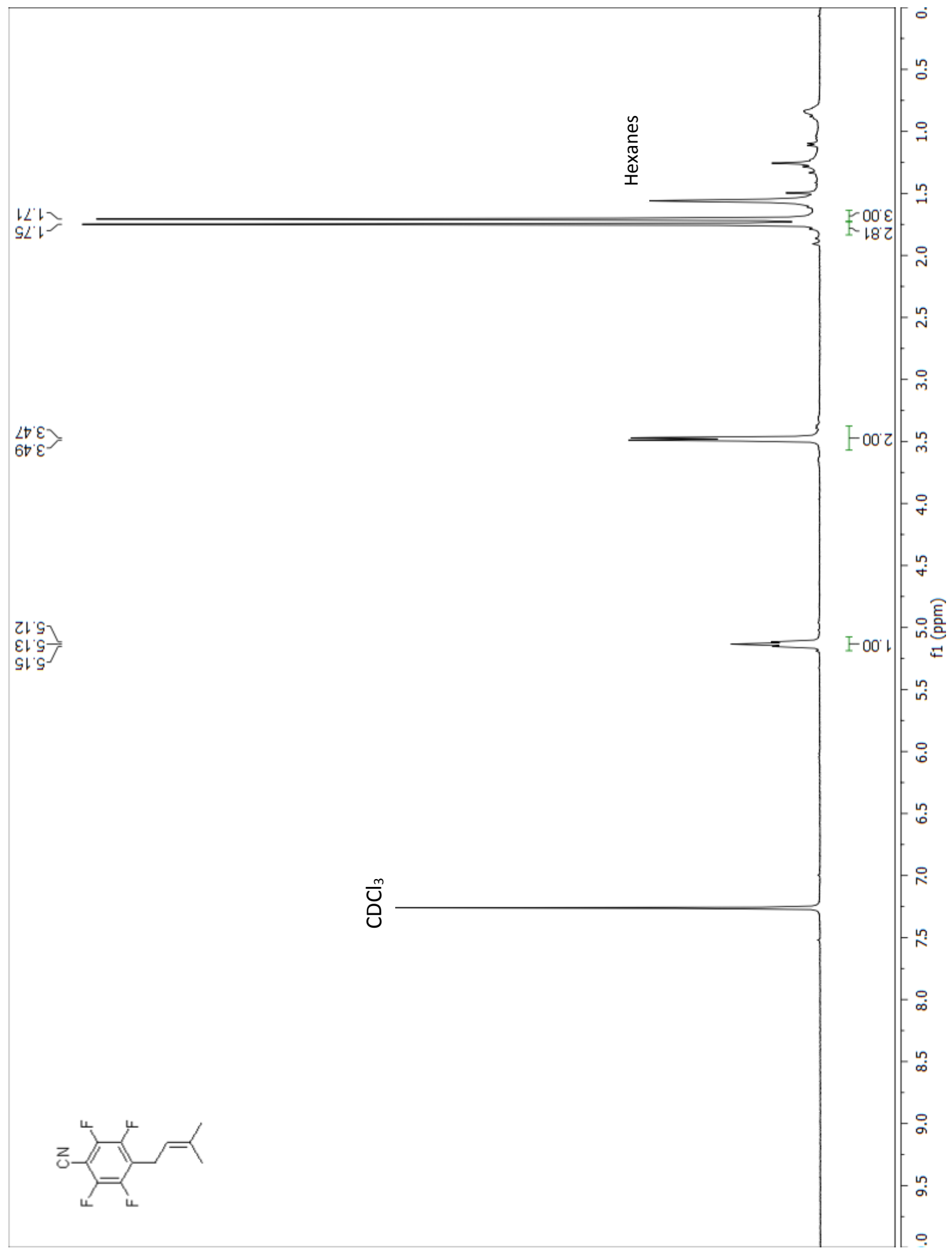


${ }^{13} \mathrm{C}$ NMR (101 MHz, CDCl3, at rt) spectrum of 2,3,5,6-tetrafluoro-4-(3-methylbut-2-en-1-

\section{yl)benzonitrile (3d)}

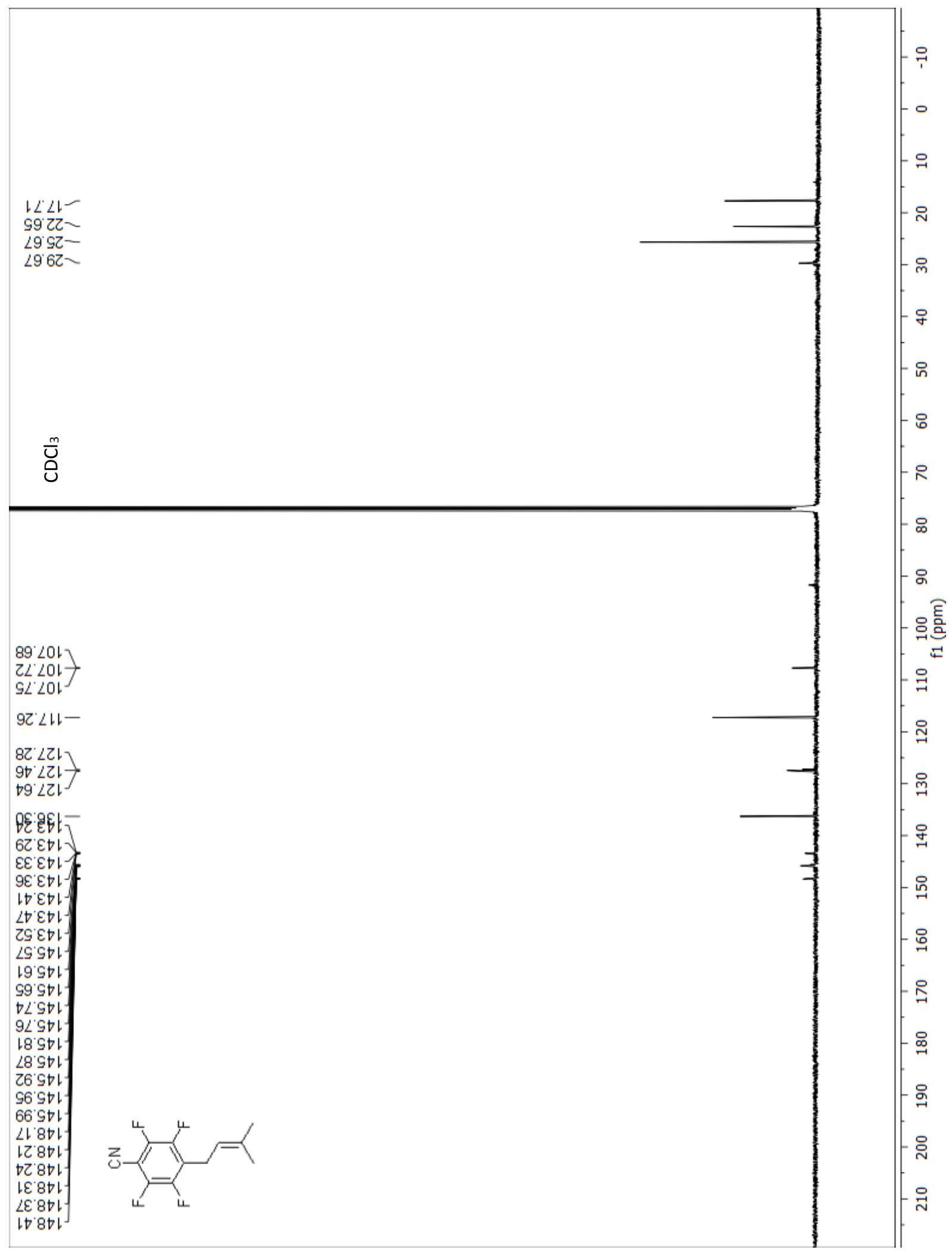


GC and MS of 2,3,5,6-tetrafluoro-4-(3-methylbut-2-en-1-yl)benzonitrile (3d)
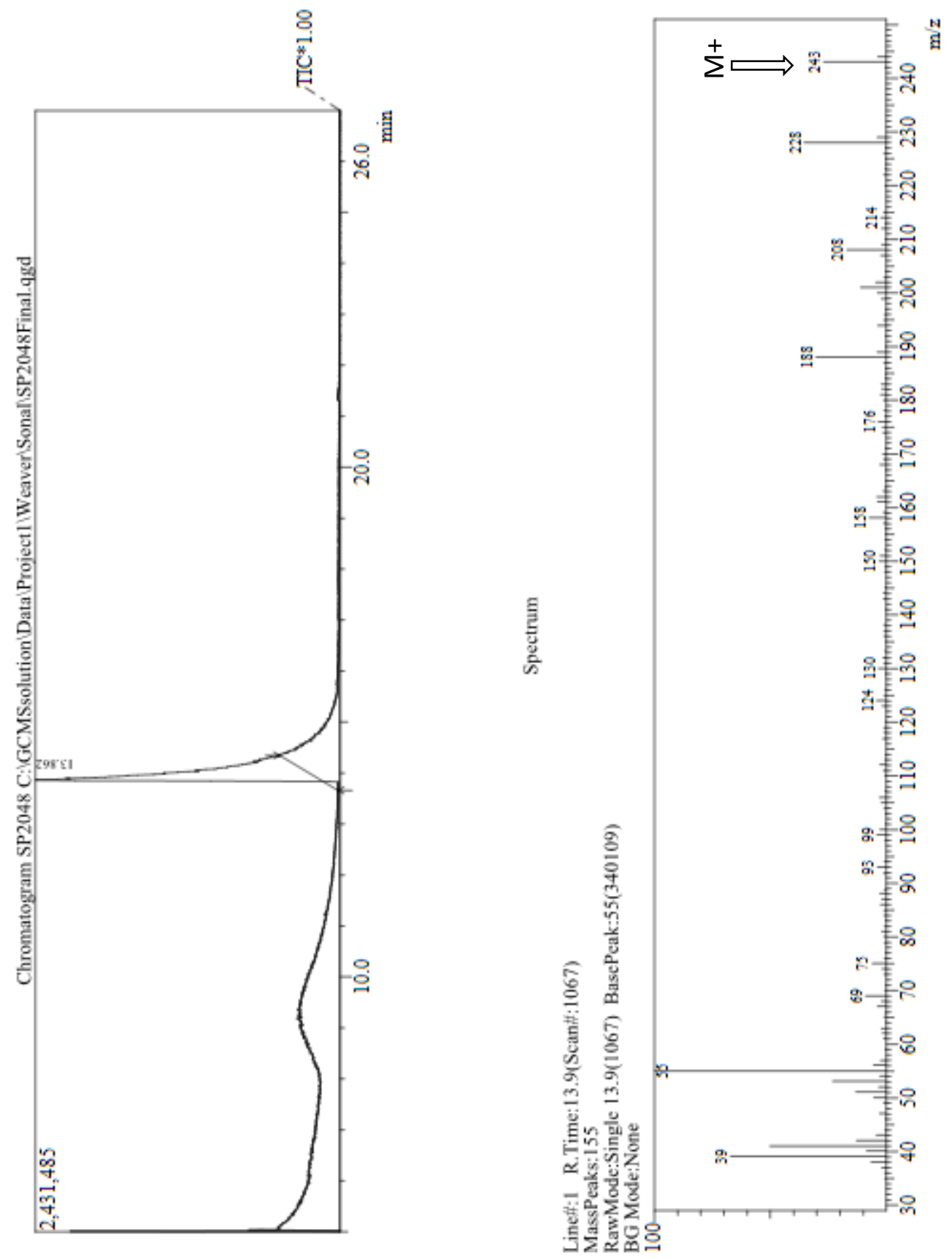
${ }^{19} \mathrm{~F}$ NMR (376 MHz, CDCl3, at rt) spectrum of 1,2,4,5-tetrafluoro-3-(3-methylbut-2-en-1-yl)-6-

(trifluoromethyl)benzene (3e)

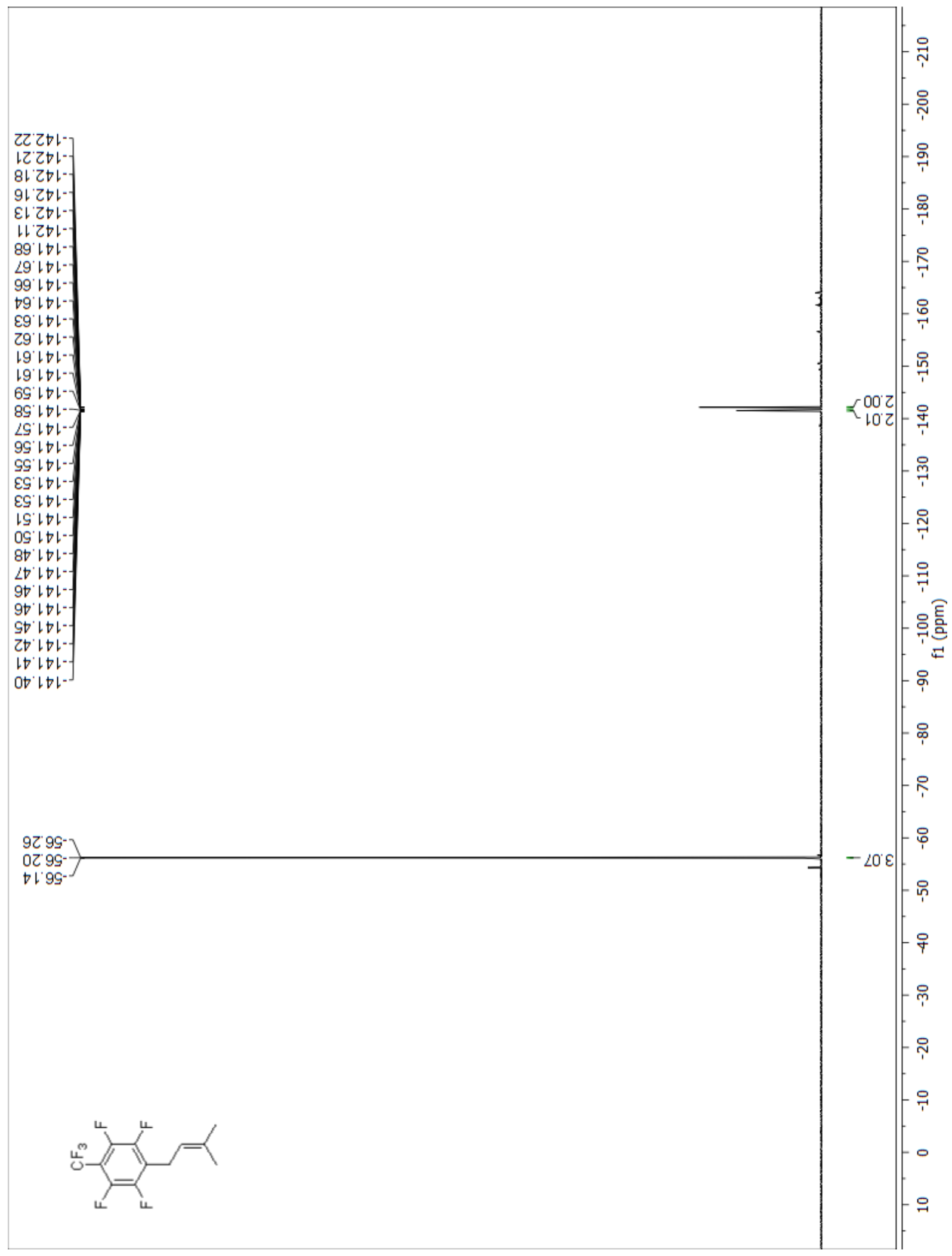


${ }^{1} \mathrm{H}$ NMR (400 MHz, CDCl3, at rt) spectrum of 1,2,4,5-tetrafluoro-3-(3-methylbut-2-en-1-yl)-6-

(trifluoromethyl)benzene (3e)

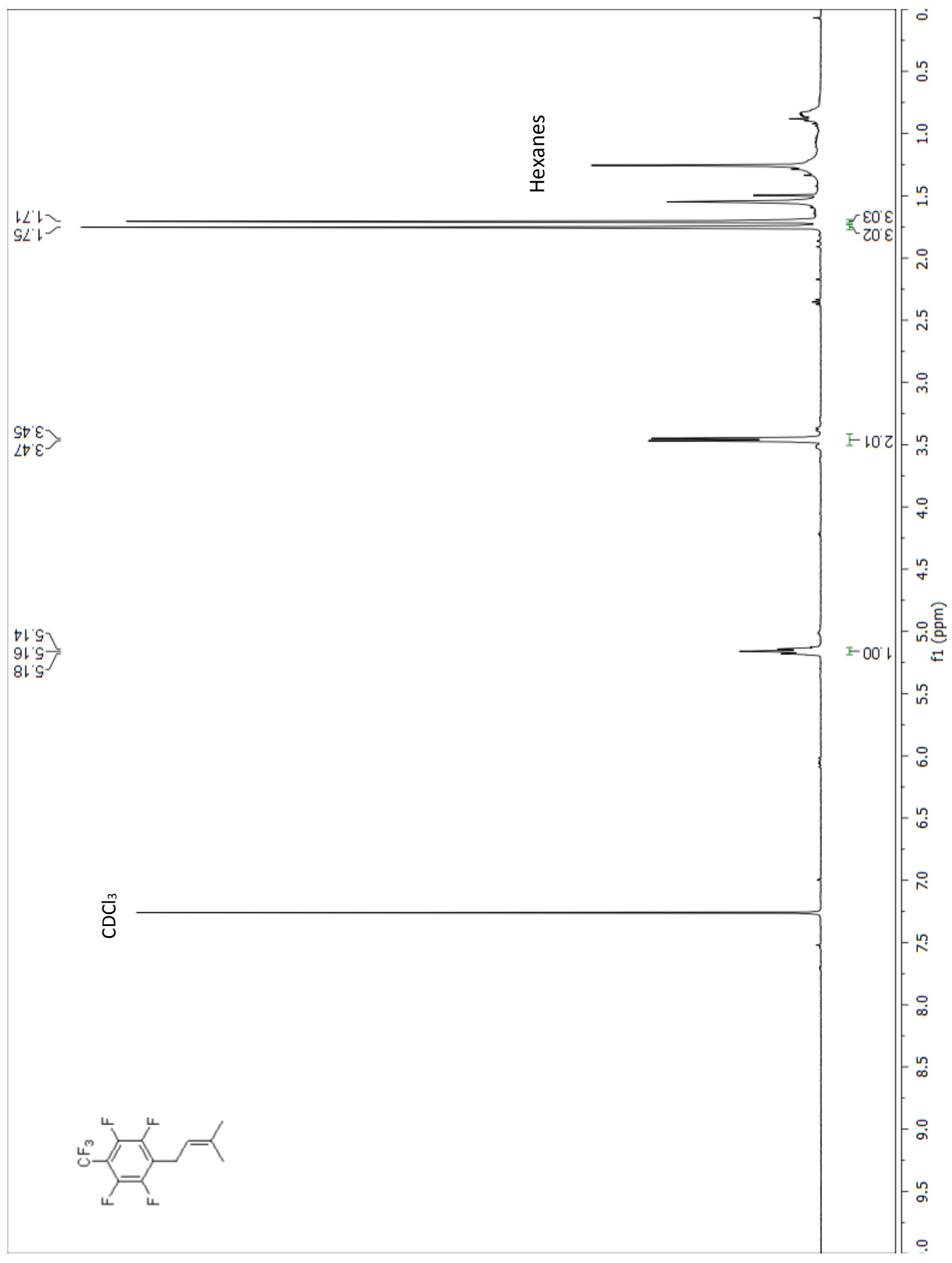


${ }^{13} \mathrm{C}$ NMR (101 MHz, CDCl3, at rt) spectrum of 1,2,4,5-tetrafluoro-3-(3-methylbut-2-en-1-yl)6-(trifluoromethyl)benzene (3e)

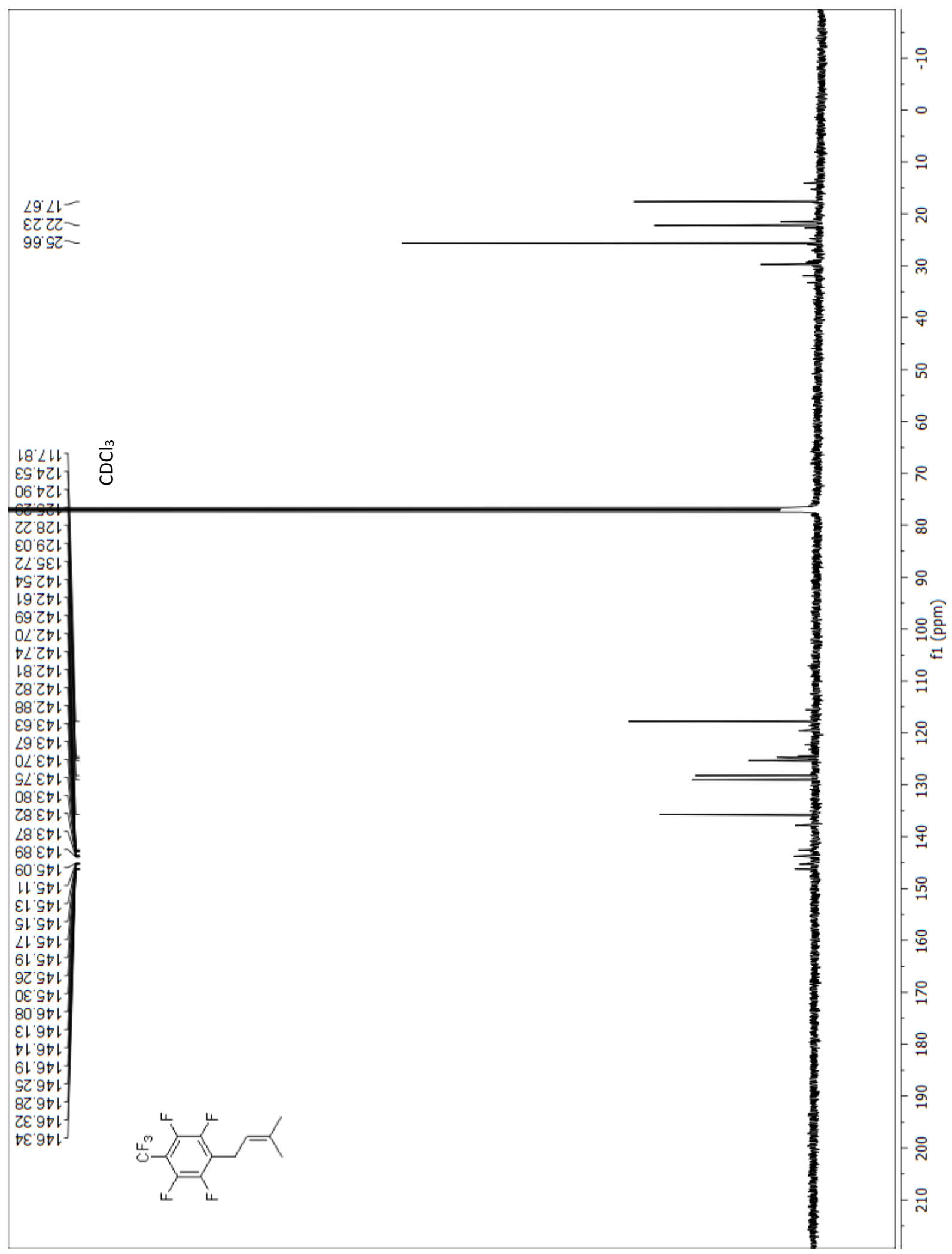


GC and MS of 1,2,4,5-tetrafluoro-3-(3-methylbut-2-en-1-yl)-6-(trifluoromethyl)benzene (3e)
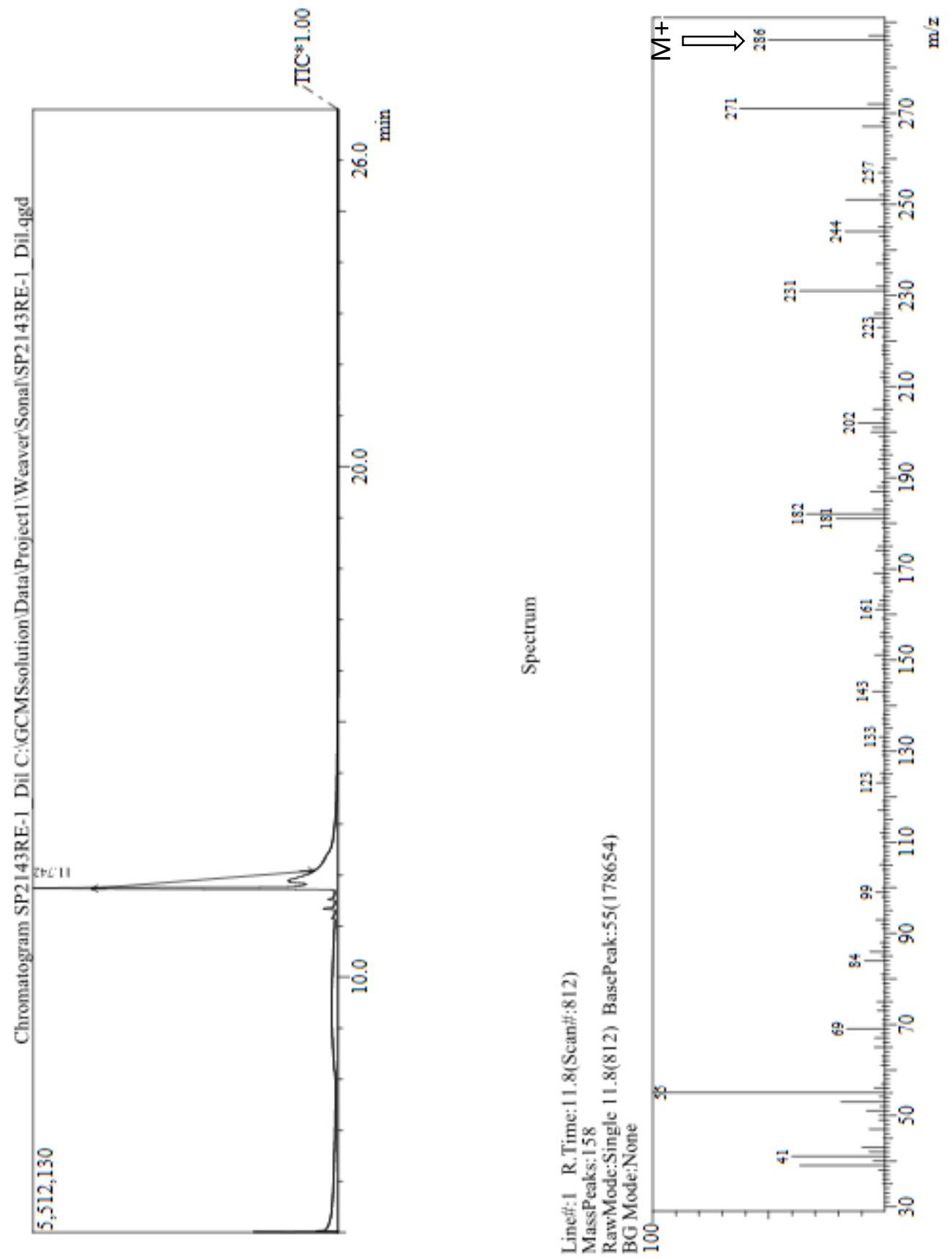
${ }^{19} \mathrm{~F}$ NMR $(376 \mathrm{MHz}, \mathrm{CDCl} 3$, at rt) spectrum of 1,2,3,4,5-pentafluoro-6-(3-methylbut-2-en-1-

yl)benzene (3f)

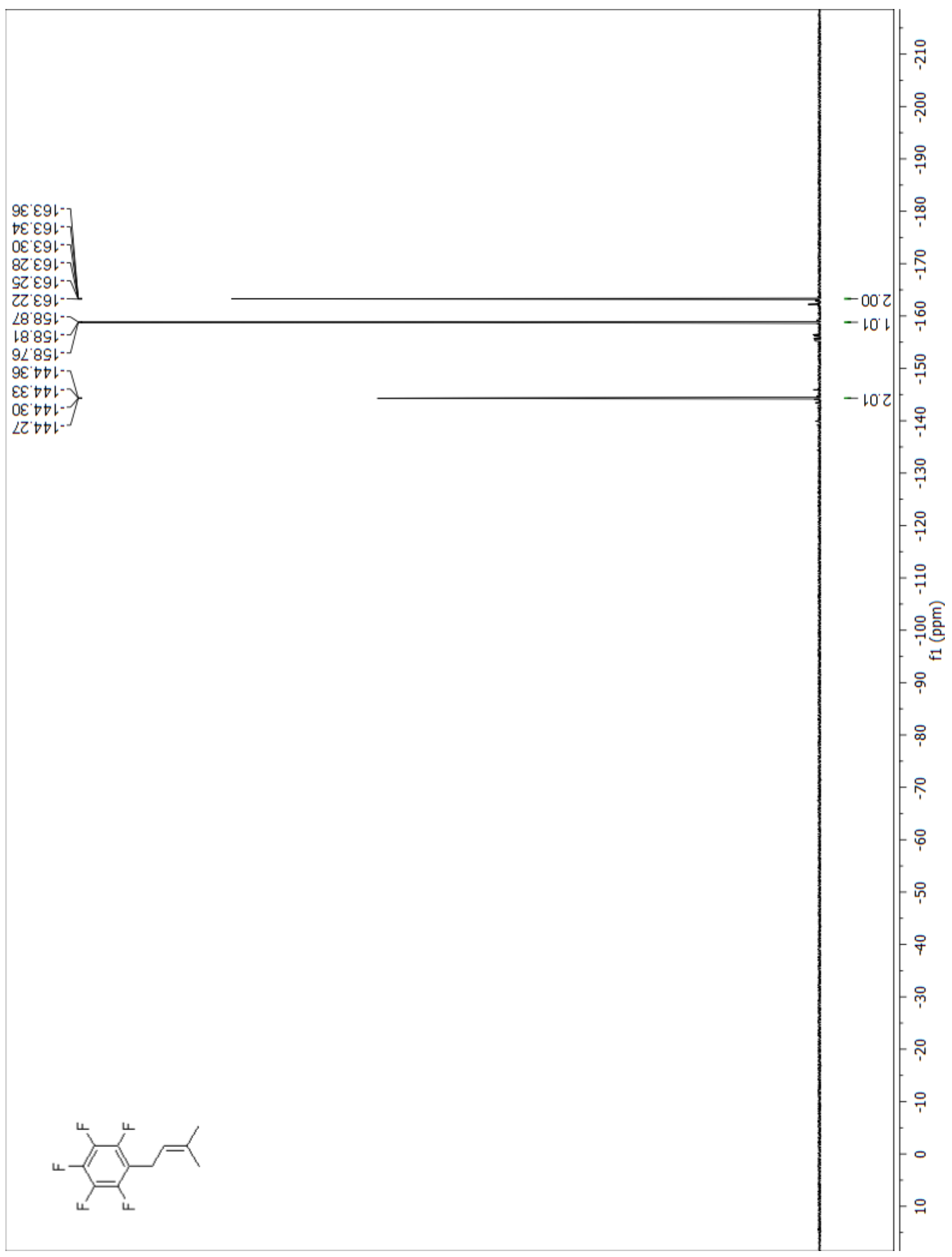


${ }^{1} \mathrm{H}$ NMR (400 MHz, CDCl3, at rt) spectrum of 1,2,3,4,5-pentafluoro-6-(3-methylbut-2-en-1-

yl)benzene (3f)

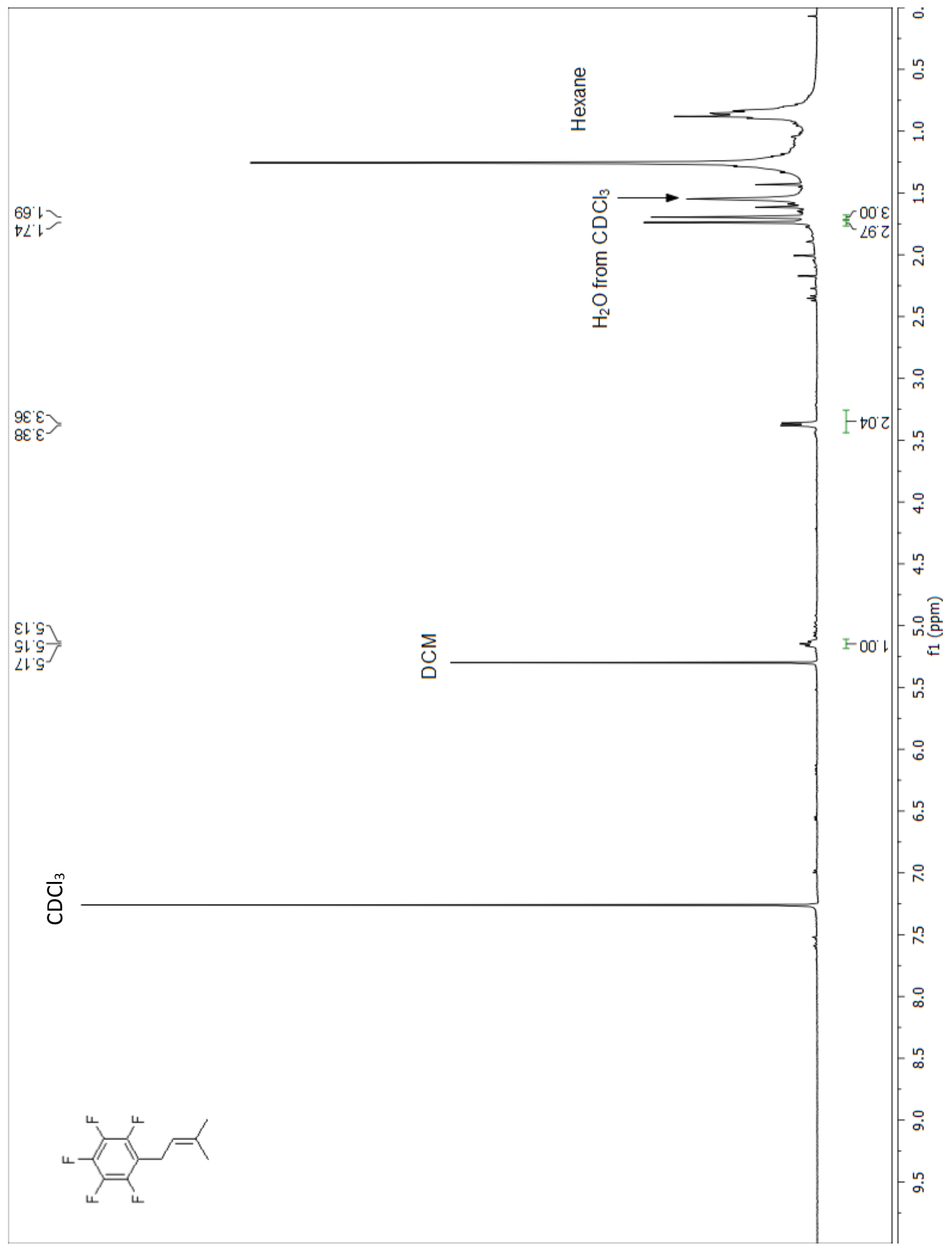

Minimal effort was given to evaporate the solvent due to low volatility of the product. 


\section{GC and MS of 1,2,3,4,5-pentafluoro-6-(3-methylbut-2-en-1-yl)benzene (3f)}

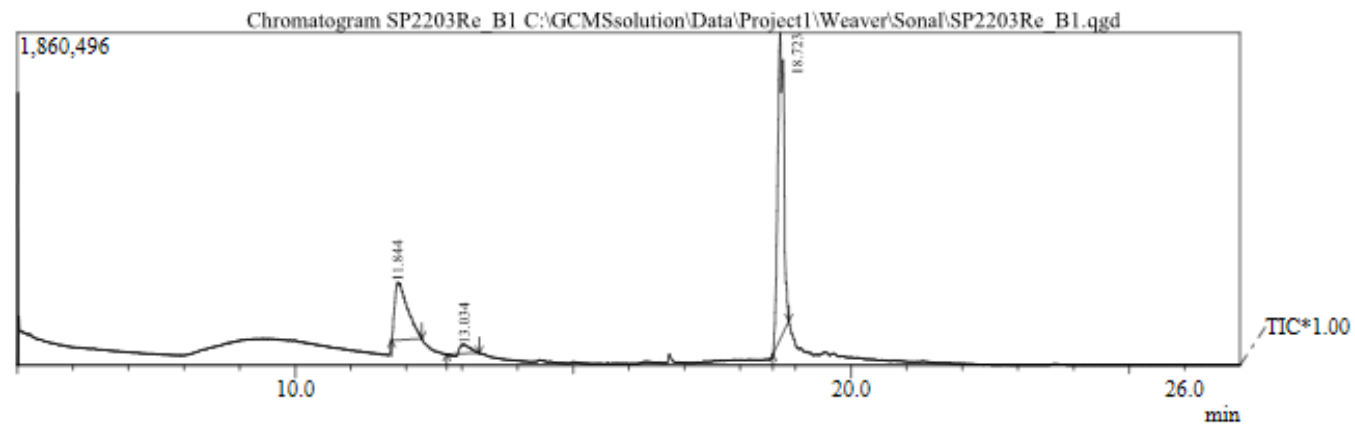

Linet:1 R.Time:11.9(Scan\#:824)

Masspeaks: 75

(B.

$M+$

BG Mode: None

100

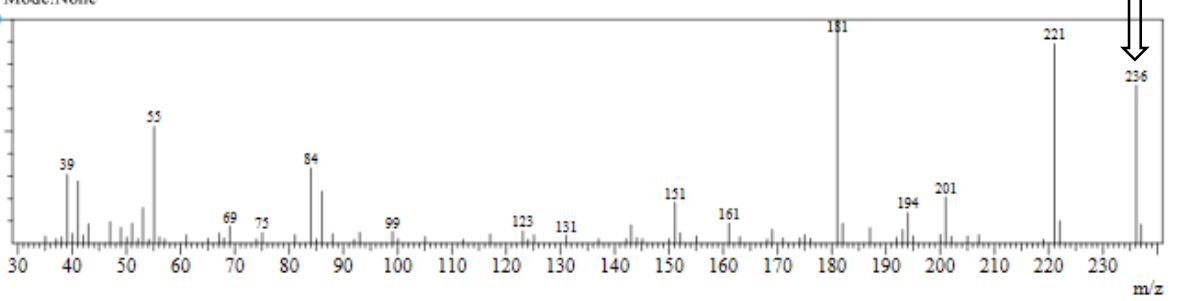

Linett:2 R.Time: 13.1(Scan\#:967)

MassPeaks: 26

13.1(967) BasePeak:89(22175)

BG Mode:None

${ }^{100}$

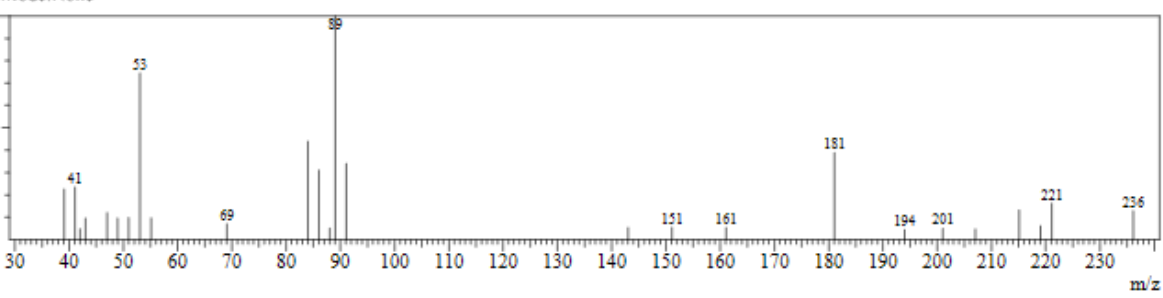

Linef: 3 R.Time: 18.7 (Scan\#:1647)

MassPcaks: 104

RawMode:Single 18.7(1647) BasePeak:167(579185) BG Mode:None

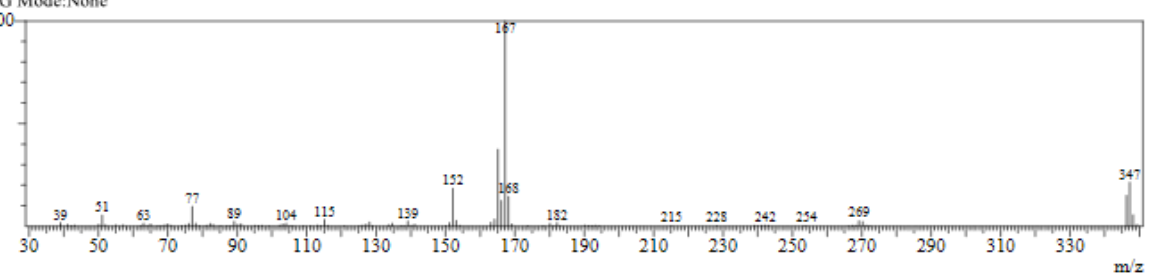


${ }^{19} \mathrm{~F}$ NMR $(376 \mathrm{MHz}, \mathrm{CDCl} 3$, at rt) spectrum of 2,3,5,6-tetrafluoro-4-(3-methylbut-2-en-1-

yl)pyridine (3g)

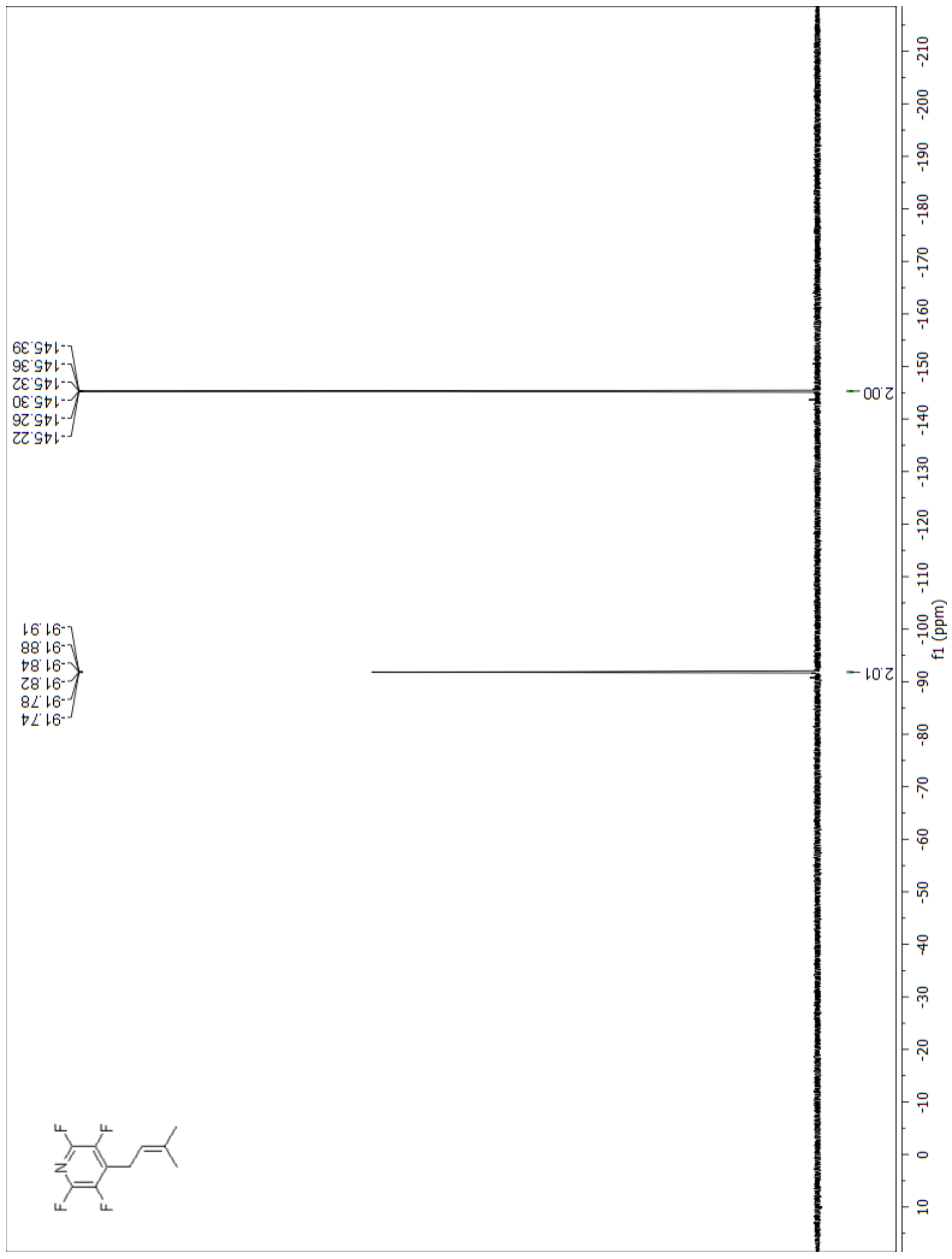


${ }^{1} \mathrm{H}$ NMR (400 MHz, CDCl3, at rt) spectrum of 2,3,5,6-tetrafluoro-4-(3-methylbut-2-en-1-

yl)pyridine (3g)

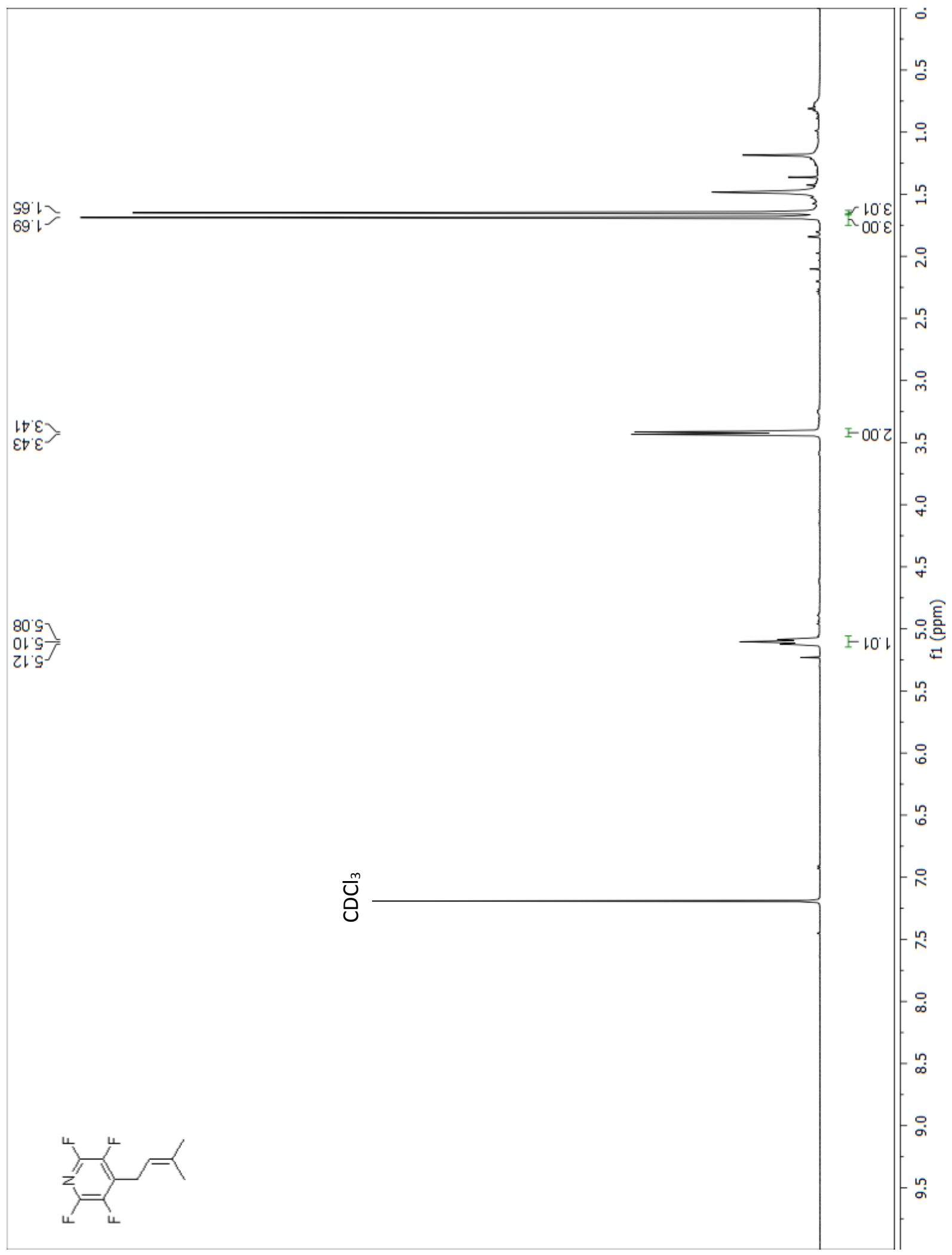


${ }^{13} \mathrm{C}$ NMR (101 MHz, CDCl3, at rt) spectrum of 2,3,5,6-tetrafluoro-4-(3-methylbut-2-en-1-

yl)pyridine (3g)

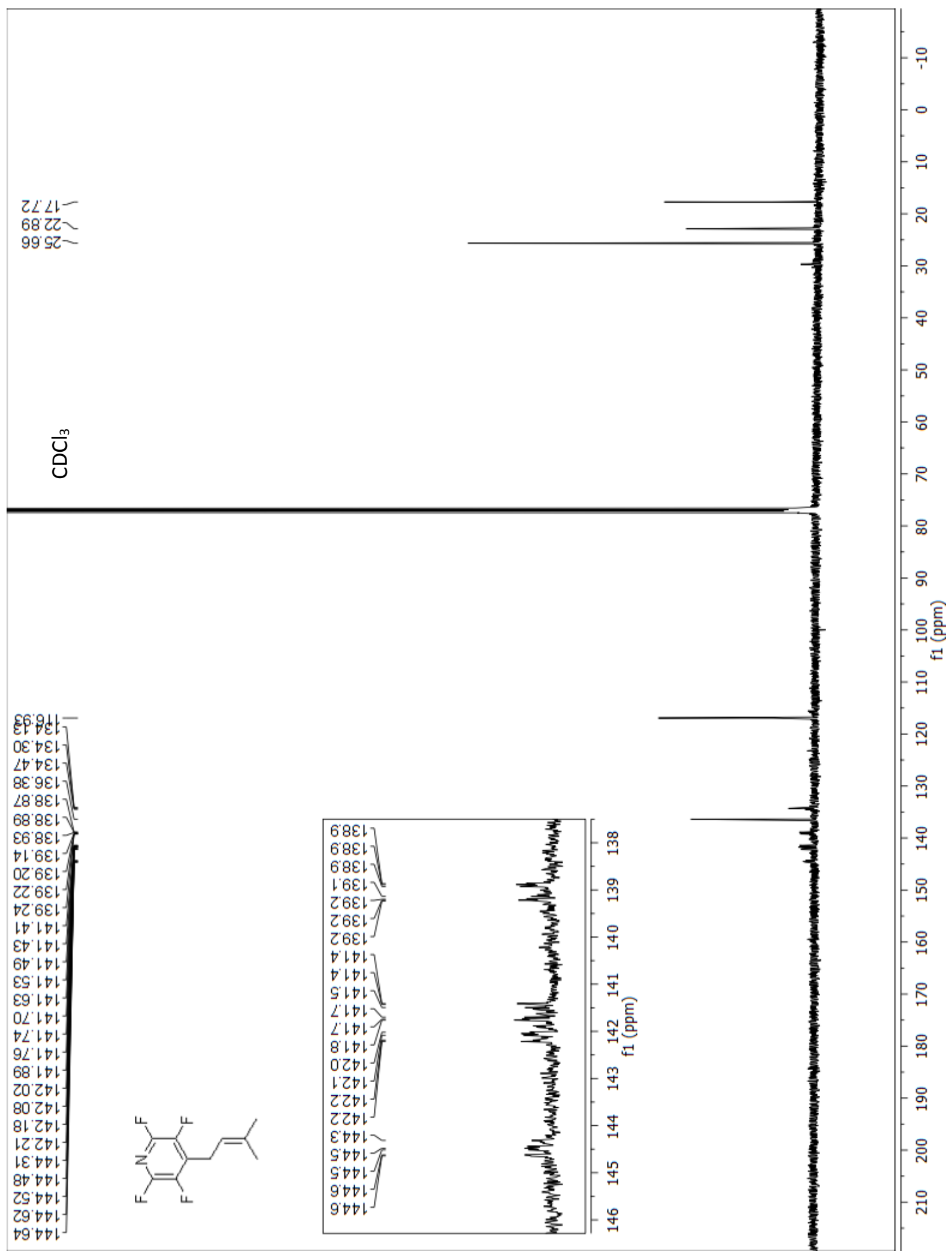


GC and MS of 2,3,5,6-tetrafluoro-4-(3-methylbut-2-en-1-yl)pyridine (3g)
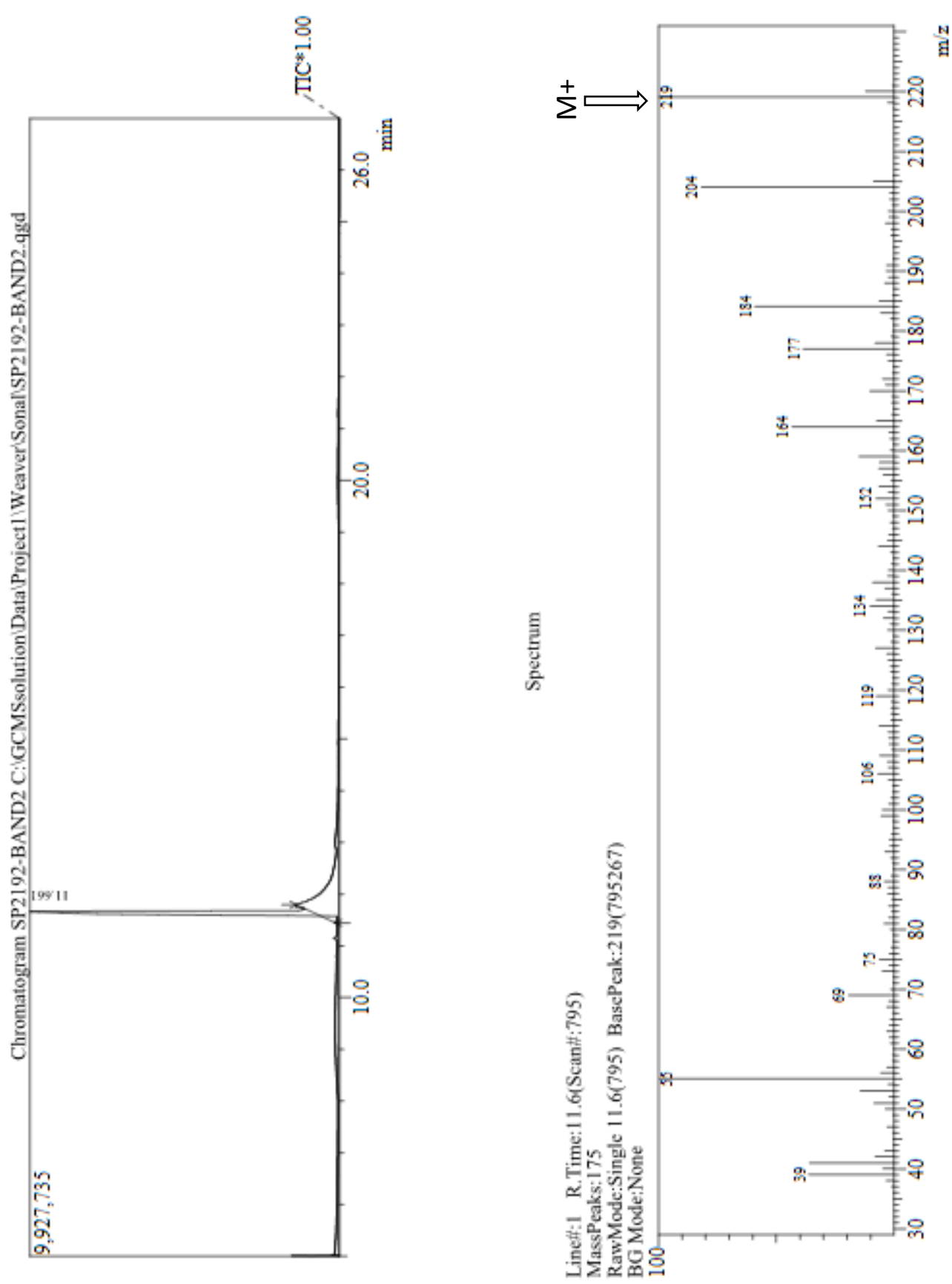
${ }^{19} \mathrm{~F}$ NMR (376 MHz, CDCl3, at rt) spectrum of 2,3,4,6-tetrafluoro-5-(3-methylbut-2-en-1-

yl)pyridine (3i)

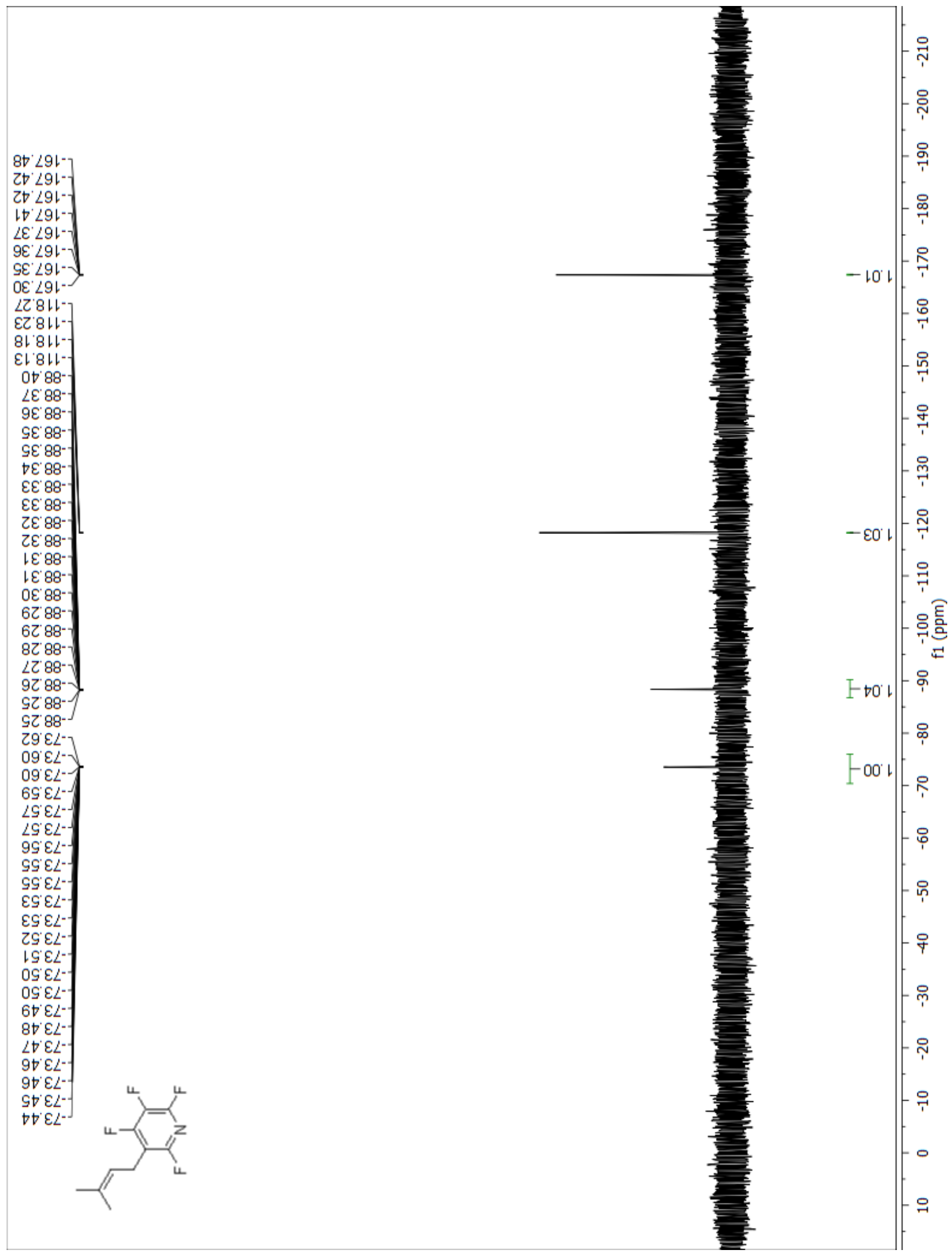


${ }^{1} \mathrm{H}$ NMR (400 MHz, CDCl3, at rt) spectrum of 2,3,4,6-tetrafluoro-5-(3-methylbut-2-en-1-

yl)pyridine (3i)

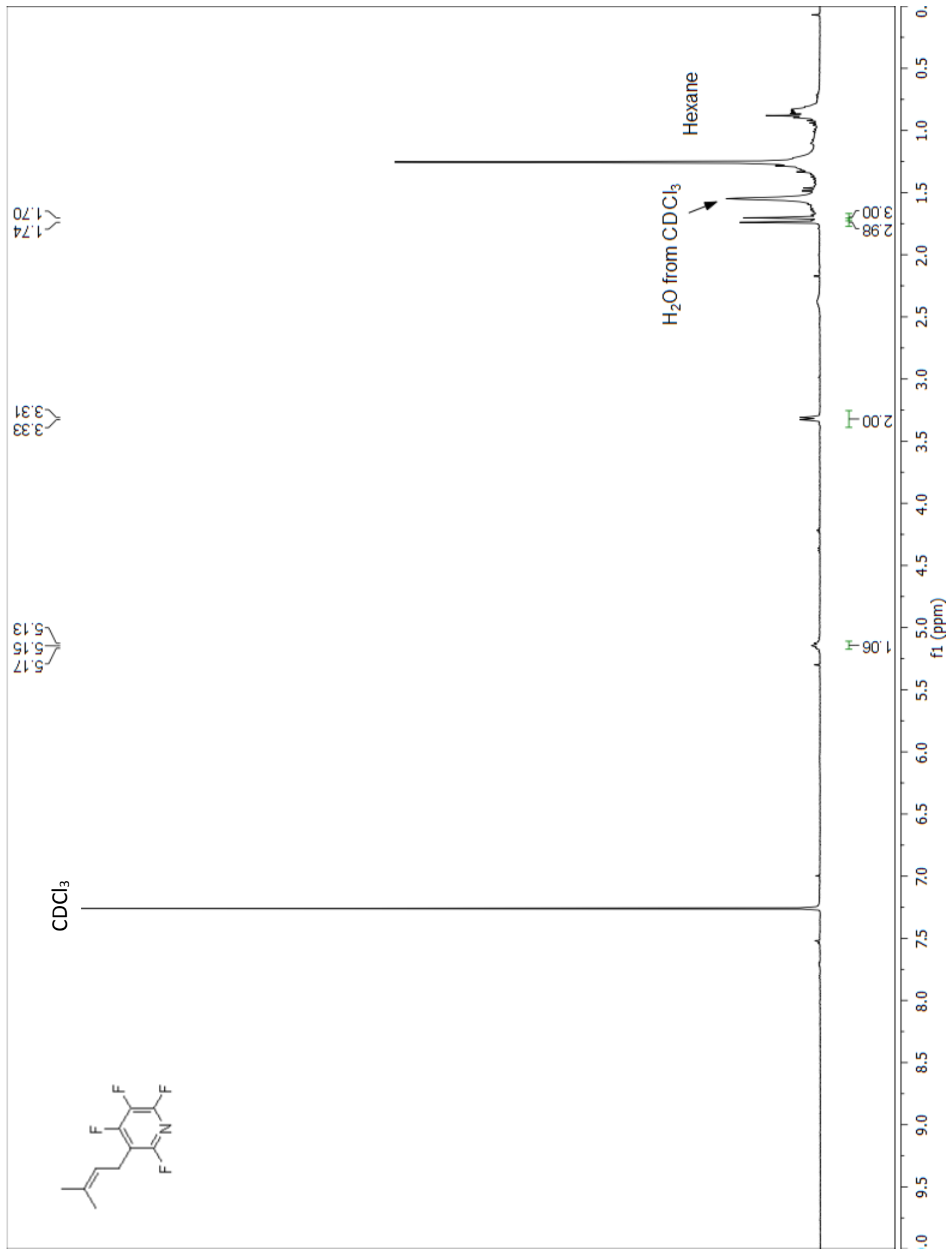


GC and MS of 2,3,4,6-tetrafluoro-5-(3-methylbut-2-en-1-yl)pyridine (3i)
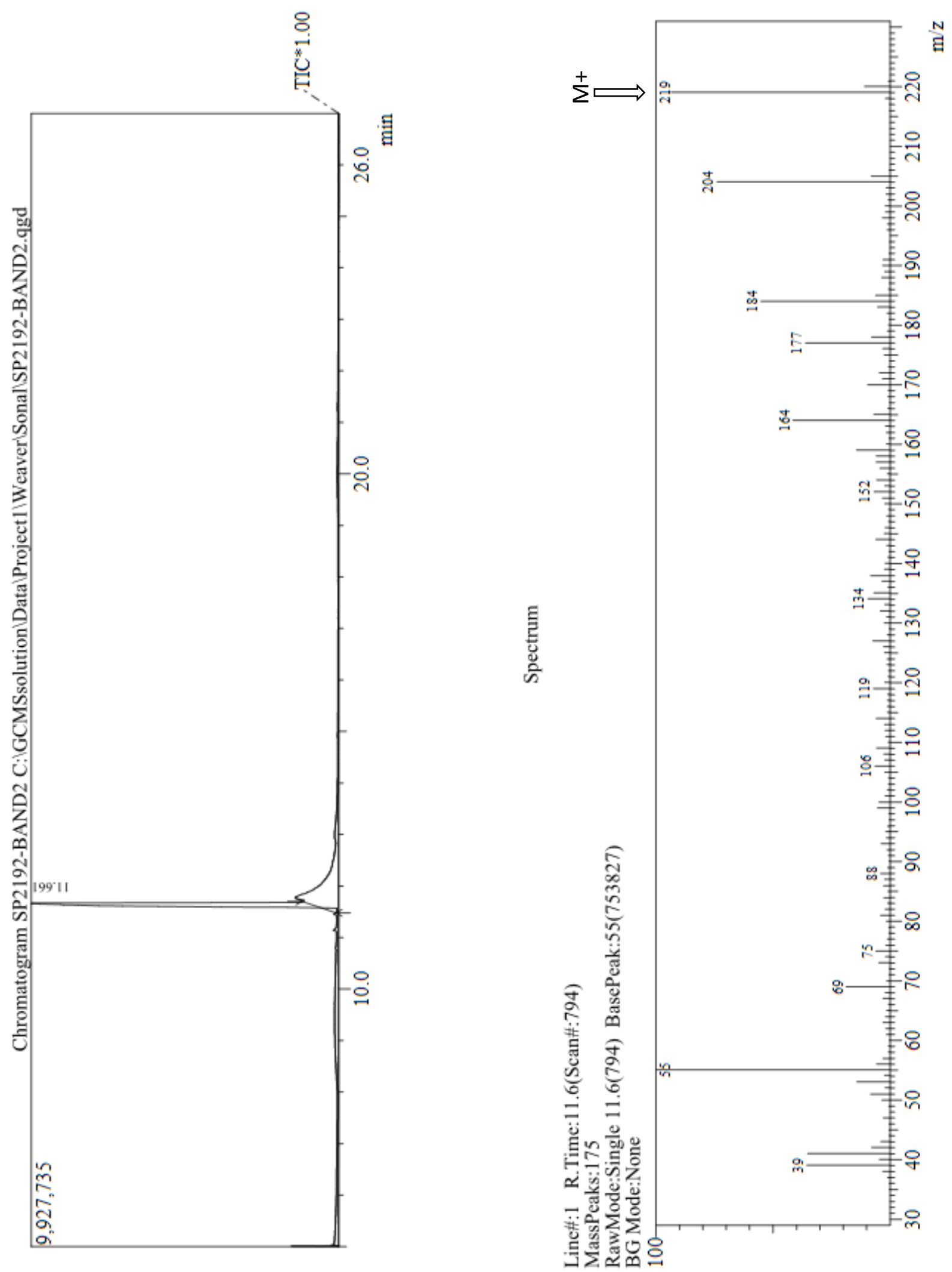
${ }^{19} \mathrm{~F}$ NMR $(376 \mathrm{MHz}, \mathrm{CDCl} 3$, at rt) spectrum of 3-chloro-2,4,6-trifluoro-5-(3-methylbut-2-en-1-

yl)pyridine (3j)

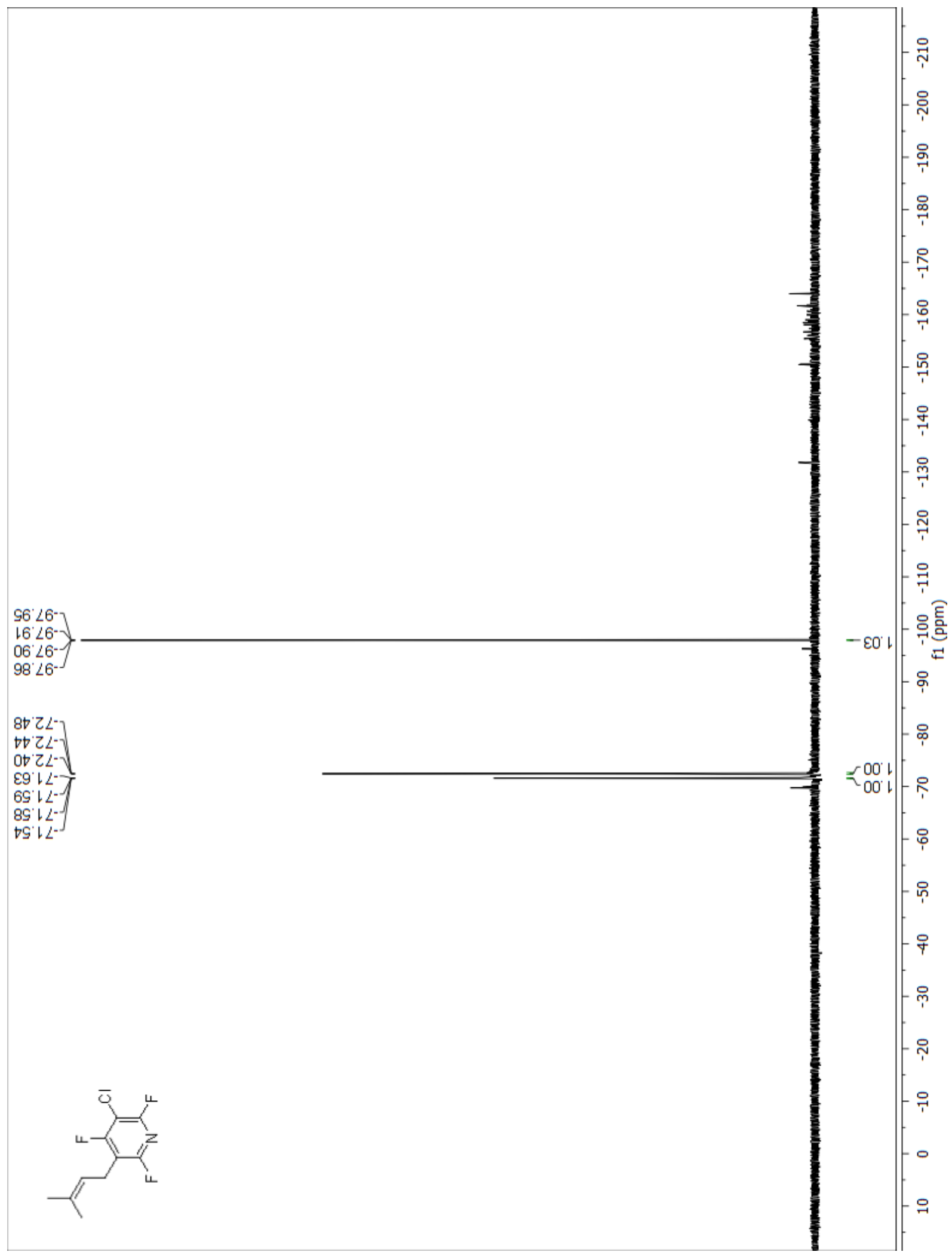


${ }^{1} \mathrm{H}$ NMR (400 MHz, CDCl3, at rt) spectrum of 3-chloro-2,4,6-trifluoro-5-(3-methylbut-2-en-1yl)pyridine (3j)

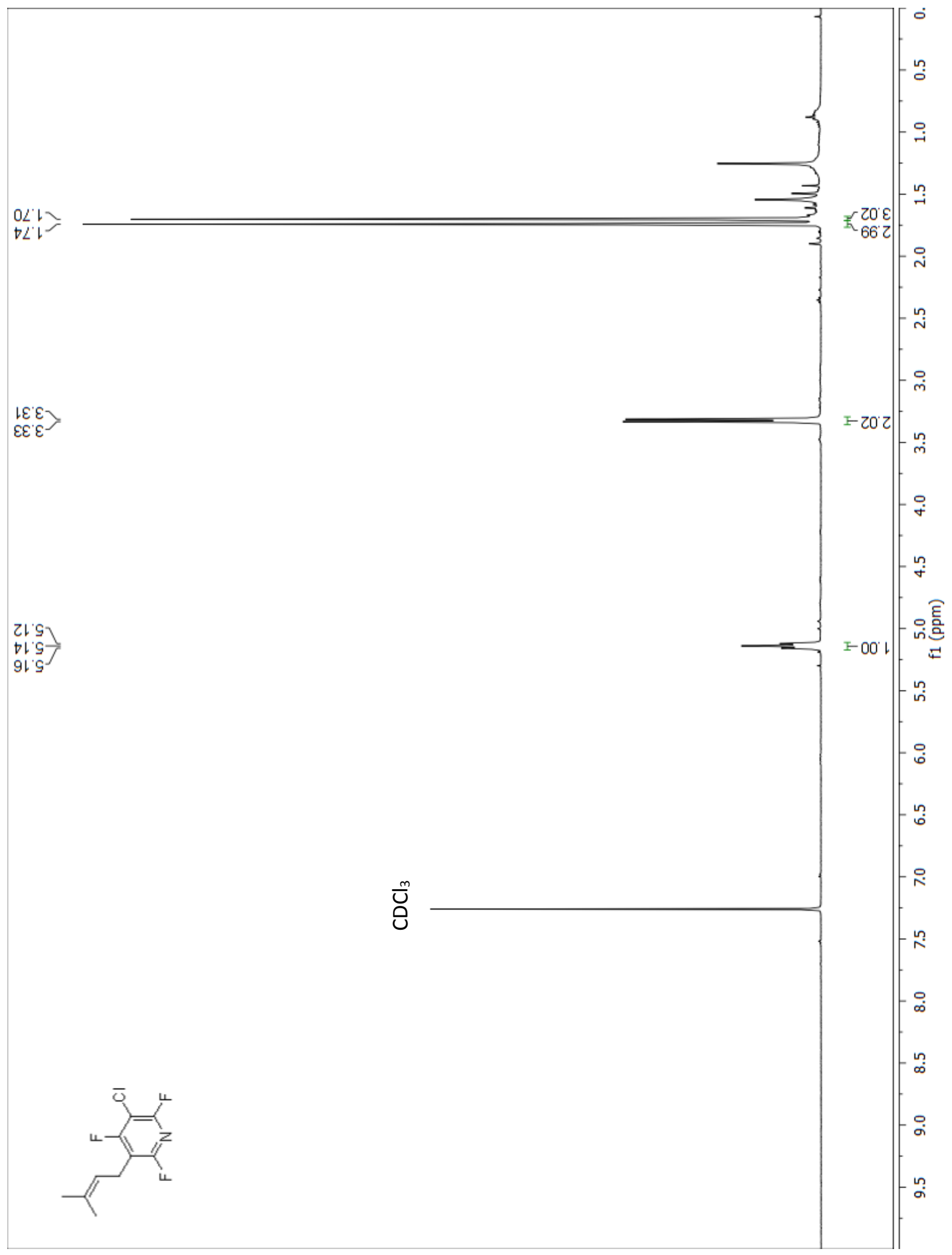


${ }^{13} \mathrm{C}$ NMR (101 MHz, CDCl3, at rt) spectrum of 3-chloro-2,4,6-trifluoro-5-(3-methylbut-2-en-1-

yl)pyridine (3j)

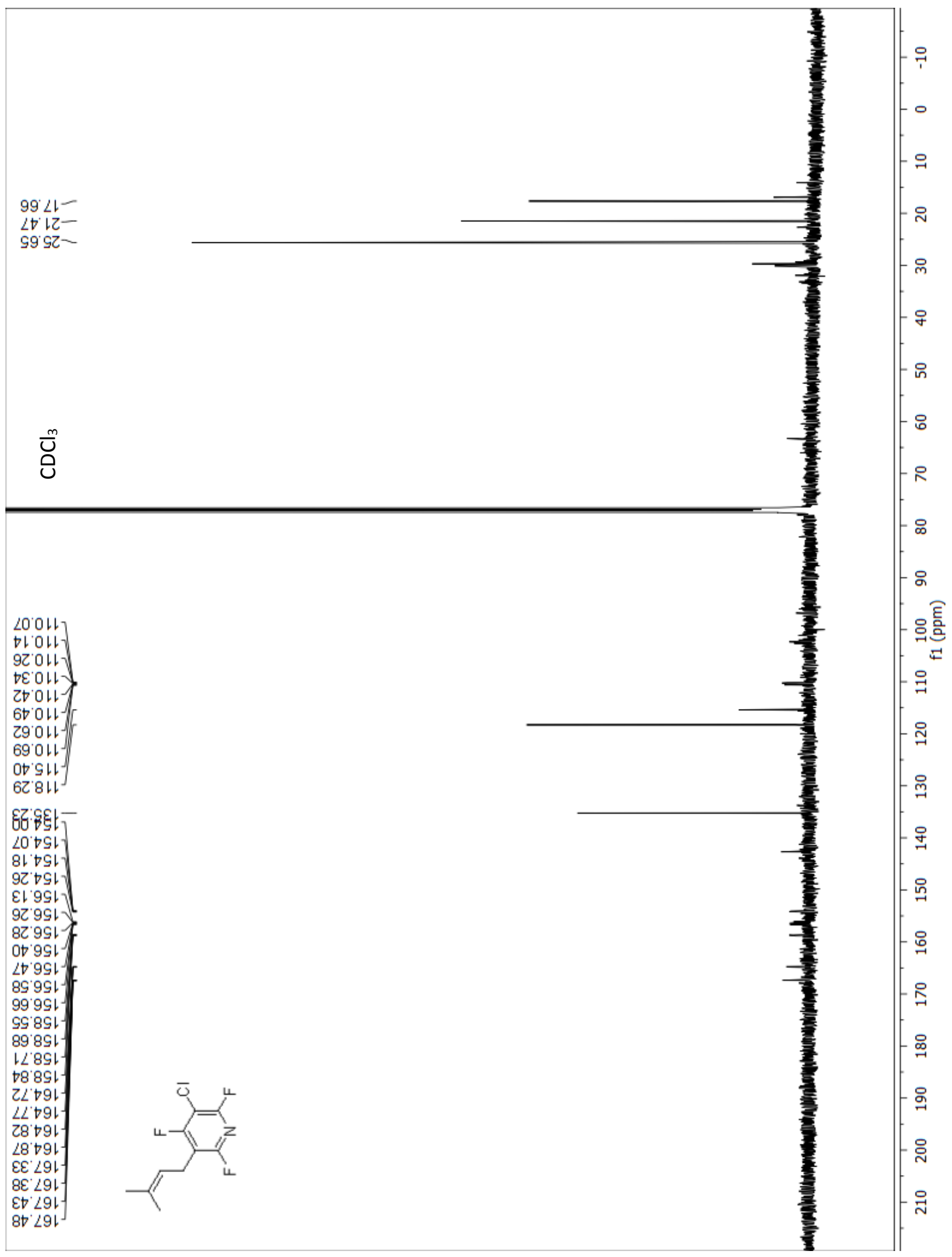


GC and MS of 3-chloro-2,4,6-trifluoro-5-(3-methylbut-2-en-1-yl)pyridine (3j)
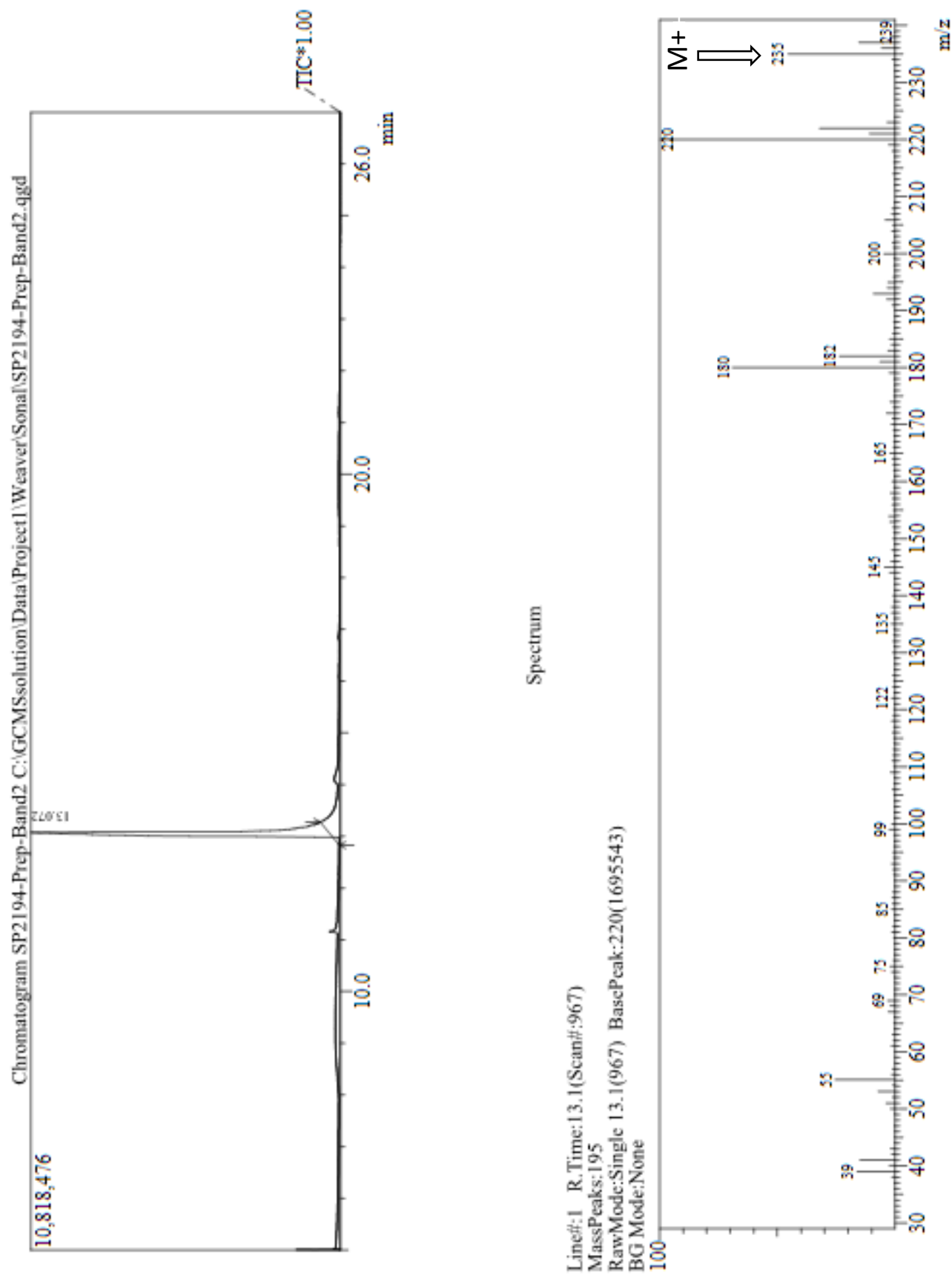
${ }^{19}$ F NMR (376 MHz, CDCl3, at rt) spectrum of 3-chloro-2,5,6-trifluoro-4-(3-methylbut-2-en-

\section{1-yl)pyridine (3k)}

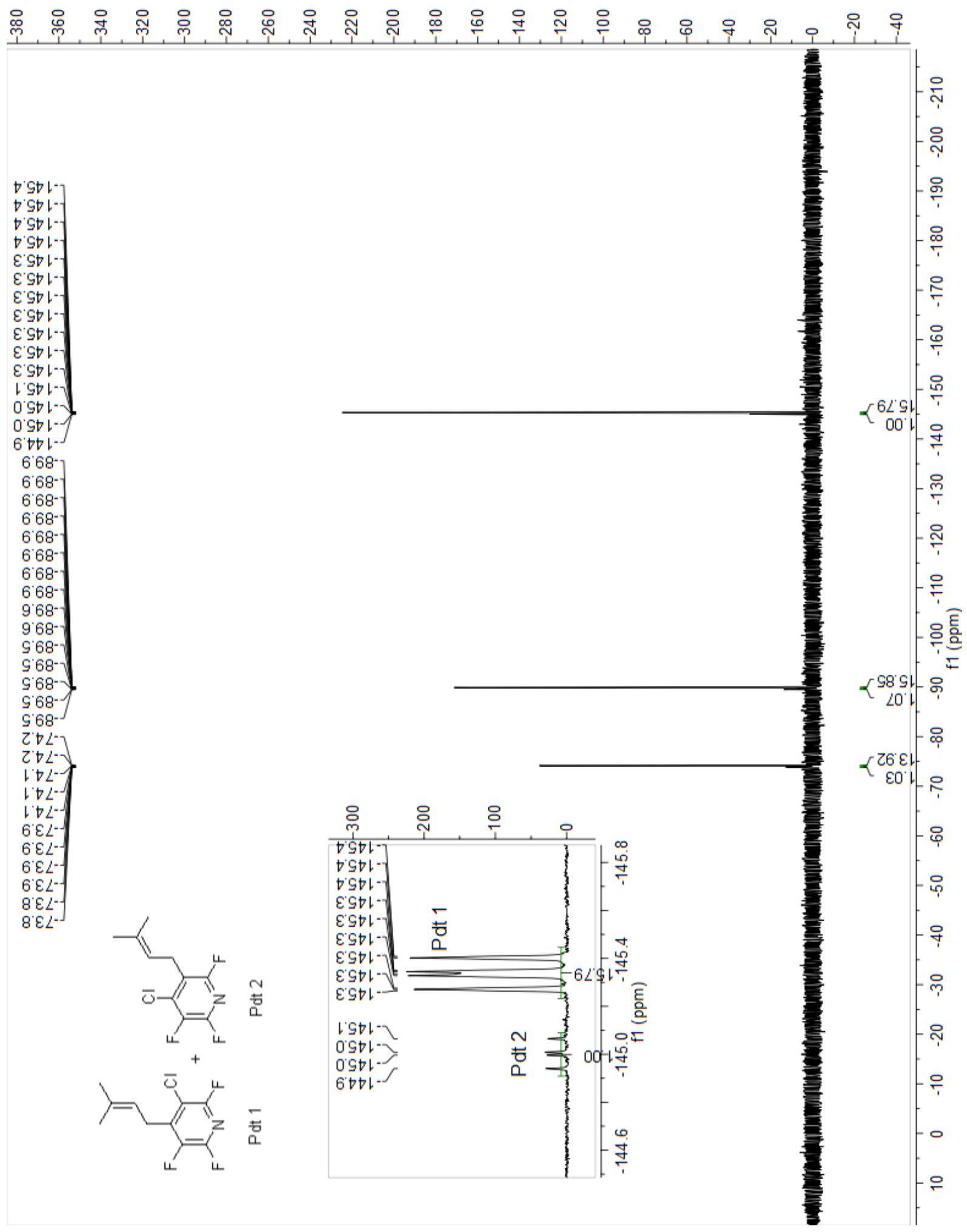


${ }^{1} \mathrm{H}$ NMR (400 MHz, CDCl3, at rt) spectrum of 3-chloro-2,5,6-trifluoro-4-(3-methylbut-2-en-1yl)pyridine (3k)

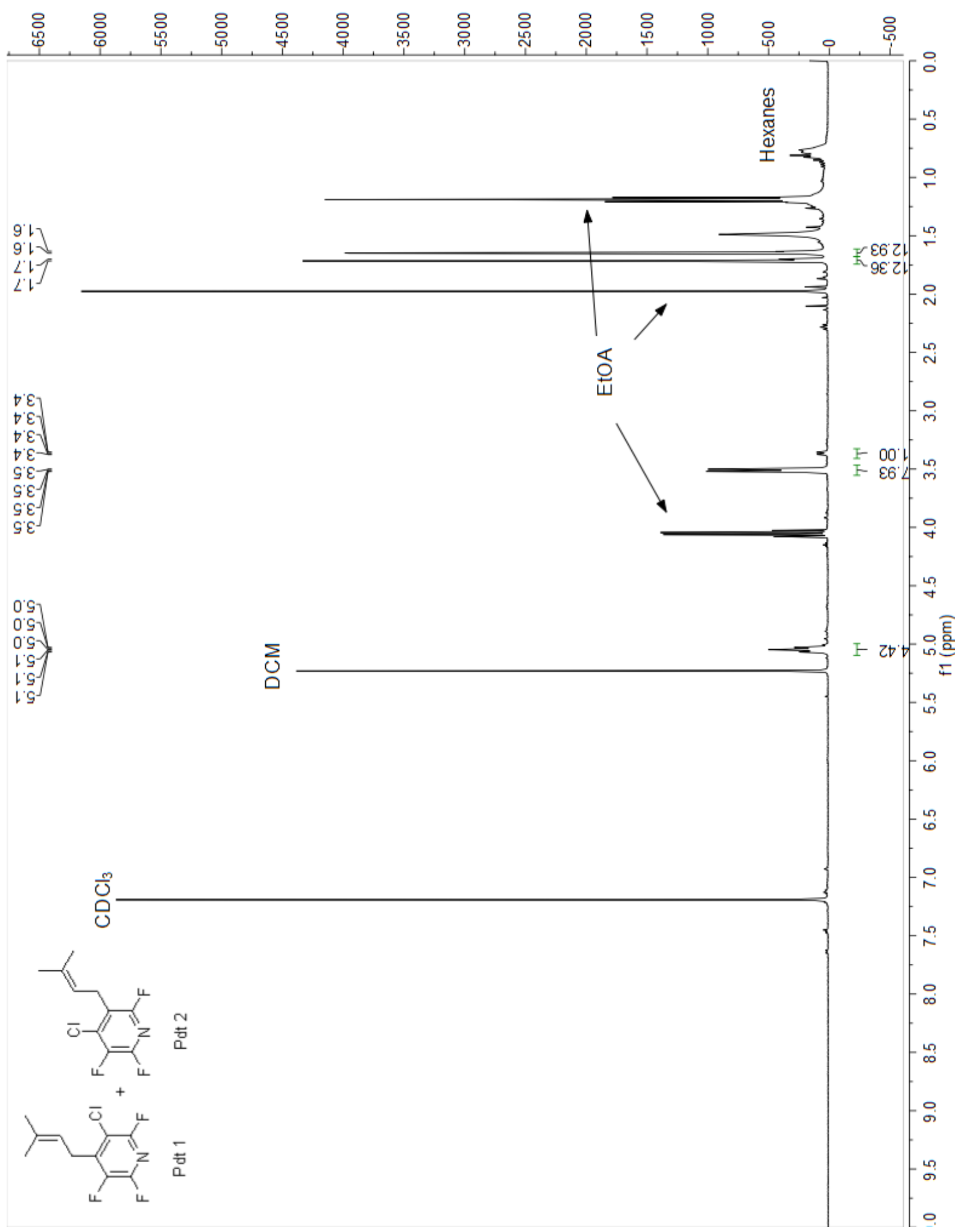




\section{GC and MS of 3-chloro-2,5,6-trifluoro-4-(3-methylbut-2-en-1-yl)pyridine (3k)}

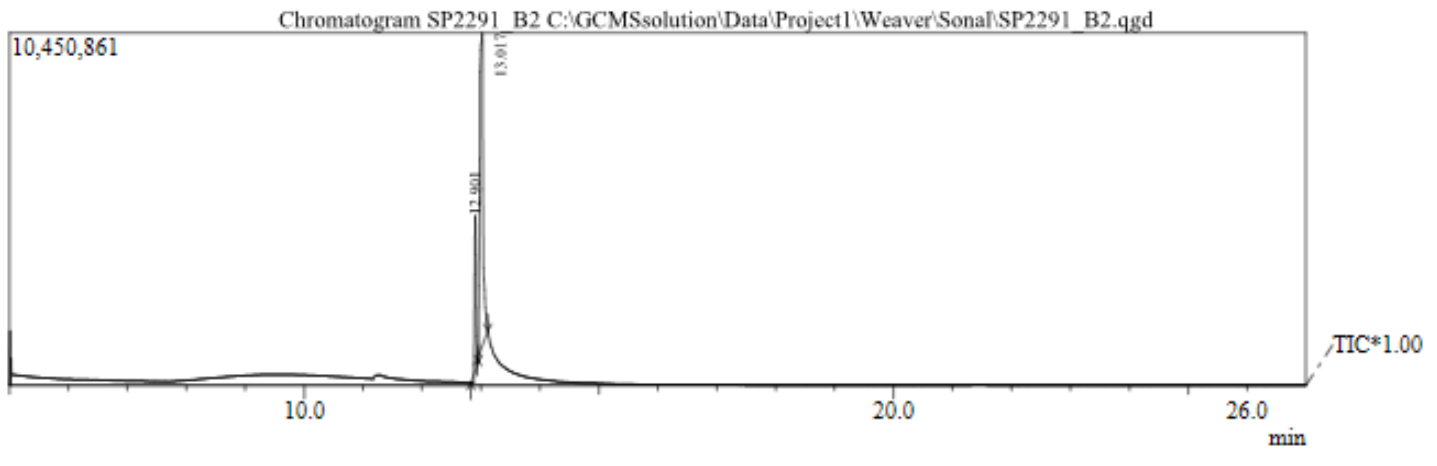

Spectrum

LineH:1 R.Time:12.9(Scant:950)

MassPeaks: 189

RawMode:Single 12.9(950) BasePeak:220(385938)

BG Mode: None

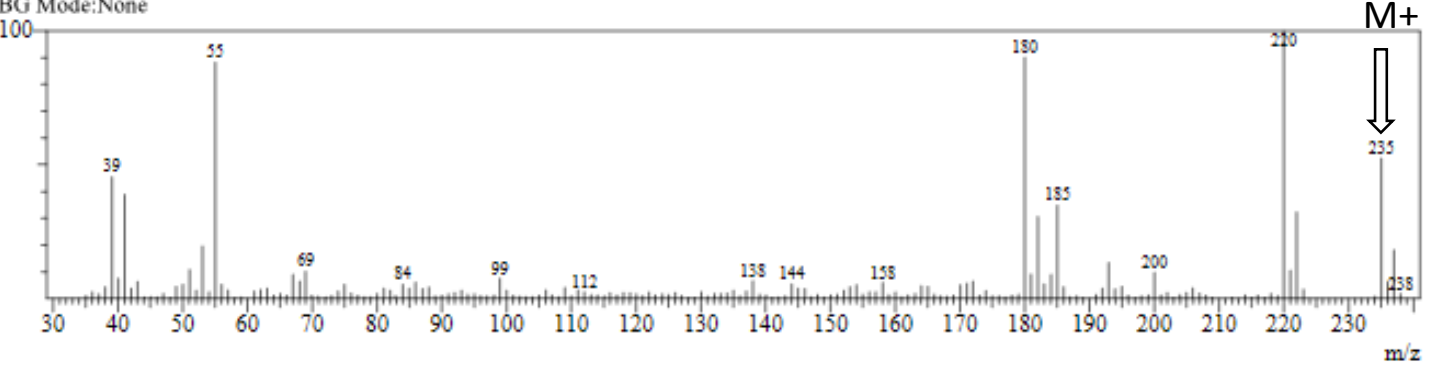

Line\#:2 R.Time: 13.0 (Scan\#:965)

MassPeaks: 191

RawMode:Single 13.0(965) BasePeak:55(870577)

BG Mode:None

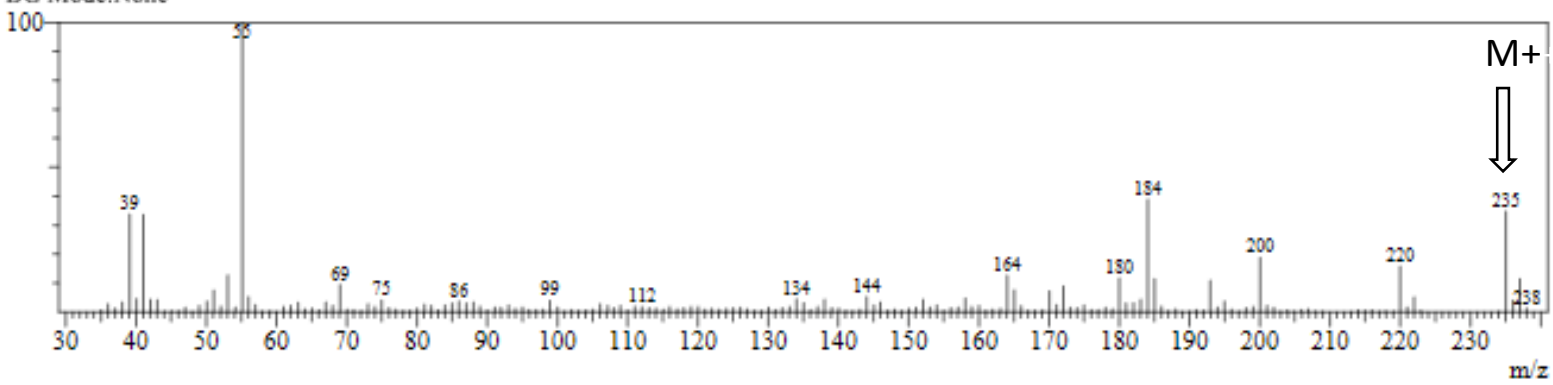


${ }^{19} \mathrm{~F}$ NMR (376 MHz, CDCl3, at rt) spectrum of 3,5-dichloro-2,6-difluoro-4-(3-methylbut-2-en-

\section{1-yl)pyridine (3I)}

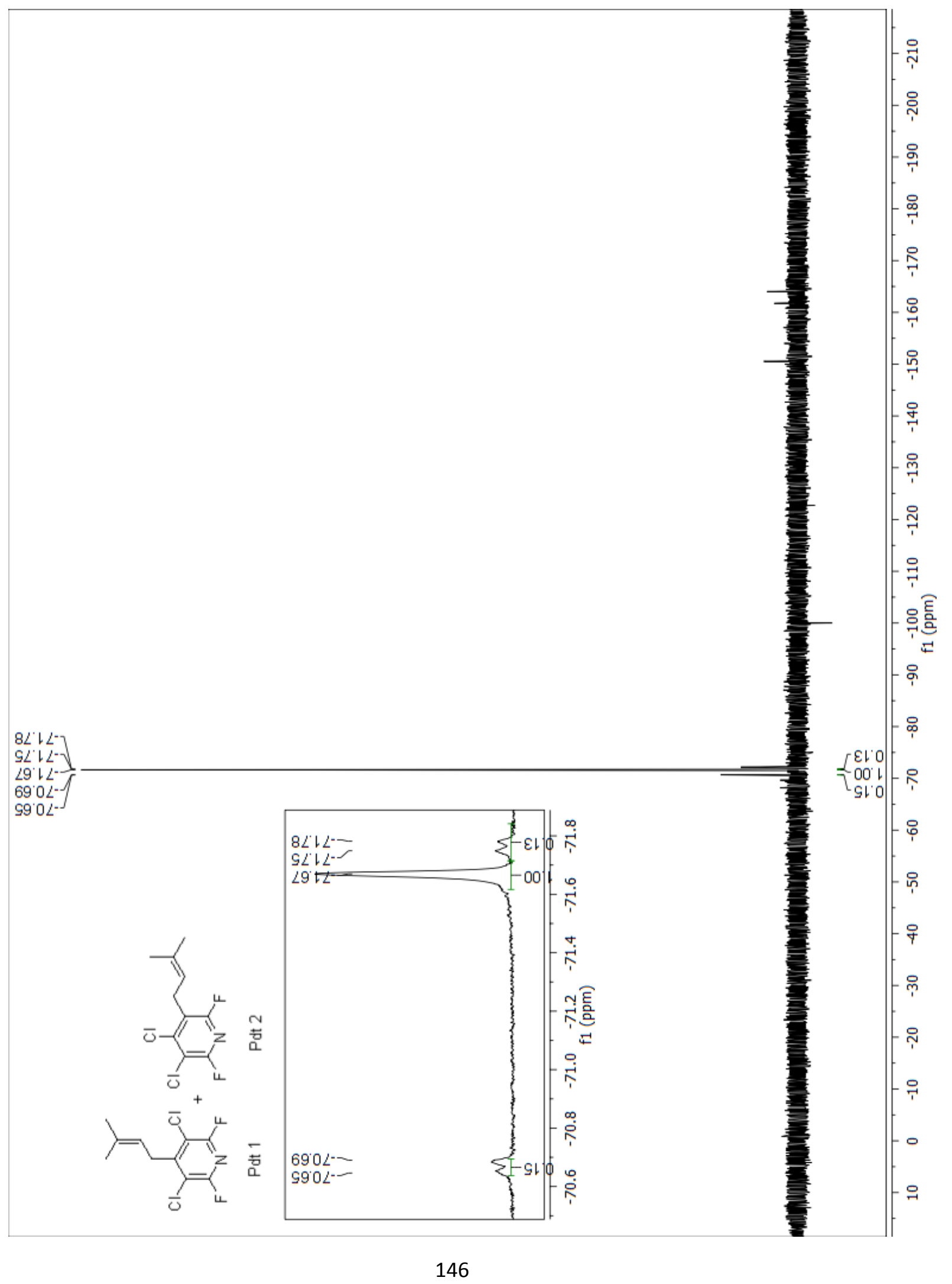


${ }^{1} \mathrm{H}$ NMR (400 MHz, CDCl3, at rt) spectrum of 3,5-dichloro-2,6-difluoro-4-(3-methylbut-2-en-

\section{1-yl)pyridine (31)}

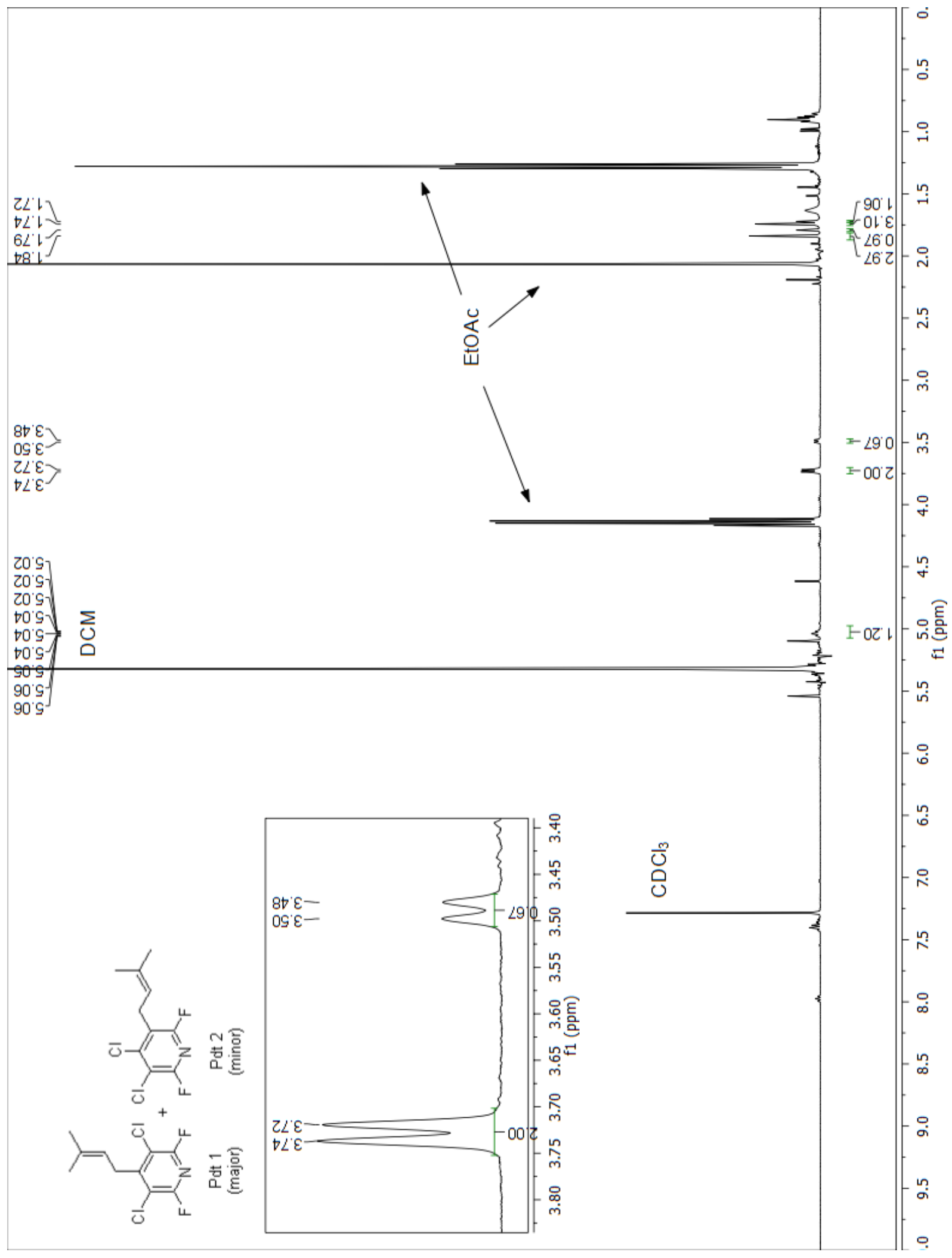




\section{GC and MS of 3,5-dichloro-2,6-difluoro-4-(3-methylbut-2-en-1-yl)pyridine (31)}

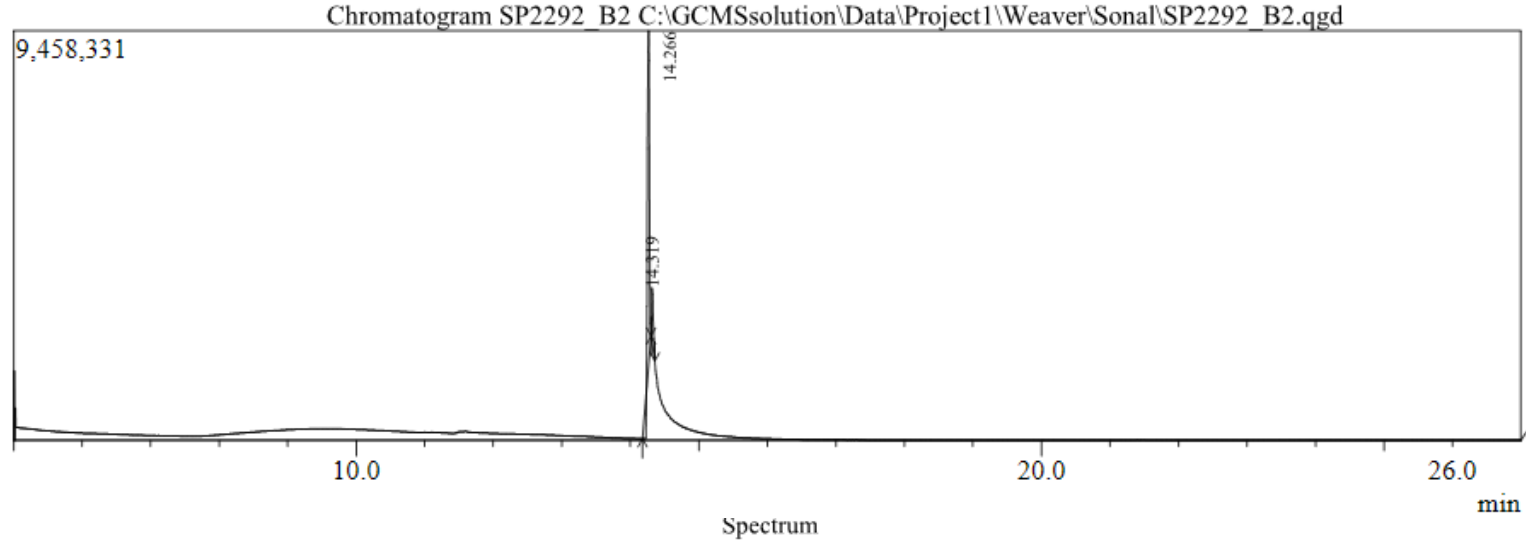

Line\#:1 R.Time:14.3(Scan\#:1111)

MassPeaks:199

RawMode:Single 14.3(1111) BasePeak:55(830922)

BG Mode:None

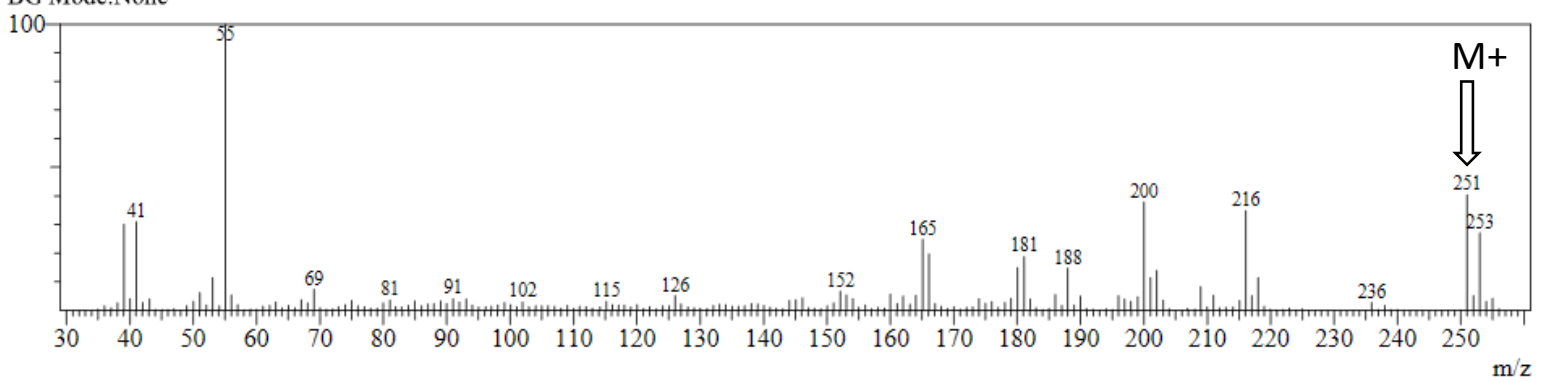

Line\#:2 R.Time:14.3(Scan\#:1119)

MassPeaks:204

RawMode:Single 14.3(1119) BasePeak:55(346766)

BG Mode:None

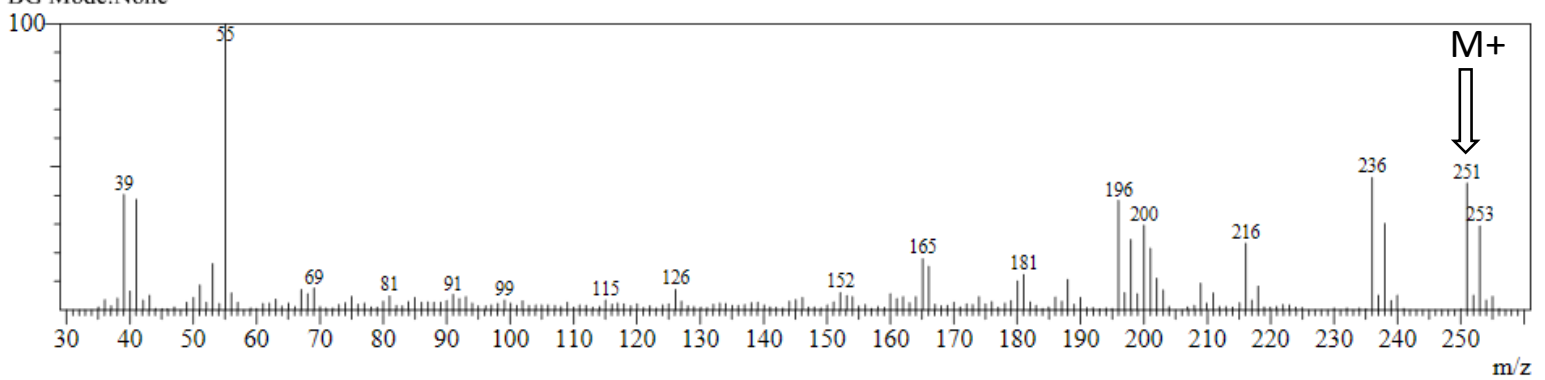


${ }^{19} \mathrm{~F}$ NMR $(376 \mathrm{MHz}, \mathrm{CDCl} 3$, at rt) spectrum of 2-(2,3,5,6-tetrafluoro-4-(3-methylbut-2-en-1-

yl)phenyl)benzo[d]oxazole (3m)

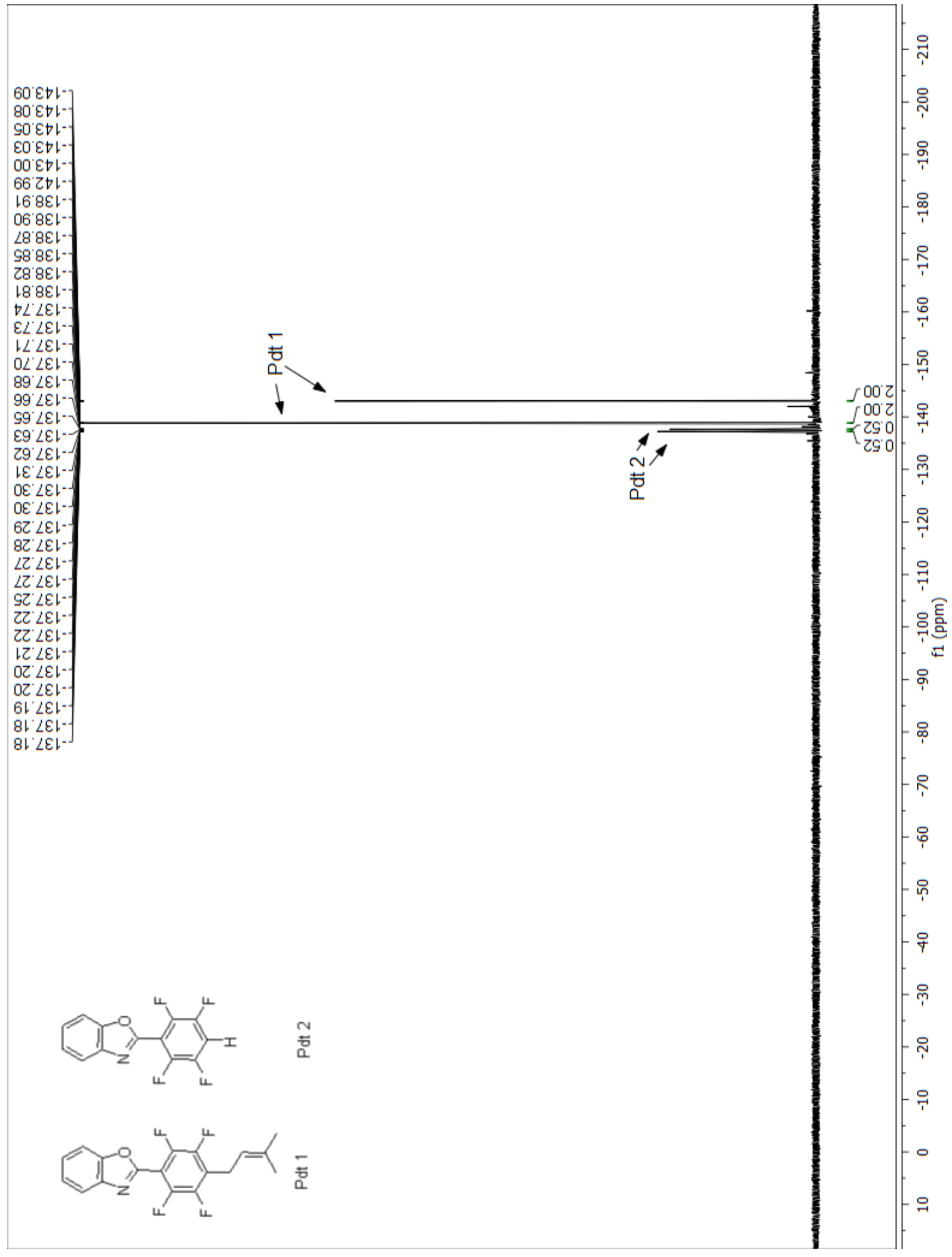


${ }^{1} \mathrm{H}$ NMR (400 MHz, CDCl3, at rt) spectrum of 2-(2,3,5,6-tetrafluoro-4-(3-methylbut-2-en-1-

yl)phenyl)benzo[d]oxazole (3m)

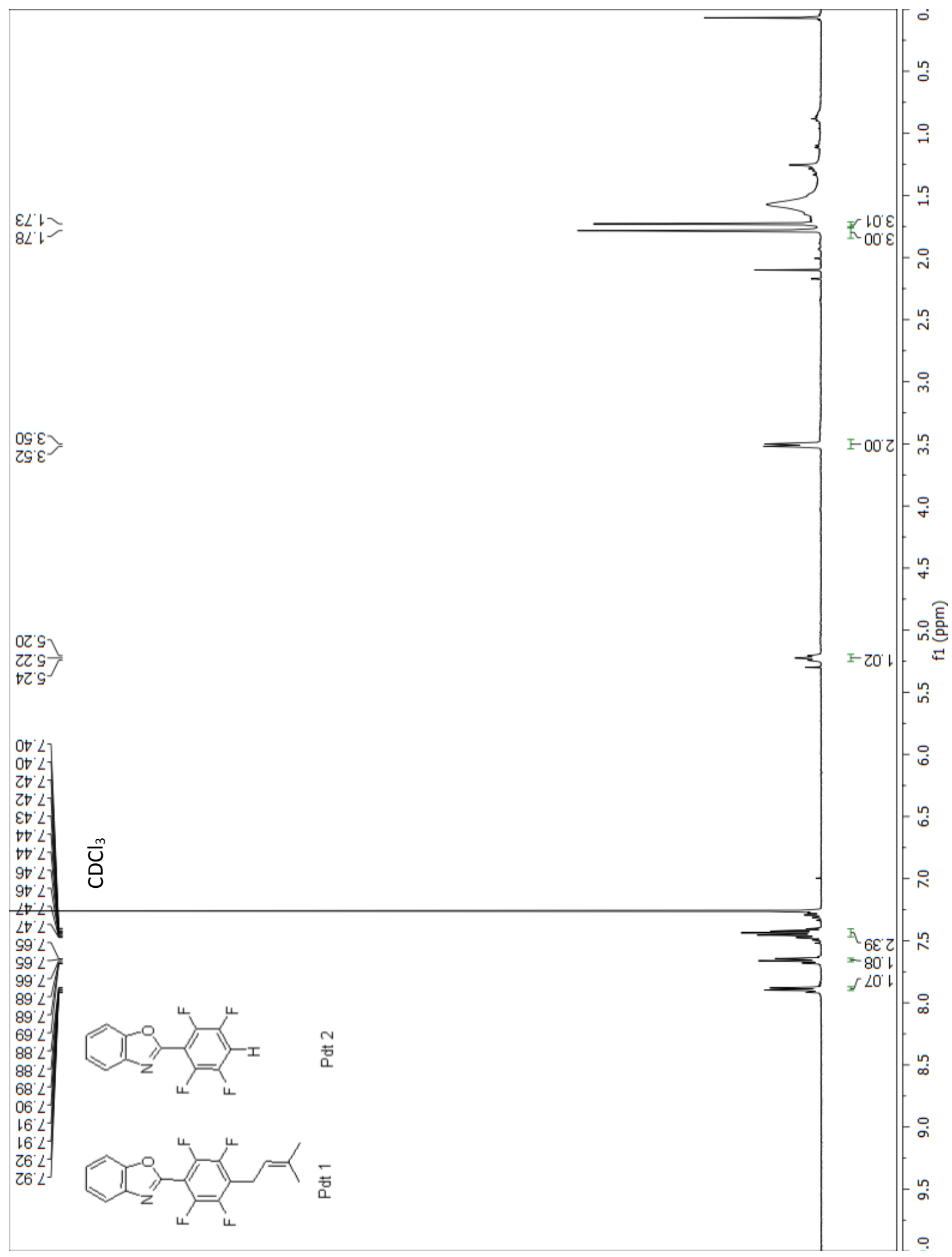


${ }^{13} \mathrm{C}$ NMR (101 MHz, CDCl3, at rt) spectrum of 2-(2,3,5,6-tetrafluoro-4-(3-methylbut-2-en-1-

yl)phenyl)benzo[d]oxazole (3m)

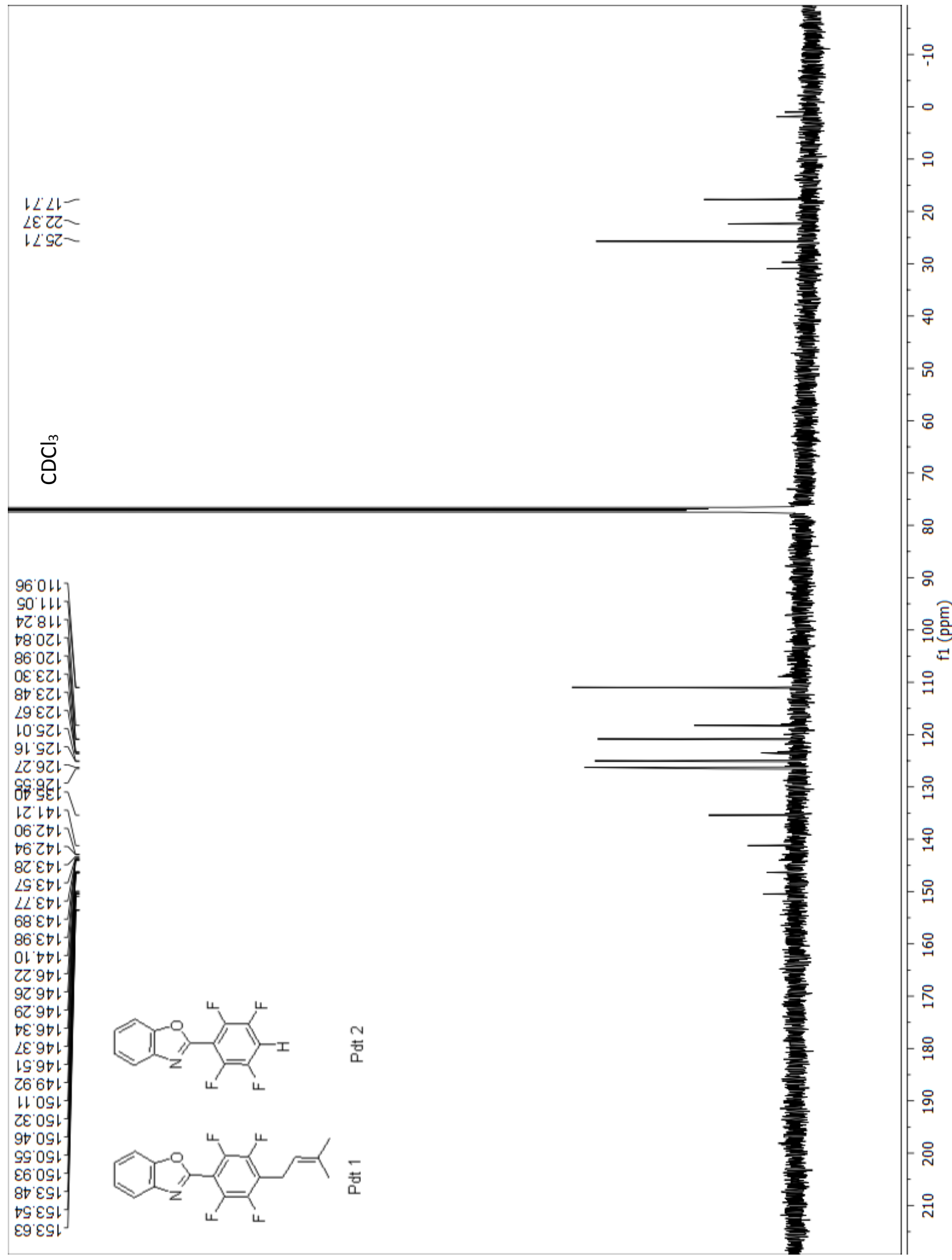


GC and MS of 2-(2,3,5,6-tetrafluoro-4-(3-methylbut-2-en-1-yl)phenyl)benzo[d]oxazole (3m)
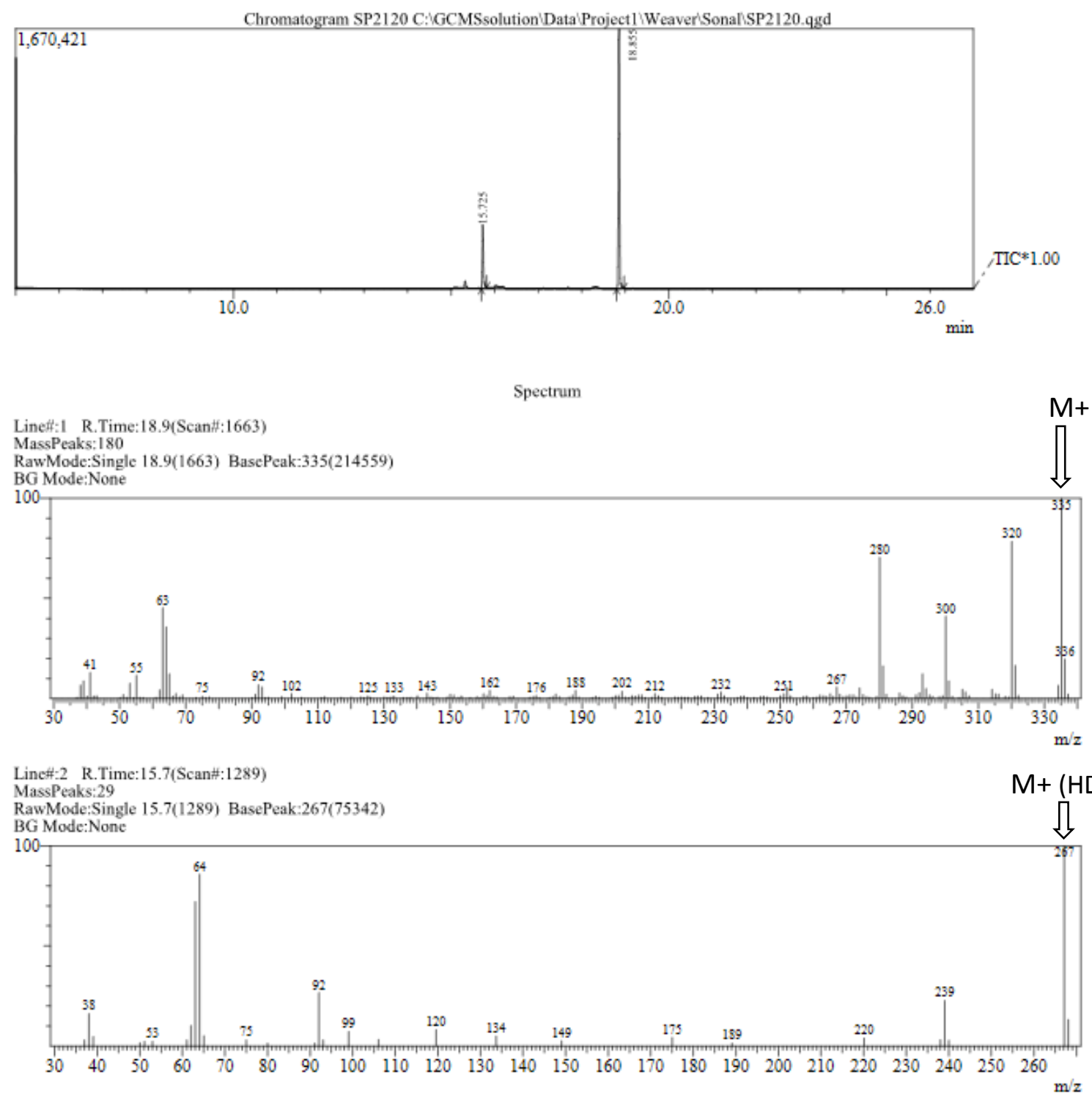
${ }^{19} \mathrm{~F}$ NMR (376 MHz, CDCl3, at rt) spectrum of 2-(2,3,5,6-tetrafluoro-4-(3-methylbut-2-en-1-

yl)phenyl)-1H-benzo[d]imidazole (3n)

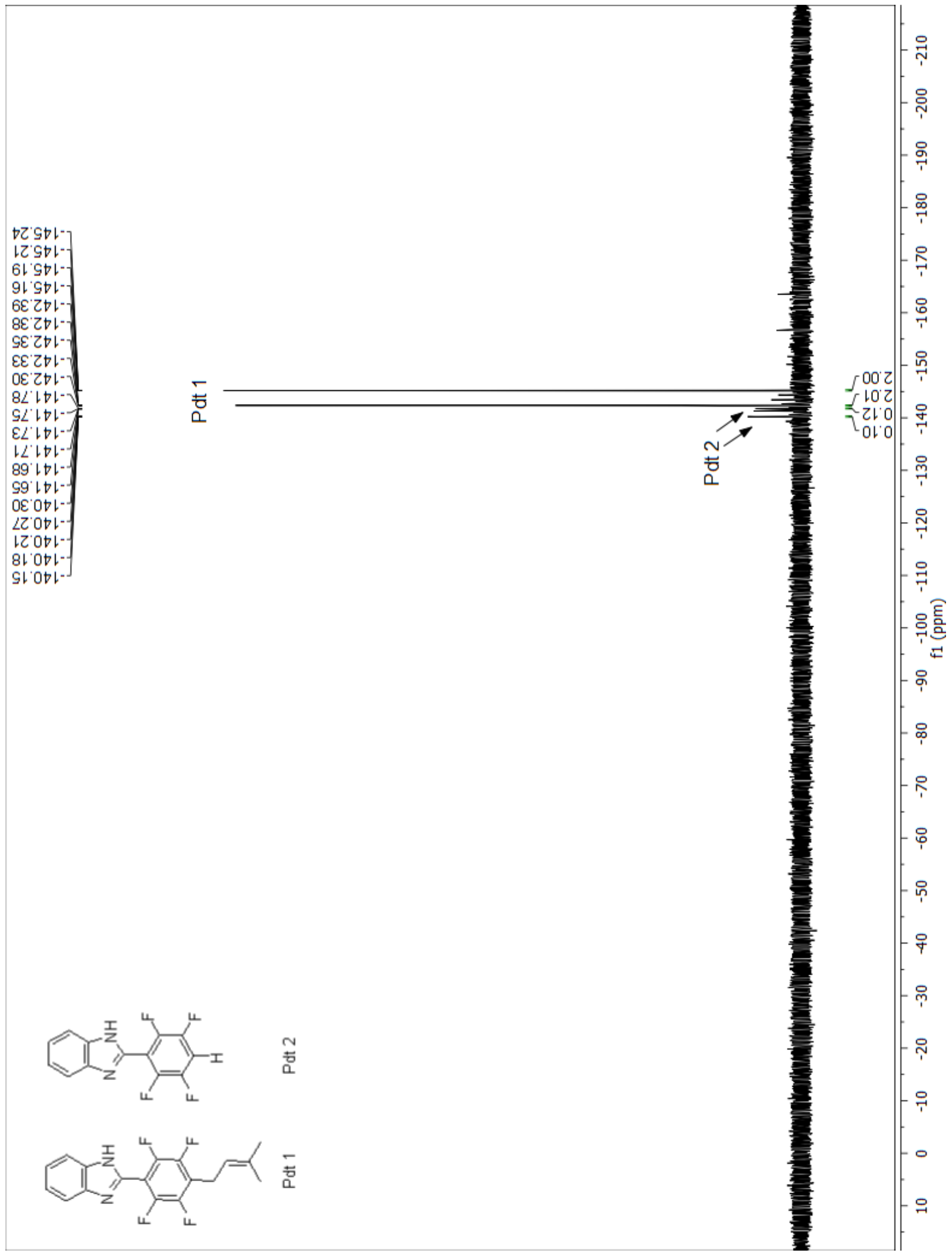


${ }^{1} \mathrm{H}$ NMR (400 MHz, CDCl3, at rt) spectrum of 2-(2,3,5,6-tetrafluoro-4-(3-methylbut-2-en-1-

yl)phenyl)-1H-benzo[d]imidazole (3n)

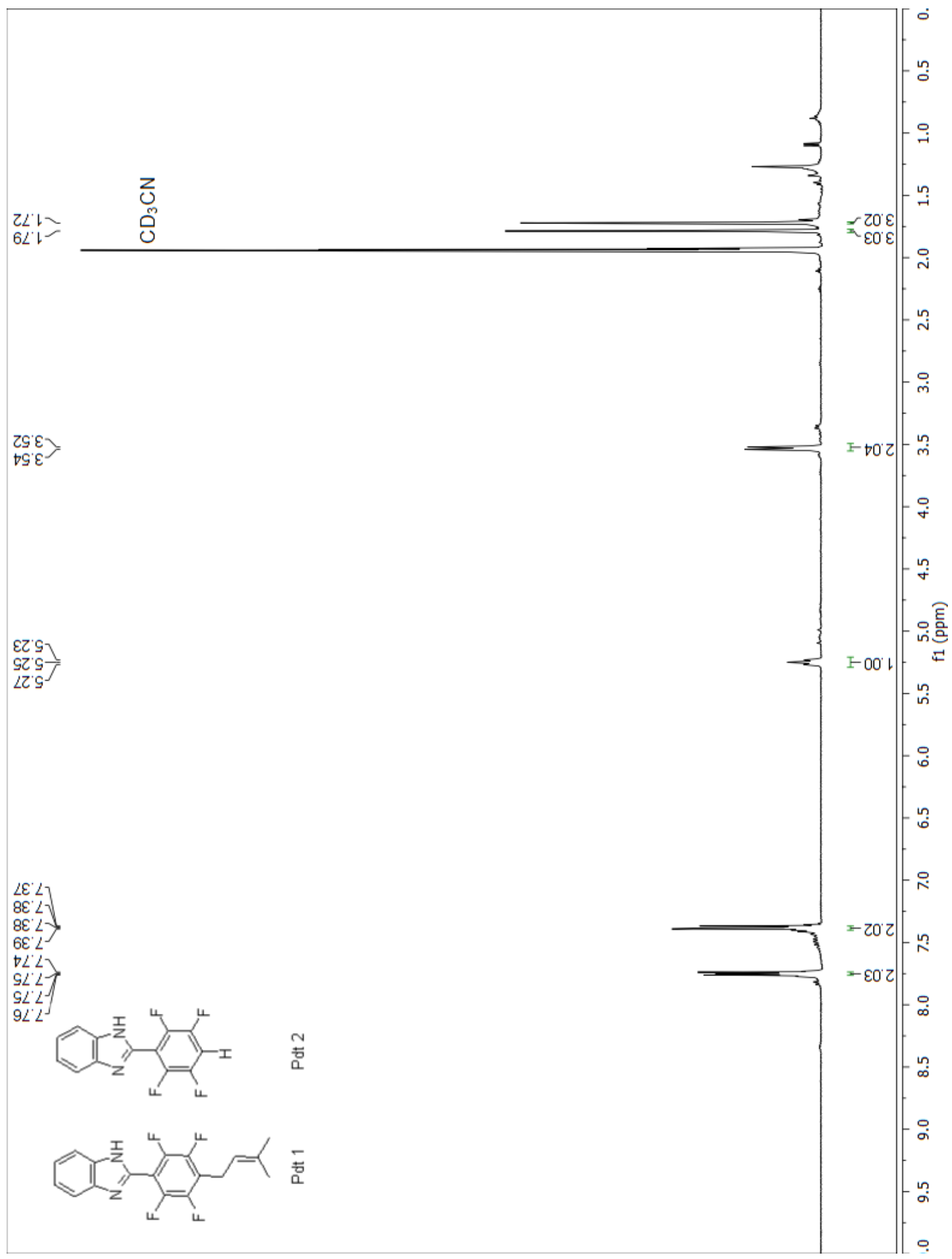


${ }^{13} \mathrm{C}$ NMR (101 MHz, CDCl3, at rt) spectrum of 2-(2,3,5,6-tetrafluoro-4-(3-methylbut-2-en-1-

yl)phenyl)-1H-benzo[d]imidazole (3n)

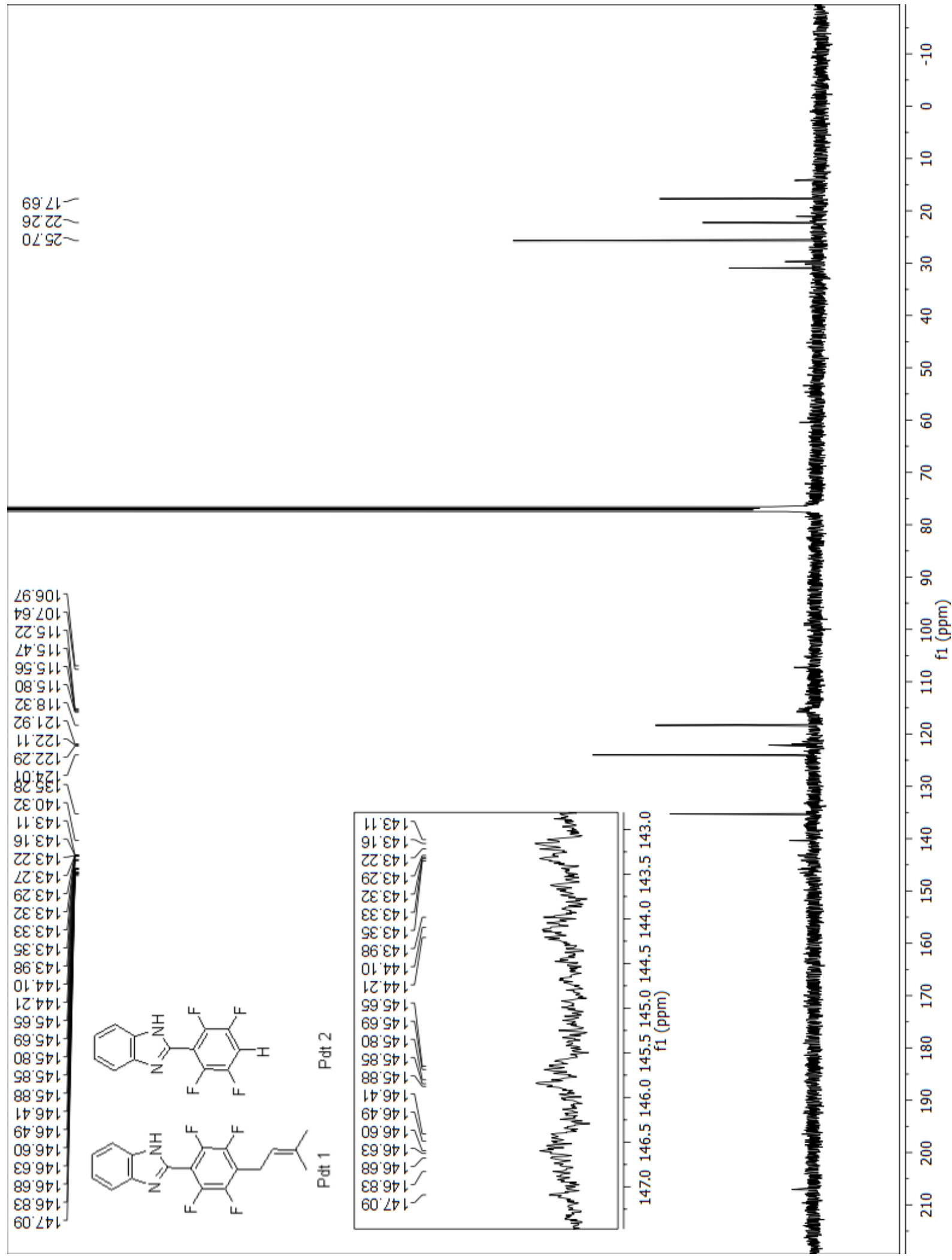


GC and MS of 2-(2,3,5,6-tetrafluoro-4-(3-methylbut-2-en-1-yl)phenyl)-1H-benzo[d]imidazole

(3n)

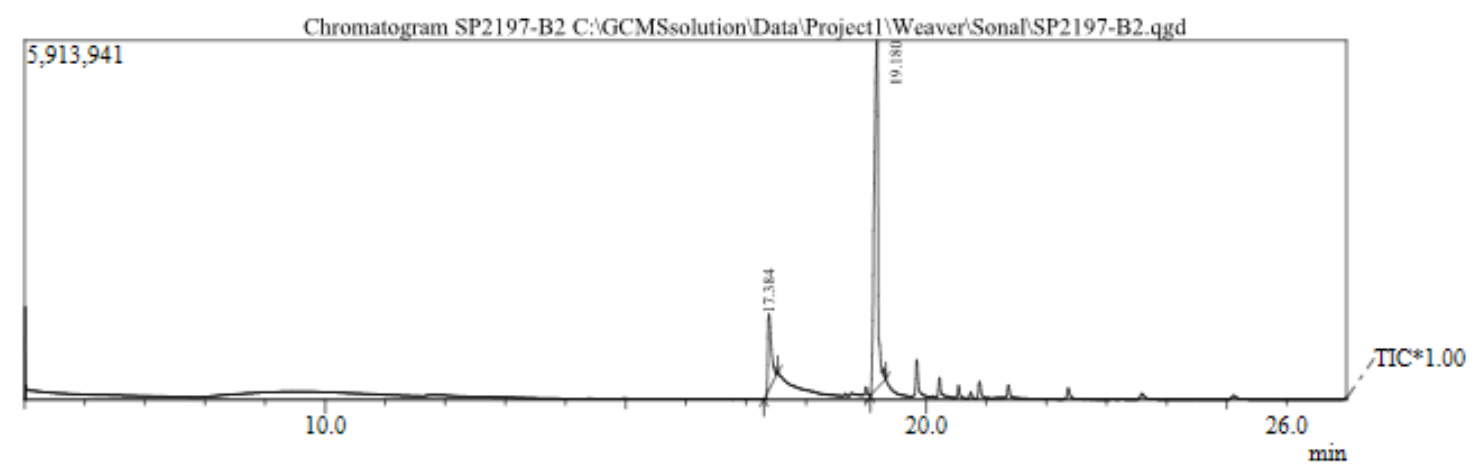

Spectrum

$\mathrm{M}+($ HDF-minor)

Line H:I R.Time: 17.4(Scan \#: 1490)

MassPeaks: 99

RawMode:Single 17.4(1490) BasePcak:266(316178)

BG Mode:None

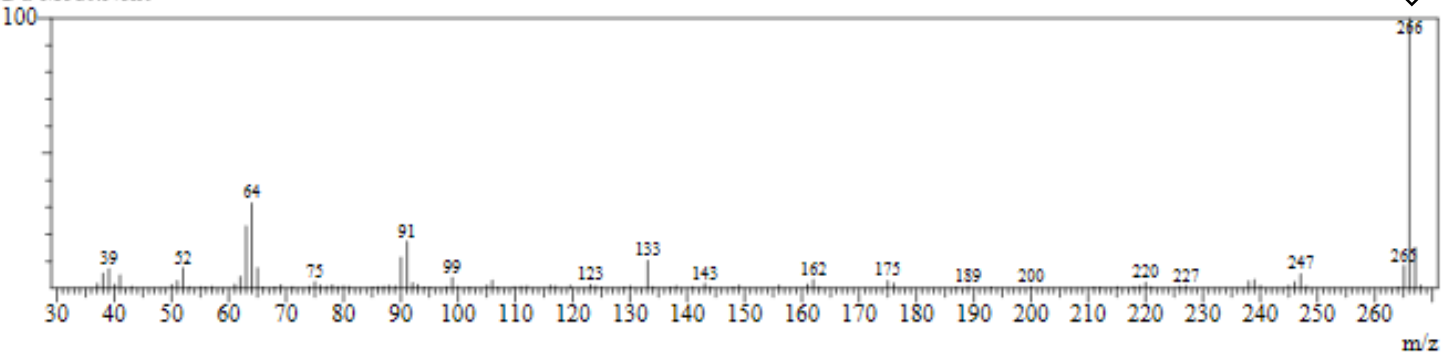

Line\#:2 R.Time: 19.2 (Scan\#:1701)

MassPeaks:275

RawMode:Single 19.2(1701) BasePeak:291(496531

BG Mode:None

100

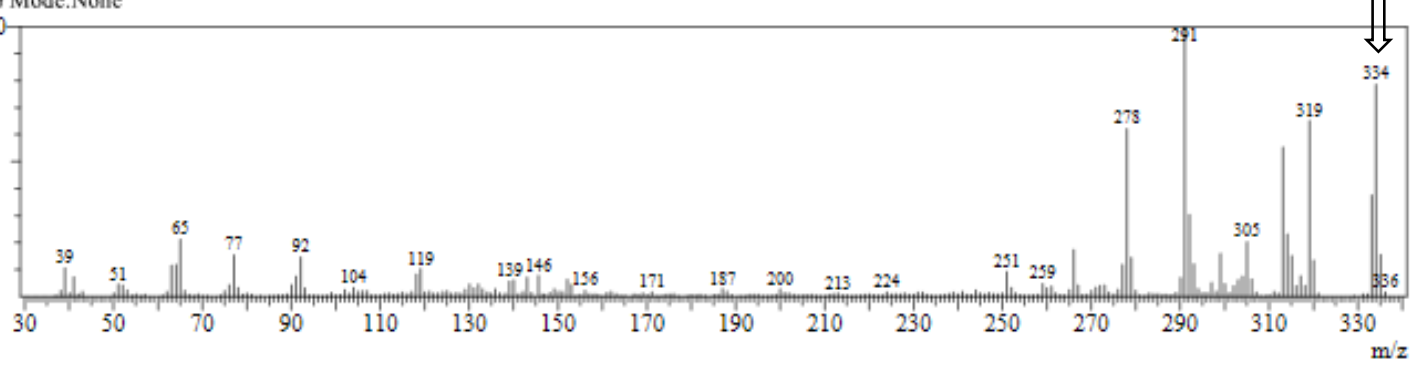


${ }^{19} \mathrm{~F}$ NMR (376 MHz, CDCl3, at rt) spectrum of 2-(2,3,5,6-tetrafluoro-4-(3-methylbut-2-en-1-

yl)phenyl)benzo[d]thiazole (3o)

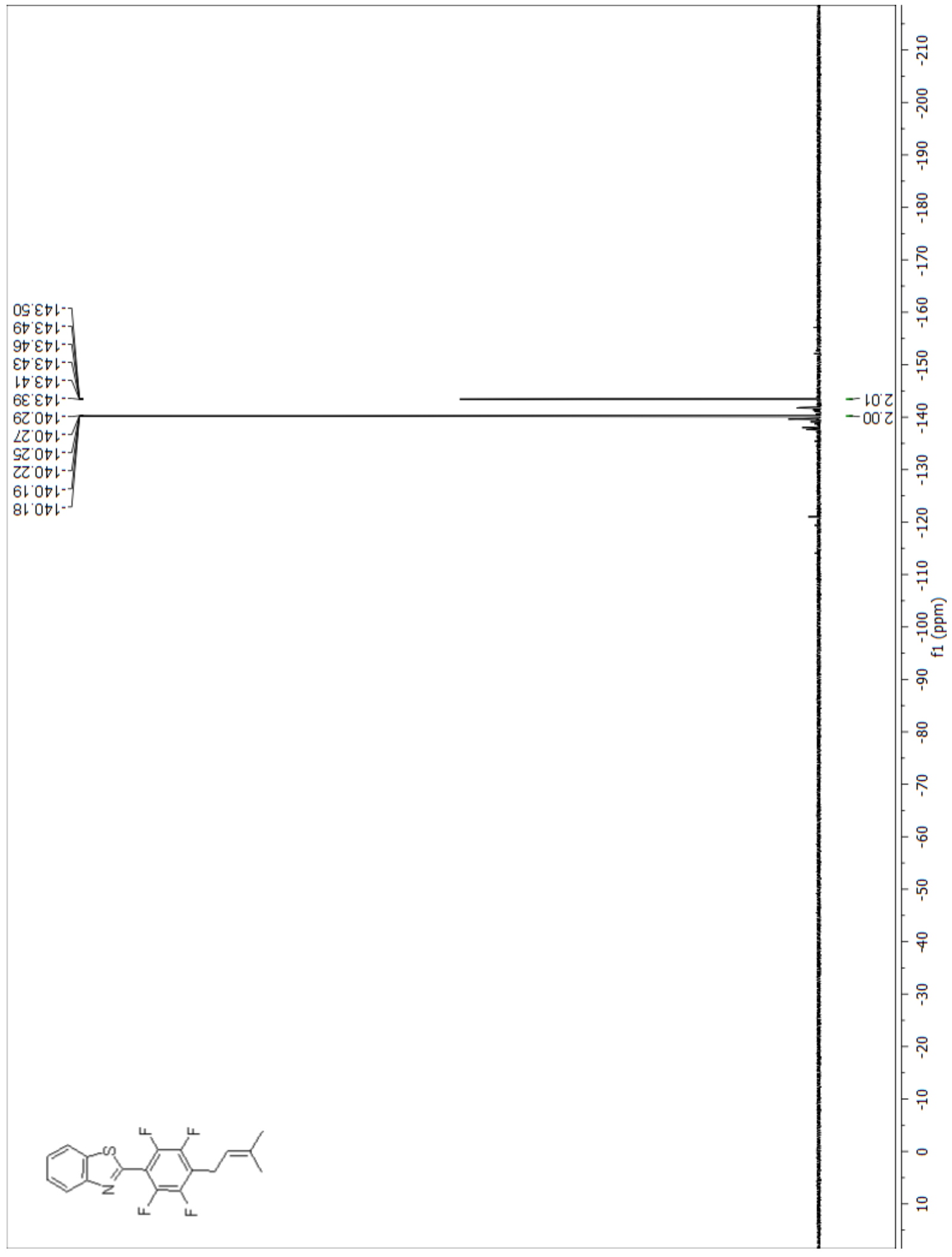


${ }^{1} \mathrm{H}$ NMR (400 MHz, CDCl3, at rt) spectrum of 2-(2,3,5,6-tetrafluoro-4-(3-methylbut-2-en-1-

\section{yl)phenyl)benzo[d]thiazole (3o)}

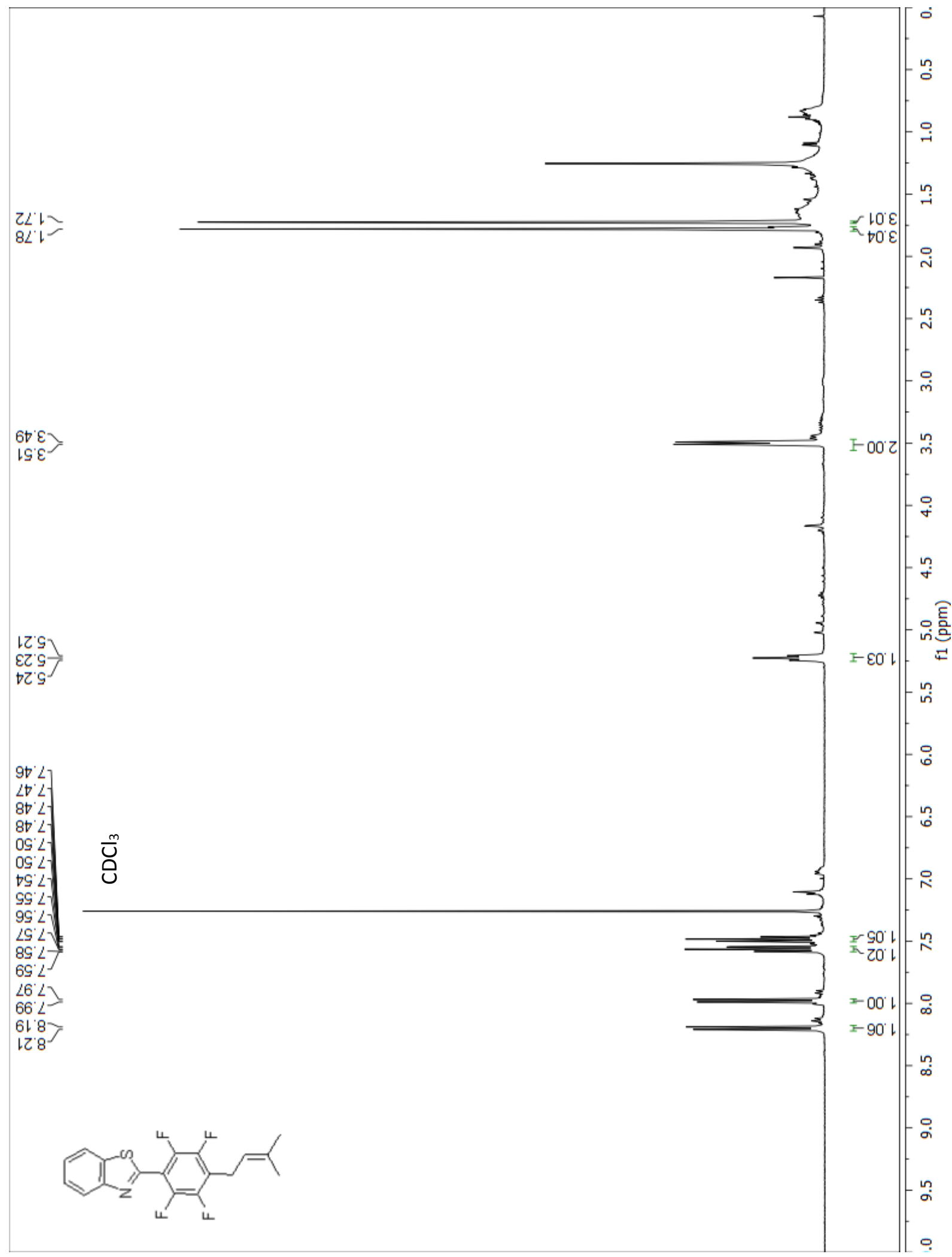


${ }^{13} \mathrm{C}$ NMR (101 MHz, CDCl3, at rt) spectrum of 2-(2,3,5,6-tetrafluoro-4-(3-methylbut-2-en-1-

yl)phenyl)benzo[d]thiazole (3o)

$0 \angle \angle L$

$6 Z \mathrm{ZZ}=$

$0 \angle \mathrm{GZ}-$

仓ั
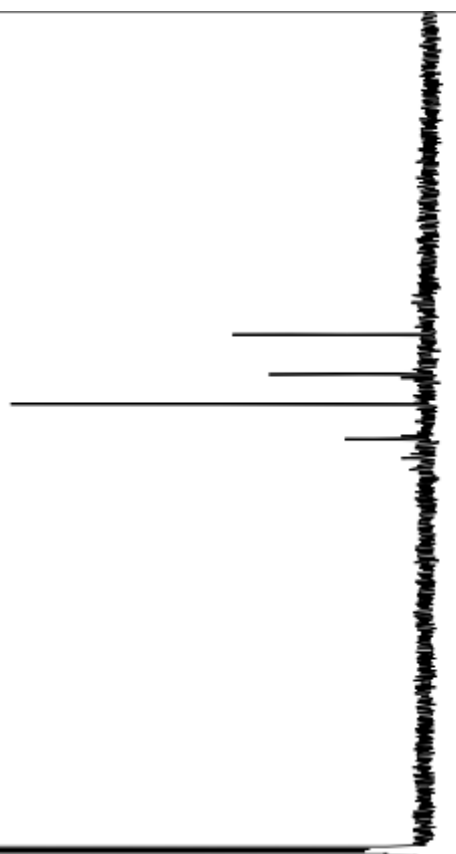

우

-

욱

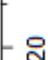

-

-

$-2$

in

8

$R$

ळ

은

$9 t^{\circ} 8 \mathrm{HL}$

$9 \varepsilon^{\prime}|Z|$

H'zZL

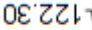

6大乙てい

$80{ }^{\circ}$ 乙レ

О।'9ट।

GS'9Z1

l乙 $G \varepsilon$

GG'GE

$\angle G ' G E L$

$89.2 \notin t$

$\angle 6 \mathrm{Z}+1-$

†० E० -

$\varepsilon\llcorner$ \& $\varepsilon \downarrow$

$\angle L E \nabla \mid$

$\angle L E \nabla L$

$\varepsilon 8$ ' $\varepsilon$ เ

เ6' $\varepsilon$

$\varepsilon 0 \nabla t$

$0 乙 \forall \nabla$

9t'St

IS'St

29.

$\angle 9 S^{\circ} \mathrm{Ll}$

L'S L

乙2 9 th

$6 C^{\prime} 901$ -

SE $901-$

ot 901 -

$\angle t^{\prime} 9 t$

$6 v^{\prime} 9 t$

68 'Gl-

$\varepsilon \vdash \nabla G$
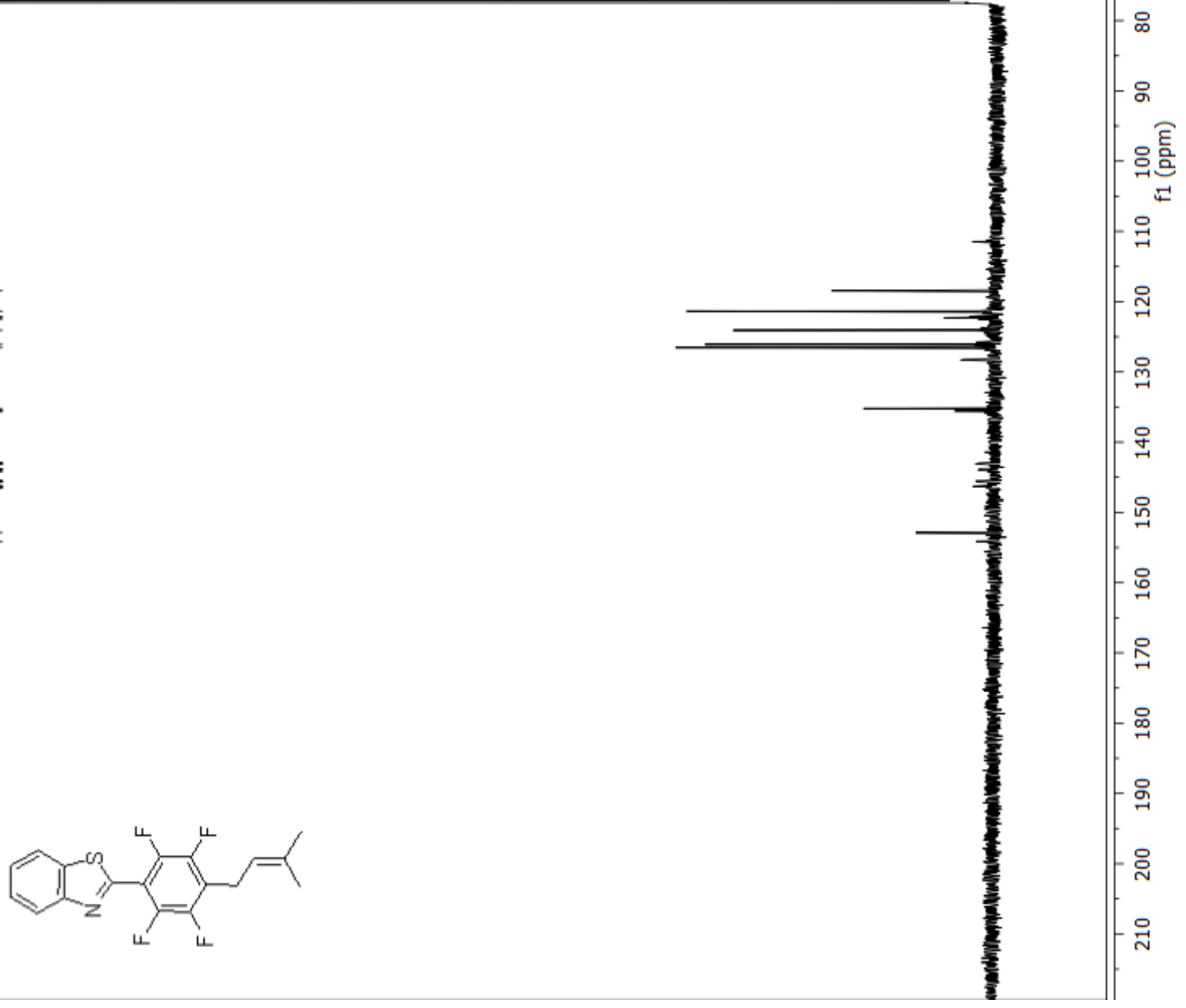
GC and MS of 2-(2,3,5,6-tetrafluoro-4-(3-methylbut-2-en-1-yl)phenyl)benzo[d]thiazole (3o)
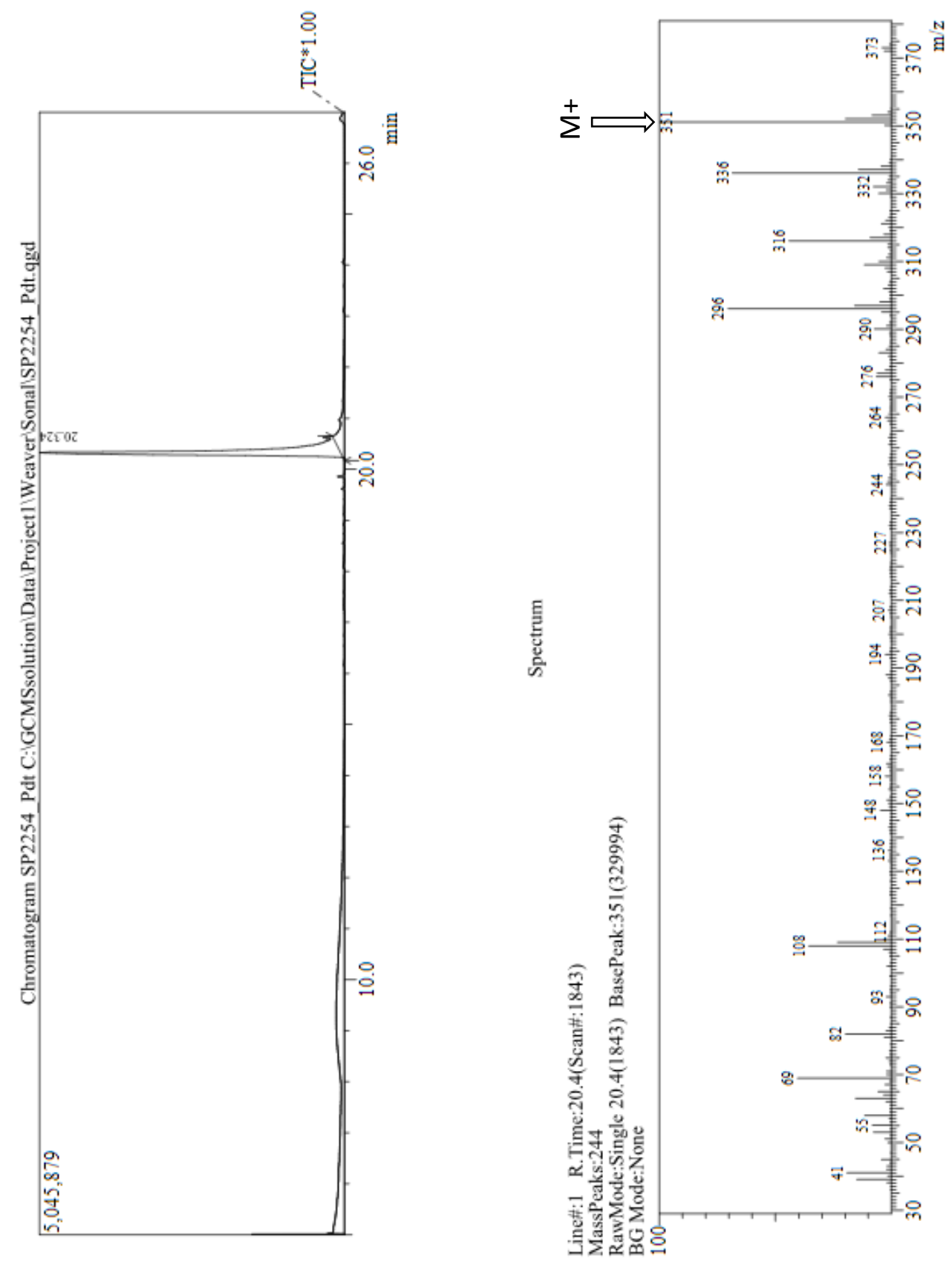
${ }^{19} \mathrm{~F}$ NMR (376 MHz, CDCl3, at rt) spectrum of methyl (E)-2-(3,7-dimethylocta-2,6-dien-1-yl)-

\section{3,4,5,6-tetrafluorobenzoate (7a) and methyl (E)-4-(3,7-dimethylocta-2,6-dien-1-yl)-2,3,5,6-}

tetrafluorobenzoate $\left(7 \mathbf{a}^{\prime}\right)$

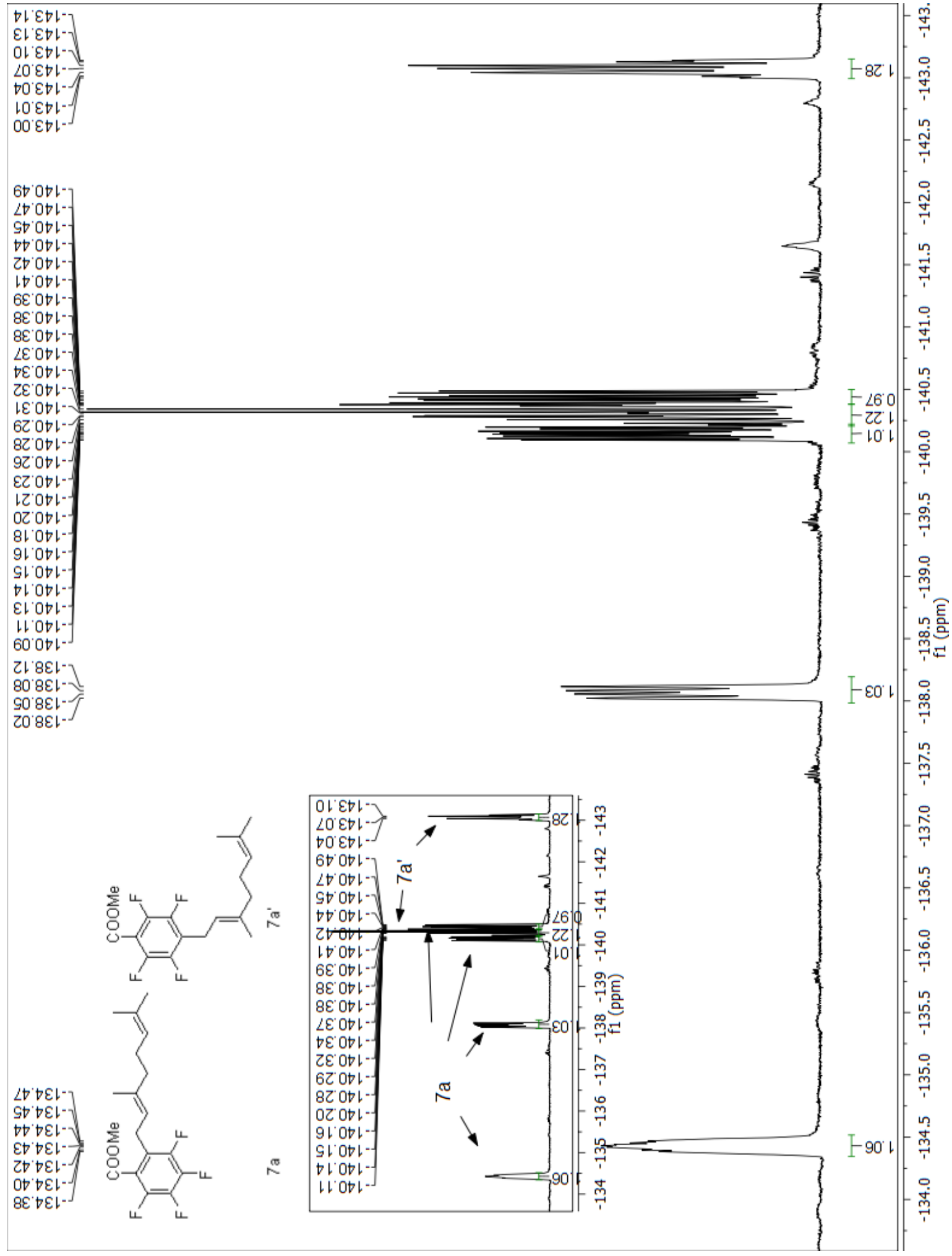


${ }^{1} \mathrm{H}$ NMR (376 MHz, CDCl3, at rt) spectrum of methyl (E)-2-(3,7-dimethylocta-2,6-dien-1-yl)-

3,4,5,6-tetrafluorobenzoate (7a) and methyl (E)-4-(3,7-dimethylocta-2,6-dien-1-yl)-2,3,5,6-

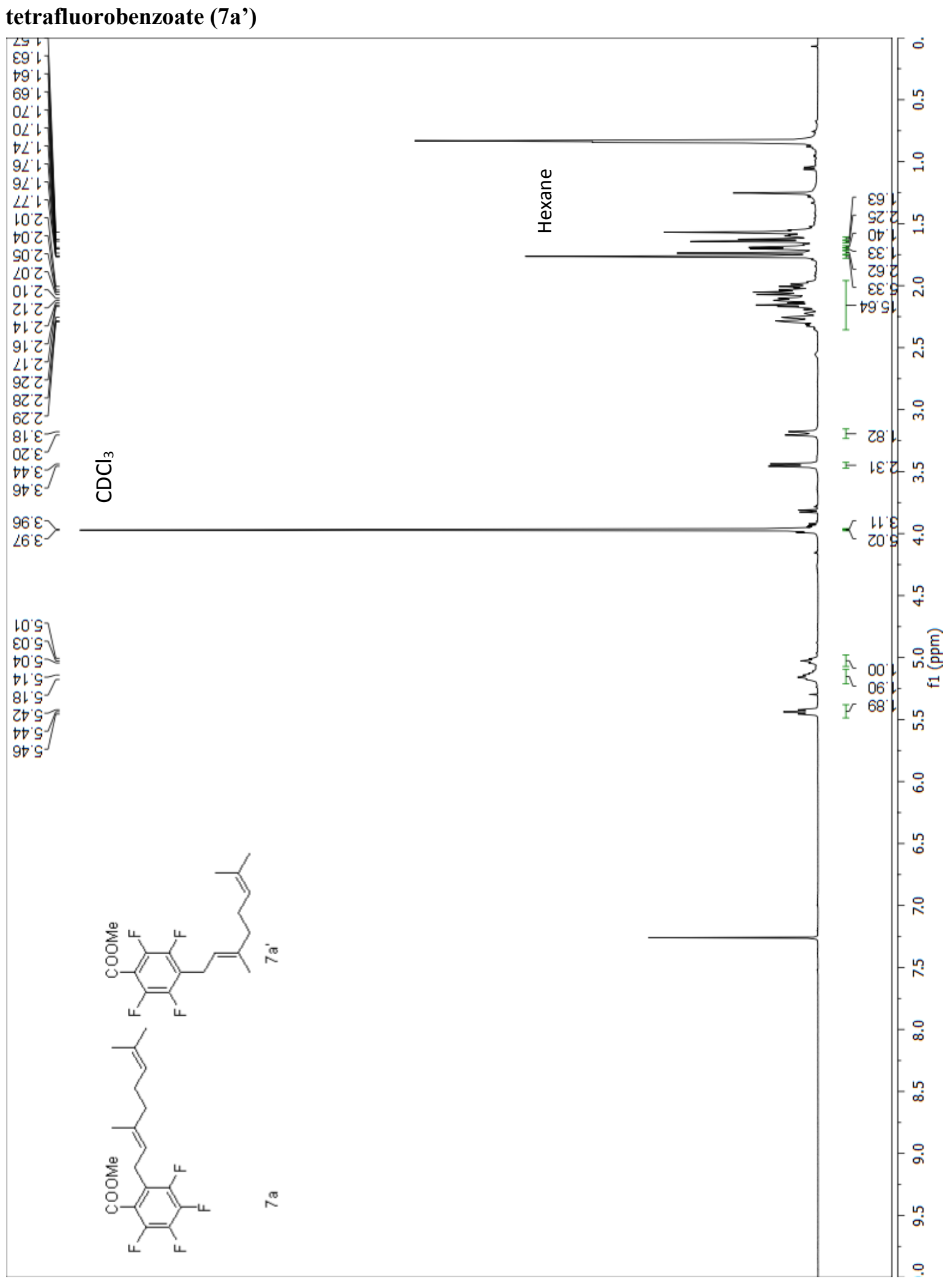


${ }^{13} \mathrm{C}$ NMR (376 MHz, CDCl3, at rt) spectrum of methyl (E)-2-(3,7-dimethylocta-2,6-dien-1-yl)3,4,5,6-tetrafluorobenzoate (7a) and methyl (E)-4-(3,7-dimethylocta-2,6-dien-1-yl)- 2,3,5,6tetrafluorobenzoate (7a')

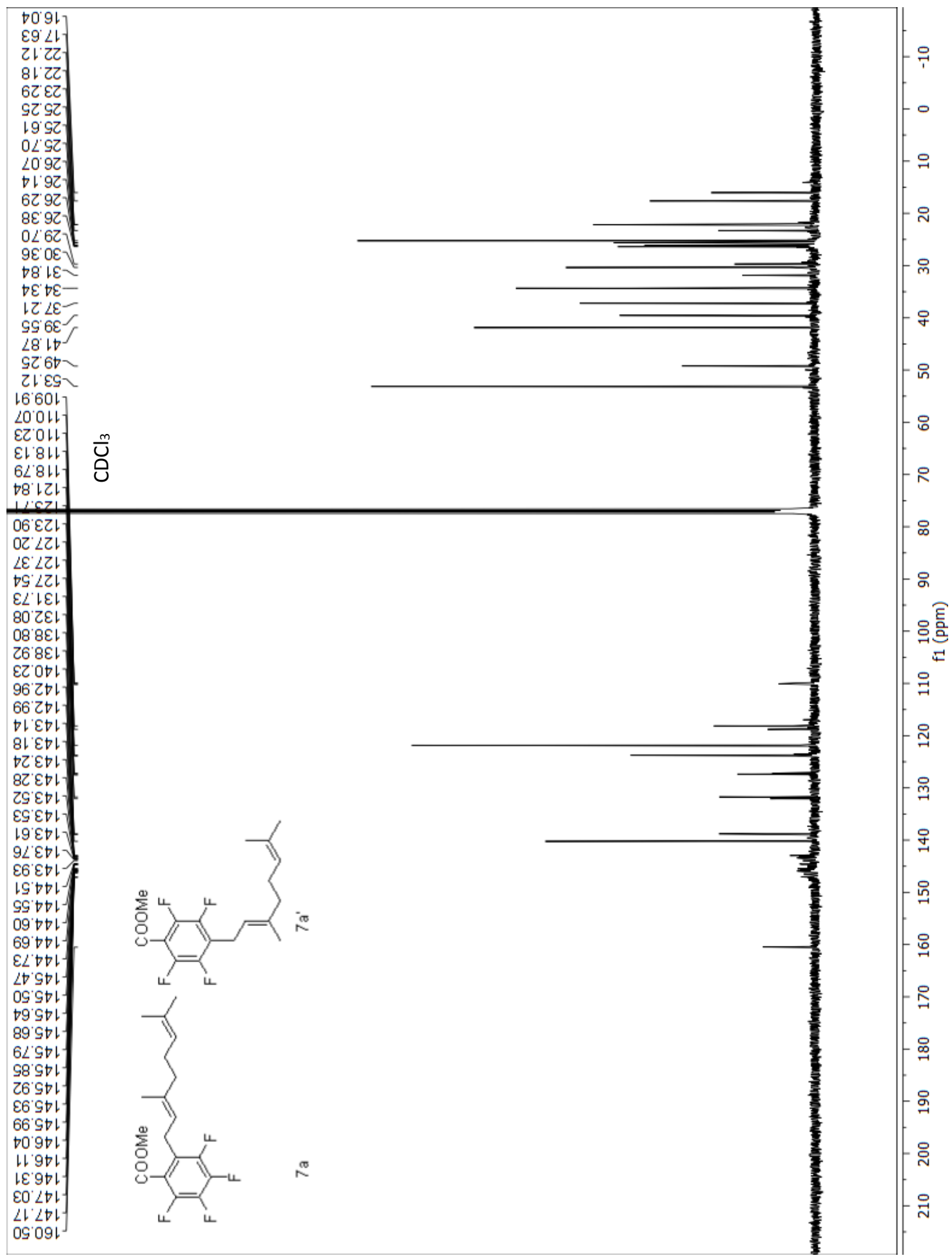


${ }^{19} \mathrm{~F}$ NMR (376 MHz, CDCl3, at rt) spectrum of methyl (E)-2-(3,7-dimethylocta-2,6-dien-1-yl)-

\section{3,4,5,6-tetrafluorobenzoate (7a)}
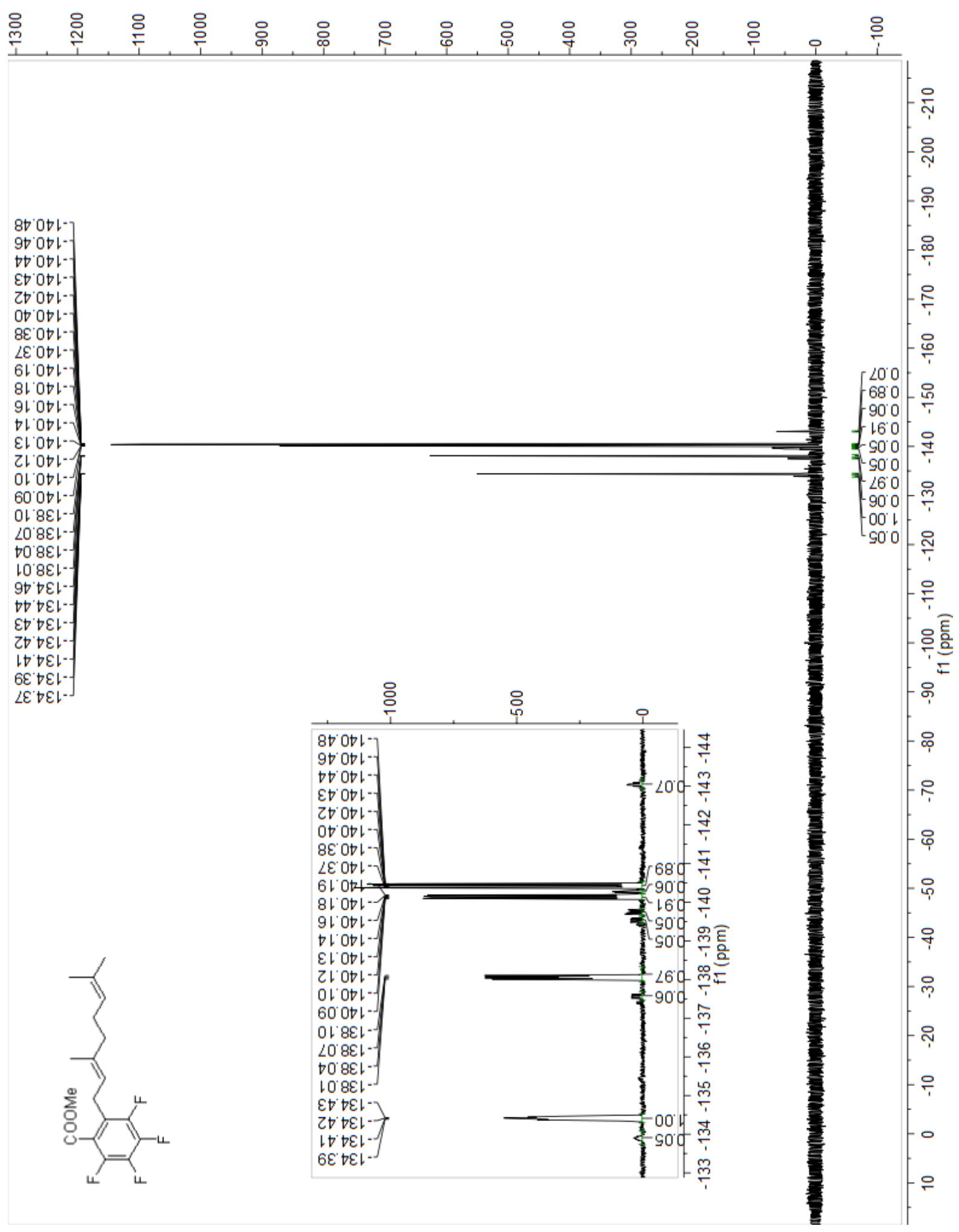
${ }^{19} \mathrm{~F}$ NMR (376 MHz, CDCl3, at rt) spectrum of methyl (E)-4-(3,7-dimethylocta-2,6-dien-1-yl)-

\section{2,3,5,6-tetrafluorobenzoate (7a')}

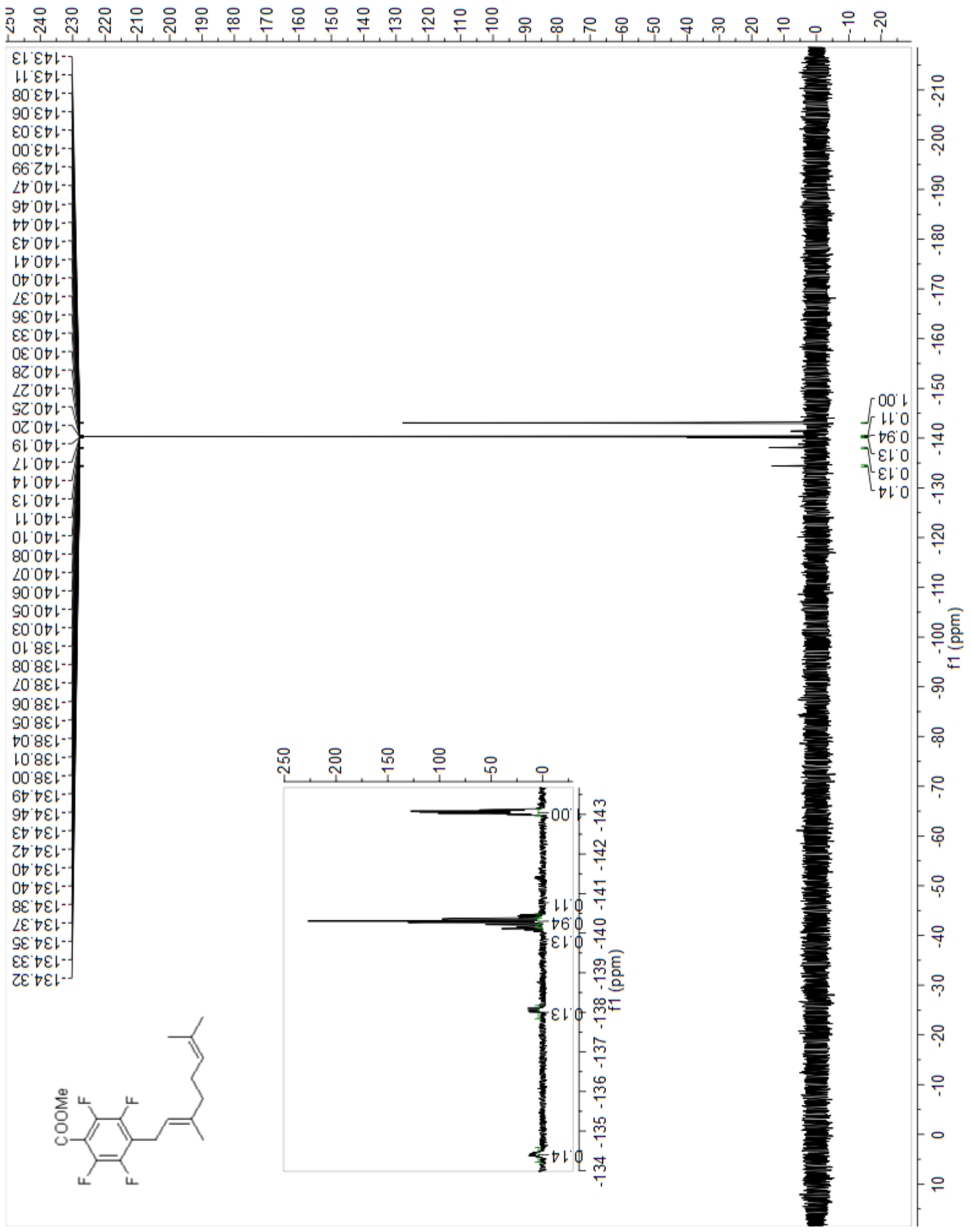


${ }^{19} \mathrm{~F}-{ }^{19} \mathrm{~F}$ TOCSY of methyl (E)-2-(3,7-dimethylocta-2,6-dien-1-yl)-3,4,5,6-tetrafluorobenzoate (7a) and methyl (E)-4-(3,7-dimethylocta-2,6-dien-1-yl)-2,3,5,6-tetrafluorobenzoate (7a')

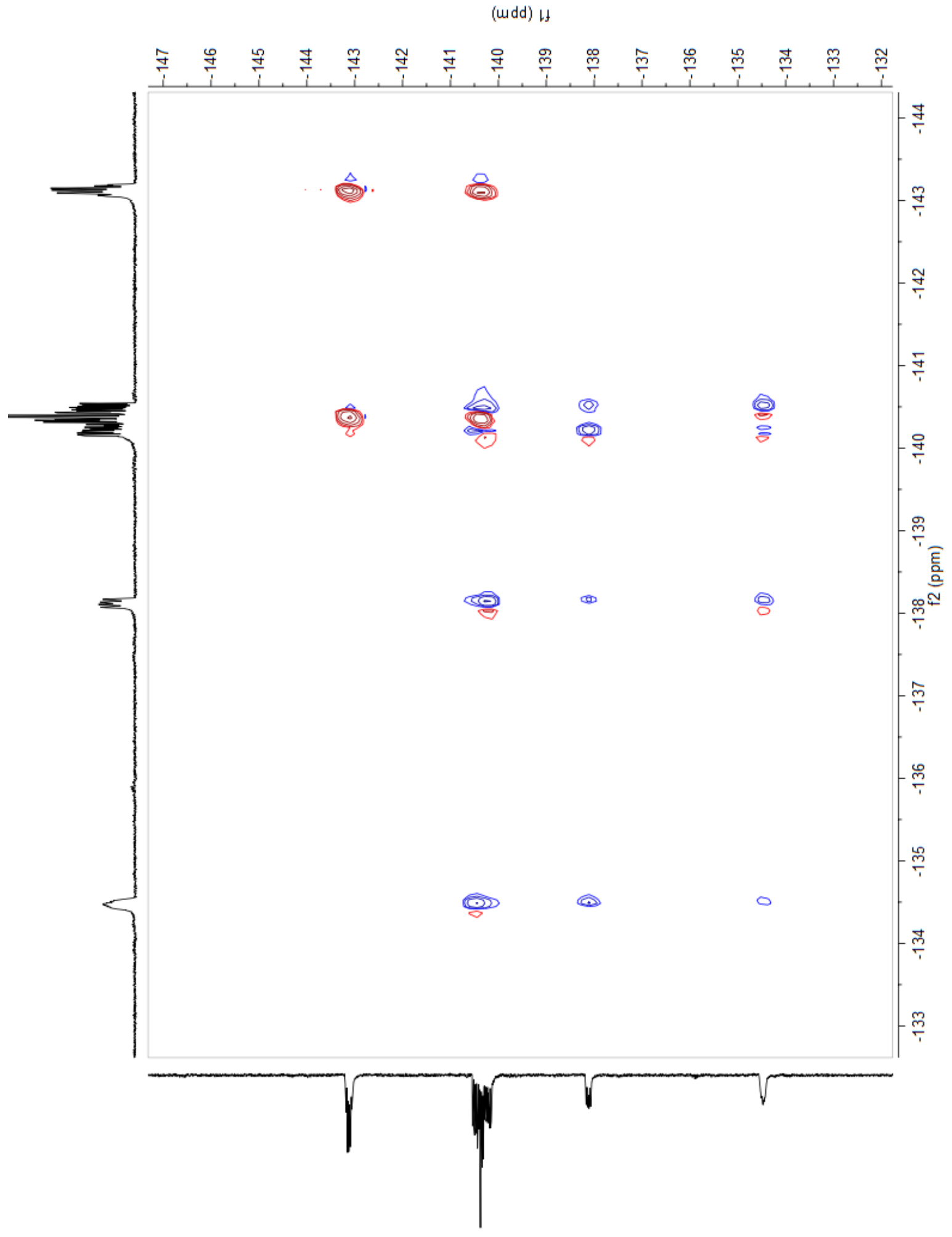


${ }^{19} \mathrm{~F}-{ }^{19} \mathrm{~F}$ COSY of methyl (E)-2-(3,7-dimethylocta-2,6-dien-1-yl)-3,4,5,6-tetrafluorobenzoate (7a) and methyl (E)-4-(3,7-dimethylocta-2,6-dien-1-yl)-2,3,5,6-tetrafluorobenzoate (7a')

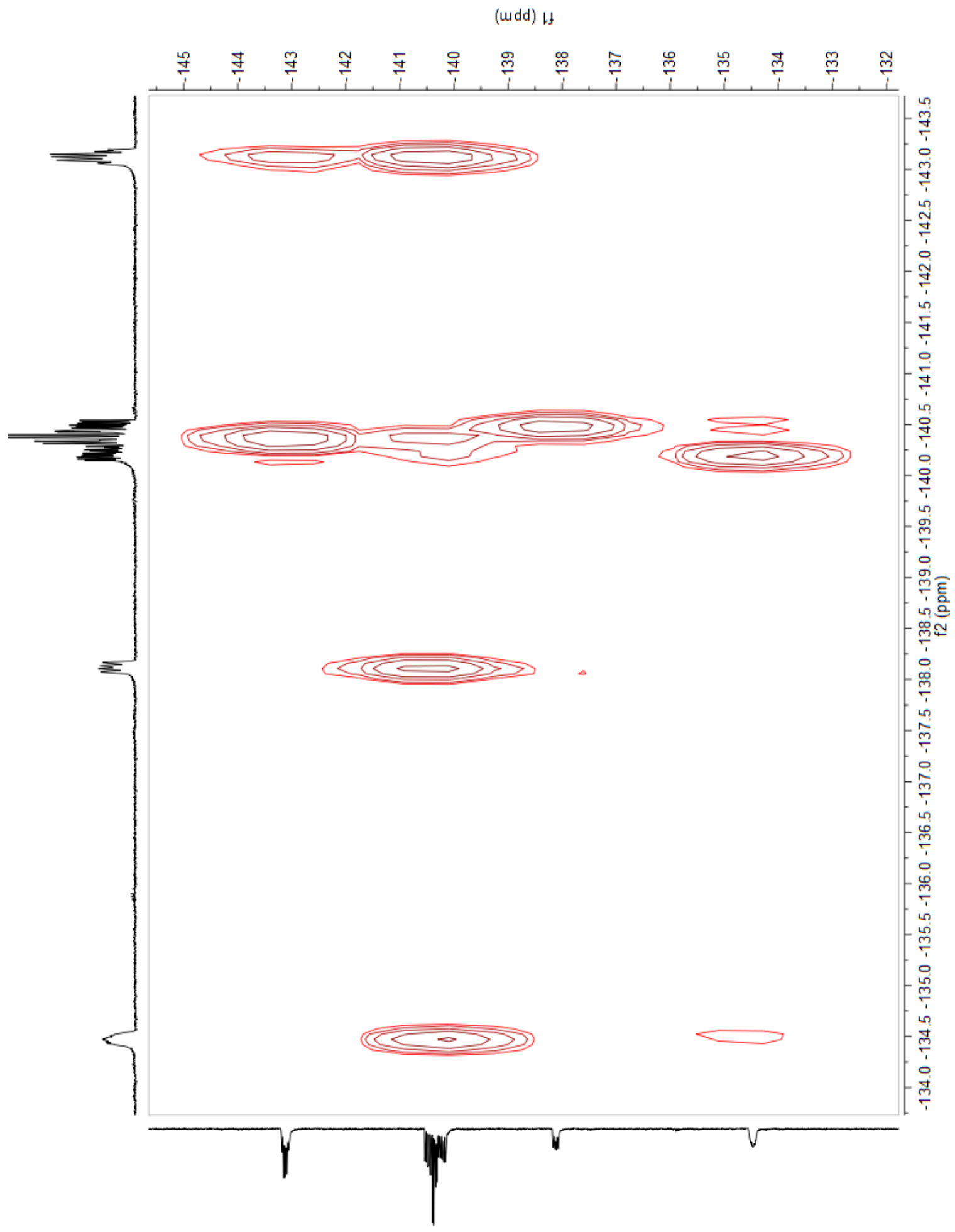


${ }^{19} \mathrm{~F}-{ }^{13} \mathrm{C}$ HSQC of methyl (E)-2-(3,7-dimethylocta-2,6-dien-1-yl)-3,4,5,6-tetrafluorobenzoate (7a) and methyl (E)-4-(3,7-dimethylocta-2,6-dien-1-yl)-2,3,5,6-tetrafluorobenzoate (7a') (in $\mathrm{MeCN}-\mathrm{d} 3)$

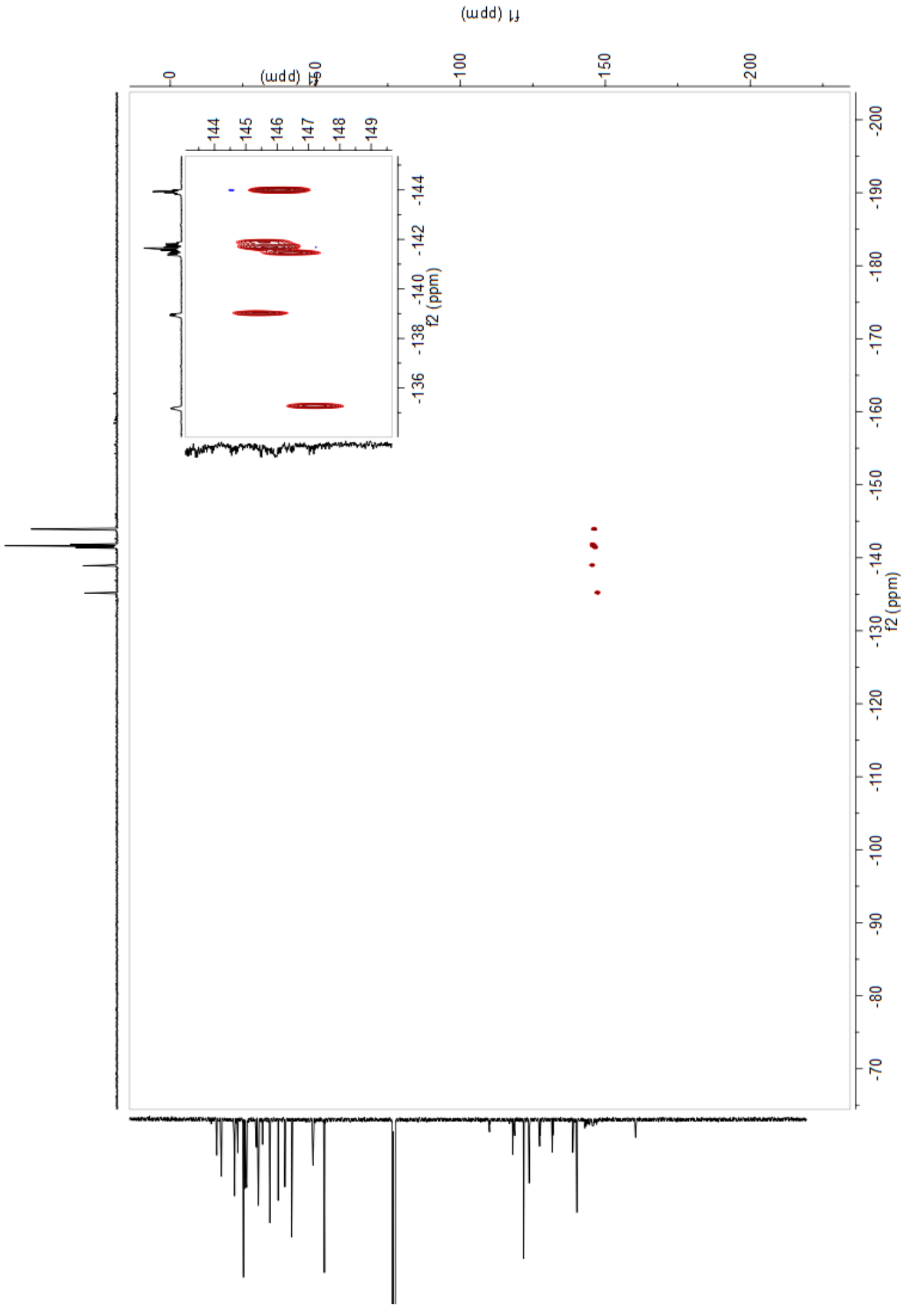


${ }^{1} \mathrm{H}-{ }^{13} \mathrm{C}$ HSQC of methyl (E)-2-(3,7-dimethylocta-2,6-dien-1-yl)-3,4,5,6-tetrafluorobenzoate

(7a) and methyl (E)-4-(3,7-dimethylocta-2,6-dien-1-yl)-2,3,5,6-tetrafluorobenzoate (7a')

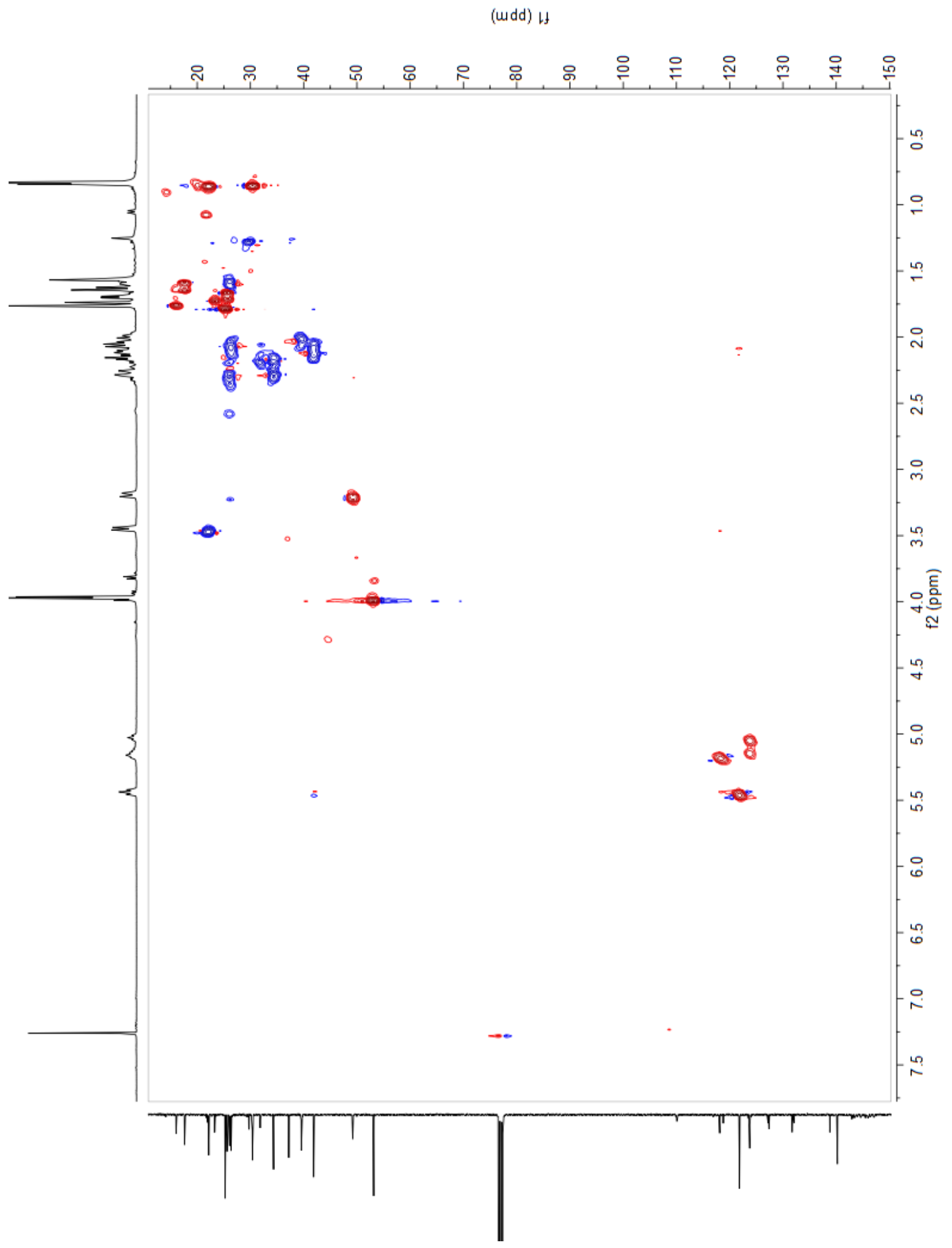


${ }^{1} \mathrm{H}-{ }^{1} \mathrm{H}$ NOESY of methyl (E)-2-(3,7-dimethylocta-2,6-dien-1-yl)-3,4,5,6-tetrafluorobenzoate

(7a) and methyl (E)-4-(3,7-dimethylocta-2,6-dien-1-yl)-2,3,5,6-tetrafluorobenzoate (7a')

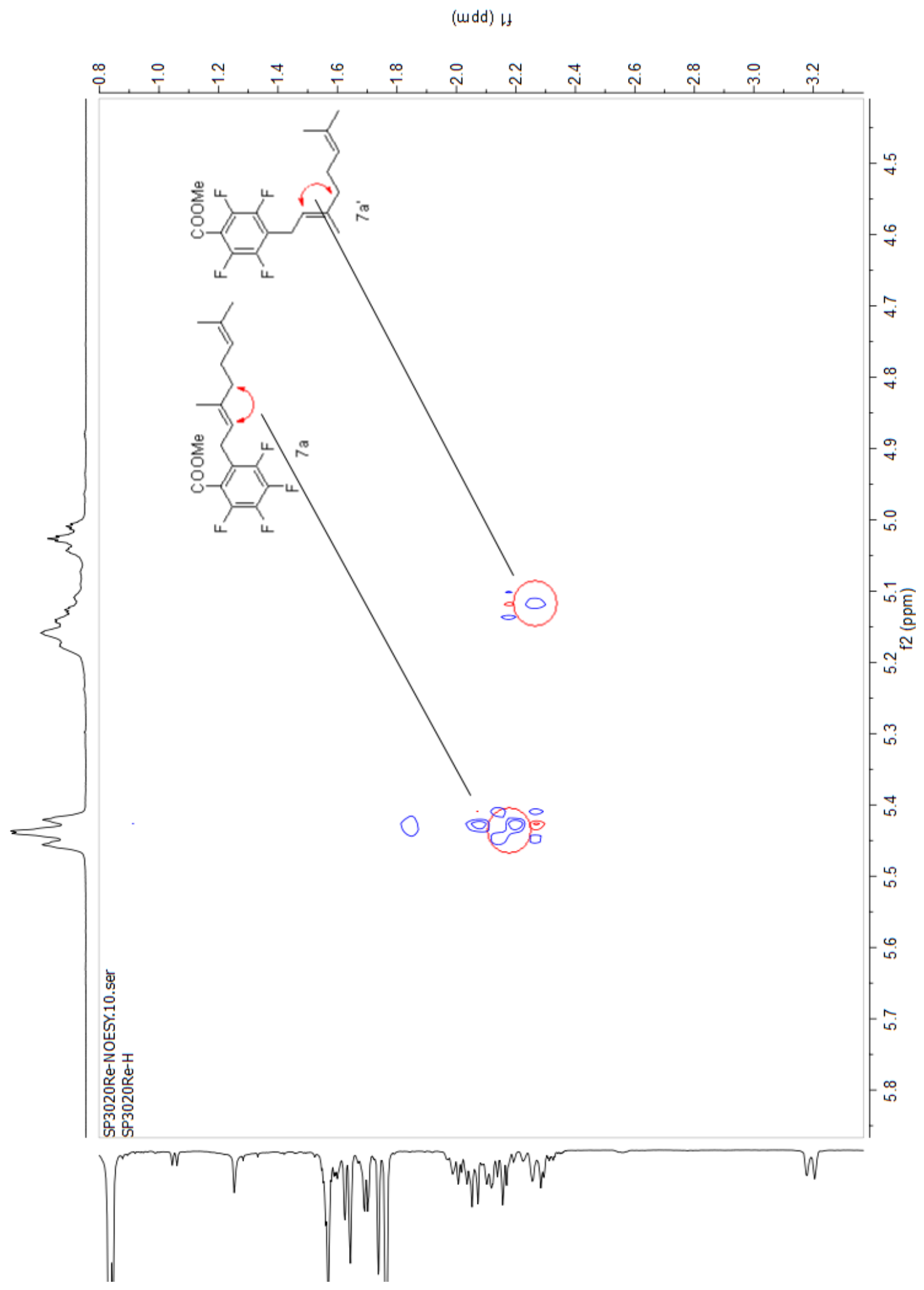


GC and MS of methyl (E)-2-(3,7-dimethylocta-2,6-dien-1-yl)-3,4,5,6-tetrafluorobenzoate (7a)

and methyl (E)-4-(3,7-dimethylocta-2,6-dien-1-yl)-2,3,5,6-tetrafluorobenzoate (7a')

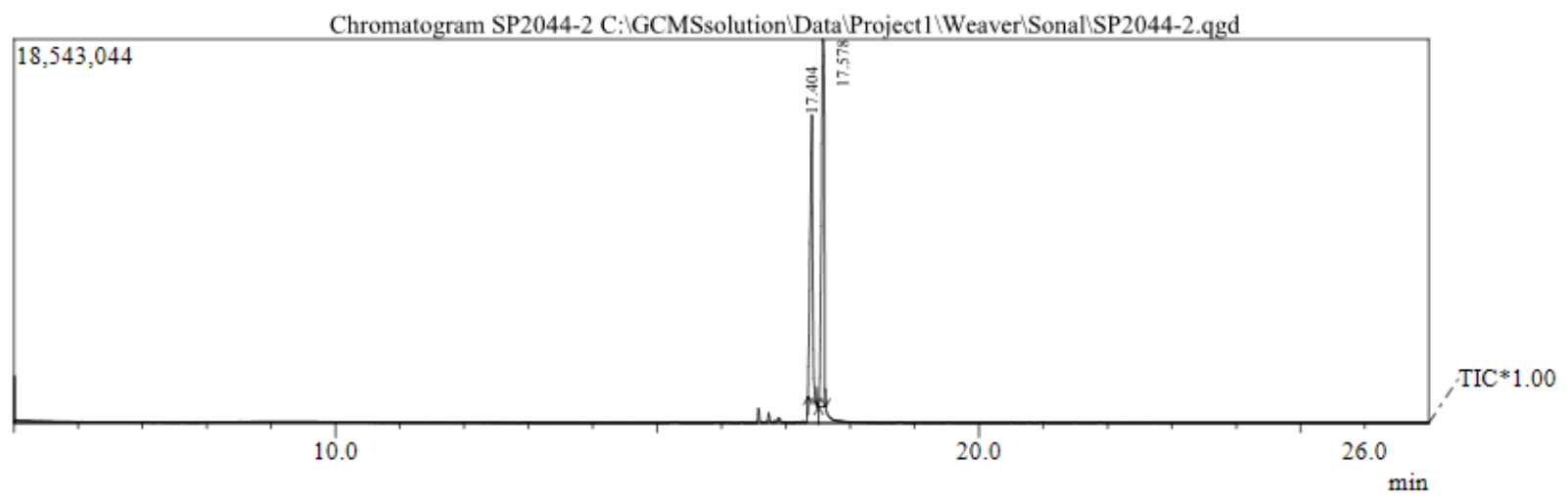

Spectrum

Line\#: 1 R.Time: 17.4(Scan\#:1489)

MassPeaks: 242

RawMode:Single 17.4(1489) BasePeak:69(4949625)

BG Mode:None

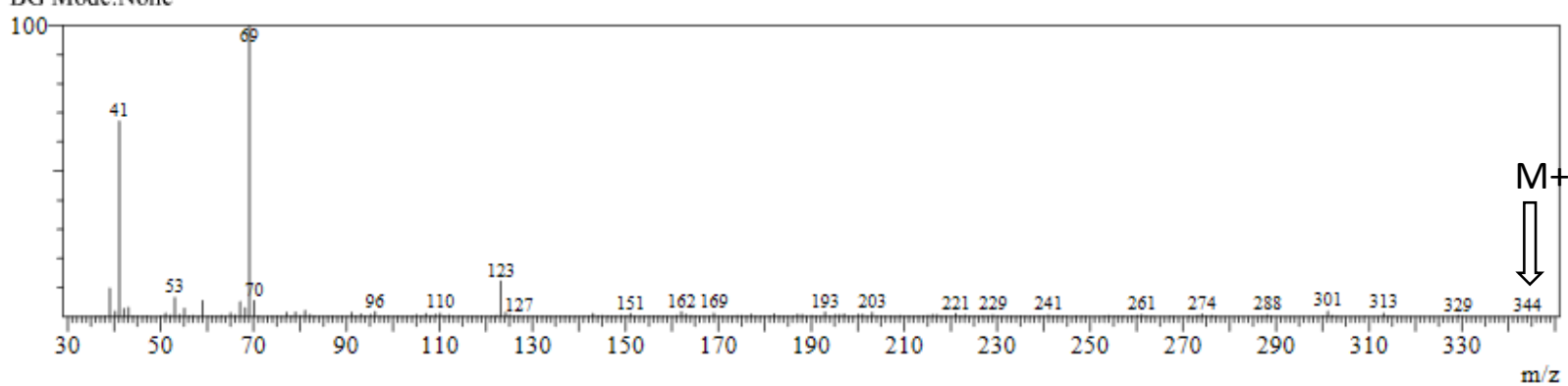

Line\#:2 R.Time:17.6(Scan\#:1509)

MassPeaks:264

RawMode:Single 17.6(1509) BasePeak:95(2063375)

BG Mode:None

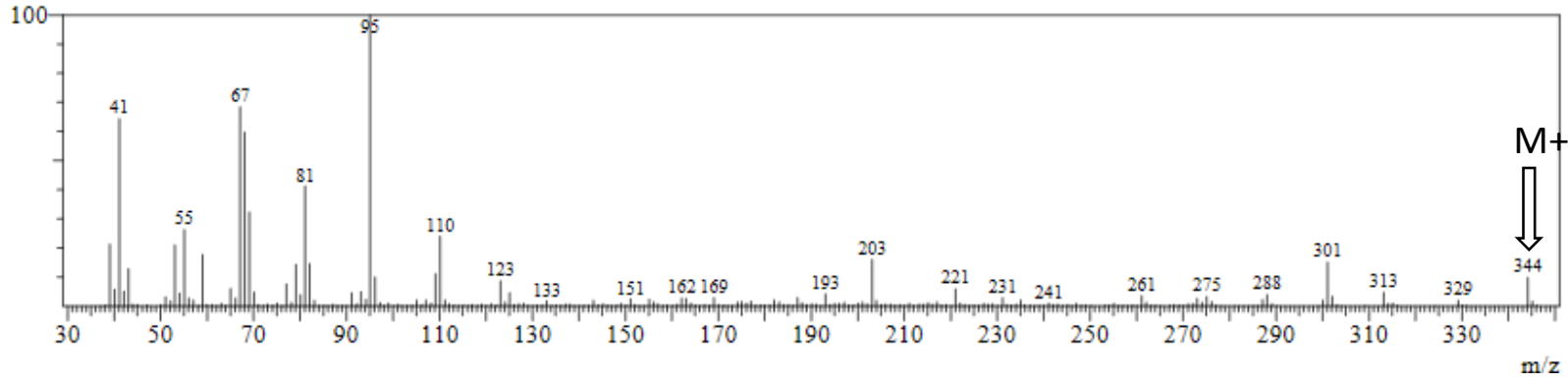


${ }^{19} \mathrm{~F}$ NMR (376 MHz, CDCl3, at rt) spectrum of isopropyl (E)-2-(3,7-dimethylocta-2,6-dien-1-

yl)-3,4,5,6-tetrafluorobenzoate (7b) and isopropyl (E)-4-(3,7-dimethylocta-2,6-dien-1-yl)-

2,3,5,6-tetrafluorobenzoate ( $\left.7 b^{\prime}\right)$

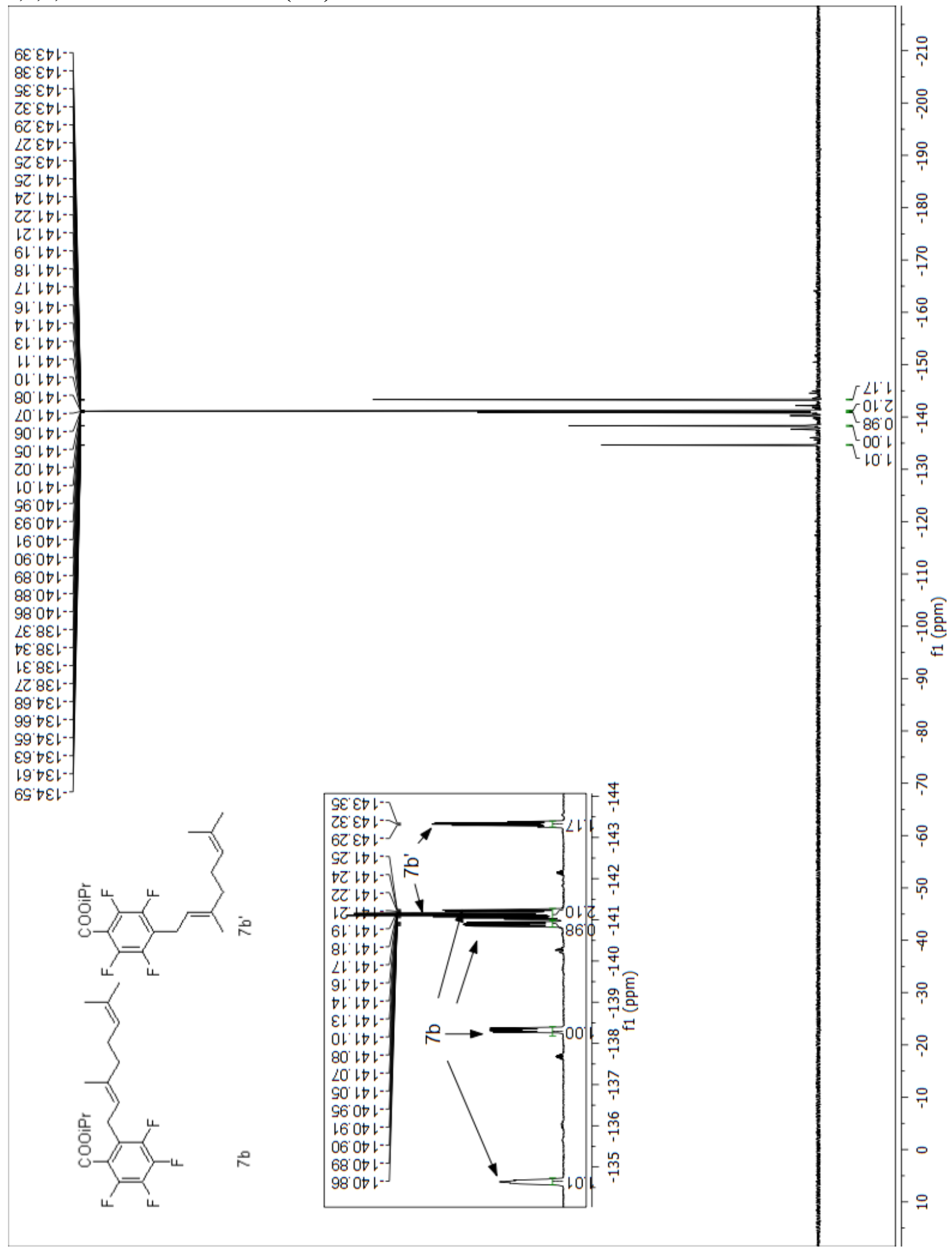


${ }^{1} \mathrm{H}$ NMR (376 MHz, CDCl3, at rt) spectrum of isopropyl (E)-2-(3,7-dimethylocta-2,6-dien-1yl)-3,4,5,6-tetrafluorobenzoate (7b) and isopropyl (E)-4-(3,7-dimethylocta-2,6-dien-1-yl)-

\section{2,3,5,6-tetrafluorobenzoate (7b')}

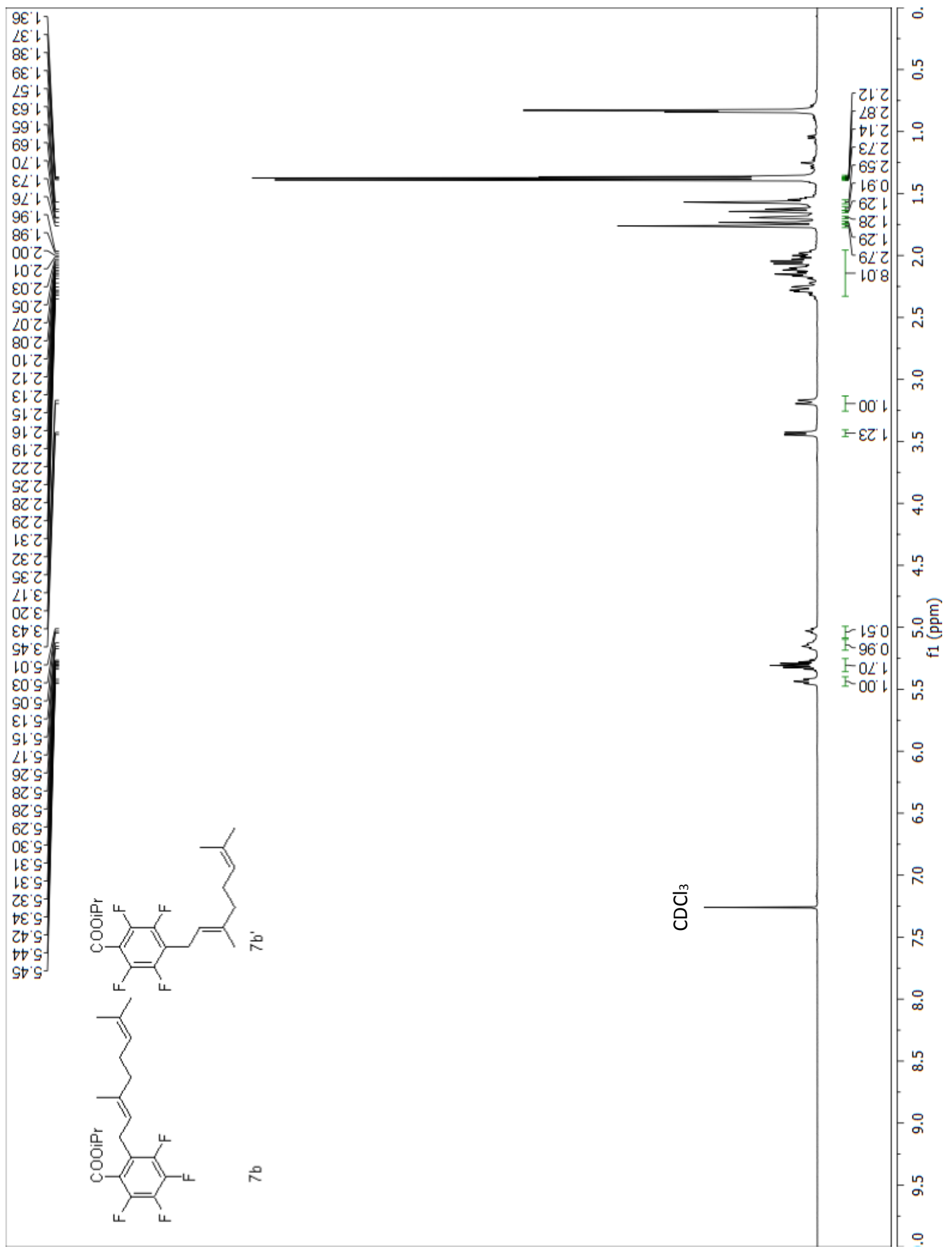


${ }^{13} \mathrm{C} \mathrm{NMR}(376 \mathrm{MHz}, \mathrm{CDCl} 3$, at rt) spectrum of isopropyl (E)-2-(3,7-dimethylocta-2,6-dien-1-

yl)-3,4,5,6-tetrafluorobenzoate (7b) and isopropyl (E)-4-(3,7-dimethylocta-2,6-dien-1-yl)-

\section{2,3,5,6-tetrafluorobenzoate (7b')}

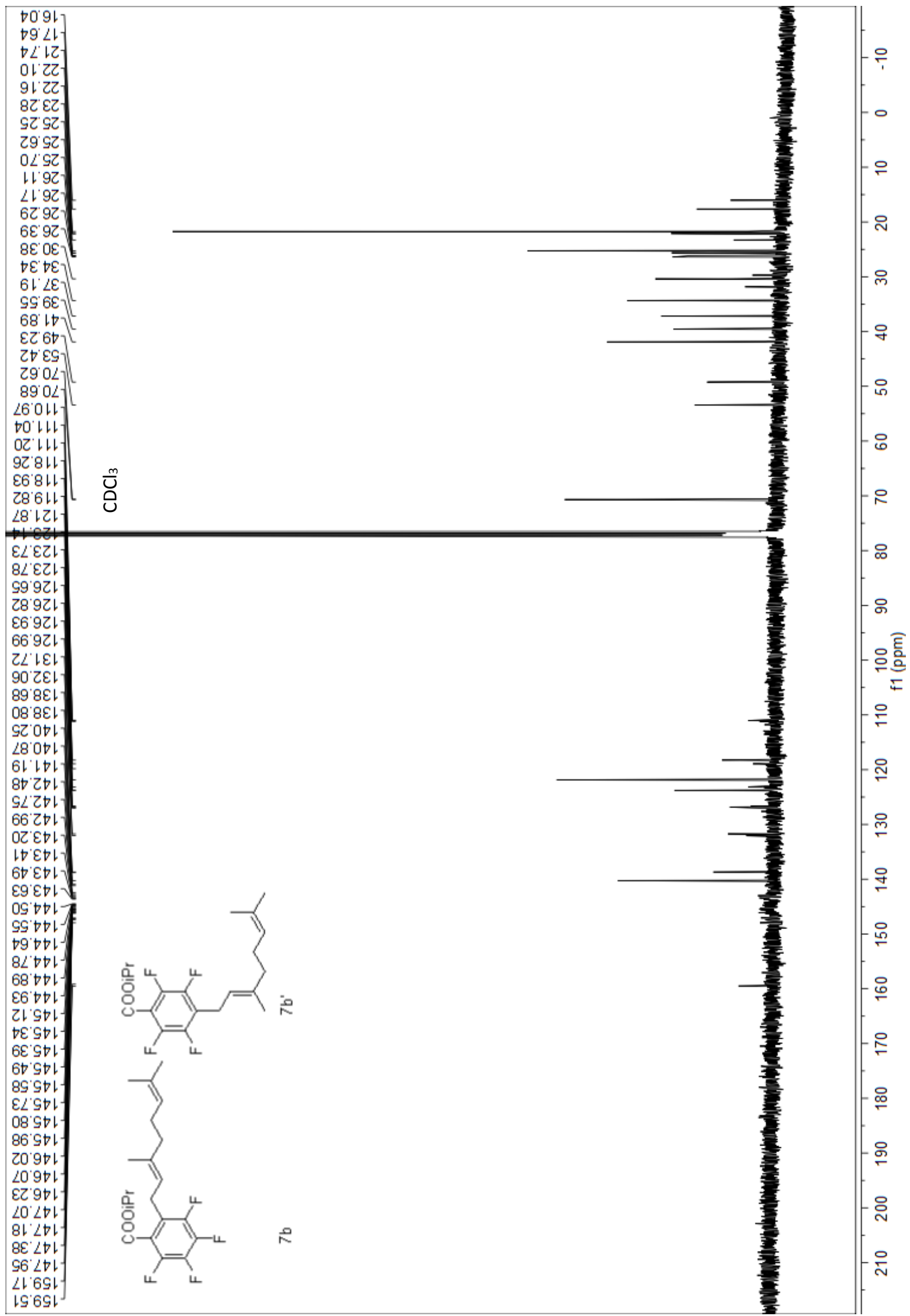


GC and MS of isopropyl (E)-2-(3,7-dimethylocta-2,6-dien-1-yl)-3,4,5,6-tetrafluorobenzoate

(7b) and isopropyl (E)-4-(3,7-dimethylocta-2,6-dien-1-yl)-2,3,5,6-tetrafluorobenzoate (7b')

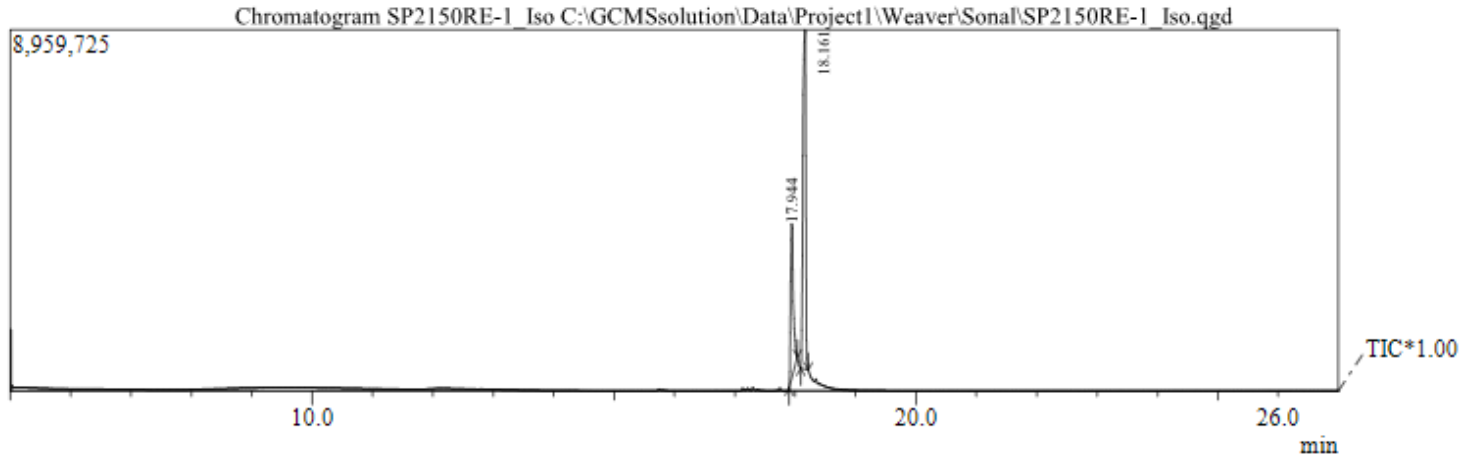

Spectrum

Line\#:1 R.Time:17.9(Scan\#:1554)

MassPeaks: 185

RawMode:Single 17.9(1554) BasePeak:69(1538834)

BG Mode: None

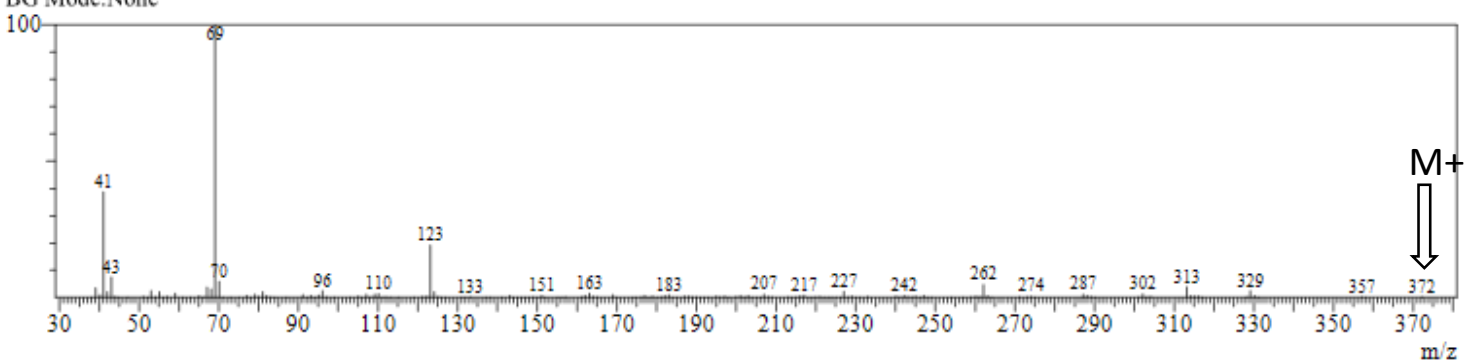

Line\#:2 R.Time:18.2(Scan\#:1579)

MassPeaks:268

RawMode:Single 18.2(1579) BasePeak:95(1183221)

BG Mode: Sone

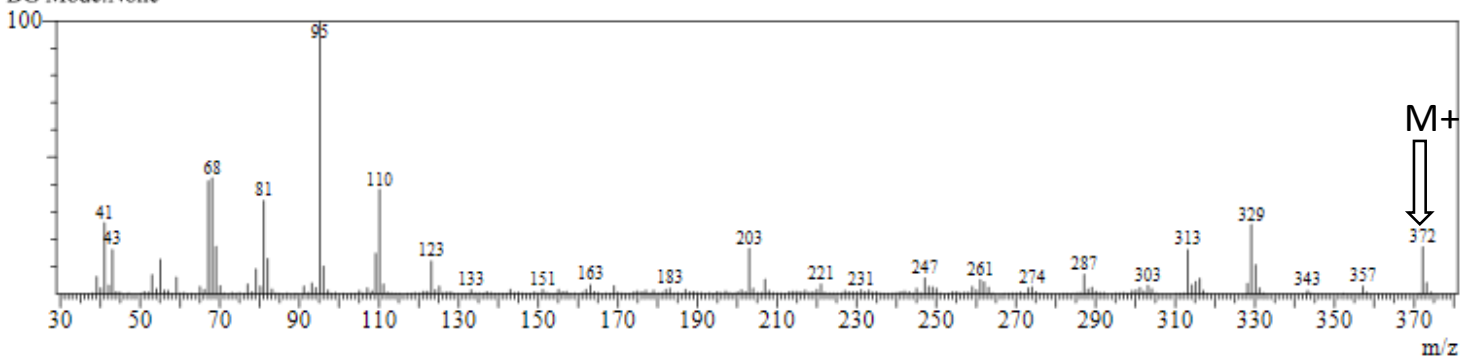


${ }^{19} \mathrm{~F}$ NMR (376 MHz, CDCl3, at rt) spectrum of (E)-2-(3,7-dimethylocta-2,6-dien-1-yl)-3,4,5,6tetrafluoropyridine (7c) and (E)-4-(3,7-dimethylocta-2,6-dien-1-yl)-2,3,5,6tetrafluoropyridine (7c')
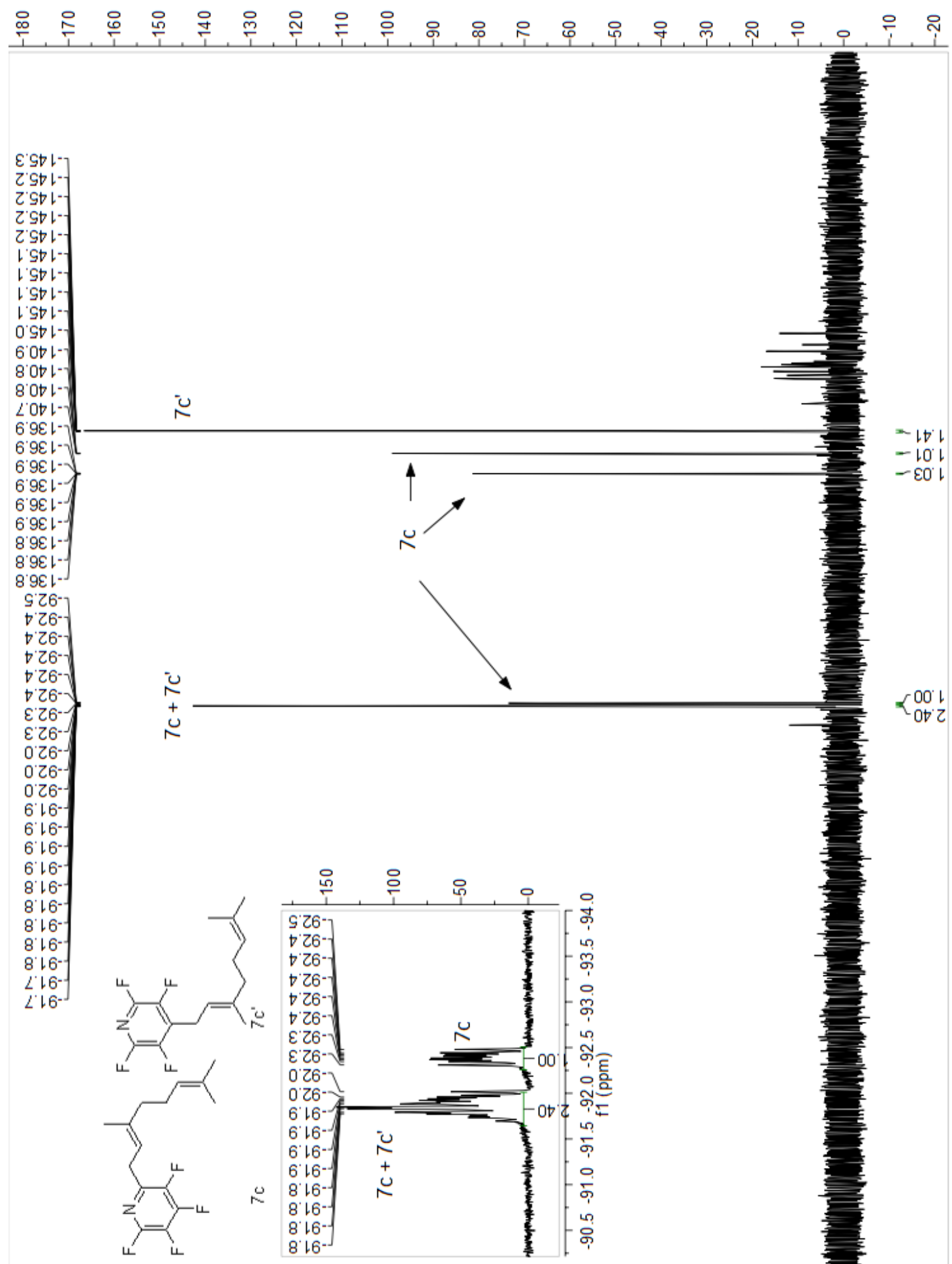

St

St

'St

St

8.07

$\angle O D$

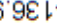

$9 \varepsilon 1$

(1)

$9 \varepsilon 1$

$9 \varepsilon$

G.26

t. 6 -

$\nabla 6^{-}$

†'Z6-

$\varepsilon 2 \sigma^{-}$

'26-

$06^{-1}$

6.16

$8+6$

816

$\angle 16$

216

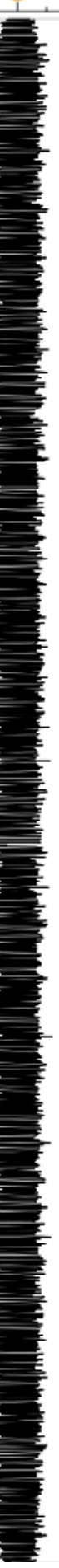

กิ

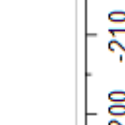


${ }^{1} \mathrm{H}$ NMR (376 MHz, CDCl3, at rt) spectrum of (E)-2-(3,7-dimethylocta-2,6-dien-1-yl)-3,4,5,6tetrafluoropyridine (7c) and (E)-4-(3,7-dimethylocta-2,6-dien-1-yl)-2,3,5,6tetrafluoropyridine (7c')

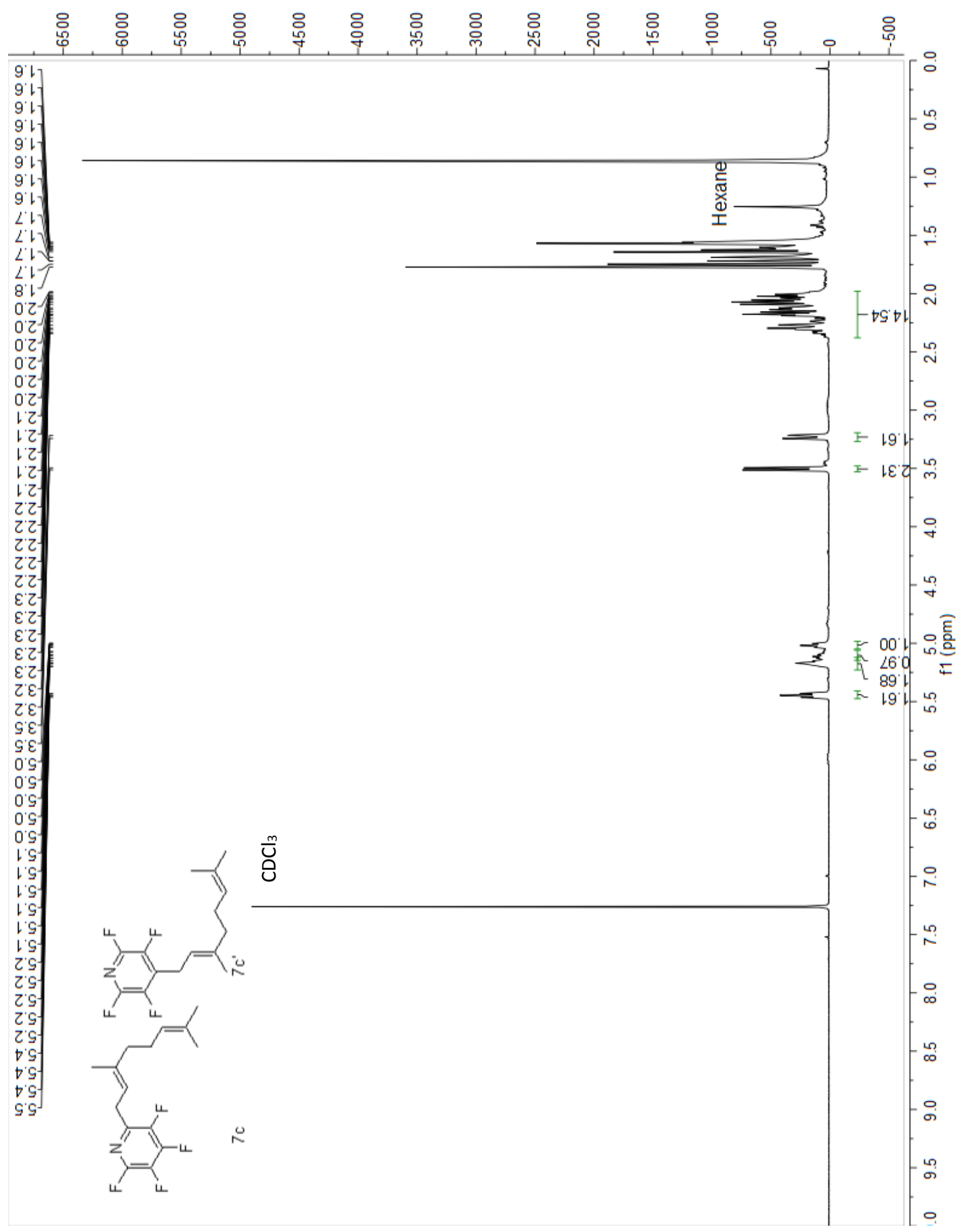


${ }^{13} \mathrm{C}$ NMR (376 MHz, CDCl3, at rt) spectrum of (E)-2-(3,7-dimethylocta-2,6-dien-1-yl)-3,4,5,6tetrafluoropyridine (7c) and (E)-4-(3,7-dimethylocta-2,6-dien-1-yl)-2,3,5,6tetrafluoropyridine (7c')

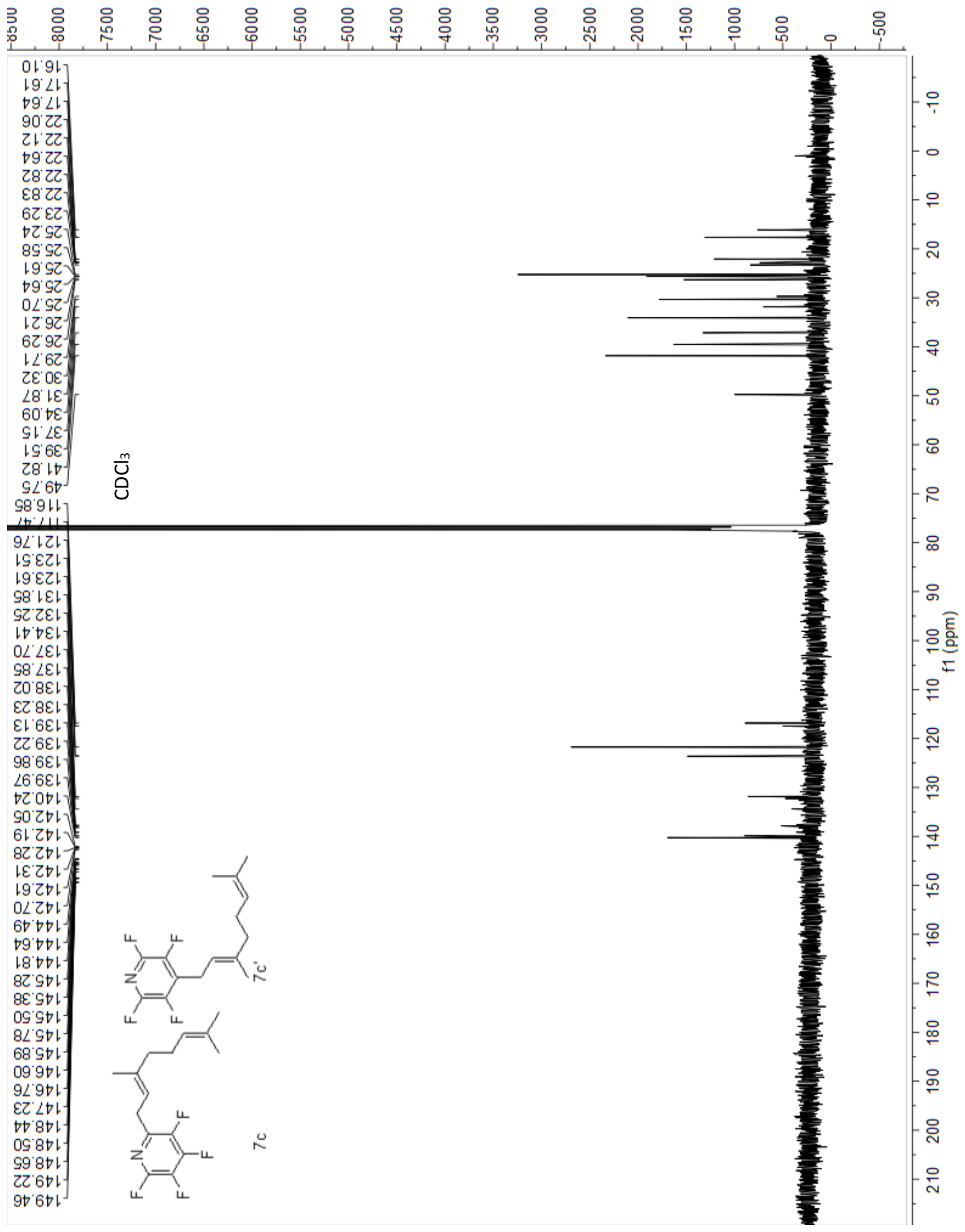


GC and MS of (E)-2-(3,7-dimethylocta-2,6-dien-1-yl)-3,4,5,6-tetrafluoropyridine (7c) and (E)-4-(3,7-dimethylocta-2,6-dien-1-yl)-2,3,5,6-tetrafluoropyridine (7c')

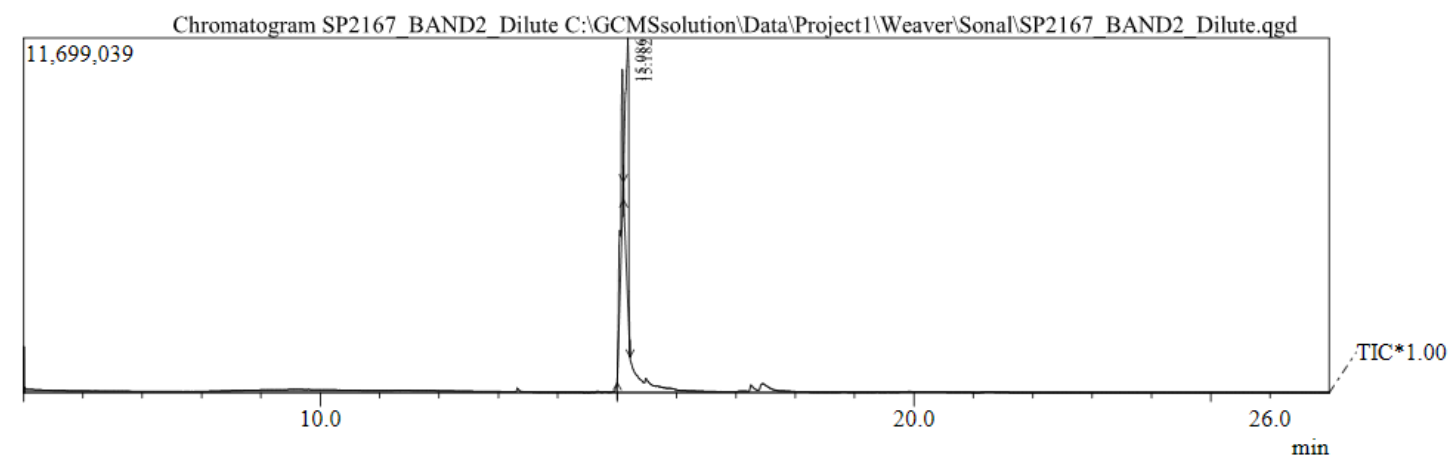

Spectrum

Line\#:1 R.Time:15.1(Scan\#:1211)

MassPeaks: 198

RawMode:Single 15.1(1211) BasePeak:69(4371859)

BG Mode:None

100

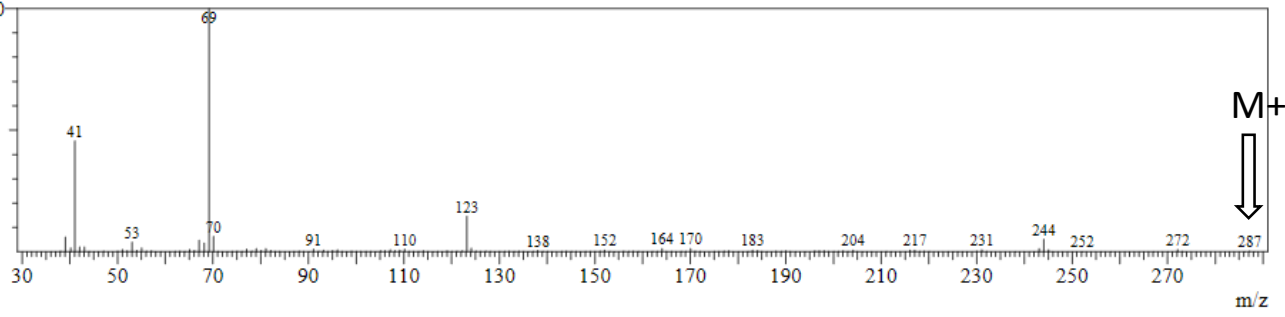

Line\#:2 R.Time:15.2(Scan\#:1220)

MassPeaks: 214

15.2(1220) BasePeak:67(947079)

BG Mode:None

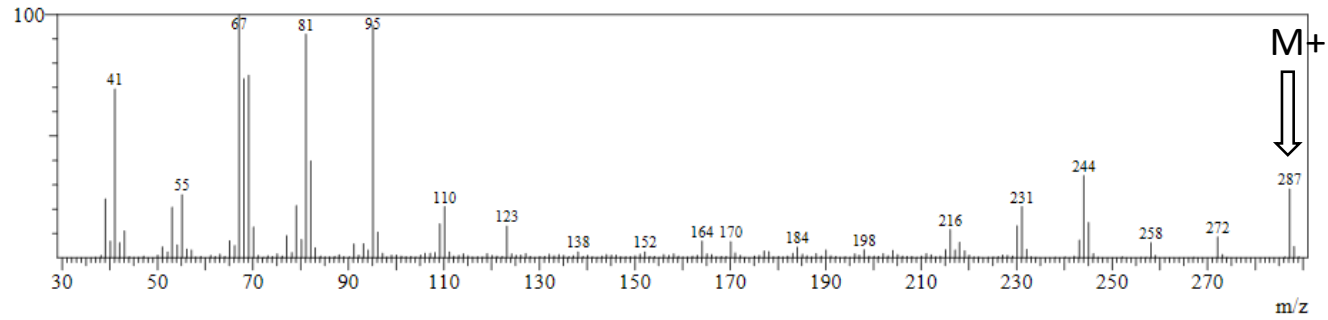


${ }^{19} \mathrm{~F}$ NMR (376 MHz, CDCl3, at rt) spectrum of (E)-2-(3,7-dimethylocta-2,6-dien-1-yl)-3,4,5,6tetrafluorobenzonitrile (7d) and (E)-4-(3,7-dimethylocta-2,6-dien-1-yl)-2,3,5,6tetrafluorobenzonitrile (7d')

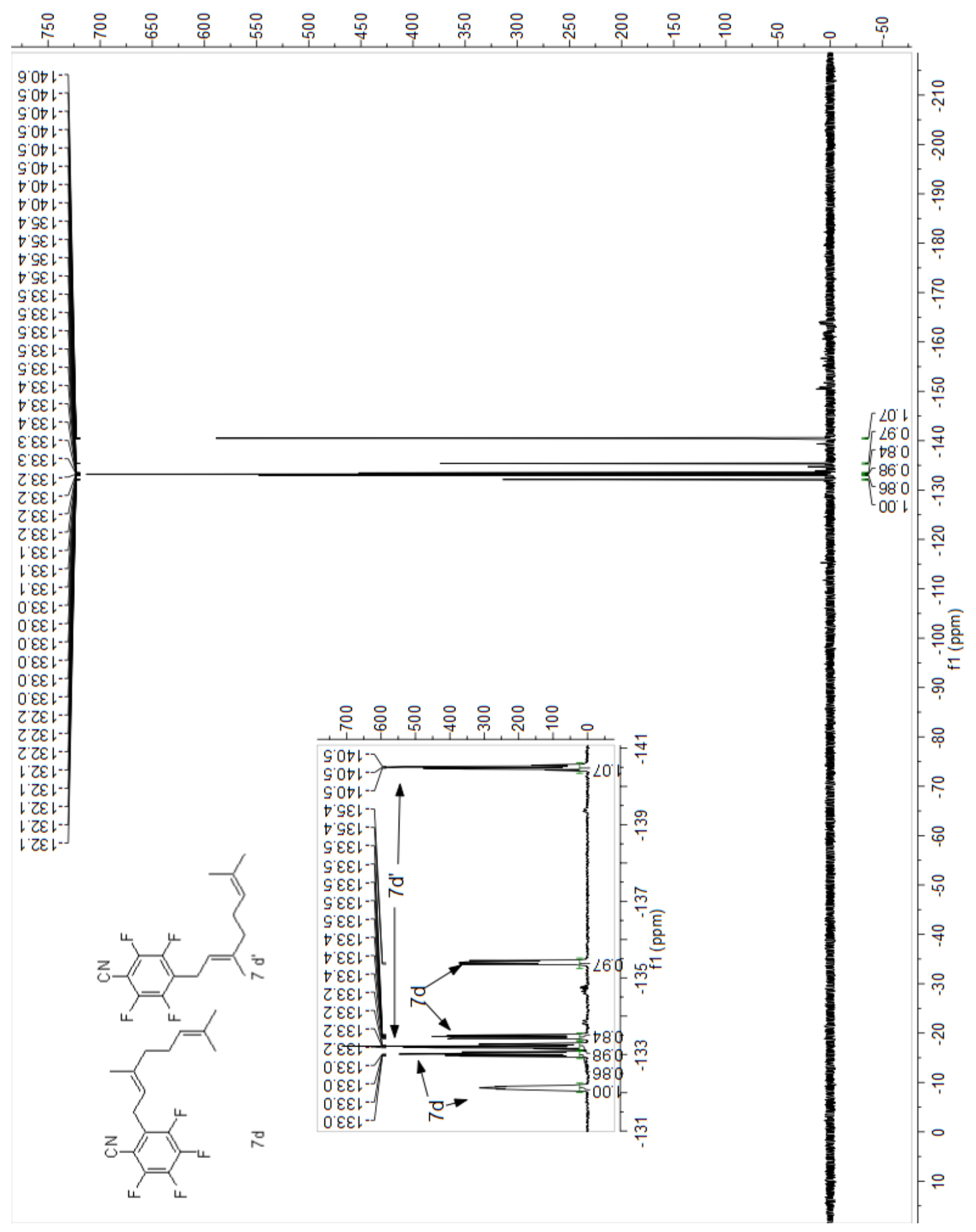


${ }^{1} \mathrm{H}$ NMR (376 MHz, CDCl3, at rt) spectrum of (E)-2-(3,7-dimethylocta-2,6-dien-1-yl)-3,4,5,6tetrafluorobenzonitrile (7d) and (E)-4-(3,7-dimethylocta-2,6-dien-1-yl)-2,3,5,6tetrafluorobenzonitrile (7d')

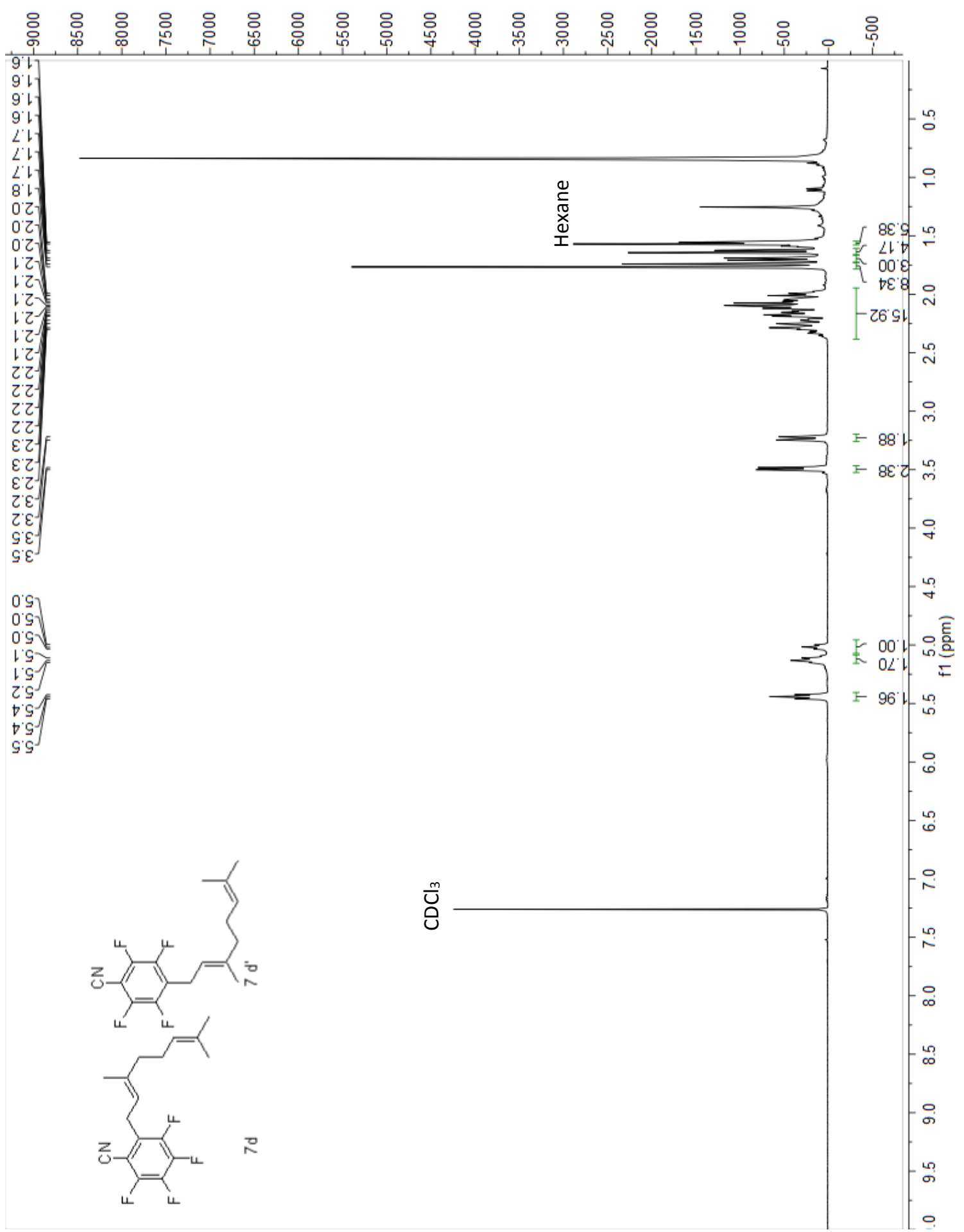


${ }^{13} \mathrm{C}$ NMR (376 MHz, CDCl3, at rt) spectrum of (E)-2-(3,7-dimethylocta-2,6-dien-1-yl)-3,4,5,6tetrafluorobenzonitrile (7d) and (E)-4-(3,7-dimethylocta-2,6-dien-1-yl)-2,3,5,6tetrafluorobenzonitrile (7d')

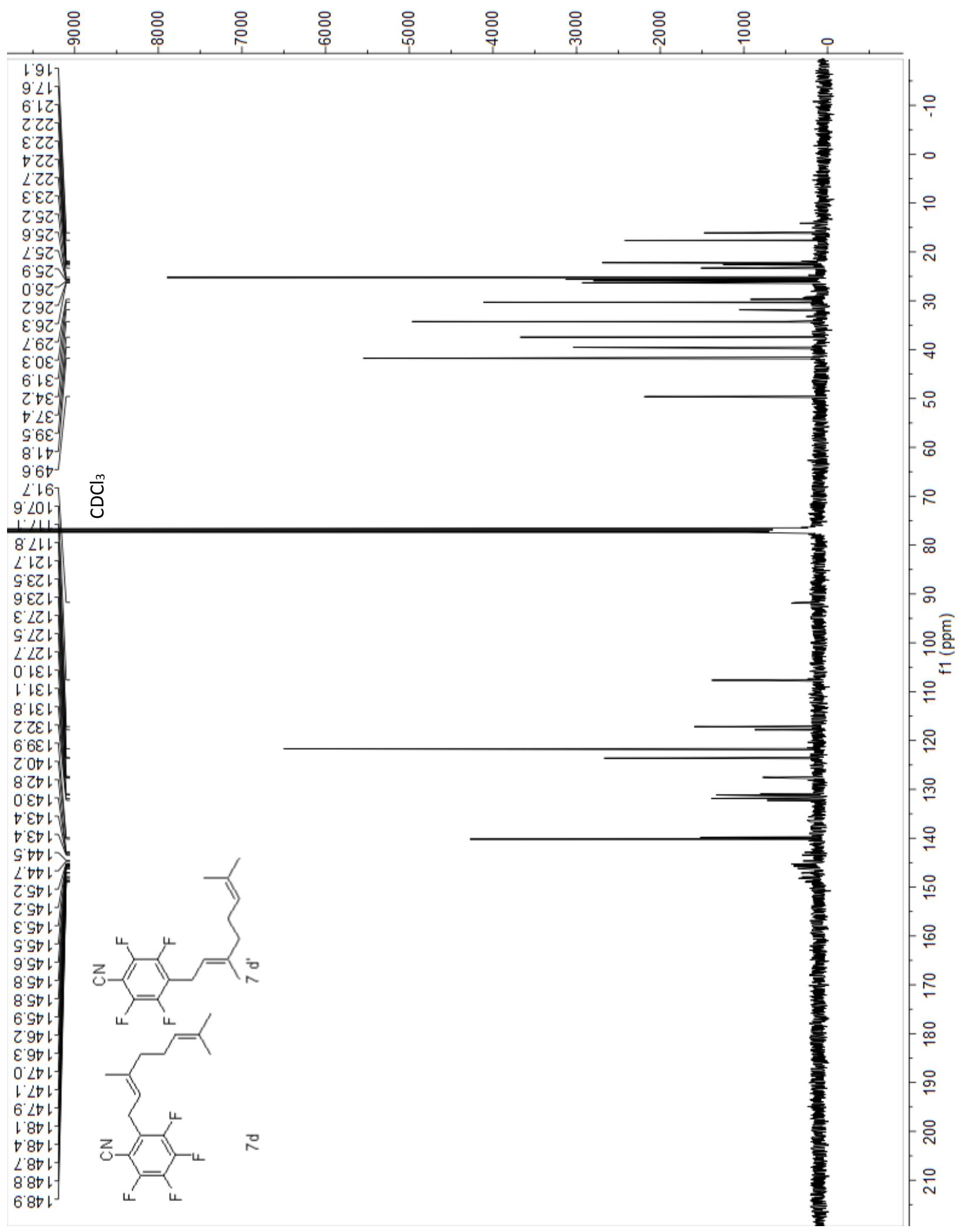


GC and MS of (E)-2-(3,7-dimethylocta-2,6-dien-1-yl)-3,4,5,6-tetrafluorobenzonitrile (7d) and

(E)-4-(3,7-dimethylocta-2,6-dien-1-yl)-2,3,5,6-tetrafluorobenzonitrile (7d')

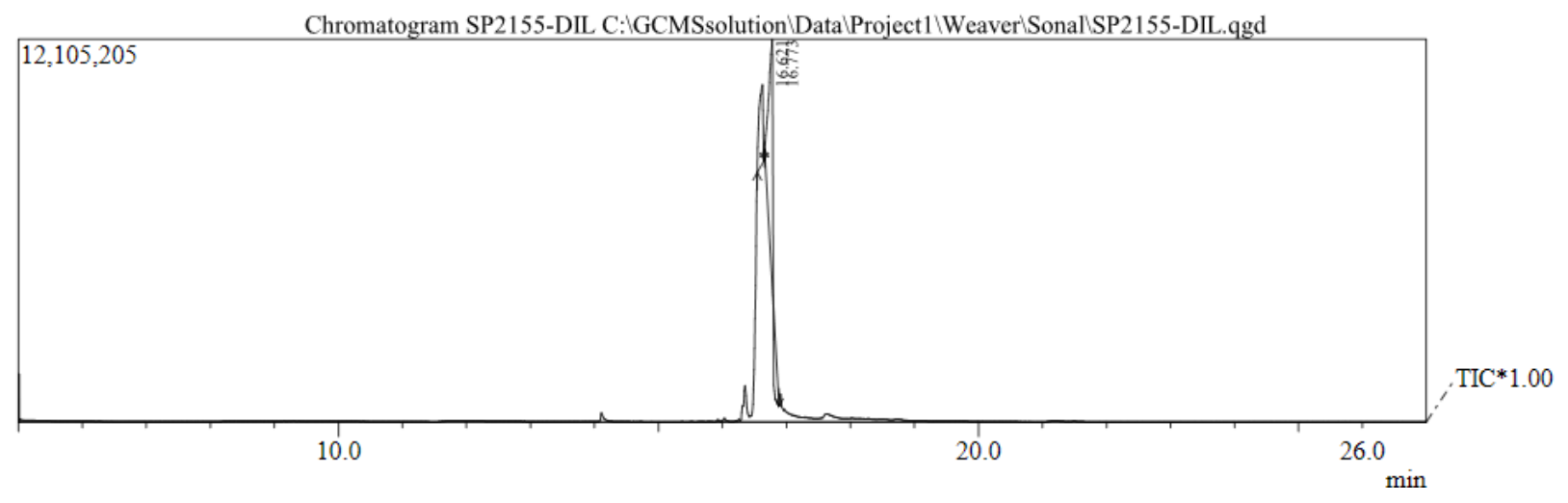

Spectrum

Line\#:1 R.Time:16.6(Scan\#:1394)

MassPeaks:212

RawMode:Single 16.6(1394) BasePeak:69(4220964)

BG Mode:None

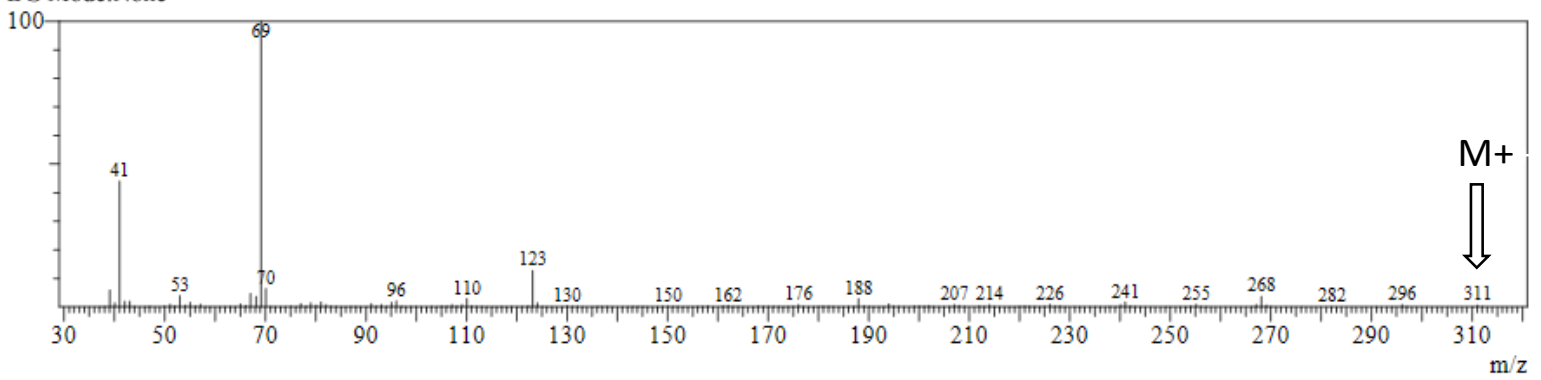

Line\#:2 R.Time:16.7(Scan\#:1408)

MassPeaks:223

RawMode:Single 16.7(1408) BasePeak:95(1292090)

BG Mode:None

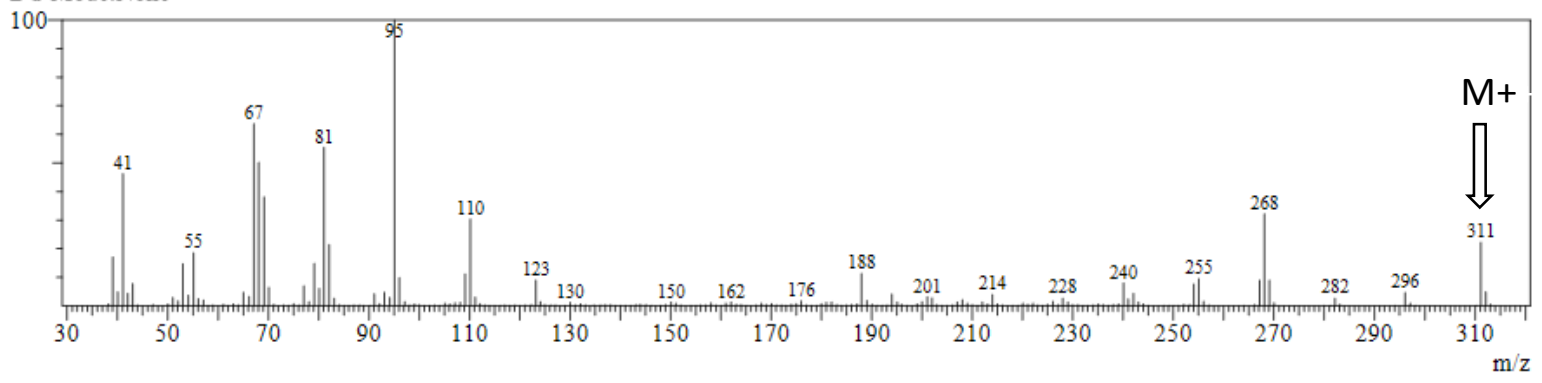




\section{REFERENCES}

1. (a) Randall, S. K.; Marshall, M. S.; Crowell, D. N., Protein isoprenylation in suspension-cultured tobacco cells. The Plant Cell 1993, 5, 433; (b) Zou, Y.; Zhan, Z.; Li, D.; Tang, M.; Cacho, R. A.; Watanabe, K.; Tang, Y., Tandem Prenyltransferases Catalyze Isoprenoid Elongation and Complexity Generation in Biosynthesis of Quinolone Alkaloids. Journal of the American Chemical Society 2015, 137, 4980; (c) Lozinski, O.; Bennetau-Pelissero, C.; Shinkaruk, S., The Synthetic and Biological Aspects of Prenylation as the Versatile Tool for Estrogenic Activity Modulation. ChemistrySelect 2017, 2, 6577; (d) Viliam, B.; Karel, S.; Jan, H.; Veronika, T., Anti-inflammatory Natural Prenylated Phenolic Compounds - Potential Lead Substances. Curr. Med. Chem. 2018, 25, 1094.

2. (a) Maimone, T. J.; Baran, P. S., Modern synthetic efforts toward biologically active terpenes. Nature Chemical Biology 2007, 3, 396; (b) Tholl, D., Terpene synthases and the regulation, diversity and biological roles of terpene metabolism. Current Opinion in Plant Biology 2006, 9, 297.

3. (a) Fernández, M. A.; Heras, B.; Garcia, M. D.; Sáenz, M. T.; Villar, A., New insights into the mechanism of action of the anti-inflammatory triterpene lupeol. Journal of Pharmacy and Pharmacology 2001, 53, 1533; (b) Paduch, R.; Kandefer-Szerszeń, M.; Trytek, M.; Fiedurek, J., Terpenes: substances useful in human healthcare. Archivum Immunologiae et Therapiae Experimentalis 2007, 55, 315.

4. Caputi, L.; Aprea, E., Use of Terpenoids as Natural Flavouring Compounds in Food Industry. Recent Patents on Food, Nutrition \& Agriculture 2011, 3, 9.

5. (a) Batish, D. R.; Singh, H. P.; Kohli, R. K.; Kaur, S., Eucalyptus essential oil as a natural pesticide. Forest Ecology and Management 2008, 256, 2166; (b) Isman, M. B., Plant essential oils for pest and disease management. Crop Protection 2000, 19, 603. 6. Gurgel do Vale, T.; Couto Furtado, E.; Santos, J. G.; Viana, G. S. B., Central effects of citral, myrcene and limonene, constituents of essential oil chemotypes from Lippia alba (Mill.) N.E. Brown. Phytomedicine 2002, 9, 709.

7. Lopes Campêlo, L. M.; Gonçalves e Sá, C.; de Almeida, A. A. C.; Pereira da Costa, J.; Costa Marques, T. H.; Mendes Feitosa, C.; Barros Saldanha, G.; Mendes de Freitas, R., Sedative, anxiolytic and antidepressant activities of Citrus limon (Burn) essential oil in mice. Die Pharmazie - An International Journal of Pharmaceutical Sciences 2011, 66, 623.

8. Bhalla, Y.; Gupta, V. K.; Jaitak, V., Anticancer activity of essential oils: a review. Journal of the Science of Food and Agriculture 2013, 93, 3643.

9. Diniz, L. R. L.; Vieira, C. F. X.; Santos, E. C. d.; Lima, G. C.; Aragão, K. K. V.; Vasconcelos, R. P.; Araújo, P. C. d. C.; Vasconcelos, Y. d. A. G.; Oliveira, A. C. d.; Oliveira, H. D. d.; Portella, V. G.; Coelho-de-Souza, A. N., Gastroprotective effects of the essential oil of Hyptis crenata Pohl ex Benth. on gastric ulcer models. Journal of Ethnopharmacology 2013, 149, 694. 
10. Kim, D.-S.; Lee, H.-J.; Jeon, Y.-D.; Han, Y.-H.; Kee, J.-Y.; Kim, H.-J.; Shin, H.-J.; Kang, J.; Lee, B. S.; Kim, S.-H.; Kim, S.-J.; Park, S.-H.; Choi, B.-M.; Park, S.-J.; Um, J.Y.; Hong, S.-H., Alpha-Pinene Exhibits Anti-Inflammatory Activity Through the Suppression of MAPKs and the NF-кB Pathway in Mouse Peritoneal Macrophages. The American Journal of Chinese Medicine 2015, 43, 731.

11. Fernandes, E. S.; Passos, G. F.; Medeiros, R.; da Cunha, F. M.; Ferreira, J.; Campos, M. M.; Pianowski, L. F.; Calixto, J. B., Anti-inflammatory effects of compounds alphahumulene and (-)-trans-caryophyllene isolated from the essential oil of Cordia verbenacea. European Journal of Pharmacology 2007, 569, 228.

12. Jansen, D. J.; Shenvi, R. A., Synthesis of medicinally relevant terpenes: reducing the cost and time of drug discovery. Future medicinal chemistry 2014, 6, 1127.

13. Wang, G.; Tang, W.; Bidigare, R. R., Terpenoids As Therapeutic Drugs and Pharmaceutical Agents. In Natural Products: Drug Discovery and Therapeutic Medicine, Zhang, L.; Demain, A. L., Eds. Humana Press: Totowa, NJ, 2005; pp 197.

14. Altmann, K.-H., Microtubule-stabilizing agents: a growing class of important anticancer drugs. Current Opinion in Chemical Biology 2001, 5, 424.

15. (a) Jarman, M., Perflouroarenes as novel and selective protecting reagents; applications in anticancer drug development. J. Fluor. Chem. 1989, 42, 3; (b) Maienfisch, P.; Hall, R. G., The Importance of Fluorine in the Life Science Industry. CHIMIA 2004, 58, 93; (c) Hagmann, W. K., The Many Roles for Fluorine in Medicinal Chemistry. $J$. Med. Chem. 2008, 51, 4359; (d) Matsumori, N.; Okazaki, H.; Nomura, K.; Murata, M., Fluorinated cholesterol retains domain-forming activity in sphingomyelin bilayers. Chem. Phys. Lipids 2011, 164, 401; (e) Gillis, E. P.; Eastman, K. J.; Hill, M. D.; Donnelly, D. J.; Meanwell, N. A., Applications of Fluorine in Medicinal Chemistry. J. Med. Chem. 2015, $58,8315$.

16. (a) Müller, K.; Faeh, C.; Diederich, F., Fluorine in Pharmaceuticals: Looking Beyond Intuition. Science 2007, 317, 1881; (b) Wang, J.; Sánchez-Roselló, M.; Aceña, J. L.; del Pozo, C.; Sorochinsky, A. E.; Fustero, S.; Soloshonok, V. A.; Liu, H., Fluorine in Pharmaceutical Industry: Fluorine-Containing Drugs Introduced to the Market in the Last Decade (2001-2011). Chemical Reviews 2014, 114, 2432.

17. (a) Sakamoto, Y.; Suzuki, T.; Miura, A.; Fujikawa, H.; Tokito, S.; Taga, Y., Synthesis, Characterization, and Electron-Transport Property of Perfluorinated Phenylene Dendrimers. Journal of the American Chemical Society 2000, 122, 1832; (b) Hird, M., Fluorinated liquid crystals - properties and applications. Chem. Soc. Rev. 2007, 36, 2070. 18. (a) Theodoridis, G., Chapter 4 Fluorine-Containing Agrochemicals: An Overview of Recent Developments. In Advances in Fluorine Science, Tressaud, A., Ed. Elsevier: 2006; Vol. 2, pp 121; (b) Fujiwara, T.; O’Hagan, D., Successful fluorine-containing herbicide agrochemicals. Journal of Fluorine Chemistry 2014, 167, 16.

19. Strunecka, A.; Patocka, J.; Connett, P., Fluorine in medicine. J. Appl. Biomed. 2004, 2,141 . 
20. Shah, P.; Westwell, A. D., The role of fluorine in medicinal chemistry. J. Enzyme Inhib. Med. Chem. 2007, 22, 527.

21. Günther, B.; Günther, S., Über aromatische Fluorverbindungen, I.: Ein neues

Verfahren zu ihrer Darstellung. Chem. Ber. 1927, 60, 1186.

22. Finger, G. C.; Kruse, C. W., Aromatic Fluorine Compounds. VII. Replacement of Aromatic - $\mathrm{Cl}$ and -NO2 Groups by -F1,2. J. Am. Chem. Soc. 1956, 78, 6034.

23. Ahrens, T.; Kohlmann, J.; Ahrens, M.; Braun, T., Functionalization of Fluorinated

Molecules by Transition-Metal-Mediated C-F Bond Activation To Access Fluorinated Building Blocks. Chem. Rev. 2015, 115, 931.

24. Kiplinger, J. L.; Richmond, T. G.; Osterberg, C. E., Activation of Carbon-Fluorine Bonds by Metal Complexes. Chem. Rev. 1994, 94, 373.

25. Amii, H.; Uneyama, K., C-F Bond Activation in Organic Synthesis. Chem. Rev. 2009, 109, 2119.

26. (a) Clot, E.; Eisenstein, O.; Jasim, N.; Macgregor, S. A.; McGrady, J. E.; Perutz, R. N., $\mathrm{C}-\mathrm{F}$ and $\mathrm{C}-\mathrm{H}$ Bond Activation of Fluorobenzenes and Fluoropyridines at Transition Metal Centers: How Fluorine Tips the Scales. Acc. Chem. Res. 2011, 44, 333; (b)

Sabater, S.; Mata, J. A.; Peris, E., Hydrodefluorination of carbon-fluorine bonds by the synergistic action of a ruthenium-palladium catalyst. Nat. Commun. 2013, 4, 2553; (c) Whittlesey, M. K.; Peris, E., Catalytic Hydrodefluorination with Late Transition Metal Complexes. ACS Catal. 2014, 4, 3152; (d) Chen, K.; Berg, N.; Gschwind, R.; König, B., Selective Single C(sp3)-F Bond Cleavage in Trifluoromethylarenes: Merging VisibleLight Catalysis with Lewis Acid Activation. J. Am. Chem. Soc. 2017, 139, 18444; (e) Eisenstein, O.; Milani, J.; Perutz, R. N., Selectivity of C-H Activation and Competition between $\mathrm{C}-\mathrm{H}$ and $\mathrm{C}-\mathrm{F}$ Bond Activation at Fluorocarbons. Chem. Rev. 2017, 117, 8710; (f) Wang, H.; Jui, N. T., Catalytic Defluoroalkylation of Trifluoromethylaromatics with Unactivated Alkenes. J. Am. Chem. Soc. 2018, 140, 163.

27. (a) Marsden, S. P.; Depew, K. M.; Danishefsky, S. J., Stereoselective Total Syntheses of Amauromine and 5-N-Acetylardeemin. A Concise Route to the Family of "ReversePrenylated" Hexahydropyrroloindole Alkaloids. J. Am. Chem. Soc. 1994, 116, 11143; (b) Trost, B. M.; Malhotra, S.; Chan, W. H., Exercising Regiocontrol in Palladium-Catalyzed Asymmetric Prenylations and Geranylation: Unifying Strategy toward Flustramines A and B. J. Am. Chem. Soc. 2011, 133, 7328.

28. Iwasaki, T.; Okamoto, K.; Kuniyasu, H.; Kambe, N., Cu-catalyzed Reductive Coupling of Perfluoroarenes with 1,3-Dienes. Chem. Lett. 2017, 46, 1504.

29. (a) Vinogradov, A. S.; Krasnov, V. I.; Platonov, V. E., Organozinc reagents from polyfluoroarenes: Preparation and reactions with allyl halides. Synthesis of allylpolyfluoroarenes. Russ. J. Org. Chem. 2008, 44, 95; (b) Fan, S.; Chen, F.; Zhang, X., Direct Palladium-Catalyzed Intermolecular Allylation of Highly Electron-Deficient Polyfluoroarenes. Angew. Chem. Int. Ed. 2011, 50, 5918; (c) Yao, T.; Hirano, K.; Satoh, T.; Miura, M., Stereospecific Copper-Catalyzed C-H Allylation of Electron-Deficient Arenes with Allyl Phosphates. Angew. Chem. Int. Ed. 2011, 50, 2990; (d) Li, Z.; Zhang, 
Y.; Liu, Z.-Q., Pd-Catalyzed Olefination of Perfluoroarenes with Allyl Esters. Org. Lett. 2012, 14, 74; (e) Yu, Y. B.; Fan, S.; Zhang, X., Copper- and Phosphine-Ligand-Free Palladium-Catalyzed Direct Allylation of Electron-Deficient Polyfluoroarenes with Allylic Chlorides. Chem. Eur. J. 2012, 18, 14643; (f) Weilong, X.; Sukbok, C., $[\mathrm{Cu}(\mathrm{NHC})]-C a t a l y z e d \mathrm{C}-\mathrm{H}$ Allylation and Alkenylation of both Electron-Deficient and Electron-Rich (Hetero)arenes with Allyl Halides. Angew. Chem. Int. Ed. 2016, 55, 1876. 30. (a) Vela, J.; Smith, J. M.; Yu, Y.; Ketterer, N. A.; Flaschenriem, C. J.; Lachicotte, R. J.; Holland, P. L., Synthesis and Reactivity of Low-Coordinate Iron(II) Fluoride Complexes and Their Use in the Catalytic Hydrodefluorination of Fluorocarbons. J. Am. Chem. Soc. 2005, 127, 7857; (b) Lv, H.; Zhan, J.-H.; Cai, Y.-B.; Yu, Y.; Wang, B.; Zhang, J.-L., $\pi-\pi$ Interaction Assisted Hydrodefluorination of Perfluoroarenes by Gold Hydride: A Case of Synergistic Effect on C-F Bond Activation. J. Am. Chem. Soc. 2012, 134, 16216; (c) Hongbin, L.; Yuan-Bo, C.; Jun-Long, Z., Copper-Catalyzed Hydrodefluorination of Fluoroarenes by Copper Hydride Intermediates. Angew. Chem. 2013, 125, 3285; (d) Senaweera, S. M.; Singh, A.; Weaver, J. D., Photocatalytic Hydrodefluorination: Facile Access to Partially Fluorinated Aromatics. J. Am. Chem. Soc. 2014, 136, 3002; (e) Khaled, M. B.; El Mokadem, R. K.; Weaver, J. D., Hydrogen Bond Directed Photocatalytic Hydrodefluorination: Overcoming Electronic Control. $J$. Am. Chem. Soc. 2017, 139, 13092.

31. Grenning, A. J.; Boyce, J. H.; Porco, J. A., Rapid Synthesis of Polyprenylated Acylphloroglucinol Analogs via Dearomative Conjunctive Allylic Annulation. J. Am. Chem. Soc. 2014, 136, 11799.

32. (a) Weaver, J.; Senaweera, S., C-F activation and functionalization of perfluoro- and polyfluoroarenes. Tetrahedron 2014, 70, 7413; (b) Singh, A.; Kubik, J. J.; Weaver, J. D., Photocatalytic C-F alkylation; facile access to multifluorinated arenes. Chem. Sci. 2015, 6, 7206; (c) Singh, A.; Teegardin, K.; Kelly, M.; Prasad, K. S.; Krishnan, S.; Weaver, J. D., Facile synthesis and complete characterization of homoleptic and heteroleptic cyclometalated Iridium(III) complexes for photocatalysis. J. Organomet. Chem. 2015, 776, 51; (d) Senaweera, S.; Weaver, J. D., Dual C-F, C-H Functionalization via Photocatalysis: Access to Multifluorinated Biaryls. Journal of the American Chemical Society 2016, 138, 2520; (e) Singh, A.; Fennell, C. J.; Weaver, J. D., Photocatalyst size controls electron and energy transfer: selectable $\mathrm{E} / \mathrm{Z}$ isomer synthesis via $\mathrm{C}-\mathrm{F}$ alkenylation. Chem. Sci. 2016, 7, 6796.

33. Singh, A.; Kubik, J. J.; Weaver, J. D., Photocatalytic C-F alkylation; facile access to multifluorinated arenes. Chemical Science 2015, 6, 7206.

34. (a) Quiclet-Sire, B.; Zard, S. Z., Fun with radicals. Some new perspectives for organic synthesis. Pure Appl. Chem. 2011, 83, 519; (b) Debien, L.; Quiclet-Sire, B.; Zard, S. Z., Allylic Alcohols: Ideal Radical Allylating Agents? Acc. Chem. Res. 2015, 48, 1237.

35. Lahousse, F.; Merényi, R.; Desmurs, J. R.; Allaime, H.; Borghese, A.; Viehe, H. G., Kinetic effects in radical addition reactions to radicophiles. Tetrahedron Letters 1984, 25, 3823. 
36. Blanksby, S. J.; Ellison, G. B., Bond Dissociation Energies of Organic Molecules. Acc. Chem. Res. 2003, 36, 255.

37. Charrier, N.; Quiclet-Sire, B.; Zard, S. Z., Allylic Alcohols as Radical Allylating Agents. An Overall Olefination of Aldehydes and Ketones. J. Am. Chem. Soc. 2008, 130, 8898.

38. Wright, J. S.; Ingold, K. U., Understanding Trends in C-H, N-H, and O-H Bond Dissociation Enthalpies. J. Chem. Educ. 2000, 77, 1062.

39. Zhan, C.-G.; Dixon, D. A., Hydration of the Fluoride Anion: Structures and Absolute Hydration Free Energy from First-Principles Electronic Structure Calculations. J. Phys. Chem. A 2004, 108, 2020.

40. Xue, F.; Deng, H.; Xue, C.; Mohamed, D. K. B.; Tang, K. Y.; Wu, J., Reaction discovery using acetylene gas as the chemical feedstock accelerated by the "stop-flow" micro-tubing reactor system. Chem. Sci. 2017, 8, 3623.

41. (a) Hexachlorobenzene is less aromatic than hexafluorobenzene due to non-planarity caused by the chloride substituents; (b) Intermolecular potential function model for crystalline hexachlorobenzene. J. Chem. Phys. 1974, 60, 2414; (c) Brown, G. M.; Strydom, O. A. W., Hexachlorobenzene, C6Cl6: the crystal and molecular structure from least-squares refinement with new X-ray data. Acta Crystallogr. A 1974, 30, 801.

42. (a) Eapen, K. C.; Tamborski, C., Synthesis of some benzimidazoles containing 2perfluoro substituents. J. Fluorine Chem. 1981, 18, 243; (b) Xie, K.; Yang, Z.; Zhou, X.; Li, X.; Wang, S.; Tan, Z.; An, X.; Guo, C.-C., Pd-Catalyzed Decarboxylative Arylation of Thiazole, Benzoxazole, and Polyfluorobenzene with Substituted Benzoic Acids. Org. Lett. 2010, 12, 1564; (c) Senaweera, S.; Weaver, J. D., SNAr catalysis enhanced by an aromatic donor-acceptor interaction; facile access to chlorinated polyfluoroarenes. Chemical Communications 2017, 53, 7545.

43. Polisetti, D. R.; Kodra, J. T.; Lau, J.; Bloch, P.; Valcarce-Lopez, M. C.; Blume, N.; Guzel, M.; Santhosh, K. C.; Mjalli, A. M. M.; Andrews, R. C.; Subramanian, G.; Ankersen, M.; Vedso, P.; Murray, A.; Jeppesen, L. Preparation of thiazolyl aryl ureas as activators of glucokinase. WO2004002481A1, 2004.

44. Dombrowski, G. W.; Dinnocenzo, J. P.; Farid, S.; Goodman, J. L.; Gould, I. R., $\alpha-$ $\mathrm{C}-\mathrm{H}$ Bond Dissociation Energies of Some Tertiary Amines. J. Org. Chem. 1999, 64, 427. 45. Lucarini, M.; Pedrielli, P.; Pedulli, G. F.; Cabiddu, S.; Fattuoni, C., Bond Dissociation Energies of O-H Bonds in Substituted Phenols from Equilibration Studies. J. Org. Chem. 1996, 61, 9259.

46. Beatty, J. W.; Stephenson, C. R. J., Amine Functionalization via Oxidative Photoredox Catalysis: Methodology Development and Complex Molecule Synthesis. Acc. Chem. Res. 2015, 48, 1474.

47. Battiste, J.; Newmark, R. A., Applications of 19F multidimensional NMR. Progress in Nuclear Magnetic Resonance Spectroscopy 2006, 48, 1.

48. Saunders, C.; Khaled, M. B.; Weaver, J. D.; Tantillo, D. J., Prediction of 19F NMR Chemical Shifts for Fluorinated Aromatic Compounds. J. Org. Chem. 2018, 83, 3220. 


\section{APPENDICES}

Single Electron Transfer (SET)

Trimethylamine (TEA, Et3N)

Di-isoprpylethylamine (DIPEA)

Dichloromethane (DCM)

Acetonitrile $(\mathrm{MeCN})$

Hydrogen atom transfer (HAT)

Methanol (MeOH)

N, N-Dimethylformamide (DMF)

Tetrahydrofuran (THF)

Thin layer chromatography (TLC) 
VITA

Sonal Priya

Candidate for the Degree of

Master of Science

\section{Thesis: PRENYL PRAXIS: A METHOD FOR DIRECT PHOTOCATALYTIC DEFLUOROPRENYLATION}

Major Field: Chemistry

Biographical:

Education:

Completed the requirements for the Master of Science in Chemistry at Oklahoma State University, Stillwater, Oklahoma in December, 2018.

Completed the requirements for the Bachelor of Science in Chemistry at University of Delhi, New Delhi, India in 2014.

Professional Memberships: American Chemical Society 